University of Rhode Island

DigitalCommons@URI

Open Access Dissertations

2017

\title{
Improvised Explosives: X-Ray Detection \& Euthectics of Erythritol Tetranitrate
}

Austin Collins Brown

University of Rhode Island, acbrown@my.uri.edu

Follow this and additional works at: https://digitalcommons.uri.edu/oa_diss

\section{Recommended Citation}

Brown, Austin Collins, "Improvised Explosives: X-Ray Detection \& Euthectics of Erythritol Tetranitrate" (2017). Open Access Dissertations. Paper 602.

https://digitalcommons.uri.edu/oa_diss/602

This Dissertation is brought to you for free and open access by DigitalCommons@URI. It has been accepted for inclusion in Open Access Dissertations by an authorized administrator of DigitalCommons@URI. For more information, please contact digitalcommons-group@uri.edu. 
IMPROVISED EXPLOSIVES: X-RAY DETECTION \& EUTECTICS OF ERYTHRITOL TETRANITRATE

BY

AUSTIN COLLINS BROWN

A DISSERTATION SUBMITTED IN PARTIAL FULFILLMENT OF THE

REQUIREMENTS FOR THE DEGREE OF

DOCTOR OF PHILOSOPHY

IN

CHEMISTRY

UNIVERSITY OF RHODE ISLAND 
DOCTOR OF PHILOSOPHY DISSERTATION

OF

AUSTIN COLLINS BROWN

APPROVED:

Dissertation Committee:

$\begin{array}{ll}\text { Major Professor } & \text { Jimmie Oxley } \\ & \text { James Smith } \\ & \text { Jason Dwyer } \\ & \text { Bongsup Cho } \\ & \text { Nasser H. Zawia } \\ \text { DEAN OF THE GRADUATE SCHOOL }\end{array}$

UNIVERSITY OF RHODE ISLAND

2017 


\begin{abstract}
This thesis focuses on the handling and detecting of improvised explosives, specifically erythritol tetranitrate $(\mathrm{ETN}) . \mathrm{ETN}$ is a nitrate ester with the unusual property of melting at a temperature significantly below its decomposition temperature. For this reason the first two manuscripts probe the potential usefulness of ETN as a military explosive and the long-term stability of this material. The third manuscript examines $\mathrm{x}$-ray detection, a technique that readily reveals covert military explosives. Discussed are ways to evaluate detection capability without actually employing the explosive.

With the recent availability of erythritol as an artificial sweetener, the synthesis of ETN has become economically feasible. This dissertation examines eutectics of ETN, to establish if it can be a useful component in melt-casted explosive formulations. To this end we report three novel ETN-energetic eutectics with trinitroazetidine (TNAZ), dinitroanisole (DNAN), and 2,3-hydroxymethyl-2,3-dinitro1,4-butanediol tetranitrate $(\mathrm{SMX})$. We also report adjusted ratios and melttemperatures for two previously reported ETN eutectics with 2,4,6-trinitrotoluene (TNT) and with pentaerythritol tetranitrate (PETN), and examine a new eutectic composed of insensitive explosives, DNAN-TNAZ. Finally, we examined the eutectic of TNT-PETN as a reference to confirm the validity of our other results. Melting was examined on a differential scanning calorimeter (DSC) and eutectic properties were determined by constructing phase diagrams and Tamman plots. Theoretical eutectic properties were calculated using the van't Hoff equation and a more recently published equation for predicting eutectics specifically of energetic compounds.
\end{abstract}


Experimental results are consistent across analysis metrics but did not correspond with the theoretical results.

With the increased ease of synthesizing ETN, and because we have been examining the usefulness of ETN, its complete characterization, especially its stability, is of great interest. This work examines the thermal decomposition of ETN and compares it to the well-studied nitrate ester PETN, both through experimental methods and computational theory.

ETN was aged isothermally at temperatures of $60,80,110,120$, and $140{ }^{\circ} \mathrm{C}$ for multiple time points. At each point, the amount of ETN remaining was quantified using liquid chromatography mass spectrometry (LCMS). Kinetic parameters of decomposition were found by fitting this data to the integrated first order rate law equation, the obtained rate constants were then fit the Arrhenius equation to calculate the activation energy $\left(E_{a}\right)$ and pre-exponential factor $(A)$. It was found that ETN is less thermally stable than PETN, however ETN is more thermally stable than results from our previous DSC kinetics study would indicate. In addition to these kinetic parameters, decomposition products were examined to elucidate the decomposition pathway of ETN. These products were also studied using LCMS and consisted primarily of erythritol trinitrate, along with minor quantities of the dinitrate and mononitrate, presumably generated by the loss of $\mathrm{NO}_{2}$ from ETN.

In addition to our work with ETN, a new approach to develop non-hazardous materials that simulate explosives, and other related threats, on x-ray detection equipment is presented in this work. Simulants for x-ray detection are needed to confirm proper working order of detection instruments in areas where actual threats 
cannot be examined (airports, vendors' facilities, etc.). Rather than trying to make universal simulants, which often do not provide adequate matches across multiple instruments, this method focuses on making accurate simulants specific to the instruments on which they are designed. This is accomplished by matching the end signal output of these instruments rather than trying to match the properties inherent to X-ray interactions with materials. Our original methodology was developed on a liquid bottle screener on which we created simulants for five concentrations of hydrogen peroxide, four concentrations of nitric acid, and nitrobenzene. The methodology was applied to a computed tomography baggage scanner to make three hydrogen peroxide simulants and prove the applicability of the simulant development method. The method was tested for its applicability to solid threats and was found to require significant additional tweaks before moving on from liquid threats. 


\section{ACKNOWLEDGMENTS}

I would like to thank the U.S. Department of Homeland Security (DHS) for funding. However, the views and conclusions contained are those of the authors and should not be interpreted as necessarily representing the official policies, either expressed or implied, of the DHS. I would also like to thank my advisors Dr. Jimmie Oxley and Dr. James Smith for their mentoring, guidance, and support. Additionally I would like to thank my fellow graduate students and undergraduates in the Oxley/Smith group for providing extra hands and eyes when needed and for letting me bounce my ridiculous ideas off of them. I would like to thank my wonderful betrothed Julie Whelan for her support and for keeping me sane while I worked on my thesis. I would like to thank the URI Chemistry Department for putting up with me for my 12 year undergraduate and graduate career. I would like to thank my parents for their support throughout my extended time at URI. 


\section{PREFACE}

This thesis has been prepared in manuscript format. Each of the three chapters is formatted for the journal of energetic materials. The second chapter is a collaborative paper with a theoretical chemistry group based in Israel. While the experiments described were performed as part of this thesis, the theoretical DFT calculations were not. The DFT sections are included as they are part of the manuscript and help describe the motivation for the experiments performed. 


\section{TABLE OF CONTENTS}

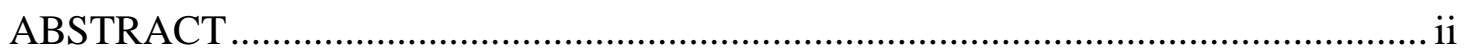

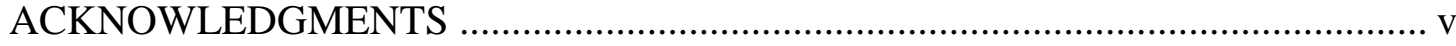

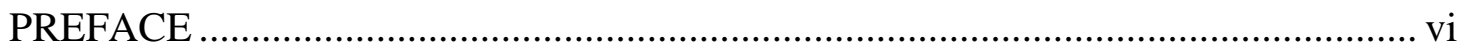

LIST OF TABLES ………………………………….................................... ix

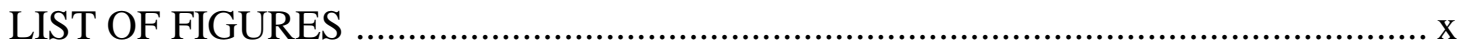

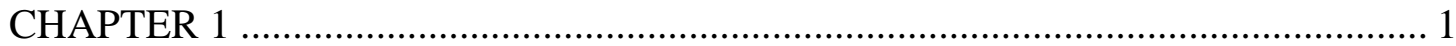

Eutectics of Erythritol Tetranitrate..............................................................................

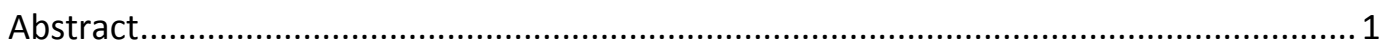

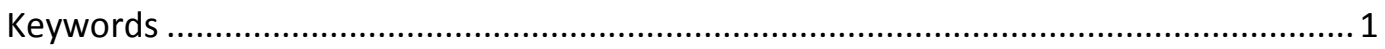

Introduction ............................................................................................

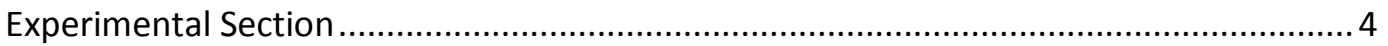

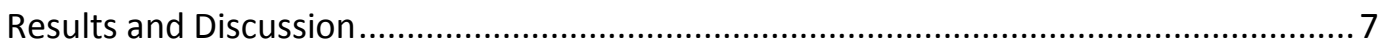

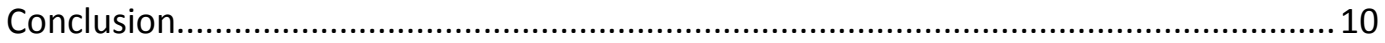

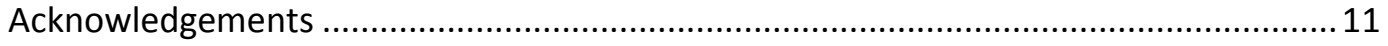

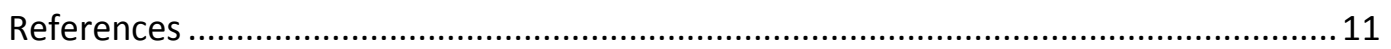

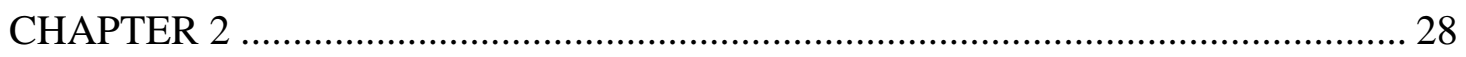

Thermal Decomposition of Erythritol Tetranitrate............................................................28

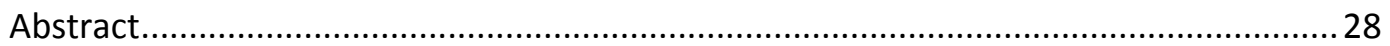

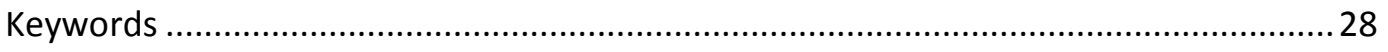

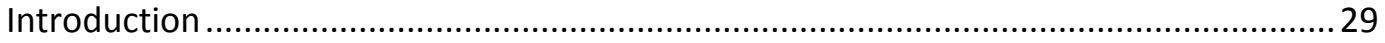

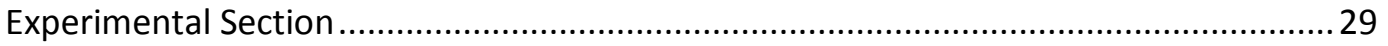

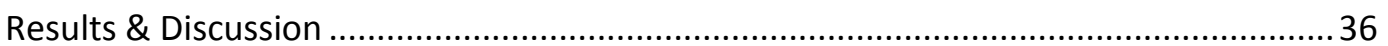

Conclusions ...................................................................................................... 41

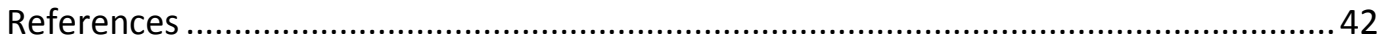

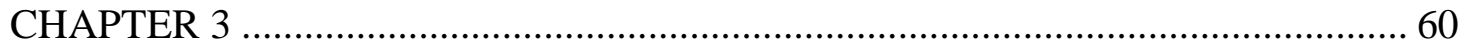

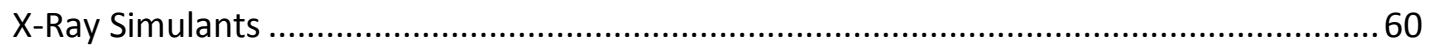




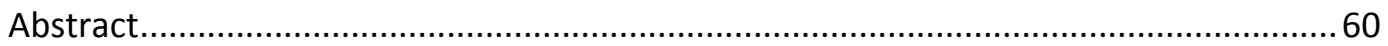

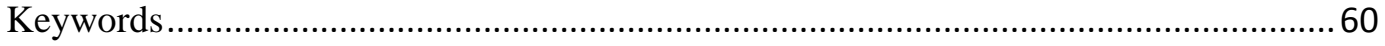

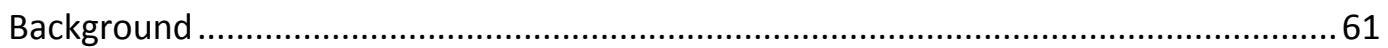

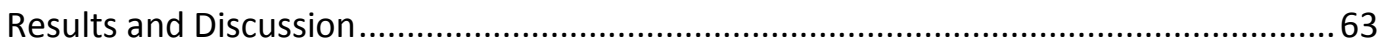

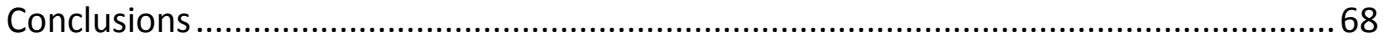

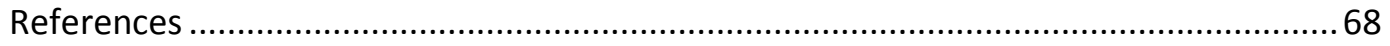

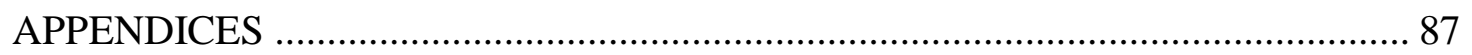

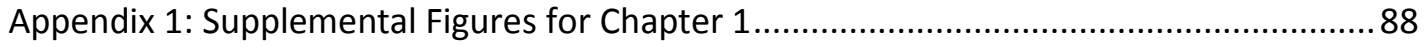

Appendix 2: Supplemental Figures for Chapter 2 .......................................................... 118

Appendix 3: Supplemental Figures for Chapter 3......................................................... 121 


\section{LIST OF TABLES}

TABLE

PAGE

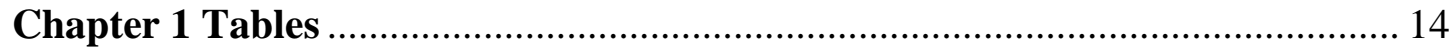

Table 1.1: Published eutectics of tetranitrate esters ............................................... 14

Table 1.2: Eutectic components pure- DSC melt \& exotherm data $\left(10^{\circ} \mathrm{C} / \mathrm{min}\right) \ldots \ldots \ldots 15$

Table 1.3: Typical DSC data for two component mixtures ................................... 16

Table 1.4: Predicted and calculated eutectic ratios and melting points .................... 17

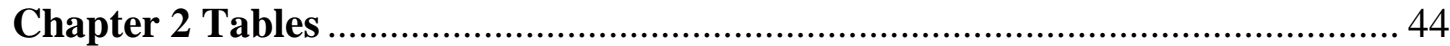

Table 2.1: Table with ETN kinetics data both neat and in benzene.......................... 44

Table 2.2: Arrhenius parameters for ETN and PETN ....................................... 45

Table 2.3: Energy (kcal/mol) comparisons (method \& basis set PBE0/cc-pvDZ) ..... 46

Table 2.4: Decomposition products searched for by high resolution LCMS ............ 47

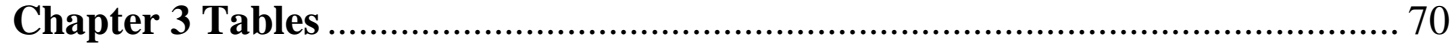

Table 3.1: Compounds used to make liquid $\mathrm{x}$-ray samples .................................. 70

Table 3.2: Innocuous liquids used to construct simulants ..................................... 71

Table 3.3: Twenty-five potential simulant mixtures of $\mathrm{BaCl}_{2}$ and $\mathrm{KBr}$................... 72

Table 3.4: Successful simulants created in this study ......................................... 73 


\section{LIST OF FIGURES}

FIGURE

PAGE

Chapter 1 Figures. 18

Figure 1.1: Solidus and liquidus melt endotherms. 18

Figure 1.2: Phase diagrams for ETN-TNT generated using a) peak DSC data, b) offset DSC data. 19

Figure 1.3: Phase diagrams for ETN-TNAZ generated using a) peak DSC data, b) offset DSC data 20

Figure 1.4: Phase diagrams for ETN-DNAN generated using a) peak DSC data, b) offset DSC data 21

Figure 1.5: Phase diagrams for ETN-PETN generated using a) peak DSC data, b)

offset DSC data 22

Figure 1.6: Phase diagrams for TNT-PETN generated using a) peak DSC data, b)

offset DSC data 23

Figure 1.7: Phase diagrams for DNAN-TNAZ generated using a) peak DSC data, b)

offset DSC data 24

Figure 1.8: Phase diagrams for ETN-SMX generated using a) peak DSC data, b) offset DSC data 25

Figure 1.9: DSC of 52-48 mol\% DNAN-TNAZ 26

Figure 1.10: Tamman plots for a) ETN-TNT, b) ETN-TNAZ, c) ETN-DNAN, d) RSalt-TNT, e) DNAN-TNAZ, f) ETN-SMX 27

Chapter 2 Figures. 48 
Figure 2.1: Nitration of erythritol to ETN, stepwise nitration of each alcohol 48

Figure 2.2: DSC overlay of ETN (Green) and PETN (Red) $\left(10^{\circ} \mathrm{C} / \mathrm{min}\right)$. 49

Figure 2.3: Arrhenius plots for ETN and PETN ............................................ 50

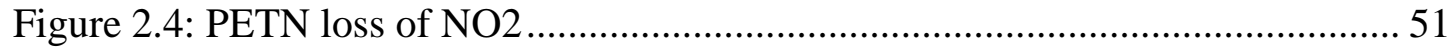

Figure 2.5: Energetics of PETN decomposition calculated by PBE0//cc-pVDZ...... 52

Figure 2.6: Energetics of ETN decomposition, calculated by B3LYP/6-311++G(d,p)

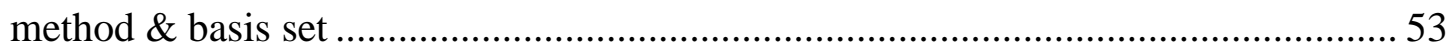

Figure 2.7: ETN intermolecular decomposition routes........................................ 54

Figure 2.8: Extracted ion chromatograms (291.9825) of erythritol trinitrate a) crude b)

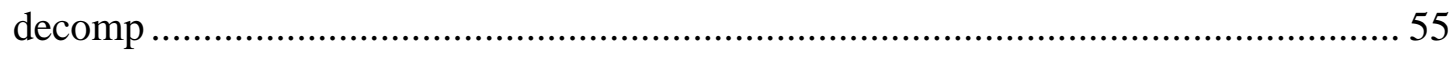

Figure 2.9: IR of ETN, theoretical (top), experimental (bottom). Red: ONO scissoring (Calc: 820-854 cm-1, Exp: 827-874 cm-1); Green: symmetric NO2 stretching (Calc: 1326-1337 cm-1, Exp: 1259-1277 cm-1); Purple: asymmetric NO2 stretching (Calc:

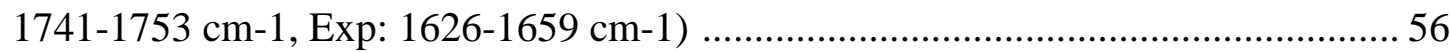

Figure 2.10: Raman of ETN, theoretical (top), experimental (bottom). Red: OCH rocking (Calc: 586-592 cm-1, Exp: $564 \mathrm{~cm}-1$ ); Green: NO2 scissoring (Calc: $854 \mathrm{~cm}-$ 1, Exp: 870 cm-1); Purple: NO2 symmetric stretching (Calc: 1337 cm-1, Exp: 1296

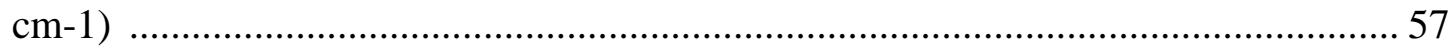

Figure 2.11: Carbon NMR of ETN in DMSO-d6 ............................................ 58

Figure 2.12: Proton NMR of ETN a) in $\mathrm{CDCl} 3 \mathrm{~b}$ ) in deuterated acetone .................. 59

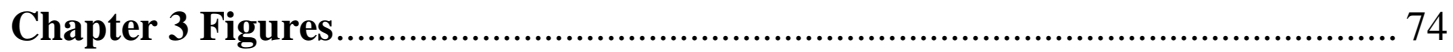

Figure 3.1: Response trendlines originating from water for many aqueous solutions.... 
Figure 3.2: $\mathrm{BaCl} 2$ response trendline shifted from origin of water to propanol passing

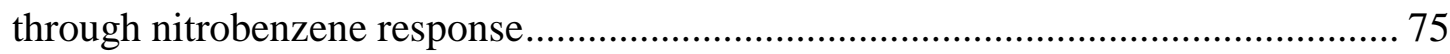

Figure 3.3: a) Single component trendlines for $\mathrm{BaCl} 2$ and $\mathrm{KBr}$, b) $\mathrm{KBr}$ trendline shifted from water "zero" to $0.23 \mathrm{wt} \% \mathrm{BaCl} 2$ "zero", c) $\mathrm{BaCl} 2$ trendline shifted from water "zero" to $0.23 \mathrm{wt} \% \mathrm{KBr}$ "zero", intersection of shifted trendlines is at threat to be simulated. 76

Figure 3.4: First attempt at simulants a) $65 \% \mathrm{HP}$, b) $90 \% \mathrm{HP}$ 77

Figure 3.5: Illustration of match between instrument response to HP and simulant . 78 Figure 3.6: Illustration of match between instrument response to NA and simulant....

Figure 3.7: Experimental results from collecting 150 and 200 data points of

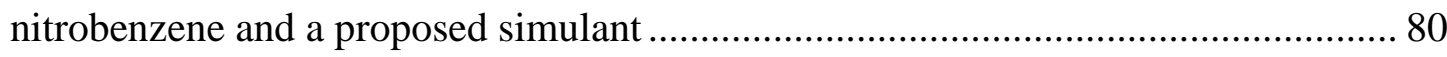

Figure 3.8: Dual-energy CT response to various aqueous solutions....................... 81 Figure 3.9: Dual-energy CT response to HP and simulants plotted with aqueous

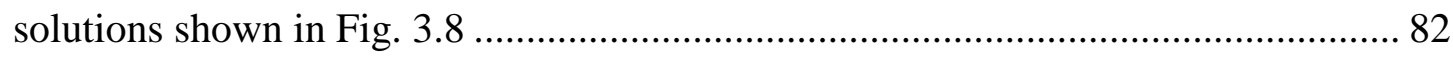
Figure 3.10: Dual-energy CT response to $\mathrm{HCl}$ and simulants plotted with aqueous solutions shown in Fig. 3.8 83

Figure 3.11: Single energy CT histograms a) simulant attempt b) simulant adjustment 84

Figure 3.12: Single-energy CT response to uniform variation in concentration a) HP in water, b) $\mathrm{MgSO} 4$ in urea 85

Figure 3.13: Two sets of urea/MgSO4 mixtures compared .................................. 86

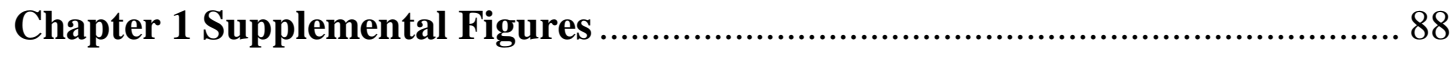


SF 1.1a: DSC trace for ETN $\left(10^{\circ} \mathrm{C} / \mathrm{min}\right)$ 88

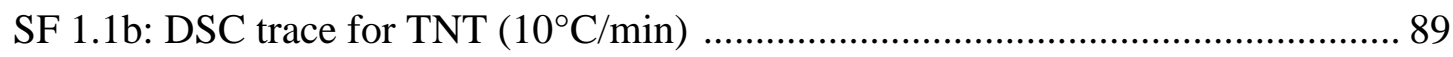

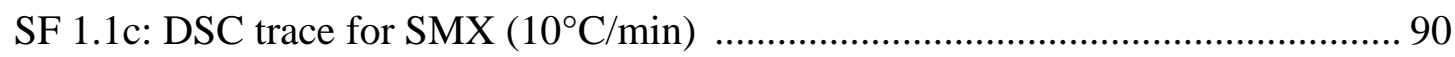

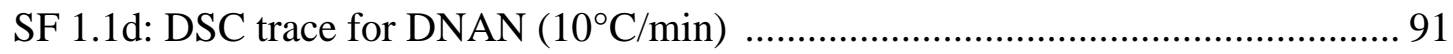

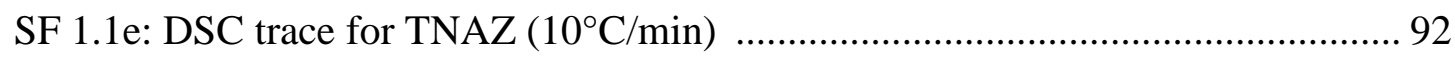

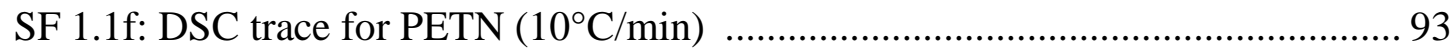

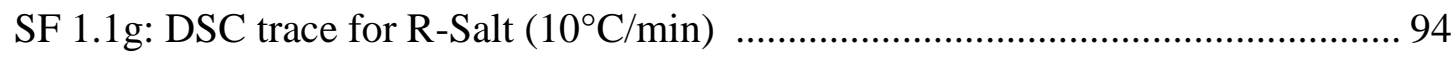

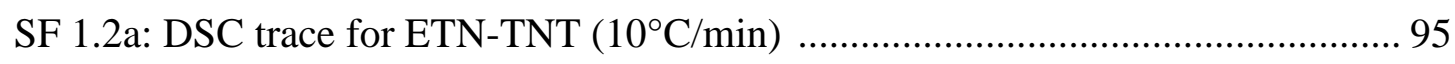

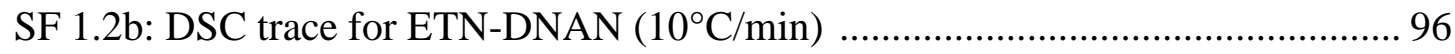

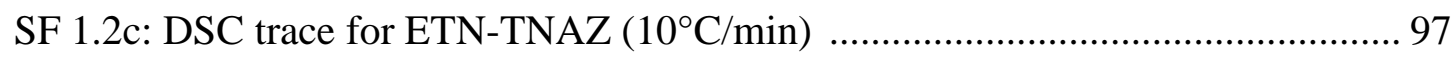

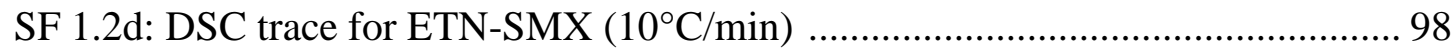

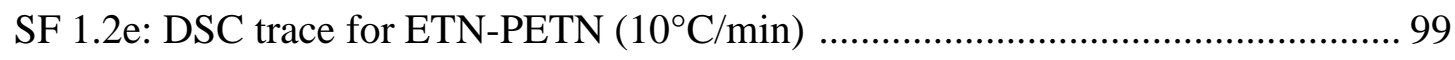

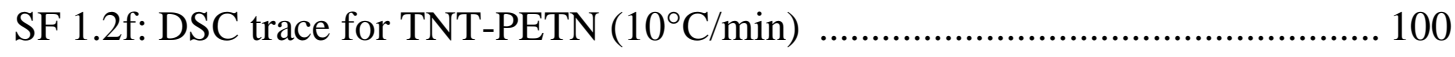

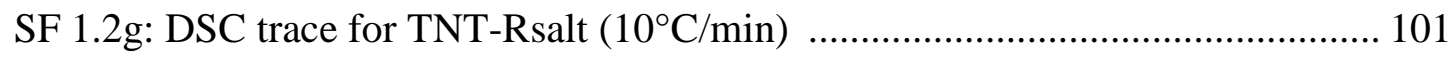

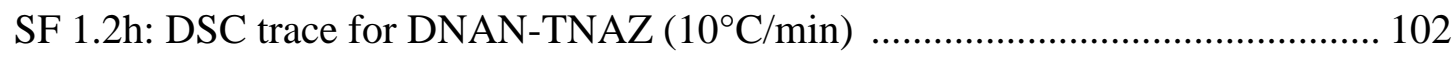

SF 1.3a: Theoretical phase diagram for ETN-TNT predicted by equation 1 ........... 103

SF 1.3b: Theoretical phase diagram for ETN-DNAN predicted by equation 1 ........ 104

SF 1.3c: Theoretical phase diagram for ETN-TNAZ predicted by equation $1 \ldots \ldots \ldots 105$

SF 1.3d: Theoretical phase diagram for ETN-SMX predicted by equation 1 ........... 106

SF 1.3e: Theoretical phase diagram for ETN-PETN predicted by equation $1 \ldots \ldots \ldots . . .107$

SF 1.3f: Theoretical phase diagram for TNT-PETN predicted by equation $1 \ldots \ldots \ldots . .108$

SF 1.3g: Theoretical phase diagram for DNAN-TNAZ predicted by equation 1 ..... 109

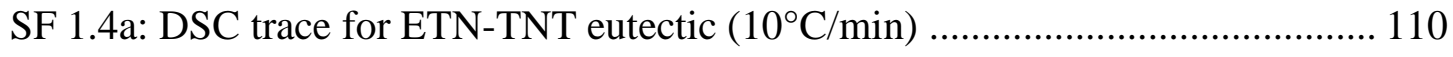


SF 1.4b: DSC trace for ETN-DNAN eutectic $\left(10^{\circ} \mathrm{C} / \mathrm{min}\right)$ 111

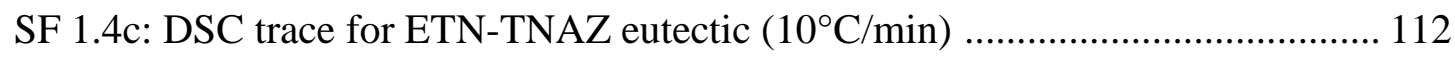

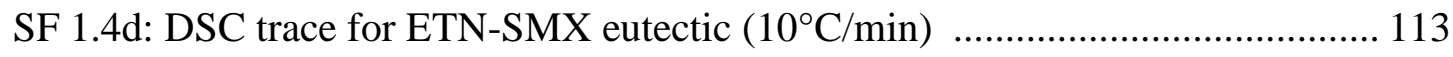

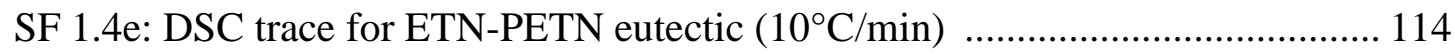

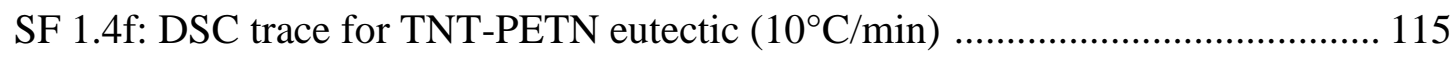

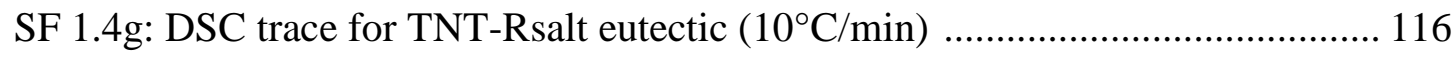

SF 1.4h: DSC trace for DNAN-TNAZ eutectic $\left(10^{\circ} \mathrm{C} / \mathrm{min}\right)$............................... 117

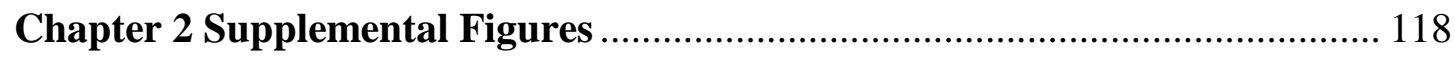

SF 2.1: Extracted ion chromatograms for ETN decomposition products: tetranitrate,

trinitrate, dinitrate, mononitrate (top to bottom) …........................................ 118

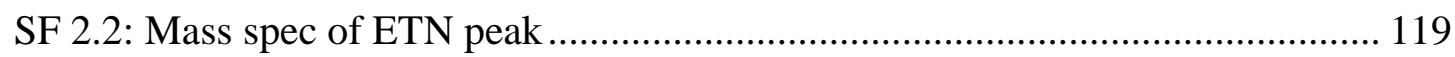

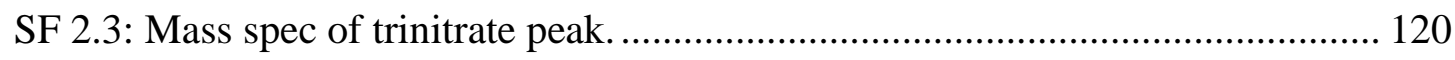

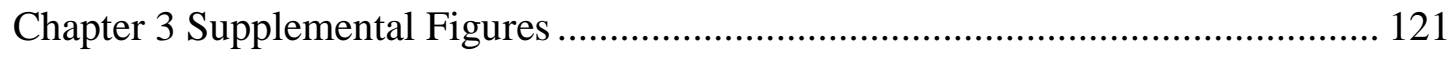

SF 3.1: Nitrobenzene simulant attempts (Success: Sim NB) …......................... 121

SF 3.2: 65\% hydrogen peroxide simulant attempts (Success: Sim II) .................... 122

SF 3.3: 80\% hydrogen peroxide simulant attempts (Success: Sim III 6+) ............... 123

SF 3.4: $85 \%$ hydrogen peroxide simulant attempts (Success: Sim IV +++)............ 124

SF 3.5: 90\% hydrogen peroxide simulant attempts (Success: Sim V 4+) ............... 125

SF 3.6: Nitric acid simulant a) first attempt, b) adjusted simulant ....................... 126 


\title{
CHAPTER 1
}

\section{Eutectics of Erythritol Tetranitrate}

\author{
Jimmie C. Oxley*; James L. Smith; Austin C. Brown \\ University of Rhode Island, Chemistry Department \\ 140 Flagg Road \\ Kingston, RI, 02881 \\ joxley@chm.uri.edu \\ Submitted to the Journal of Energetic Materials
}

\begin{abstract}
With the recent availability of erythritol as an artificial sweetener, the synthesis of erythritol tetranitrate (ETN) has become economically feasible. This paper examines eutectics of ETN, to see if it can be a useful component in melt-casted explosive formulations. To this end we report several novel ETN-energetic eutectics, correct ratios and melt-temperature for a previously reported eutectic, and examine a new eutectic composed of insensitive explosives.
\end{abstract}

\section{Keywords}

Eutectic; explosive; melt-cast; erythritol tetranitrate 


\section{Introduction}

Erythritol tetranitrate (ETN) is a nitrate ester that was first synthesized over 100 years ago; ${ }^{1}$ however, its alcohol precursor has only recently become widely available. $^{2}$ With the increased availability of the precursor erythritol, ETN began showing up on law enforcements radar. ${ }^{3}$ While our previous studies have focused on characterizing the threat associated with ETN, we now are evaluating its potential benefits. ${ }^{2}$ ETN is one of few explosives that has a stable molten state (m.p. $=61{ }^{\circ} \mathrm{C}$ ), suggesting it can be melt cast. Melt casting allows shaping of an explosive or explosive mixture by pouring the molten explosive or explosive slurry containing particles of a second explosive into a mold to solidify. 2,4,6- Trinitrotoluene (TNT) is the usual explosive employed for melt casting; it is heated between $80-120{ }^{\circ} \mathrm{C}$ using steam or water bath. ${ }^{4}$ TNT has long been the choice for melt casting even though it has a number of drawbacks in terms of performance, toxicity, and availability. Yet, TNT is the base matrix for explosives, such as Composition B and Octol, because there are few alternatives. In the 1990's TNAZ was considered as a potential TNT replacement in this role, ${ }^{5}$ but it melted higher than TNT $\left(101{ }^{\circ} \mathrm{C}\right)$; and, worse, it had a strong tendency to sublime. ${ }^{6}$ Recently, 2,4-dinitroanisole (DNAN) has been employed as the melted matrix in preparing insensitive explosives $;^{7}$ however, like TNT, DNAN is toxic, ${ }^{8}$ and it offers poorer performance than even TNT. ${ }^{9}$ Because ETN has a long stable melt region, it appeared desirable to consider its potential for eliminating or supplementing TNT. ETN is more powerful than TNT. It is easy to synthesize and less toxic than nitroarenes; in fact, its use has been approved as a vasodialator. ${ }^{10}$ However, ETN it is more sensitive than TNT, with a drop weight $\mathrm{H}_{50}$ slightly lower than PETN. ${ }^{2}$ 
Neat ETN may not be a viable option as a replacement for TNT due to sensitivity; however, eutectic mixtures with ETN might allow for some substitution of ETN into melt cast formulations.

Eutectics of explosives have been investigated in several studies over the years. ${ }^{11-14}$ In the 1930's Urbanski studied a number of energetic eutectics, including some with ETN. ${ }^{15-19}$ His work can be found in the original Polish or partially translated in his book ${ }^{20}$ and in the Encyclopedia of Explosives (Table 1.1). ${ }^{21}$ Chapman used published eutectic ratios for 74 binary energetic materials to create a trend line. Chapman modified the van't Hoff equation (Eq 1) to create equation $2 .^{22}$ The van't Hoff equation (Eq 1) predicts the relationship between pure melting compounds and their melting point in a eutectic mixture, based on the temperature and heat of fusion of pure melts. ${ }^{23}$ Equation 2 estimates the theoretical eutectic ratio for explosives based only on the melting temperatures of the pure compounds.

$$
\begin{aligned}
& \mathrm{R} * \ln (X)=\Delta \mathrm{H}_{\text {fus }} *\left(-1 / \mathrm{T}+1 / T^{m}\right) \\
& \ln \left(\frac{X_{A}}{x_{B}}\right)=-4077.04\left(\frac{1}{T_{B}^{m}}-\frac{1}{T_{A}^{m}}\right)-0.0979
\end{aligned}
$$

where $\mathrm{A}$ is solute, $\mathrm{B}$ is solvent; $\mathrm{T}$ is liquidus melting temperature of the mixture $(\mathrm{K})$; $\mathrm{R}$ is the gas constant $1.987 \mathrm{cal} / \mathrm{K}^{*} \mathrm{~mol} ; X$ is the mol fraction of A or $\mathrm{B} ; \Delta \mathrm{H}_{\text {fus }}$ is the heat of fusion of $\mathrm{A}$ or $\mathrm{B}$; and $T^{n}$ is the melting temperature of pure $\mathrm{A}$ or $\mathrm{B} .{ }^{14,11}$

Eutectic mixtures have a decreased melting point from either of the pure compounds from which they are composed. ${ }^{24}$ Eutectics can be used to decrease melting point, in some cases taking two solids and creating a liquid, ${ }^{25}$ and eliminate other undesirable properties, e.g. hygroscopisity. ${ }^{24}$ Ideally a eutectic mixture containing ETN could provide more desirable properties than ETN alone. 


\section{Experimental Section}

Compounds chosen for study were generally those which have relatively stable liquid phases, the exception being PETN which was chosen due to its inclusion in current melt cast compositions. Because a eutectic is defined by its unique melting point, somewhat lower than either component, DSC is ideal for examination of various two component mixtures in a variety of ratios. The chosen compounds are shown in Table 1.2 along with experimentally found differential scanning calorimetry (DSC) results.

To provide accurate mass of each component, DSC samples were prepared by weighing individual components into the same aluminum hermetic pan, such that their combined mass was 0.9 to $1.1 \mathrm{mg}$. Samples represented a range of mole percentages from $0-100 \%$ for each compound. Samples were scanned on a DSC Q100 (TA Instruments) and analyzed using TA UA 2000 software. The DSC was calibrated to indium, $\left(\mathrm{mp}=156.6^{\circ} \mathrm{C}, \Delta \mathrm{H}=28.71 \mathrm{~J} / \mathrm{g}\right)$, and samples were run under a flow of nitrogen $(50 \mathrm{~mL} / \mathrm{min})$ with ramp rate of $10^{\circ} \mathrm{C} / \mathrm{min}$ starting at $20^{\circ} \mathrm{C}$. The final temperature of each DSC run was slightly above the melting point of the higher

melting species. Termination temperatures for the mixtures are shown in Table 1.3. DSC traces described in Table 1.2 and 1.3 can be found in supplemental information (SF 1.1, SF 1.2).

A binary eutectic mixture will always begin to melt at its eutectic temperature; however, only a specific ratio of components will result in the entire mixture melting at this lower temperature. This specific eutectic ratio will always have an isolated melt at the eutectic temperature. This is called the solidus melt since it is the temperature 
below which the mixture is entirely solid. ${ }^{26}$ At all ratios other than the eutectic ratio, there will be a second melt at a temperature higher than the solidus melt. This second melt is the point above which the solution is entirely liquid and is called the liquidus melt. ${ }^{27}$ The liquidus melt corresponds to the excess of one component melting after the other component has been used up in the solidus melt. As apparent in the DSC trace of each two component mixture, there was a low temperature endotherm, the solidus melt, and a higher temperature endotherm, the liquidus melt (Fig. 1.1). The solidus melt occurred at the eutectic melting temperature and corresponded to an isolated melt of the ideal eutectic composition. The eutectic melt consumes one of the two components in the mixture, leaving an excess of the other. The liquidus melt temperature varied with the composition of the mixture and corresponded to the remaining excess component melting into the previously melted eutectic composition. The first time a mixture was melted it sometimes had multiple liquidus peaks due to insufficient mixing of the solid powder components. These samples were termed "first melts;" and if they had not been run to their decomposition temperature, they could be cooled to room temperature and heated again. The second run gave a much cleaner DSC trace than the first since the compounds were more thoroughly mixed after the first melt. However, some mixtures showed significant decomposition after being melted the first time, resulting in less heat absorbed in the solidus melt or no solidus melt at all. Re-melted sample data where decomposition was apparent and first melt data where the sample was clearly not mixed were discarded. The data judged as "good" was analyzed independently-- first run data separate from pre-melted data--and eutectic ratio calculated. 
The temperature and heat absorbed as indicated on the DSC traces were used to assign the eutectic ratio between component $\mathrm{A}$ and component $\mathrm{B}$. Eutectic melting points were determined by the onset of the solidus melt endotherm (Table 1.3). The eutectic ratio of each component was calculated by three methods.

1) Using temperature of the endothermic maxima (e.g. 42.69 and $55.26^{\circ} \mathrm{C}$ on Figure 1.1), phase diagrams, (Figs 1.2-1.8a) were constructed. The composition where the two liquidus lines intersected was lowest melting, i.e. the eutectic composition.

2) A second method used the temperatures of the start of the endotherm and its return to baseline (e.g. 41.07 and $57.46^{\circ} \mathrm{C}$ on Figure 1.1) to construct phase diagrams (Figs 1.2-1.8b). As the molar ratios approached the eutectic composition ratio, from either side, the liquidus endotherm shifted closer to the solidus endotherm until the two peaks merged at the eutectic ratio. This resulted in two lines moving in and down from the edges of the plot $(0 \%$ and $100 \%$ ETN) towards the middle and intersecting at the eutectic composition.

3) A third method for analyzing the DSC data was construction of Tamman plots (Fig 1.10). They were constructed by integrating the solidus peak and plotting the enthalpy of the solidus melt versus the mole percentage of one of the components. Since the components always melt as much as possible in the eutectic ratio at the solidus melt, the heat of fusion of the solidus melt increased as the overall composition approached the eutectic ratio as a whole. In this case the two lines approaching from either side $(0 \%$ and $100 \%$ 
component) moved up and intersected at a maximum corresponding to the eutectic ratio.

In addition to DSC experiments, theoretical phase diagrams were constructed by solving for $\mathrm{T}$ in the van't Hoff equation (Eq 1) at mole fractions from 0-100 in increments of 5 mole fractions. Heats of fusion for input into equation (1) were taken from DSC runs at $10{ }^{\circ} \mathrm{C} / \mathrm{min}$. Plotting the $\mathrm{T}$ values for compound A alongside those for compound B produced two intersecting lines. These lines represent the theoretical phase diagram and meet at the eutectic melting point and ratio (see supplemental information SF 1.3).

\section{Results and Discussion}

Construction of Theoretical Phase Diagrams: Calculated eutectic melting points and eutectic ratios for each mixture are given in Table 1.4 along with the experimentally determined values. (Attempts to create eutectics of ETN with RDX failed to give a clear eutectic melting point, possibly because the RDX melting point was too far from the melting point of ETN.) The van't Hoff equation (Eq 1) implies that the molar ratio and melting point depression of a eutectic mixture primarily depend on two factors, the melting points of the two pure compounds and the heat of fusion of each. If the pure compounds have similar melting points, the melting point depression in the eutectic would be larger than if the melting points of the two compounds were far

apart. For example, the melting point of a eutectic between two compounds with a melting point differing over $100^{\circ} \mathrm{C}$ will essentially be no different than the melting point of the pure compound with the lowest melting point. Additionally, the overall heat of fusion of both compounds affects the melting point depression. Lower heats of 
fusion lead to increased melting point depression, while higher heats of fusion lead to higher theoretical eutectic melting temperatures. Thus, since ETN was the lowest melting component studied, the theoretical ETN eutectic melting points paralleled the melting points of the higher-melting second compounds TNT $<$ DNAN $<$ TNAZ $<$ PETN. The predicted mol\% ETN in the eutectic ratio also tended to parallel the melting point of the second compound. The temperature dependence of the eutectic ratio is the premise of equation 2 , which was also used to calculate theoretical eutectic ratios (Table 1.4).

Peak Temperature Analysis: Phase diagrams generated from the DSC endotherm peak temperature are shown in Figures 1.2a-1.8a. The eutectic temperatures and ratios determined from peak data can be found in Table 1.4; these values were generally slightly lower than those found from the theoretical phase diagrams. ${ }^{*}$ Due to the minimal eutectic temperature depression in PETN mixtures, on the excess ETN or TNT side, the eutectic ratios were taken as the point where the liquidus line from the excess PETN side met the solidus line (Fig. 1.5-1.6). On the excess ETN or TNT side the DSC traces contained only a single endotherm peak. This resulted in no data other than the solidus peak temperature trendline to compare to the PETN liquidus trendline. Using this same approach for the TNT-PETN mixture allowed calculation of a TNTPETN eutectic ratio which matched the literature value. This success supports the use of this method to provide reasonable estimations of eutectic ratios.

Generally the closer two compounds are in their pure melting points, the closer the ratio will be to 50-50 and the lower the eutectic melting point. If compounds have the same melting temperature and heat of fusion, then the theoretical eutectic ratio will 
be 50:50. If they have the same melting temperature, but compound $\mathrm{A}$ has a higher heat of fusion than compound $\mathrm{B}$, the eutectic ratio will favor compound B. For example, DNAN and TNAZ have close melting points, $96^{\circ} \mathrm{C}$ and $101^{\circ} \mathrm{C}$, respectively. When mixed in ratios between $48 / 52$ to $52 / 48$ a melt at $66^{\circ} \mathrm{C}$ was observed; but unmelted material was observed when examined on a hot-stage microscope, and the DSC showed a long endothermic region trailing from the solidus melt returning to baseline in the $93-99^{\circ} \mathrm{C}$ range (Fig. 1.9). The TNT-R salt eutectic exhibited a similar trailing region but to a lessor degree.

Offset Method: The further the eutectic melting point was from the melt of pure ETN, the easier it was to analyze because the phase diagrams were constructed using the liquidus and solidus peaks. With higher melting eutectic mixtures, the liquidus peak on the ETN excess side was often merged with the solidus peak causing difficulty in identifying the liquidus data. Decreasing DSC ramp rate below $10^{\circ} \mathrm{C} / \mathrm{min}$ provided increased resolution (separating the peaks) but not enough to give additional usable data in ratios where the solidus and liquidus peaks were merged. Instead, to help analyze mixtures with eutectic melting points too close to the pure ETN melt, the temperature of the return to baseline of the liquidus peak was plotted (Figures 1.2b1.8b). Sample masses and ramp rate were held constant enough that it was assumed these had minimal effect on the peak shape of the endotherm. For those data sets that both the peak and return to baseline temperatures could be plotted, the calculated eutectic ratio matched for both methods (Table 1.4).

Tamman Method: The ETN-TNAZ return to baseline plot (the offset method) did not provide decent data to analyze by the same methods of fitting a curve. The return to 
baseline on the excess TNAZ side had a shallow rise giving temperatures close to the pure TNAZ melt temperature right up to the point where the liquidus peaks and solidus peak merged. This results in a sharp temperature drop in the 60 mol\% ETN area from $97^{\circ} \mathrm{C}$ to $61^{\circ} \mathrm{C}$. A more successful method of evaluating eutectic composition was based on the Tamman method, based on the heat of fusion of the solidus endotherm (Fig. 1.10). Tamman results closely matched the phase diagram results for the other ETN eutectics (Table 1.4). Unfortunately, Tamman plots for PETN mixtures suffered from the same peak-merging problem mentioned above as well as lack of available data on the excess ETN or TNT side. Only the excess PETN side provided decent solidus heats of fusion for plotting. Unlike the peak phase diagrams, with only one side providing good data, Tamman plots could not be used to analyze PETN eutectics. On-the-other-hand, Tamman plots may be the only way to analyze mixtures where one or more of the components exhibits additional phase changes. The TNT-Rsalt eutectic is an example of this. R-salt has a phase transition at $95^{\circ} \mathrm{C}$ and a melt at $105^{\circ} \mathrm{C}$. This makes it difficult to construct phase diagrams based on the liquidus temperature. The eutectic ratio can be more easily estimated using a Tamman plot (Fig. 1.10). DSC traces for the melt of the eutectic ratios are included in supplemental information (SF 1.4).

\section{Conclusion}

Both melting points and heats of fusions of the individual components affect whether a successful eutectic can be created and the ratio of components used to make it. Present theoretical methods proved inadequate in predicting many ETN eutectics. In all cases mol\% ETN and temperature of the eutectic melt observed were lower than 
the theoretical predictions, although the predicted melting point matched observations more closely than predicted component ratios. Nevertheless, ETN eutectic formulations show potential and require further sensitivity and long-term stability studies. Unfortunately, the high melting point of PETN makes it impossible to form eutectics with low melting ETN or TNT in any ratio close to 50/50. However, even though ETN melts $20^{\circ} \mathrm{C}$ below TNT, its eutectic incorporates more PETN than that with TNT. The eutectic-like behavior of the two insensitive explosives, DNAN and TNAZ, deserves further study.

\section{Acknowledgements}

The authors thank the U.S. Department of Homeland Security (DHS) for funding. However, the views and conclusions contained are those of the authors and should not be interpreted as necessarily representing the official policies, either expressed or implied, of the DHS.

\section{References}

(1) Fedoroff, B. T.; Sheffield, O. E. Encyclopedia of Explosives and Related Items, Vol. 5.; Picatinny Arsenal: Dover, NJ, 1972.

(2) Oxley, J. C.; Smith, J. L.; Brady, J. E.; Brown, A. C. Propellants, Explos. Pyrotech. 2012, 37 (1), 24-39.

(3) Cook, M. Escondido: Authorities to burn "bomb factory" house http://www.sandiegouniontribune.com/news/2010/nov/30/escondido-authorities-toburn-bomb-factory-house/.

(4) Ravi, P.; Badgujar, D. M.; Gore, G. M.; Tewari, S. P.; Sikder, A. K. Propellants, Explos. Pyrotech. 2011, 36 (5), 393-403. 
(5) Watt, D. S.; Cliff, M. D. TNAZ Based Melt Cast Explosives: Technology Review and AMRL Research Directions; Melbourne, 1998.

(6) Sikder, N.; Sikder, A. K.; Bulakh, N. R.; Gandhe, B. R. J. Hazard. Mater. 2004, 113 (1-3), 35-43.

(7) Lee, K. E.; Balas-Hummers, W. A.; Di Stasio, A. R.; Patel, C. H.; Samuels, P. J.; Roos, B. D.; Fung, V. In Insensitive Munitions and Energetic Materials Technology Symposium; Munich, Germany, 2010; pp 1-13.

(8) Dodard, S. G.; Sarrazin, M.; Hawari, J.; Paquet, L.; Ampleman, G.; Thiboutot, S.; Sunahara, G. I. J. Hazard. Mater. 2013.

(9) Davies, P. J.; Provatas, A. Characterisation of 2, 4-Dinitroanisole: An Ingredient for use in Low Sensitivity Melt Cast Formulations; Edinburgh, South Australia, Australia, 2006.

(10) DrugBank http://www.drugbank.ca/drugs/DB01613.

(11) Liu, Z.-R.; Shao, Y.; Yin, C.-M.; Kong, Y.-H. Thermochim. Acta 1995, 250, $65-76$.

(12) Yin, C.-M.; Liu, Z.-R.; Shao, Y.-H.; Kong, Y.-H. Thermochim. Acta 1995, 250 (1), 77-83.

(13) McKenney, R. L.; Stevens, W. E.; Floyd, T. G. J. Energ. Mater. 2006, 16 (4), $245-277$.

(14) Yin, C. M.; Liu, Z. R.; Kong, Y. H.; Jia, C. L.; Guo, X. M. Thermochim. Acta 1995.

(15) Urbanski, T. Rocz. Chem. 1933, 13, 399-434.

(16) Urbanski, T. Rocz. Chem. 1934, 14, 925-940. 
(17) Urbanski, T. Rocz. Chem. 1935, 15, 191-197.

(18) Urbanski, T. Rocz. Chem. 1936, 16, 359-365.

(19) Urbanski, T. Rocz. Chem. 1937, 17, 585-590.

(20) Urbanski, T. Chemistry and Technology of Explosives Volume 2; 1961.

(21) Fedoroff, B. T.; Sheffield, O. E. ENCYCLOPEDIA OF EXPLOSIVES AND RELATED ITEMS; 1974; Vol. 6.

(22) Chapman, R. D. Propellants, Explos. Pyrotech. 1998, 23, 50-55.

(23) Reisman, A. Phase Equilibria; Academic Press: New York, 1970.

(24) Cherukuvada, S.; Nangia, A. Chem. Commun. 2014, 50, 906-923.

(25) Broberg, B. F. J.; Evers, H. C. A. US Pat., 4529601, 1985.

(26) http://www.oxforddictionaries.com/us/definition/ american_english/solidus.

(27) http://www.oxforddictionaries.com/us/definition/ american_english/liquidus. 
Table 1.1: Published eutectics of tetranitrate esters

\begin{tabular}{|c|c|c|c|c|c|}
\hline \multicolumn{6}{|c|}{ ETN (m.p. $61^{\circ} \mathrm{C}$ ) Euctectics } \\
\hline & \multicolumn{2}{|c|}{ m.p. $\left({ }^{\circ} \mathrm{C}\right)$} & wt $\%$ & mole \% & \multirow[b]{2}{*}{ Ref } \\
\hline B & Pure B & Eutectic & A & A & \\
\hline m-Dinitrobenzene & 89.5 & 42 & 70 & 56 & $15,20,21$ \\
\hline Mannitol hexanitrate & 112.5 & 58 & 81.5 & 87 & 15,21 \\
\hline Pentaerythritol tetranitrate & 140 & 60 & 95 & 95 & $15,20,21$ \\
\hline p-Mononitrotoluene & 54.5 & 32 & 47 & 29 & $15,20,21$ \\
\hline p-Nitrophenetole & 57.8 & 41 & 50 & 36 & 16 \\
\hline 2,4,6-Trinitrotoluene & 81 & ? & $81^{*}$ & ? & 16 \\
\hline 2,4-Dinitrotoluene & 69.4 & 40 & 61 & 49 & $17,20,21$ \\
\hline Diethyl diphenyl urea & 71.8 & 42 & 37 & 34 & 17 \\
\hline 2,4,6-Trinitroanisole & 68.4 & 59 & $16 ?$ & 13 & 17,21 \\
\hline 2,4,6-Trinitroanisole & 68.4 & 52 & 76 & 72 & 17,21 \\
\hline Trinitrobenzene & 121.5 & 46 & 67 & 59 & $17,20,21$ \\
\hline 2,4,6-Trinitrophenetole & 78.1 & 46 & 62 & 58 & 18 \\
\hline 2,4,5-Trinitrotoluene & 104 & 51 & 76 & 70 & 19 \\
\hline \multicolumn{6}{|c|}{$\begin{array}{l}\text { * ETN/TNT phase diagram appears to have } 2 \text { nd minima; not observed in our studies } \\
\text { ? Value of second minima appears to be closer to } 26 \% \text { rather than } 16 \% \text { in Polish text }\end{array}$} \\
\hline \multicolumn{6}{|c|}{ PETN (m.p. $140^{\circ} \mathrm{C}$ ) Euctectics } \\
\hline Mannitol hexanitrate & 113 & 101 & 80 & 85 & 21 \\
\hline p-Mononitrotoluene & 55 & 50 & 10 & 5 & 15,21 \\
\hline m-Dinitrobenzene & 90 & 82 & 20 & 12 & 15,21 \\
\hline 3,5-Dinitroanisole* & 104 & 95 & 20 & 14 & 15,21 \\
\hline Trinitrobenzene & 122 & 101 & 30 & 22 & 15,21 \\
\hline 2,4,6-Trinitrotoluene & 80 & 76 & 13 & 10 & 15,21 \\
\hline 2,4-Dinitrotoluene & 70 & 67 & 10 & 6 & 16 \\
\hline Diphenylamine & 53 & 53 & 1 & 1 & 16 \\
\hline Camphor & 180 & 91 & 36 & 21 & 16 \\
\hline Tetryl & 131 & 111 & 30 & 28 & 16 \\
\hline p-Nitroanisole & 52 & 51 & 5 & 2 & 15 \\
\hline 1-Nitronaphthalene & 59 & 55 & 4 & 2 & 15 \\
\hline 2,4-Chlorodinitrobenzene & 50 & 49 & 3 & 2 & 15 \\
\hline Naphthalene & 81 & 79 & 7 & 3 & 15 \\
\hline Dimethyl diphenyl urea & 123 & 103 & 32.5 & 27 & 15 \\
\hline Diethyl diphenyl urea & 72 & 68 & 12 & 10 & 15 \\
\hline Phthalide & 72 & 66 & 20 & 10 & 17 \\
\hline Phenylcarbamate ethyl & 49 & 49 & 1 & 1 & 17 \\
\hline Dinitrodimethyloxamide & 125 & 100 & 38 & 29 & 17 \\
\hline m-Nitroaniline & 112 & 105 & 38 & 21 & 18 \\
\hline Methyl oxalate & 54 & 51 & 15 & 6 & 18 \\
\hline \multicolumn{6}{|c|}{ * incorrectly identified as 2,4-dinitroanisole in EoE } \\
\hline
\end{tabular}


Table 1.2: Eutectic components pure- DSC melt \& exotherm data $\left(10^{\circ} \mathrm{C} / \mathrm{min}\right)$

\begin{tabular}{|c|c|c|c|c|c|}
\hline Sample & Compound Name & $\mathrm{mp}\left({ }^{\circ} \mathrm{C}\right)$ & $\begin{array}{c}\Delta \mathrm{H} \\
(\mathrm{J} / \mathrm{g})\end{array}$ & $\begin{array}{c}\text { Exo } \\
\text { Onset } \\
\left({ }^{\circ} \mathrm{C}\right)\end{array}$ & $\begin{array}{c}\text { Exo } \\
\text { Peak } \\
\left({ }^{\circ} \mathrm{C}\right)\end{array}$ \\
\hline ETN & Erythritol Tetranitrate & $60-61$ & 150 & $180-181$ & $191-196$ \\
\hline TNT & $2,4,6-$ Trinitrotoluene & $80-81$ & 115 & $310-320$ & $319-323$ \\
\hline SMX & $\begin{array}{c}2,3-\text { Hydroxymethyl-2,3-dinitro-1,4 } \\
\text { butanediol tetranitrate }\end{array}$ & $85-86$ & 98.8 & $160-170$ & $184-186$ \\
\hline DNAN & $2,4-$ Dinitroanisole & $95-96$ & 106 & $350-360$ & $366-371$ \\
\hline TNAZ & 1,3,3-Trinitroazetedine & $100-101$ & 147 & $244-246$ & $264-266$ \\
\hline PETN & Pentaerythritol Tetranitrate & $140-141$ & 182 & $192-193$ & $200-203$ \\
\hline R-Salt & Cyclotrimethylene Trinitrosamine & $105-106$ & 17 & $196-198$ & $200-202$ \\
\hline
\end{tabular}


Table 1.3: Typical DSC data for two component mixtures

\begin{tabular}{|c|c|c|c|c|}
\hline Sample & $\begin{array}{c}\mathrm{mp} \\
\left({ }^{\circ} \mathrm{C}\right)\end{array}$ & $\begin{array}{c}\text { Exo Onset } \\
\left({ }^{\circ} \mathrm{C}\right)\end{array}$ & $\begin{array}{c}\text { Exo Peak } \\
\left({ }^{\circ} \mathrm{C}\right)\end{array}$ & $\begin{array}{c}\text { Temp of termination of } \\
\text { DSC of mix }\left({ }^{\circ} \mathrm{C}\right)\end{array}$ \\
\hline ETN-TNT & $40-42$ & $175-177$ & $194-196$ & 110 \\
\hline ETN-DNAN & $47-49$ & $172-173$ & $189-195$ & 105 \\
\hline ETN-TNAZ & $53-54$ & $176-181$ & $194-196$ & 110 \\
\hline ETN-SMX & $53-55$ & $166-169$ & $180-190$ & 100 \\
\hline ETN-PETN & $56-58$ & $178-182$ & $199-202$ & 155 \\
\hline TNT-PETN & $72-75$ & $181-186$ & $203-208$ & 155 \\
\hline TNT-Rsalt & $57-60$ & $164-171$ & $176-180$ & 120 \\
\hline DNAN-TNAZ & $65-67$ & $230-240$ & $250-257$ & 115 \\
\hline
\end{tabular}


Table 1.4: Predicted and calculated eutectic ratios and melting points

\begin{tabular}{|cc|c|c|c|c|c|c|c|c|}
\hline & & \multicolumn{3}{|c|}{ Theoretical Calculation } & \multicolumn{4}{c|}{ Experimental Data Analyzed: 3 Methods } \\
\multicolumn{2}{|c|}{ Mixture } & \multicolumn{2}{|c|}{ Eq (1) } & Eq (2) & & Peak & Offset & Tamman & Ave. \\
\hline A & B & m.p. $\left({ }^{\circ} \mathrm{C}\right.$ ) & mol\% A & mol\% A & m.p. $\left({ }^{\circ} \mathrm{C}\right)$ & mol\% A & mol\% A & mol\% A & mol\% A \\
\hline ETN & TNT & 49.9 & 57.2 & 68.6 & $40-42$ & 48 & 48 & 49 & 48 \\
ETN & DNAN & 50.9 & 60.1 & 77 & $46-49$ & 50 & 50 & $55^{* *}$ & 52 \\
\hline ETN & TNAZ & 54.5 & 72.4 & 80.3 & $53-54$ & 60 & $58^{*}$ & 60 & 60 \\
ETN & SMX & 54.6 & 72.6 & 71.4 & $53-55$ & 69 & $65 *$ & $69^{* *}$ & 69 \\
\hline ETN & PETN & 60.6 & 98.2 & 92.1 & $56-58$ & 87 & 87 & N/A & 87 \\
TNT & PETN & 77.0 & 92.2 & 85.5 & $72-75$ & 90 & 90 & N/A & 90 \\
TNT & R-Salt & N/A & N/A & N/A & $57-60$ & N/A & N/A & 61 & 61 \\
DNAN & TNAZ & 67.9 & 58.6 & 57.2 & $65-67$ & 52 & $47^{*}$ & 49 & 51 \\
\hline
\end{tabular}

*Offset plot has sharp dropoff, value taken as location of dropoff, not included in Ave.

$* *$ On excess ETN side $\Delta \mathrm{H}$ used was combined solidus and liquidus due to merged peaks 
Sample: $80 / 20$ ETN/TNT

Size: $0.9980 \mathrm{mg}$

Method: Ramp 10C/min 20-110C

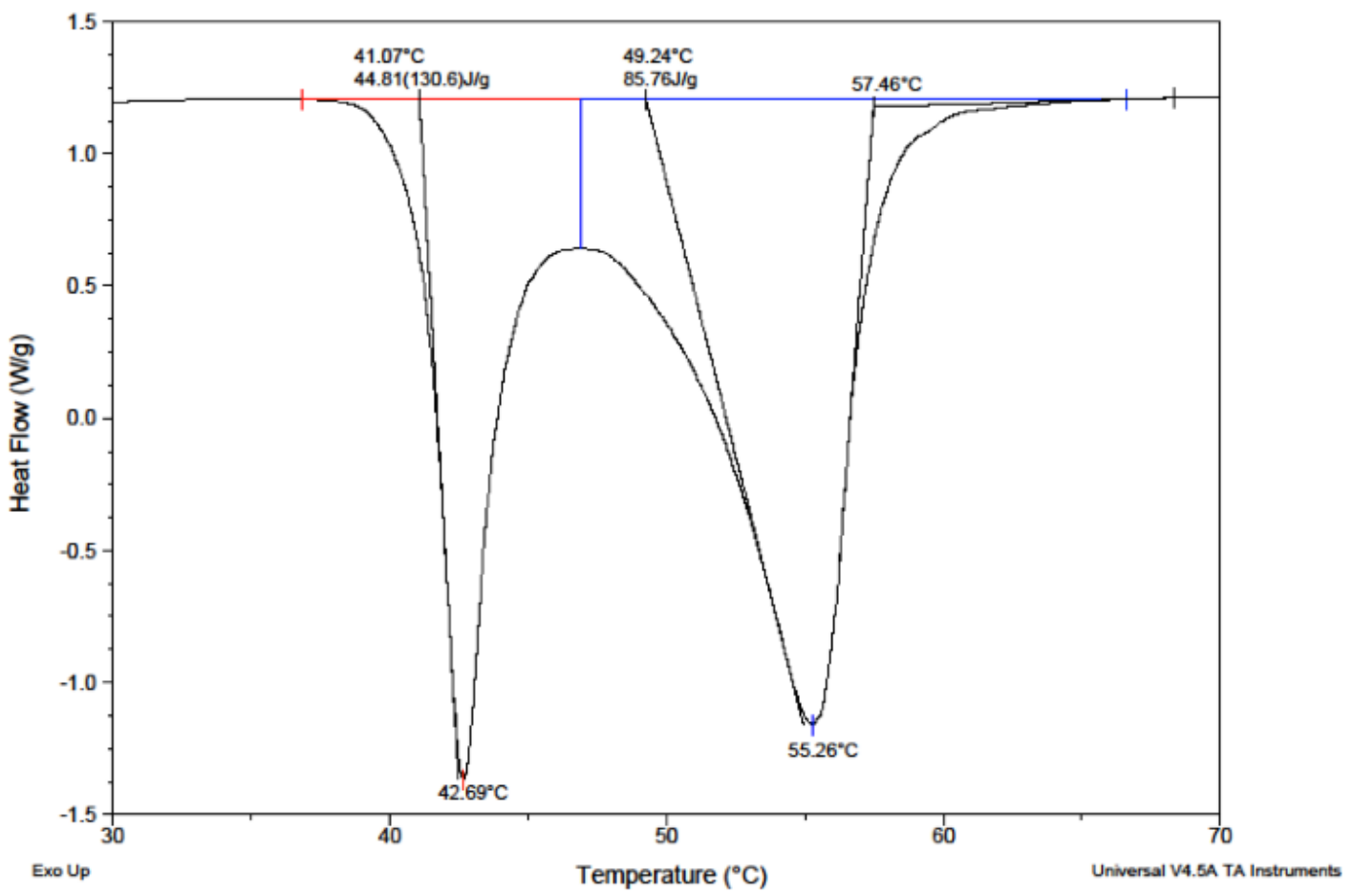

Figure 1.1: Solidus and liquidus melt endotherms 
a)

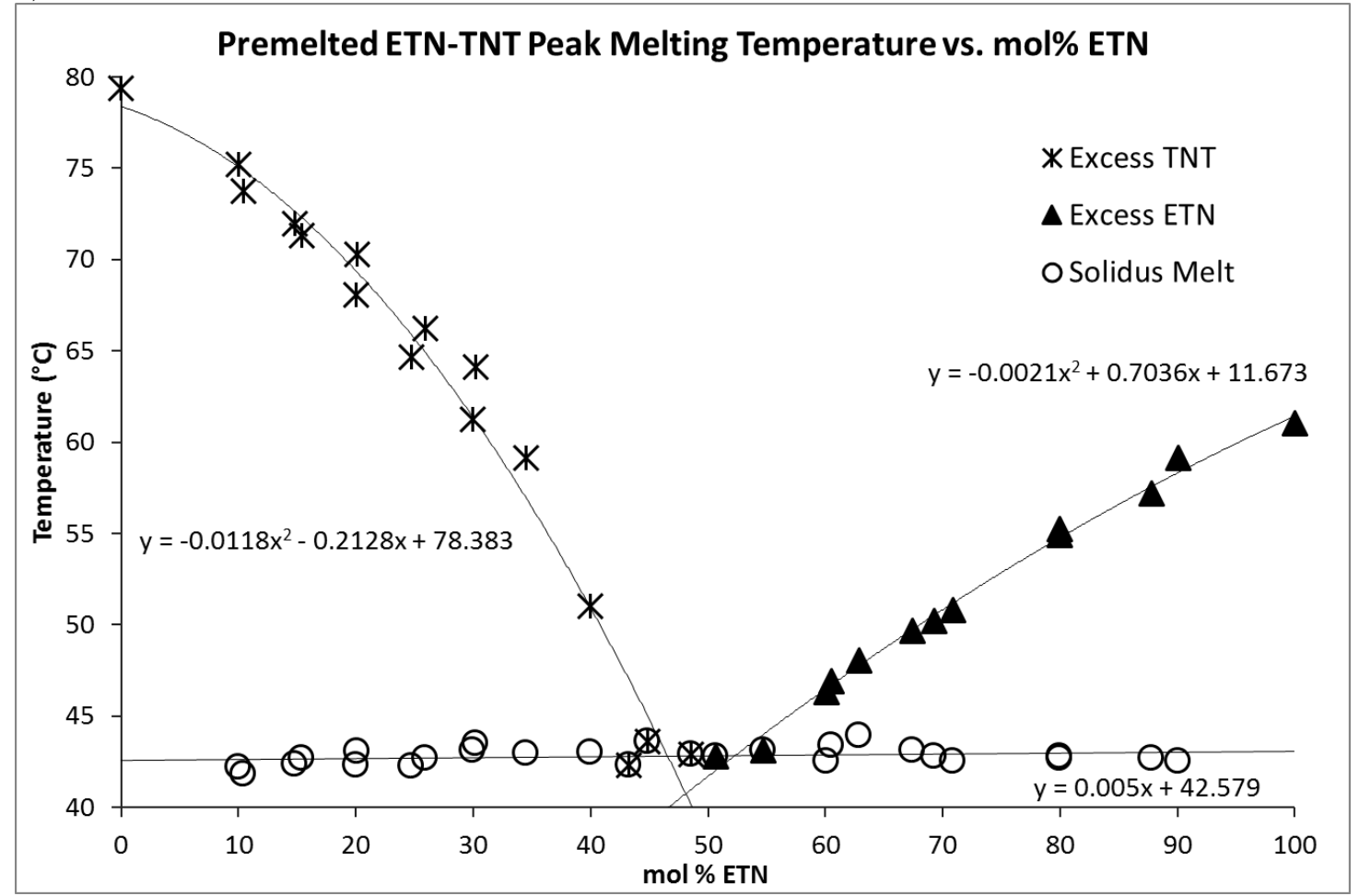

b)

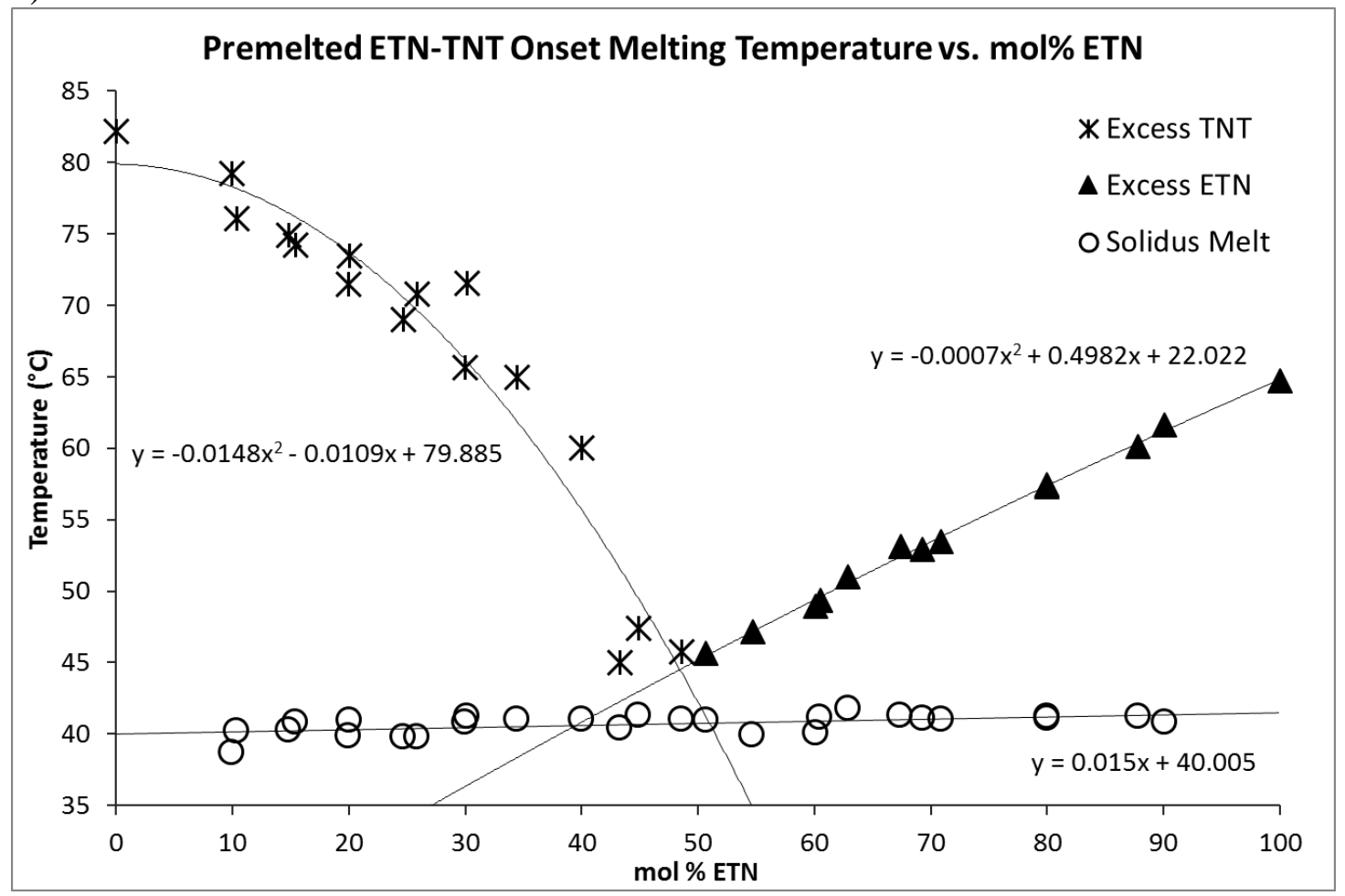

Figure 1.2: Phase diagrams for ETN-TNT generated using a) peak DSC data, b) offset DSC data 
a)

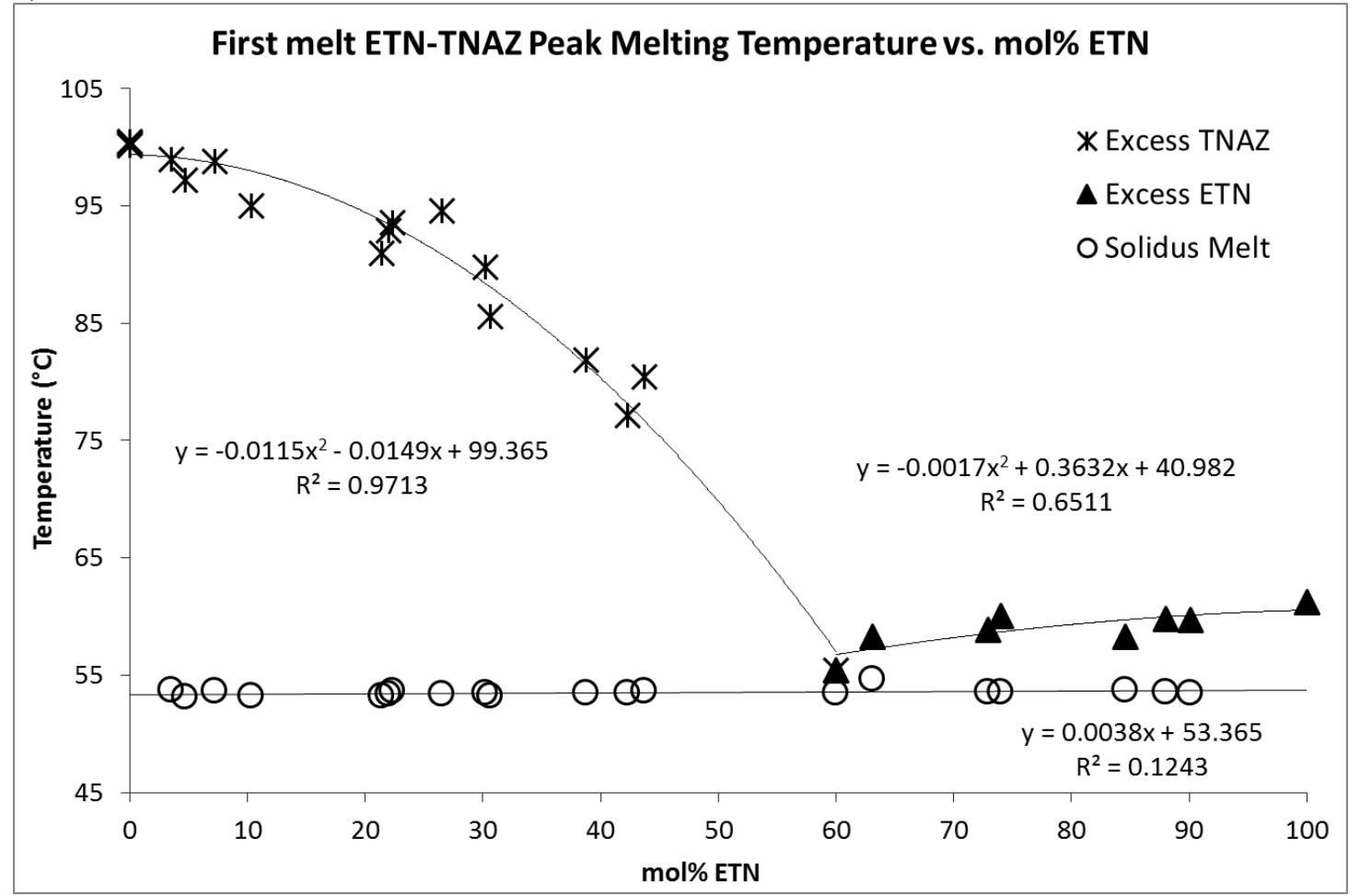

b)

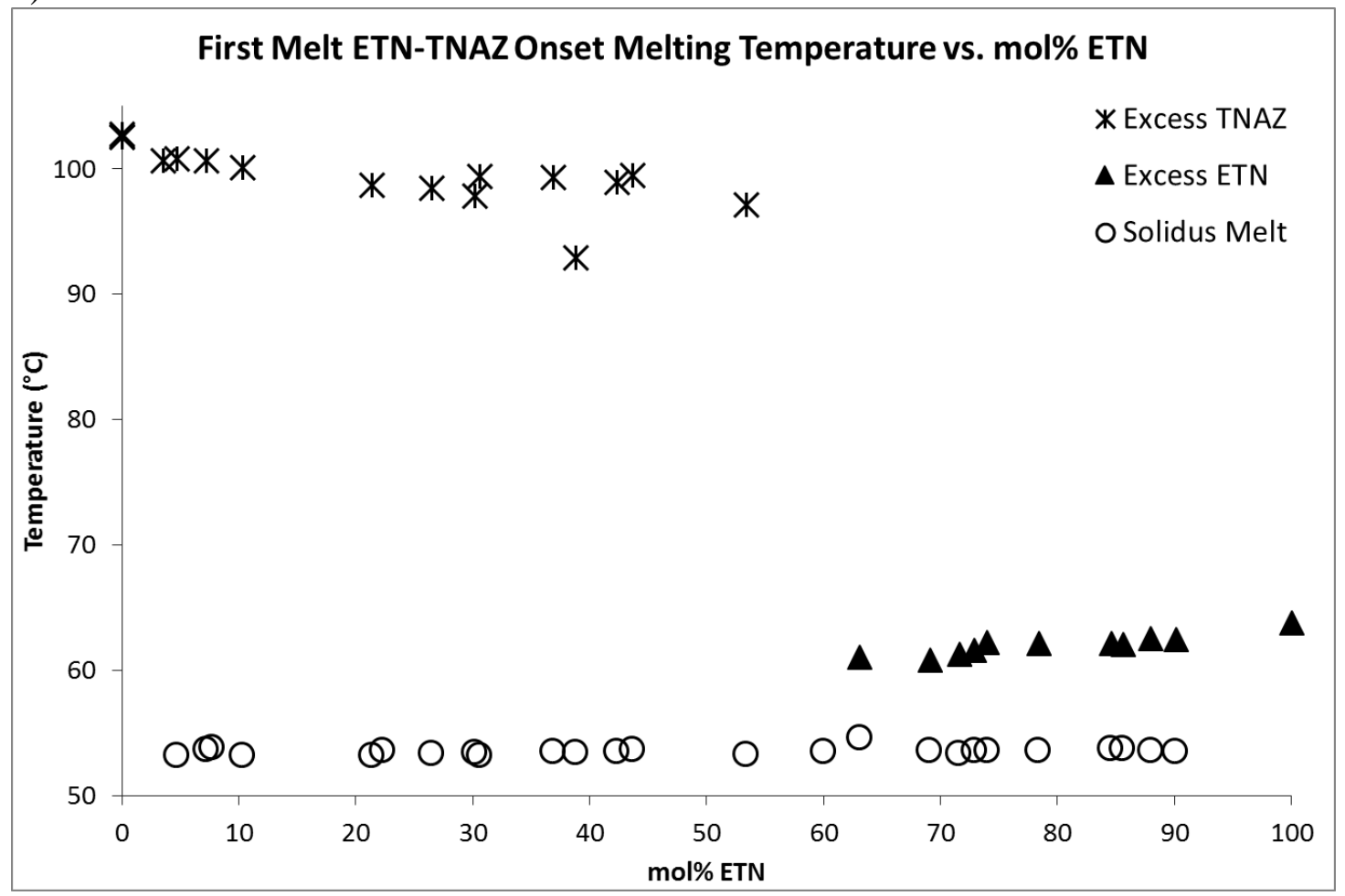

Figure 1.3: Phase diagrams for ETN-TNAZ generated using a) peak DSC data, b) offset DSC data 
a)

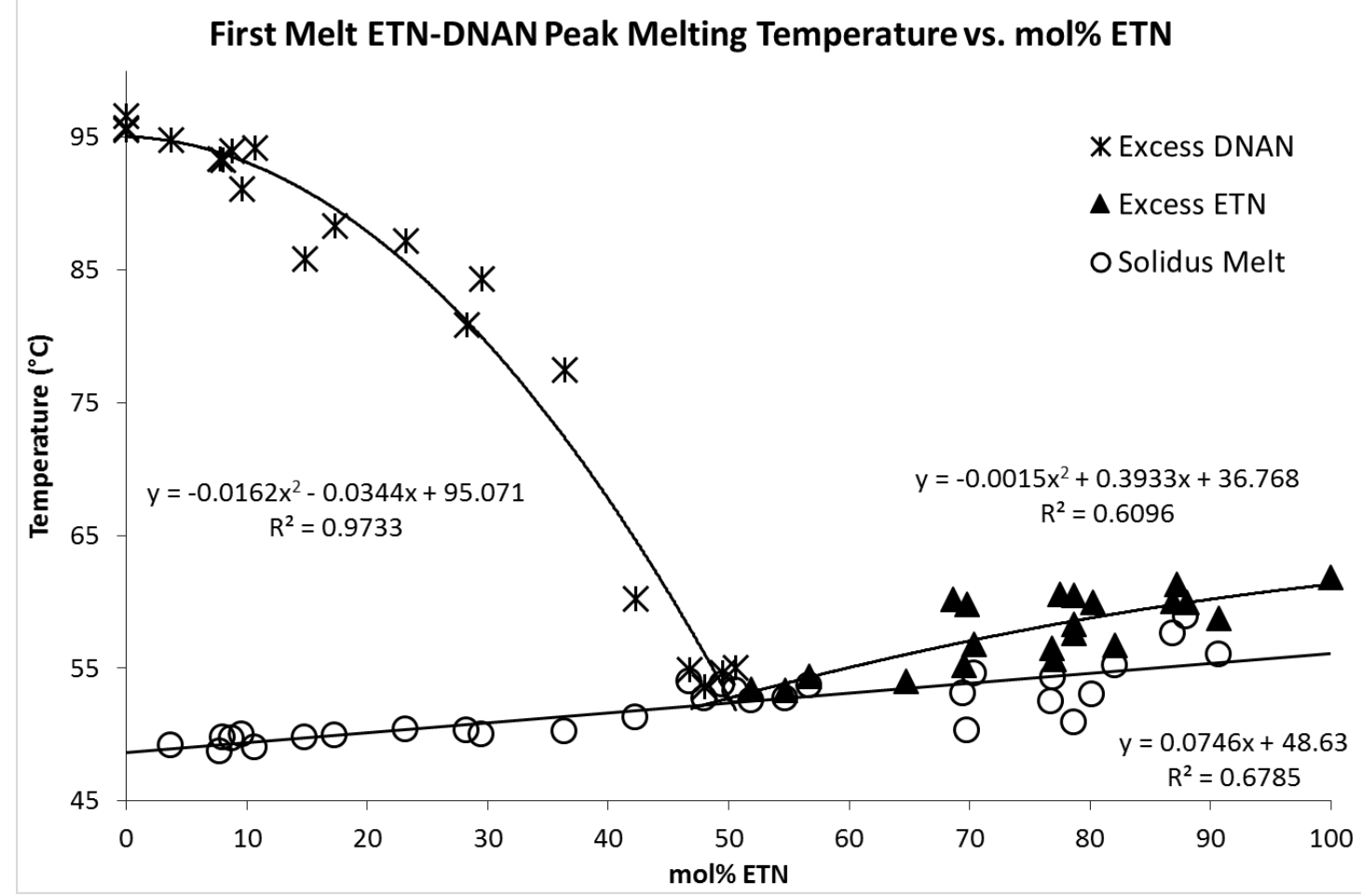

b)

First Melt ETN-DNAN Onset Melting Temperature vs. mol\% ETN

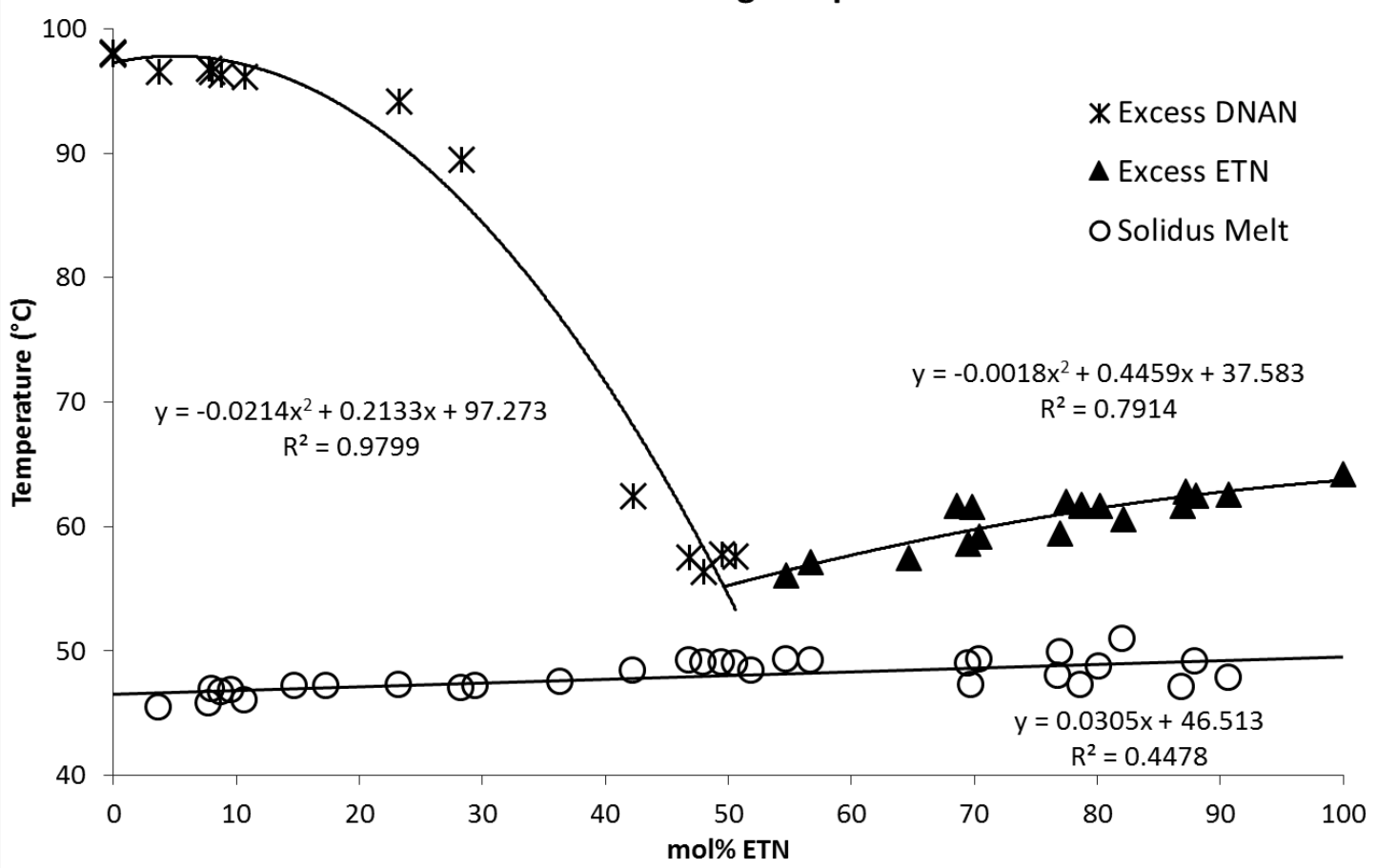

Figure 1.4: Phase diagrams for ETN-DNAN generated using a) peak DSC data, b) offset DSC data 
a)

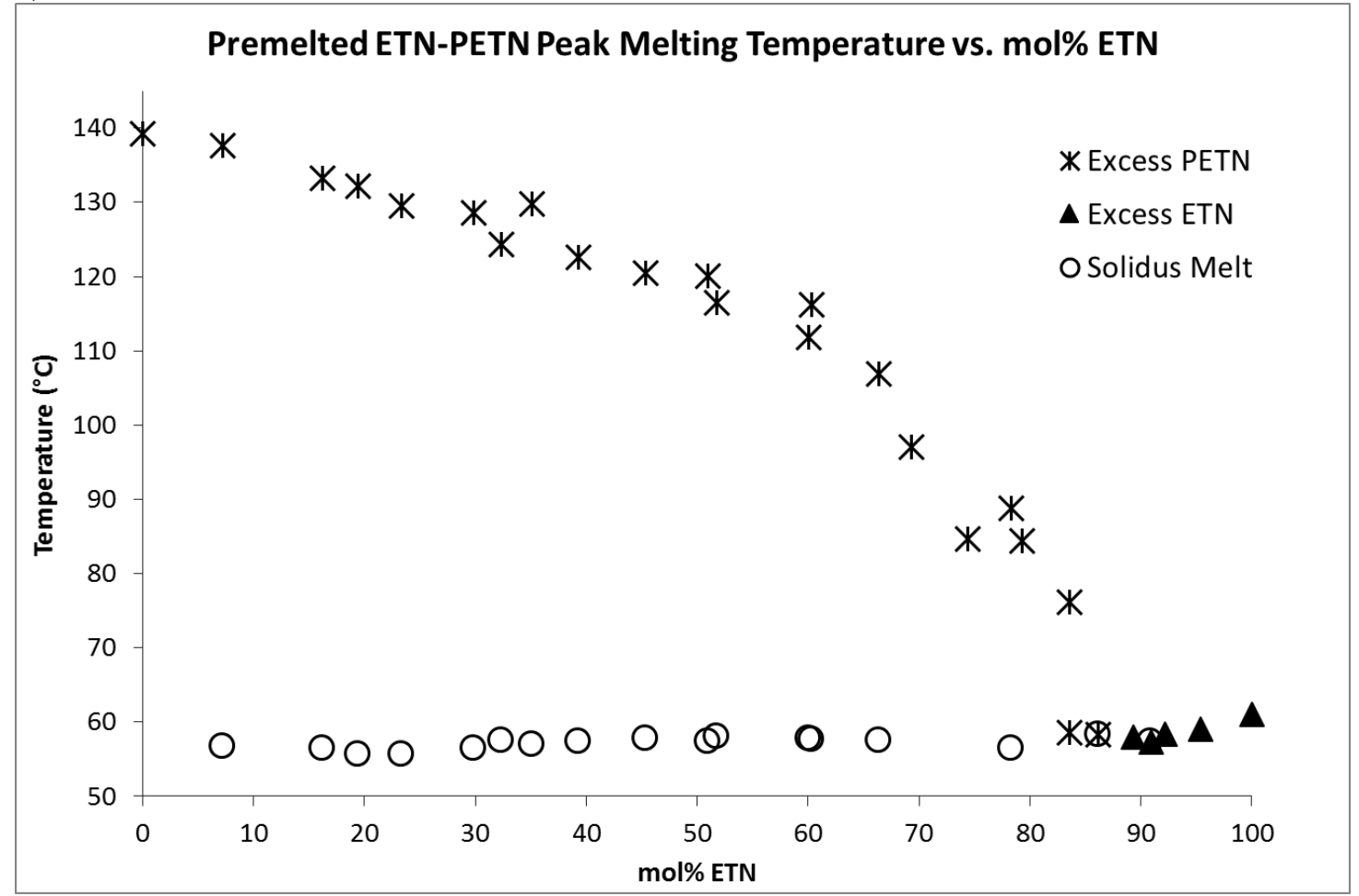

b)

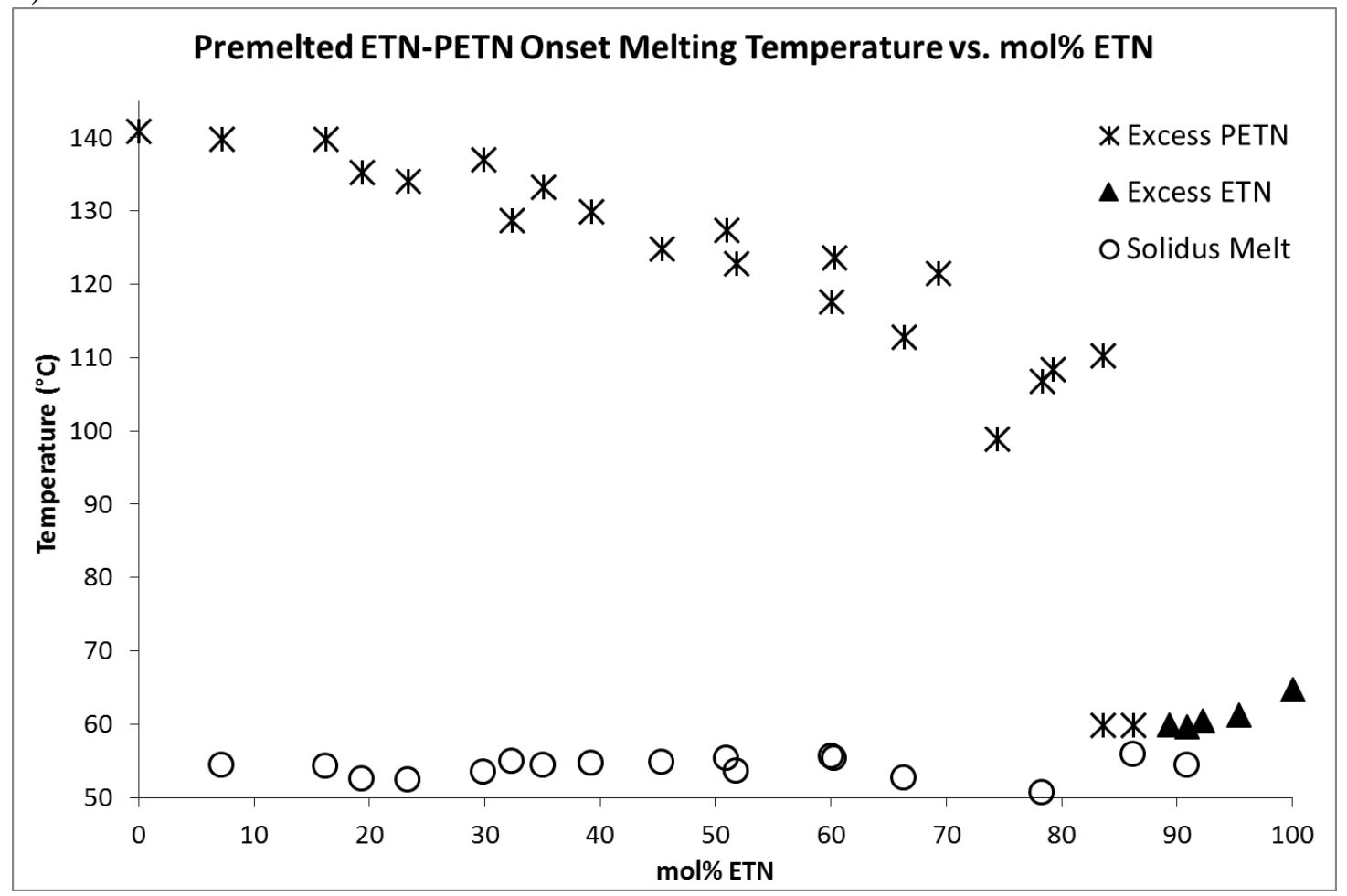

Figure 1.5: Phase diagrams for ETN-PETN generated using a) peak DSC data, b) offset DSC data 
a)

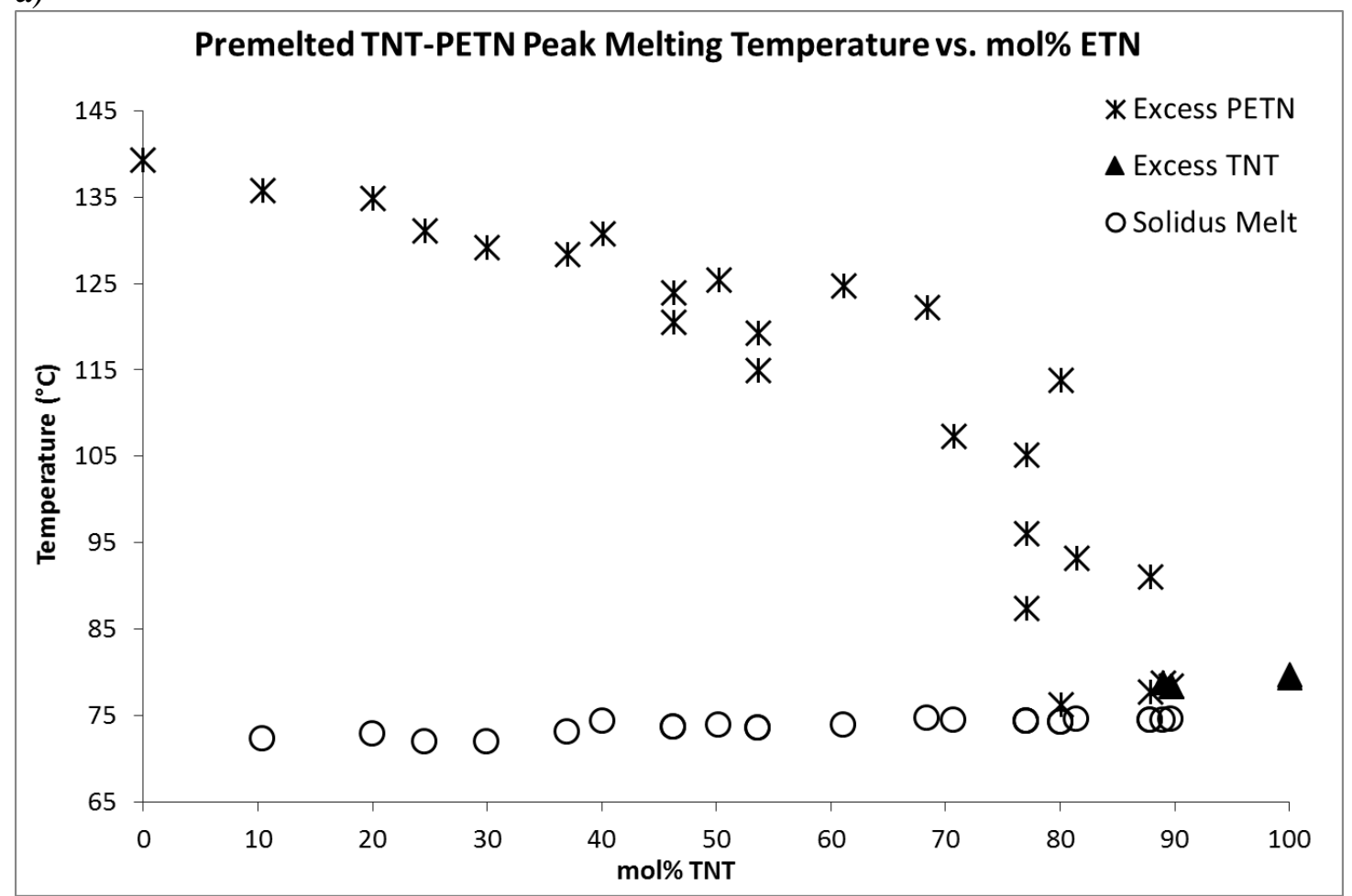

b)

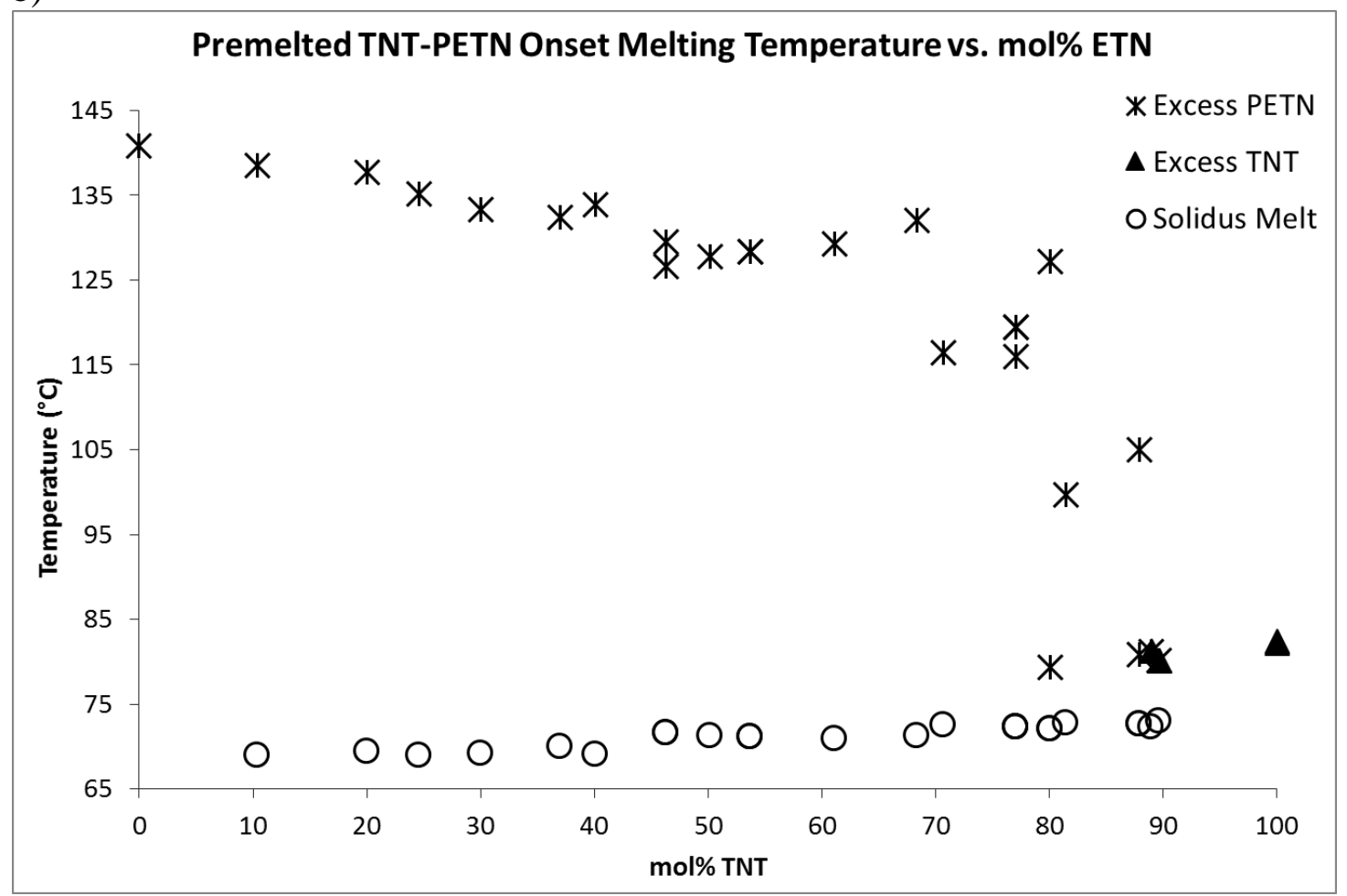

Figure 1.6: Phase diagrams for TNT-PETN generated using a) peak DSC data, b) offset DSC data 
a)

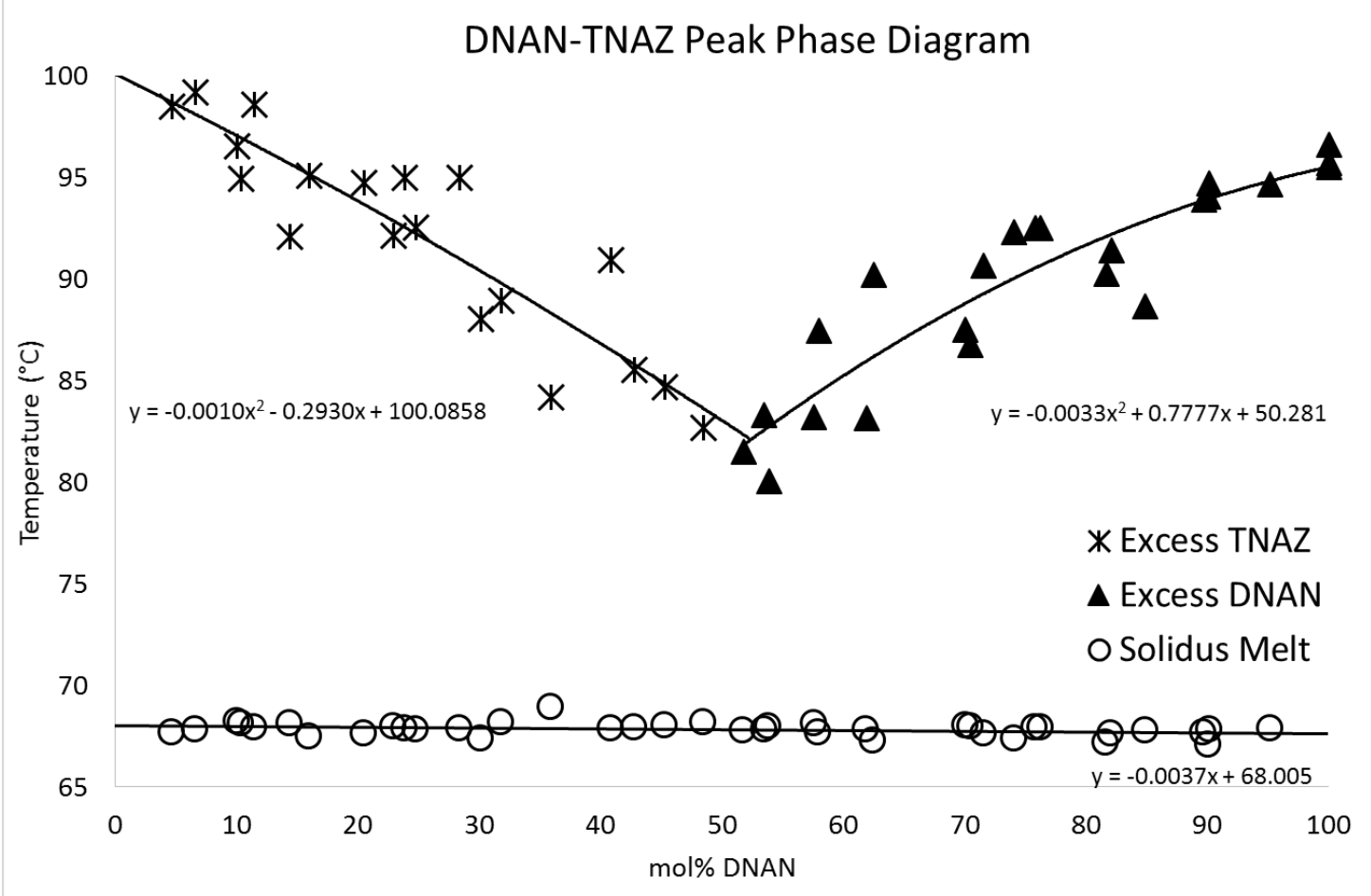

b)

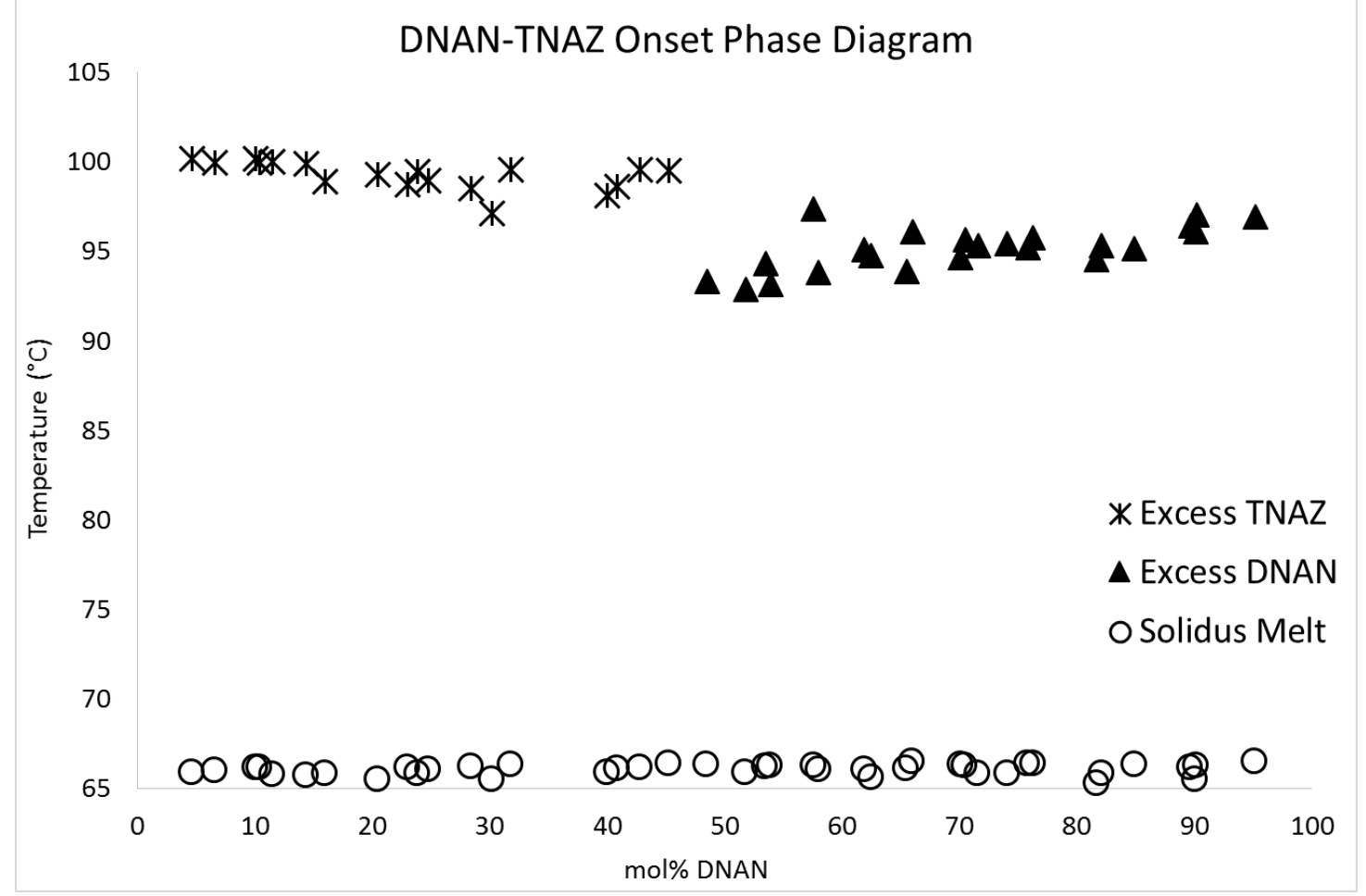

Figure 1.7: Phase diagrams for DNAN-TNAZ generated using a) peak DSC data, $b$ ) offset DSC data 
a)

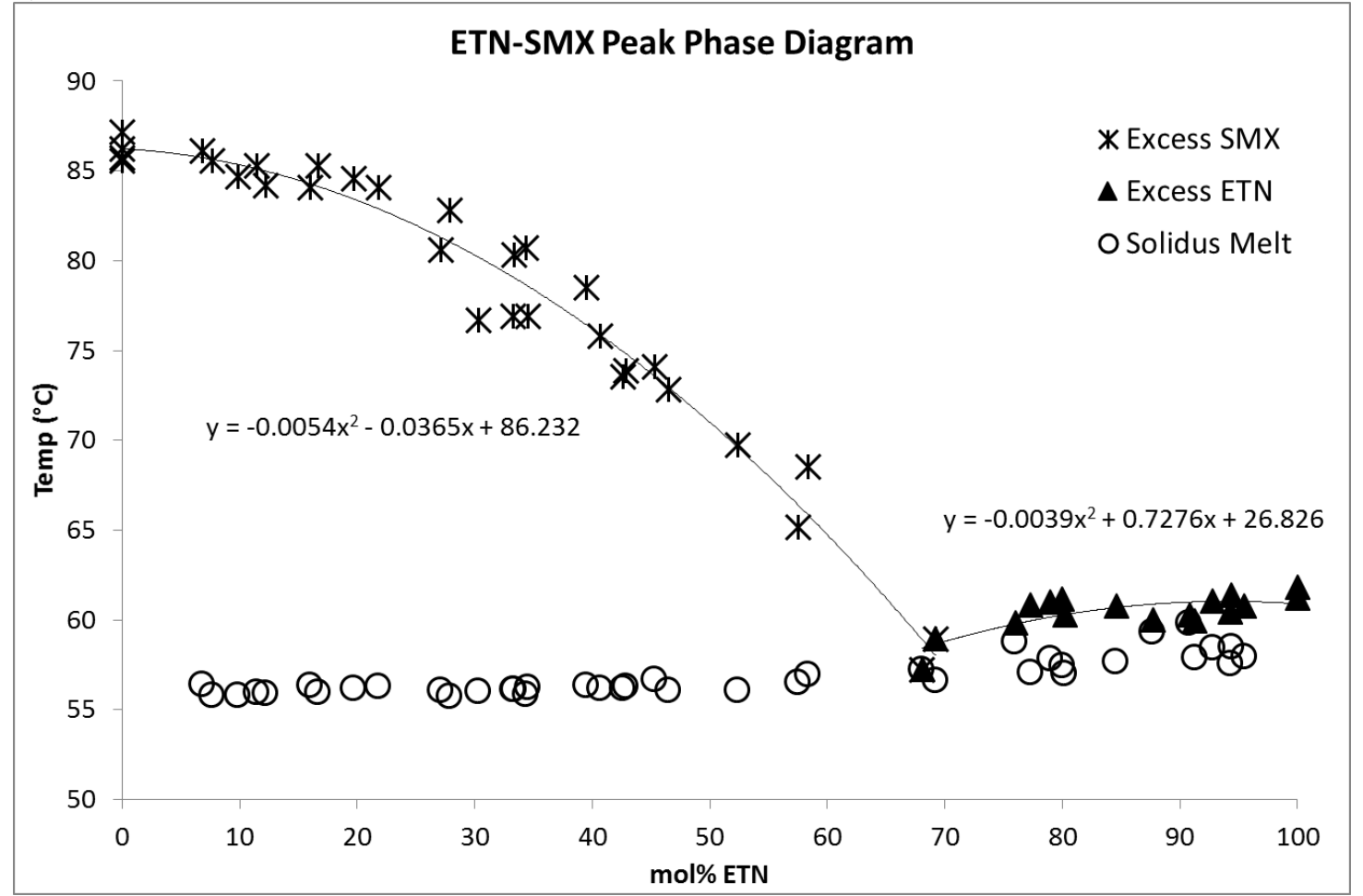

b)

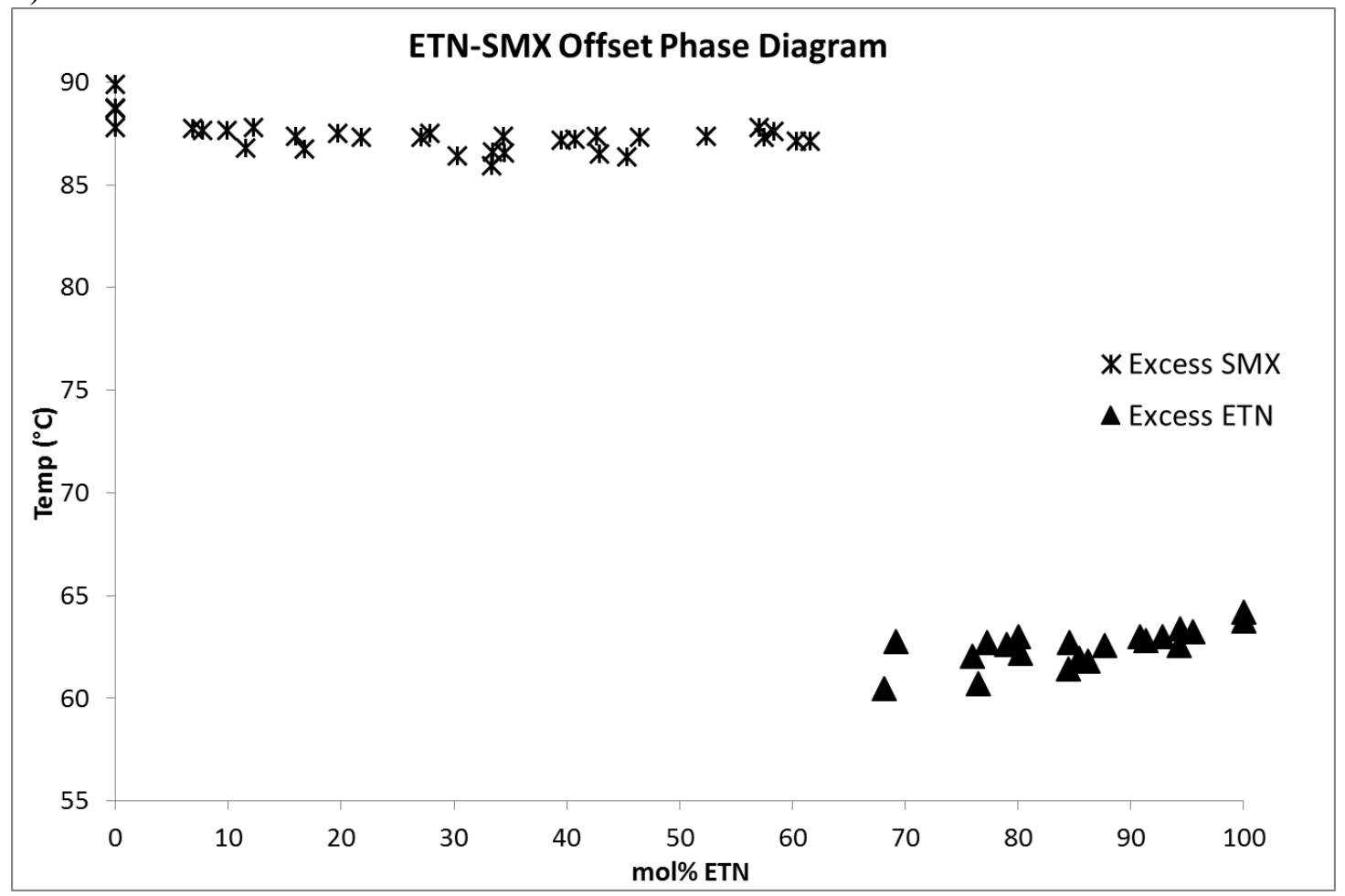

Figure 1.8: Phase diagrams for ETN-SMX generated using a) peak DSC data, b) offset DSC data 


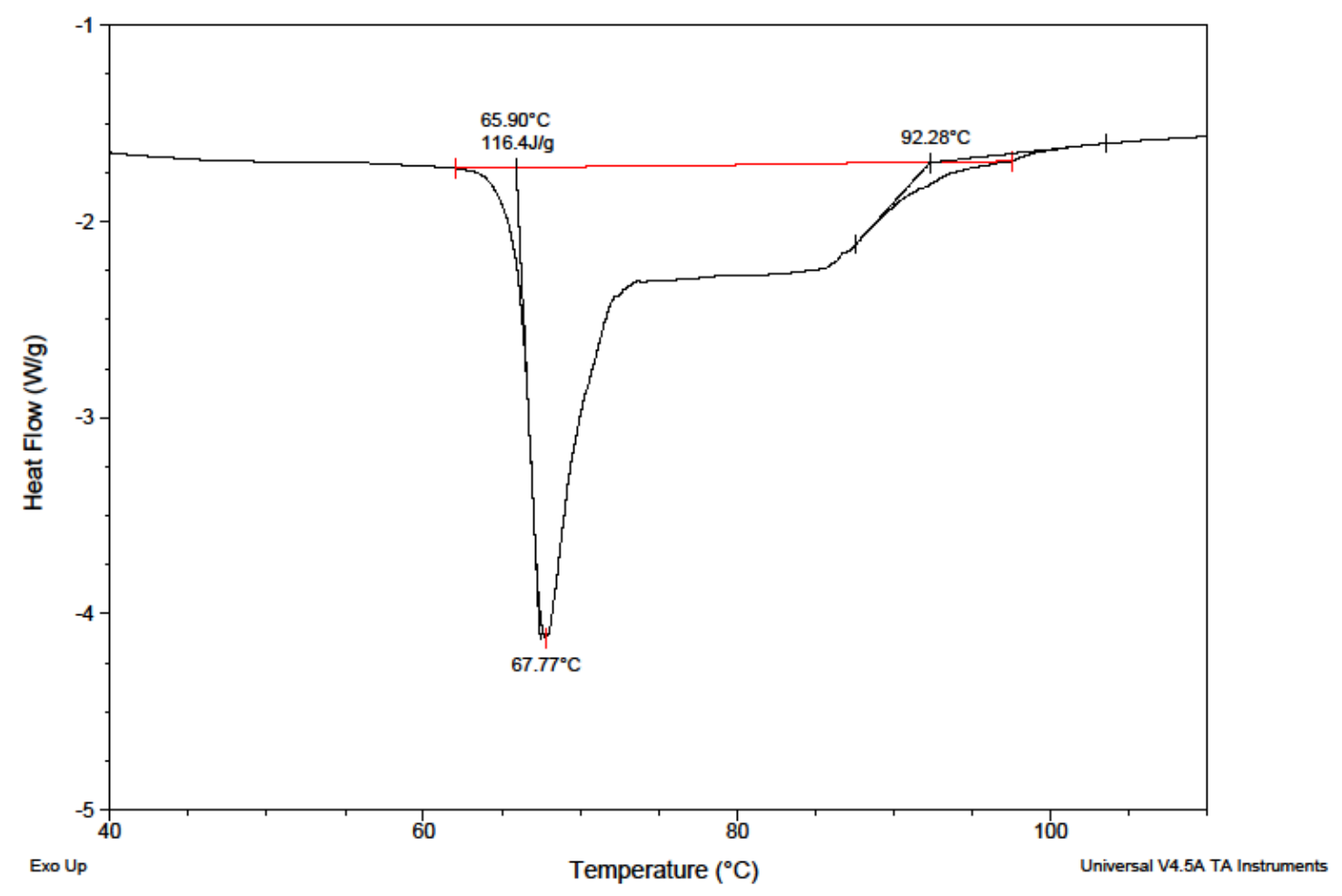

Figure 1.9: DSC of 52-48 mol\% DNAN-TNAZ 
a)

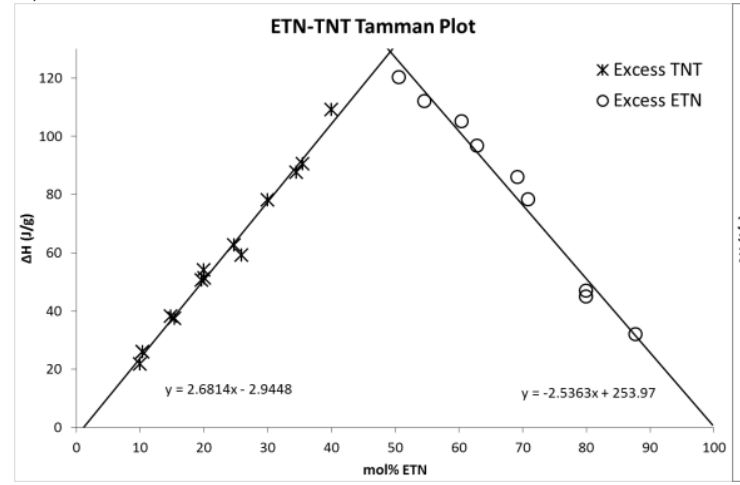

c)

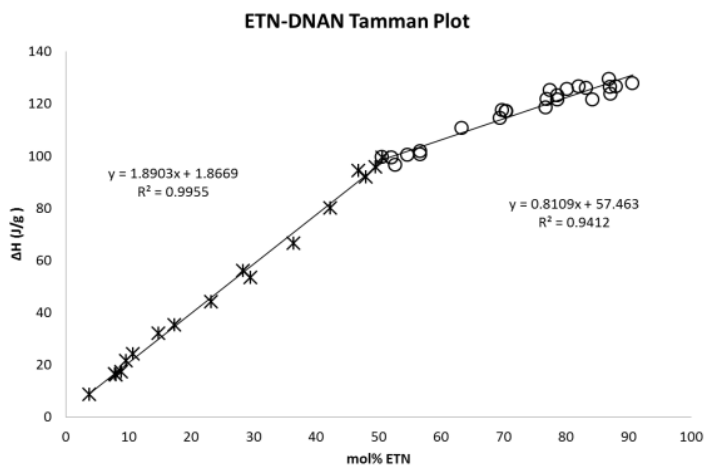

b)

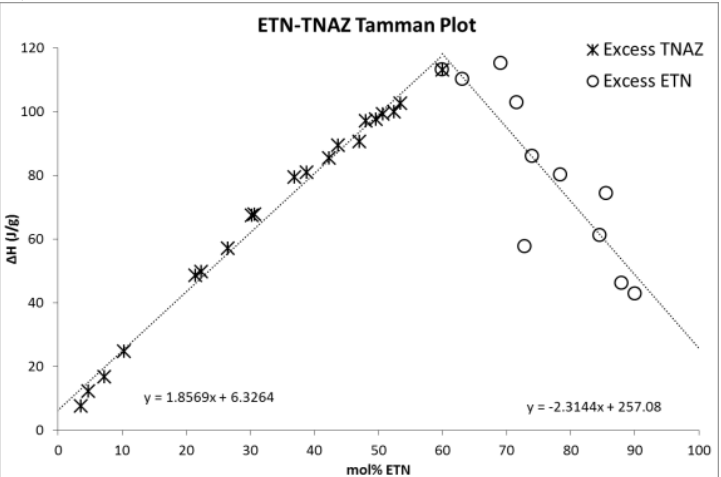

d)

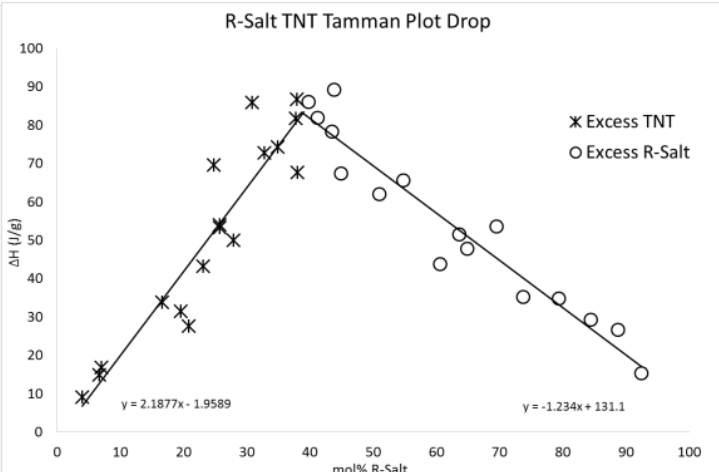

f)

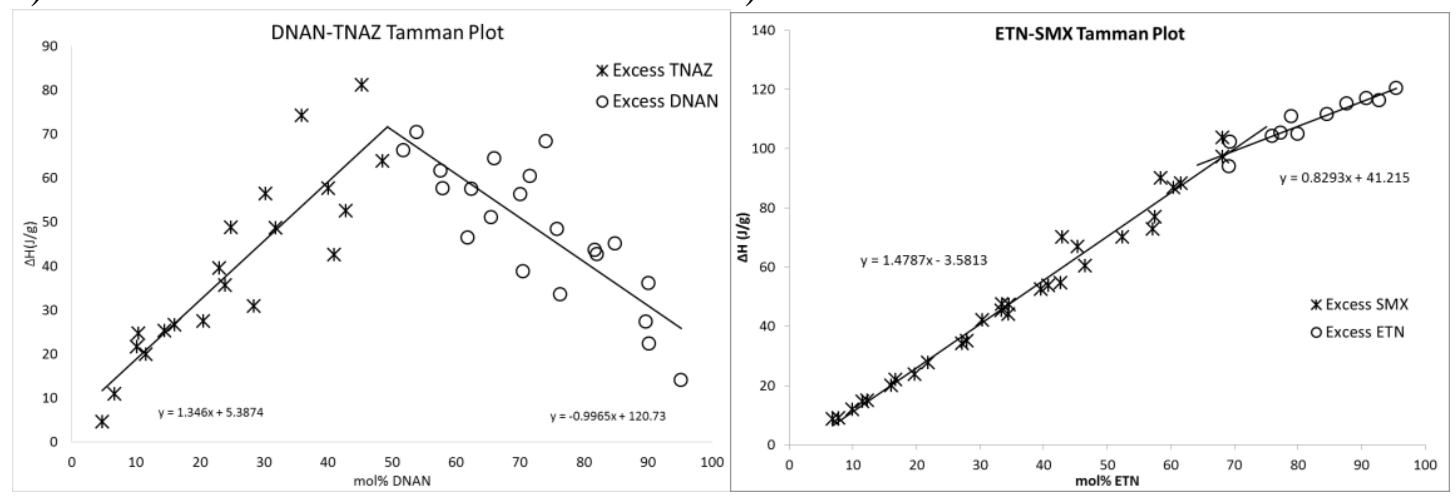

Figure 1.10: Tamman plots for a) ETN-TNT, b) ETN-TNAZ, c) ETN-DNAN, d) RSalt-TNT, e) DNAN-TNAZ, f) ETN-SMX 


\title{
CHAPTER 2
}

\section{Thermal Decomposition of Erythritol Tetranitrate}

\author{
Jimmie C. Oxley*, James L. Smith, Austin C. Brown \\ University of Rhode Island, Chemistry Department \\ 140 Flagg Road \\ Kingston, RI, 02881 \\ joxley@chm.uri.edu \\ Yehuda Zeiri; Ronnie Kosloff; David Furman; Faina Dubnikova \\ Hebrew University Jerusalem, Israel \\ joxley@chm.uri.edu \\ Prepared for submission to the Journal of Energetic Materials
}

\begin{abstract}
Pentaerythritol tetranitrate finds many uses in the energetic materials community. Due to the recent availability of erythritol, erythritol tetranitrate (ETN) can now be readily synthesized. Accordingly, its complete characterization, especially its stability, is of great interest. This work examines the thermal decomposition of ETN, both through experimental methods and computational theory. In addition to kinetic parameters, decomposition products were examined to elucidate its decomposition pathway.
\end{abstract}

\section{Keywords}

Erythritol tetranitrate; explosive; thermal decomposition; kinetics 


\section{Introduction}

In the U.S., erythritol tetranitrate (ETN) has become a material of concern because the precursors are readily obtained and nitration with mixed acid is relatively straightforward. ${ }^{1}$ Because ETN has the same number of nitro groups and better oxygen balance than pentaerythritol tetranitrate (PETN), we have examined it for possible replacement of PETN in formulations. ${ }^{2}$ However, its low melting point $\left(60{ }^{\circ} \mathrm{C}\right)$ requires that its thermal stability be carefully examined. To investigate the thermal stability of ETN, isothermal aging was employed to provide an assessment of thermal kinetic parameters. Decomposition products were analyzed using mass spectrometry (MS) to determine if ETN decomposition is similar to PETN.

\section{Experimental Section}

\section{Materials}

ETN was prepared by nitration with acetyl nitrate, a route which results in a high yield of product more completely nitrated than by the mixed acid method. ${ }^{3}$ Glacial acetic acid $(16.7 \mathrm{~mL})$ and acetic anhydride $(16.7 \mathrm{~mL})$ were added to a round bottom flask and suspended in an ice bath. White fuming nitric acid (8.4 mL, 99\%) was added dropwise maintaining a reaction temperature below $10{ }^{\circ} \mathrm{C}$. The reaction mixture was allowed to stir for 30 minutes; then meso-erythritol ( $2 \mathrm{~g}$ ) was added portionwise keeping the temperature below $10{ }^{\circ} \mathrm{C}$. This mixture was allowed to stir for 2 hours at $0{ }^{\circ} \mathrm{C}$ before it was removed from the ice bath and stirred another 2 hours at room temperature. The reaction mixture was poured into a beaker of ice water, filtered, rinsed with copious amount of ice water, and allowed to dry. The crude 
product $(4.54 \mathrm{~g})$ was recrystallized from isopropanol and filtered to give the pure product $(3.90 \mathrm{~g})$. Purity was checked by melting point and liquid chromatography/mass spectrometry (LC-MS) detector.

Our experiments also required crude, partially nitrated ETN. Since mixed acid nitration generally produces less complete nitration, this method was used with slight modifications. ${ }^{4}$ Sulfuric acid $(3.0 \mathrm{~mL}, 96.5 \%)$ was added to a round bottom flask and cooled to $0{ }^{\circ} \mathrm{C}$. White fuming nitric acid $(4.6 \mathrm{~mL}, 99 \%)$ was added dropwise maintaining a reaction temperature below $10{ }^{\circ} \mathrm{C}$. The mixture was allowed to stir for 30 minutes at $0{ }^{\circ} \mathrm{C}$, and erythritol ( $\left.1 \mathrm{~g}\right)$ was added portionwise keeping the temperature below $10{ }^{\circ} \mathrm{C}$. This mixture was allowed to stir one hour at $0{ }^{\circ} \mathrm{C}$ rather than $30{ }^{\circ} \mathrm{C}$. The nitration mixture was also not allowed to stand for an additional half hour; instead it was precipitated in a beaker of ice water and neutralized with sodium bicarbonate. The resultant crude product was filtered, rinsed with ice water, and allowed to dry. It was not recrystallized. Figure 2.1 shows the nitration of erythritol to ETN.

\section{IR, Raman, and NMR Spectra}

IR spectrum of solid ETN was obtained on a Thermo Scientific FTIR Nicolet 6700 ATR IR. Raman spectrum of solid ETN was obtained using an Ondax 785.4 nm $225 \mathrm{~mW}$ laser and an Andor Shamrock 500i- D2-R spectrometer. The "Step and Glue" function was used, allowing the spectrometer to focus on a 2000 pixel portion of the spectrum at a time, and then assemble a continuous spectrum. Each spectrum is a summation of ten spectra each with one second exposure time. The spectral range was 
from $755 \mathrm{~nm}$ to $1040 \mathrm{~nm}$. The grating of the spectrometer was set to 1200 lines $/ \mathrm{mm}$ and a blaze of 850 .

One proton NMR sample was prepared by dissolving ETN in deuterated chloroform $\left(\mathrm{CDCl}_{3}\right)$. The spectrum was collected on a Brüker Ultrashield 300 with a frequency of $300.13 \mathrm{MHz}$, a sweep width of $6188.199 \mathrm{~Hz}$, a center of $1853.43 \mathrm{~Hz}$, calibrated on tetramethylsilane at $0 \mathrm{ppm}$ in $\mathrm{CDCl}_{3}$ using the pulse program zg30, a $1 \mathrm{D}$ pulse program with a $30^{\circ}$ flip angle, using 16 scans and 2 dummy scans.

A second proton NMR sample was prepared by dissolving ETN in deuterated acetone. The spectrum was collected on a JEOL Eclipse Fourier Transform Nuclear Magnetic Resonance Spectrometer equipped with a 400Mhz Oxford liquid refrigerant cooled superconducting magnet with a frequency of $400.13 \mathrm{MHz}$, a sweep width of $8802.55 \mathrm{~Hz}$, a center of $513.5938 \mathrm{~Hz}$, calibrated on acetone at $2.05 \mathrm{ppm}$ in deuterated acetone using the pulse program zg30, a 1D pulse program with a $30^{\circ}$ flip angle, using 17 scans.

Carbon NMR samples were prepared by dissolving ETN in deuterated dimethylsulfoxide (DMSO-d6). The spectrum was collected on a JEOL Eclipse Fourier Transform Nuclear Magnetic Resonance Spectrometer equipped with a $400 \mathrm{MHz}$ Oxford liquid refrigerant cooled superconducting magnet with a frequency of 100.61 MHz, a sweep width of $25124.86 \mathrm{~Hz}$, a center of $9532.6904 \mathrm{~Hz}$, calibrated on DMSO at 39.51 in DMSO-d6 using the pulse program zgpg30, a 1D pulse program with a $30^{\circ}$ flip angle, using 1117 scans. 


\section{Kinetics}

Samples were quantified using a liquid chromatograph on a $2.1 \times 50 \mathrm{~mm}, 3 \mu \mathrm{m}$, $120 \AA$ A , Acclaim ${ }^{\mathrm{TM}}$ Polar Advantage II C18 (PA2) column coupled to a Thermo Electron Quantiva triple quadrupole mass spectrometer (LC-MS) with a heated electrospray ionization (HESI) source. Conditions for HESI analysis were: negative ion spray voltage $2800 \mathrm{~V}$; sheath gas 65 AU; auxiliary gas 15 AU; sweep gas 2 AU; ion transfer tube $250{ }^{\circ} \mathrm{C}$; and vaporizer temperature was $220^{\circ} \mathrm{C}$. Data collection and analysis was performed with Thermo Xcalibur software version 2.2, SP 1.48. LC solvent flow was composed of water with $200 \mu \mathrm{M}$ ammonium chloride, $200 \mu \mathrm{M}$ ammonium acetate, and $0.1 \%$ formic acid (A); and acetonitrile (B). The solvent flow rate was $300 \mu \mathrm{L} / \mathrm{min}$ with the following gradient program (A\%-B\%): 0 to $1 \mathrm{~min}$ isocratic $70 \%-30 \%, 1$ to $4 \mathrm{~min}$ gradient from $70 \%-30 \%$ to $5 \%-95 \%$, 4 to $5.5 \mathrm{~min}$ isocratic $5 \%-95 \%, 5.5$ to $6 \mathrm{~min}$ gradient from $5 \%-95 \%$ to $70 \%-30 \%, 6$ to $7 \mathrm{~min}$ isocratic 70\%-30\%. Methanol $(\mathrm{MeOH})$, acetonitrile $(\mathrm{ACN})$, and water $\left(\mathrm{H}_{2} \mathrm{O}\right)$ used to prepare samples and for all LC-MS work was Optima ${ }^{\mathrm{TM}}$ LC-MS Grade.

ETN (1.000mg +/- 0.050mg) was added to melting point capillaries, which were then sealed with a flame sealer. Sealed capillaries were placed in a sand bath in an oven and aged isothermally for various time intervals. The capillaries were broken into vials containing $20.0 \mathrm{~mL}$ of methanol. The vials were placed on a shaker for 1 hour and sonicated for 1 hour. The resulting solution was syringe filtered to remove any glass particles. These samples were diluted $\left(100 \mu \mathrm{L}\right.$ sample, $0.9 \mathrm{~mL}$ ACN: $\mathrm{H}_{2} \mathrm{O}$ 50:50 v:v) into LC vials. An internal standard $(0.05 \mathrm{~mL}$ of $5 \mu \mathrm{g} / \mathrm{mL} 2,4-$ dichlorophenoxyacetic acid in $\mathrm{ACN}: \mathrm{H}_{2} \mathrm{O}$ ) was added to each LC vial. ETN standards 
were prepared in $\mathrm{ACN}: \mathrm{H}_{2} \mathrm{O}$ at concentrations of $1,2,3,4,5$, and $6 \mu \mathrm{g} / \mathrm{mL} .1 .0 \mathrm{~mL}$ of each standard was added to LC vials and spiked with the same quantity of the internal standard as the samples. Standards and samples were run using the LC-MS method described above and quantified based on the area under the chromatogram curves for ETN (retention time $=3.9 \mathrm{~min}$ ).

For ETN in benzene the thermolysis process described for neat ETN was used with slight alterations in samples preparation. Stock solutions of ETN in benzene were prepared $(100+/-10 \mu \mathrm{g} / \mathrm{mL}$ ETN $)$ and ampules were charged with $1.0 \mathrm{~mL}$ of stock solution then sealed. Ampules were cooled in liquid nitrogen to solidify the benzene before being flame sealed using a propane-oxygen torch. Following thermal aging, ampules were broken into empty vials. Since the benzene was not miscible with ACN: $\mathrm{H}_{2} \mathrm{O}$ the vials were then placed on an Organomation N-EVAP 116 nitrogen evaporator to remove the benzene. Once the vials were dry $20.0 \mathrm{~mL}$ of $\mathrm{ACN}: \mathrm{H}_{2} \mathrm{O}$ was pipeted into the vials. The vials were placed on a shaker for 1 hour and sonicated for 1 hour. The resulting solution was syringe filtered to remove any glass particles. 1.00 $\mathrm{mL}$ of the filtered solution was added to LC vials, no additional dilution was necessary. An internal standard $(0.05 \mathrm{~mL}$ of $5 \mu \mathrm{g} / \mathrm{mL} 2,4$-dichlorophenoxyacetic acid in ACN: $\mathrm{H}_{2} \mathrm{O}$ ) was added to each LC vial. Samples were run using the LC-MS method described above and quantified based on the area under the chromatogram curves for ETN.

Plotting the natural logarithm of the fraction of ETN remaining versus heating

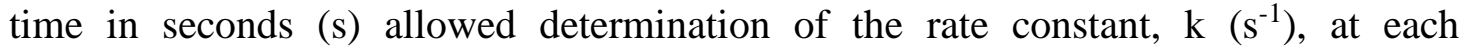
temperature from the slope (Table 2.1). Plotting the natural logarithm of the rate 
constant against $-1 / \mathrm{RT}$, (where $\mathrm{R}=0.00831 \mathrm{~kJ} / \mathrm{K} \bullet \mathrm{mol}$; and $\mathrm{T}$, temperature in Kelvin) gave a slope with activation energy, $E_{a},(\mathrm{~kJ} / \mathrm{mol})$ and $\mathrm{y}$-intercept of the natural logarithm of the pre-exponential factor, $\mathrm{A}\left(\mathrm{s}^{-1}\right)$.

\section{Product Analysis}

To identify potential decomposition products, partially decomposed samples were reexamined by LC-MS. These partially decomposed samples, representing 10$25 \%$ decomposition, produced at various temperatures, were analyzed on a Quantiva LC-MS using a precursor ion scan. The mobile phase gradient, column, and ion source parameters were the same as for the quantification method described in the kinetics experimental section. To scan for decomposition products the MS was set for a precursor ion scan to look for precursor ions that fragmented into ions with $\mathrm{m} / \mathrm{z}$ of 62 $\left(\mathrm{NO}_{3}{ }^{-}\right)$and $46\left(\mathrm{NO}_{2}\right)$. The first quadrupole was set to allow ions with $\mathrm{m} / \mathrm{z}$ 80-800 through one $\mathrm{m} / \mathrm{z}$ at a time. Each ion was then fragmented in the second quadrupole using argon collision gas at 1.5 mTorr with a collision energy ramp from 10 to $20 \mathrm{~V}$. The third quadrupole scanned for anything that created fragments of m/z 62 and 46 . The resulting chromatograms showed what parent ions in the decomposition products generated these fragments.

The partially decomposed samples were also run on a Thermo Exactive Orbitrap High Resolution Mass Spectrometer with an Atmospheric Pressure Chemical Ionization (APCI) source coupled to an LC, using the same LC parameters as on the Quantiva. Conditions for APCI analysis were: sheath gas 35 AU; auxiliary gas 17 AU; sweep gas $0 \mathrm{AU}$; discharge current $10 \mu \mathrm{A}$; capillary temperature $150{ }^{\circ} \mathrm{C}$; capillary 
voltage $-25.00 \mathrm{~V}$; tube lens voltage $-100.00 \mathrm{~V}$; skimmer voltage $-18.00 \mathrm{~V}$; and vaporizer temperature was $200{ }^{\circ} \mathrm{C}$. The Orbitrap MS was set to negative mode, high resolution (50,000), $50 \mathrm{~ms}$ maximum inject time, and a scan range of 100-1000 m/z. The resultant data was analyzed by generating extracted ion chromatograms for the exact mass $(\mathrm{m} / \mathrm{z}+/-5 \mathrm{ppm})$ of potential decomposition products of ETN. Decomposition product chromatograms were compared to crude, non-fully nitrated ETN chromatograms to verify some of the products.

\section{Computation}

The quantum chemical calculations were carried out using the Gaussian-09 package $^{5}$. The B3LYP hybrid density functional ${ }^{6}$ was used in conjunction with the Pople triple $\xi(6-311 G)$ basis set. The energetics for local minima and transitions states was recalculated using augmented by diffuse functions $(6-311++(\mathrm{d}, \mathrm{p}))$ basis set. Relative energy of proposed chemical reactions include the zero-point energy (ZPE) correction of the corresponding species. All the calculated frequencies, the zero point energies, and the thermal energies correspond to harmonic approximation. The calculations of intrinsic reaction coordinates (IRC) using internal coordinates were performed in order to examine whether the transition states under consideration connect the expected reactants and products. 


\section{Results \& Discussion}

Kinetics

We have previously compared the rate of decomposition of ETN and PETN by differential scanning calorimetry (DSC); ETN appeared to decompose more rapidly. Figure 2.2 illustrates this. To assign reliable values to the ETN decomposition, isothermal studies were performed on neat ETN over the temperature range 60 to 140 ${ }^{\circ} \mathrm{C}$. In one set of experiments $\operatorname{ETN}(100 \mu \mathrm{g} / \mathrm{mL})$ was heated in benzene at $80{ }^{\circ} \mathrm{C}$; under these conditions ETN decomposed somewhat slower than observed in the condensed phase (Table 2.1). Percent ETN remaining was assessed from liquid chromatography; only in a few instances did any ETN survive past $70-75 \%$ remaining. Sample decomposition tended to accelerate rapidly from $25-30 \%$ decomposition to $100 \%$ decomposition. This autocatalytic decomposition can be attributed to the reactive nature of ETN as well as that of its decomposition products (discussed in next section).

Rate constants $\left(\mathrm{k} \mathrm{in} \mathrm{s}^{-1}\right)$ at each temperature were determined and plotted in Arrhenius fashion. The Arrhenius parameters are listed in Table 2.2. Figure 2.3 shows the Arrhenius plots generated from our isothermal ETN decomposition data as well as that of German ${ }^{7}$ for PETN. The rest of the lines have generated from reported Arrhenius parameters. ${ }^{3,8,9}$ The isothermal ETN data overlaps with Roth's ${ }^{8}$ values for PETN, but Roth's reported kinetics are significantly faster than both those of Robertson $^{9}$ and of German. ${ }^{7}$ Robertson reported Arrhenius parameters for the decomposition of PETN neat and in dicyclohexyl phthalate solution. He observed a slight slowing of the decomposition in solution, and in the present study a similar 
retarding of decomposition was observed when ETN was heated in benzene. The preponderance of data suggests ETN decomposes faster than PETN. This is not surprising since ETN melts at a much lower temperature than PETN, and many explosives decompose immediately upon melting. However, from its DSC trace, ETN appears to have a wider temperature stability range than PETN (Fig. 2.2); like TNT, its decomposition does not immediately follow its melt. Elsewhere we have reported our attempts to exploit this feature. ${ }^{2}$

It is generally accepted that "the decomposition of primary and secondary aliphatic nitrate esters involve the initial, reversible, rate determining scission of the O-NO ${ }_{2}$ bond" (Figure 2.4). ${ }^{10,11}$ This is expected to be the first step in ETN decomposition, as well. However, unlike in PETN, the nitro groups in ETN are not all equivalent. Density functional theory (DFT) computations as well as experimental product analysis were performed to probe ETN decomposition routes.

\section{Product Analysis}

The LC-MS Quantiva precursor ion scan showed only two parent ions which produced $\mathrm{m} / \mathrm{z}$ fragments of $62\left(\mathrm{NO}_{3}{ }^{-}\right)-$-ETN and erythritol trinitrate $\mathrm{C}_{4} \mathrm{H}_{7} \mathrm{~N}_{3} \mathrm{O}_{10}$ (EtriN). Under the fragmentation conditions, no parent ions were found to produce fragment $\mathrm{m} / \mathrm{z}$ of $46\left(\mathrm{NO}_{2}^{-}\right)$. The LC-MS Orbitrap found additional evidence of decomposition products erythritol dinitrate $\mathrm{C}_{4} \mathrm{H}_{8} \mathrm{~N}_{2} \mathrm{O}_{8}$ (EdiN) and erythritol mononitrate $\mathrm{C}_{4} \mathrm{H}_{9} \mathrm{~N}_{1} \mathrm{O}_{6}($ EmonoN). These may not have been observed in the Quantiva because either they did not produce a $\mathrm{m} / \mathrm{z}$ fragment of 62 or, more likely, the Orbitrap was simply more sensitive to the mono and di-nitrated species, especially when using 
an extracted ion chromatogram. The increased resolution of the Orbitrap allowed examination of an extracted ion chromatogram in a mass window of less than 0.005 amu. This reduced background signal to almost nothing since, for small molecules, the only interfering ions would be those with identical chemical formulas as the analyte. LC-MS extracted ion chromatograms and mass spectra are included in supplemental information (SF 2.1-2.3).

Density Functional Theory (DFT) calculations were performed to assess and compare potential first steps in the PETN and ETN decompositions. Two possible unimolecular decompositions were considered (Figures 2.5, 2.6). Breaking the O-NO 2 bond would form two radicals -- $\mathrm{NO}_{2}$ and the rest of molecule. This reaction proceeds via a transition state for which the energy barrier is approximately the same as the energy of reaction; it corresponds to bond dissociation energy. Subsequent reactions would involve ejection of other radicals, and these would proceed via low energy barriers. With free $\mathrm{NO}_{2}$ in the formulation, autocatalytic decomposition would be expected. The exothermic ejection of HONO was also considered as a potential firststep in decomposition. For ETN decomposition, creation of two radicals by elimination of $\mathrm{NO}_{2}$ proceeds via an energy barrier about $9 \mathrm{kcal} / \mathrm{mol}$ lower than elimination of HONO. This route is more favored than it is for PETN. In PETN, HONO elimination proceeds via an energy barrier only slightly higher than the decomposition path forming two radicals by about $3.5 \mathrm{kcal} / \mathrm{mol}$. Unlike PETN, the carbons in ETN are inequivalent. The $\mathrm{O}-\mathrm{N}$ bond energy $(\mathrm{kcal} / \mathrm{mol})$ in $\mathrm{CH}_{2} \mathrm{O}-\mathrm{NO}_{2}$ (terminal $\mathrm{C}$ ) and $\mathrm{CHO}-\mathrm{NO}_{2}$ (internal $\mathrm{C}$ ) differ. Computed energy level diagrams show that $\mathrm{NO}_{2}$ elimination is favored from the internal carbon (Figure 2.6). Computation 
also reveals that potential bimolecular $\mathrm{H}$-atom migration between two PETN or two ETN molecules is unfavorable (Figure 2.7). The lack of bimolecular ETN decomposition is supported by the observation that the rate of ETN decomposition at $80{ }^{\circ} \mathrm{C}$ remained essentially identical whether performed neat or in benzene solution (Table 2.1).

Table 2.3 compares the energies involved in various decomposition routes of PETN $^{12}$ and of ETN. The energy differences for the elimination reactions between ETN and PETN are not large; both can access $\mathrm{NO}_{2}$ or $\mathrm{HONO}$ elimination routes at significantly lower energy cost than cyclotrimethylenetrinitramine (RDX). ${ }^{13,14}$ The big difference between the two nitrate esters is in $\mathrm{H}$-interexchange reaction, where ETN can transfer an internal $\mathrm{H}$ at lower energy cost than can PETN or RDX. However, such a reaction would be expected to form a strong carbonyl bond along with $\mathrm{NO}_{2}$ ejection. This is not observed under our experimental conditions.

The decomposition products observed by LC-MS were derivatives of ETN in which, to some extent, $\mathrm{CO}-\mathrm{NO}_{2}$ had been replaced by $\mathrm{CO}-\mathrm{H}$, reforming the tri-, di-, and mono- nitrate esters of erythritol. To assess whether H-transfer had formed ketone or aldehyde groups (Figure 2.7) which had been transformed into alcohol species during the experimental workup, partially nitrated erythritol was prepared as described in the Experimental Section. On the Orbitrap LC-MS, extracted ion chromatogram monitoring of $\mathrm{m} / \mathrm{z} 291.9825$ detected three peaks (Figure 2.8a). The peak at retention time $4.09 \mathrm{~min}$ was assigned to ETN, that at $3.54 \mathrm{~min}$ to erythritol trinitrate, and the small peak at 3.36 min may also be trinitrate which was nitrated on different carbons. Extracted ion chromatograms were also generated for $\mathrm{m} / \mathrm{z} 246.9975$ and $\mathrm{m} / \mathrm{z}$ 
202.0124, looking for evidence of erythritol dinitrate and mononitrate, respectively. Only the tetra- and tri-nitrates were observed. The $291.9825 \mathrm{~m} / \mathrm{z}$ extracted ion chromatogram was compared to that of pure ETN which had been partially decomposed (Figure 2.8b). Two peaks were observed corresponding to the undecomposed ETN (retention time $=4.09$ ) and the trinitrate (retention time $=3.54$ ). The retention time for the erythritol trinitrate matched the largest trinitrate peak in the crude material. Thus, the main decomposition product was erythritol trinitrate, in which an alcohol group replaced one nitrate and that alcohol was an original decomposition product of ETN, not a product of subsequent analytical workup. The chromatograms of the partially decomposed ETN were searched for additional products, including the ketone and polymerized ETN. Structures and $\mathrm{m} / \mathrm{z}$ searched for are shown in Table 2.4; no decomposition products other than the lesser nitrates were discovered. In well-sealed and highly decomposed samples, red gas, assumed to be $\mathrm{NO}_{2}$, was observed. This generation of $\mathrm{NO}_{2}$ from ETN would explain the autocatalytic decomposition observed in ETN kinetics experiments.

We have previous reported the IR and Raman spectra of ETN. ${ }^{3}$ Theoretical computations now permit assignment of major features. Figure 2.9 shows three major IR peaks assigned as ONO scissoring, symmetric $\mathrm{NO}_{2}$ stretching, and asymmetric $\mathrm{NO}_{2}$ stretching. In Raman spectra three major peaks are assigned as $\mathrm{OCH}$ rocking, $\mathrm{NO}_{2}$ scissoring, and $\mathrm{NO}_{2}$ symmetric stretching (Figure 2.10). The ${ }^{1} \mathrm{H}$ decoupled ${ }^{13} \mathrm{C}$ NMR in DMSO-d6 showed two singlets-terminal $\mathrm{C}$ at 68.7 and internal $\mathrm{C}$ at $76.5 \mathrm{ppm}$, which compares well to ETN in $\mathrm{CDCl}_{3}$ with terminal C 74.9 and internal C $67.4 \mathrm{ppm}$ reported by Matyas ${ }^{15}$ (Figure 2.11). Proton NMR of ETN was performed in deuterated 
acetone and $\mathrm{CDCl}_{3}$. In $\mathrm{CDCl}_{3}$ four doublets were observed at 4.65, 4.69, 4.91, and $4.96 \mathrm{ppm}$ representing the four protons on the terminal carbons. A multiplet at 5.51 ppm corresponded to the two protons on the internal carbons. The acetone proton NMR was similar with four doublets observed at 5.01, 5.05, 5.25, and 5.29 as well as a multiplet at 6.04 (Figure 2.12).

\section{Conclusions}

Isothermal aging of ETN samples has provided insight into the thermal stability of ETN as well as details on the resulting decomposition products. Despite the ability to exist in a molten state, ETN has a lower thermal stability than its counterpart PETN. However, it was found that ETN was significantly more stable than

estimated from DSC data. ${ }^{3}$ Decomposition products identified were exclusively formed by loss of $\mathrm{NO}_{2}$ which is often the case for nitrate esters. DFT computations indicated that the first step in ETN or PETN decomposition could be $\mathrm{NO}_{2}$ or $\mathrm{HONO}$ ejection, though the former is more energetically favored. After the first step a number of decomposition routes become available. In experimental tests it was observed that ETN decomposition frequently accelerated rapidly beyond $25-30 \%$ to $100 \%$ decomposition; this can be explained by the reactive nature of the $\mathrm{NO}_{2}$ produced. 


\section{References}

(1) Cook, M. Escondido: Authorities to burn "bomb factory" house http://www.sandiegouniontribune.com/news/2010/nov/30/escondidoauthorities-to-burn-bomb-factory-house/.

(2) Oxley, J. C; Smith, J. L.; Brown, A. C. Eutectics of Erythritol Tetranitrate, submitted

Oxley, J. C.; Smith, J. L.; Brady, J. E.; Brown, A. C. Propellants, Explos. Pyrotech. 2012, 37 (1), 24-39.

(4) Ledgard, J. B. The Preparatory Manual of Explosives, 3rd ed.; 2007.

(5) Gaussian 09, Revision A.1, Frisch, M. J.; Trucks, G. W.; Schlegel, H. B.; Scuseria, G. E.; Robb, M. A.; Cheeseman, J. R.; Scalmani, G.; Barone, V.; Mennucci, B.; Petersson, G. A.; Nakatsuji, H.; Caricato, M.; Li, X.; Hratchian, H. P.; Izmaylov, A. F.; Bloino, J.; Zheng, G.; Sonnenberg, J. L.; Hada, M.; Ehara, M.; Toyota, K.; Fukuda, R.; Hasegawa, J.; Ishida, M.; Nakajima, T.; Honda, Y.; Kitao, O.; Nakai, H.; Vreven, T.; Montgomery, Jr., J. A.; Peralta, J. E.; Ogliaro, F.; Bearpark, M.; Heyd, J. J.; Brothers, E.; Kudin, K. N.; Staroverov, V. N.; Kobayashi, R.; Normand, J.; Raghavachari, K.; Rendell, A.; Burant, J. C.; Iyengar, S. S.; Tomasi, J.; Cossi, M.; Rega, N.; Millam, J. M.; Klene, M.; Knox, J. E.; Cross, J. B.; Bakken, V.; Adamo, C.; Jaramillo, J.;

Gomperts, R.; Stratmann, R. E.; Yazyev, O.; Austin, A. J.; Cammi, R.; Pomelli, C.; Ochterski, J. W.; Martin, R. L.; Morokuma, K.; Zakrzewski, V. G.; Voth, G. A.; Salvador, P.; Dannenberg, J. J.; Dapprich, S.; Daniels, A. D.; Farkas, Ö.; Foresman, J. B.; Ortiz, J. V.; Cioslowski, J.; Fox, D. J. Gaussian, Inc., 
Wallingford CT, 2009.

(6) Becke, A. D. J. Phys. Chem. 1993, 98, 5648-5652.

(7) German, V. N.; Grebennikova, S. E.; Lobanova, S. P.; Fomicheva, L. V. Int.

Detonation Symp. 2002.

(8) Fedoroff, B. T.; Sheffield, O. F. Encyclopedia of Explosives and Related Items; 1980; Vol. 8.

(9) Robertson, A. J. B. J. Soc. Chem. Ind. 1948, 67 (June), 221-224.

(10) Roos, B. D.; Brill, T. B. Combust. Flame 2002, 128 (1-2), 181-190.

(11) Chambers, D.; Brackett, C.; Sparkman, O. UCRLID-148956, July 2002.

(12) Liu, W. G.; Zybin, S. V.; Dasgupta, S.; Klapotke, T. M.; Goddard, W. A. I. J. Am. Chem. Soc. 2009, 131 (22), 7490-7491.

(13) Chakraborty, D.; Muller, R. P.; Dasgupta, S.; Goddard, W. A. I. J. Phys. Chem. A 2000, 104 (11), 2261-2272.

(14) Wu, C. J.; Fried, L. E. J. Phys. Chem. A 1997, 101 (46), 8675-8679.

(15) Matyáš, R.; Lyčka, A.; Jirásko, R.; Jakový, Z.; Maixner, J.; Mišková, L.; Künzel, M. J. Forensic Sci. 2016, 61 (3), 759-764. 
Table 2.1: Table with ETN kinetics data both neat and in benzene.

\begin{tabular}{|cccc|}
\hline $\mathrm{T}\left({ }^{\circ} \mathrm{C}\right)$ & $\begin{array}{c}1 / \mathrm{RT} \\
(\mathrm{mol} / \mathrm{kJ})\end{array}$ & $\mathrm{k}\left(\mathrm{s}^{-1}\right)$ & $\ln (\mathrm{k})$ \\
\hline 60 & 0.361 & $1.48 \mathrm{E}-07$ & -15.7 \\
80 & 0.341 & $1.47 \mathrm{E}-06$ & -13.4 \\
80 & & $9.80 \mathrm{E}-07$ & in benzene \\
110 & 0.314 & $3.12 \mathrm{E}-05$ & -10.4 \\
120 & 0.306 & $4.51 \mathrm{E}-05$ & -10.0 \\
140 & 0.291 & $2.14 \mathrm{E}-04$ & -8.45 \\
\hline
\end{tabular}


Table 2.2: Arrhenius parameters for ETN and PETN

\begin{tabular}{|c|c|c|c|c|c|c|c|}
\hline Compound & Method & $\mathrm{Ea}(\mathrm{kJ} / \mathrm{mol})$ & $\mathrm{A}\left(\mathrm{s}^{-1}\right)$ & $\mathrm{k}_{240^{\circ} \mathrm{C}}\left(\mathrm{s}^{-1}\right)$ & $\mathrm{k}_{200^{\circ} \mathrm{C}}\left(\mathrm{s}^{-1}\right)$ & $\mathrm{k}_{140^{\circ} \mathrm{C}}\left(\mathrm{s}^{-1}\right)$ & Ref. \\
\hline ETN & Isothermal (LCMS) & 104.3 & $3.72 \mathrm{E}+09$ & $8.9 \mathrm{E}-02$ & $1.1 \mathrm{E}-02$ & $2.4 \mathrm{E}-04$ & This Work \\
\hline ETN & DSC & 95.0 & $2.35 \mathrm{E}+10$ & $5.0 \mathrm{E}+00$ & $7.5 \mathrm{E}-01$ & $2.3 \mathrm{E}-02$ & 3 \\
\hline \hline PETN & Manometric & 196.6 & $6.31 \mathrm{E}+19$ & $5.9 \mathrm{E}-01$ & $1.2 \mathrm{E}-02$ & $8.4 \mathrm{E}-06$ & 9 \\
\hline PETN & Monometric* & 165.3 & $1.26 \mathrm{E}+16$ & $1.9 \mathrm{E}-01$ & $7.0 \mathrm{E}-03$ & $1.6 \mathrm{E}-05$ & 9 \\
\hline PETN & Weight Loss & 161.5 & $1.58 \mathrm{E}+15$ & $5.6 \mathrm{E}-02$ & $2.3 \mathrm{E}-03$ & $5.9 \mathrm{E}-06$ & 8 \\
\hline PETN & Chemical Analysis & 132.2 & $2.00 \mathrm{E}+13$ & $6.8 \mathrm{E}-01$ & $5.0 \mathrm{E}-02$ & $3.8 \mathrm{E}-04$ & 8 \\
\hline PETN & DSC & 136.5 & $7.47 \mathrm{E}+14$ & $9.4 \mathrm{E}+00$ & $6.3 \mathrm{E}-01$ & $4.0 \mathrm{E}-03$ & 3 \\
\hline PETN & Manometric & 217.4 & $4.70 \mathrm{E}+21$ & $3.4 \mathrm{E}-01$ & $4.6 \mathrm{E}-03$ & $1.5 \mathrm{E}-06$ & 7 \\
\hline
\end{tabular}

$* 5 \%$ in dicyclohexylphthalate 
Table 2.3: Energy (kcal/mol) comparisons (method \& basis set PBE0/cc-pvDZ)

\begin{tabular}{|l|l|l|l|}
\hline reaction & $\begin{array}{l}\text { ETN } \\
\text { (lowest })\end{array}$ & PETN & RDX \\
\hline & \multicolumn{3}{|c|}{ Elimination reactions } \\
\hline$+\mathrm{NO}_{2}($ radical $)(\mathrm{BDE})$ & 37.3 & $35.3(39.0)^{\mathrm{a}}$ & $41.5(39.0)^{\mathrm{b}}(38.0)^{\mathrm{c}}$ \\
\hline$+\mathrm{HONO}\left(\Delta \mathrm{E}^{\#}\right)$ & 34.8 & 38.8 & $40.5(39.2)^{\mathrm{b}}$ \\
\hline$+\mathrm{HONO}\left(\Delta \mathrm{E}_{\text {react }}\right)$ & -16.4 & -10.4 & -1.9 \\
\hline & \multicolumn{3}{|c|}{ H-atom exchange } \\
\hline H-atom shift $\left(\Delta \mathrm{E}^{\#}\right)$ & 41.2 & \multicolumn{3}{|c|}{} \\
\hline H-atom shift $\left(\Delta \mathrm{E}_{\text {react }}\right)$ & 12.7 & 59.9 & 50.2 \\
\hline
\end{tabular}

a. M06/6-311G** result from Liu, W.-G.; Zybin, S. V.; Dasgupta, S.; Klapotke, T.; Goddard W. III JACS, 2009, 131, $7490-7491 .^{12}$

b. B3LYP/6-31G* results from Chakraborty, D.; Muller, R. P.; Dasgupta, S.; Goddard W. III J.Phys. Chem. A, 2000, 104, 2261 - 2272.13

c. B3LYP/cc-pvdz from Wu, C. J.; Fried, L. J.Phys.Chem. A 1997, 101, 86758679. ${ }^{14}$ 
Table 2.4: Decomposition products searched for by high resolution LCMS

\begin{tabular}{|c|c|c|c|c|c|}
\hline \multirow{2}{*}{ Product } & \multirow{2}{*}{ Structure } & \multirow{2}{*}{ Adduct } & \multirow{2}{*}{ Mass } & \multicolumn{2}{|c|}{ Found? } \\
\hline & & & & Yes & No \\
\hline \multirow{4}{*}{$\begin{array}{c}\text { ETN } \\
\left(\mathrm{C}_{4} \mathrm{H}_{6} \mathrm{~N}_{4} \mathrm{O}_{12}\right)\end{array}$} & \multirow{4}{*}{$\mathrm{O}_{2} \mathrm{NO}^{\prime}$} & Chloride & 336.9676 & $x$ & \\
\hline & & Formate & 346.9964 & $x$ & \\
\hline & & Proton Loss & 300.9909 & & $X$ \\
\hline & & Acetate & 361.0121 & & $x$ \\
\hline \multirow{4}{*}{$\begin{array}{c}\text { EtriN } \\
\left(\mathrm{C}_{4} \mathrm{H}_{7} \mathrm{~N}_{3} \mathrm{O}_{10}\right)\end{array}$} & \multirow{4}{*}{$\mathrm{O}_{2} \mathrm{NO}^{-}$} & Chloride & 291.9825 & $x$ & \\
\hline & & Formate & 302.0113 & $x$ & \\
\hline & & Proton Loss & 256.0059 & $x$ & \\
\hline & & Acetate & 316.0270 & & $x$ \\
\hline \multirow{4}{*}{$\begin{array}{c}\text { EdiN } \\
\left(\mathrm{C}_{4} \mathrm{H}_{8} \mathrm{~N}_{2} \mathrm{O}_{8}\right)\end{array}$} & \multirow{4}{*}{$\left.\right|_{\mathrm{ONO}_{2}} ^{\mathrm{O}_{2} \mathrm{NO}^{\prime}}$} & Chloride & 246.9975 & $x$ & \\
\hline & & Formate & 257.0263 & $x$ & \\
\hline & & Proton Loss & 211.0208 & $x$ & \\
\hline & & Acetate & 271.0419 & & $x$ \\
\hline \multirow{4}{*}{$\begin{array}{l}\text { EmonoN } \\
\left(\mathrm{C}_{4} \mathrm{H}_{9} \mathrm{NO}_{6}\right)\end{array}$} & \multirow{4}{*}{$\mathrm{O}_{2} \mathrm{NO}^{\prime}$} & Chloride & 202.0124 & $x$ & \\
\hline & & Formate & 212.0412 & $x$ & \\
\hline & & Proton Loss & 166.0357 & & $x$ \\
\hline & & Acetate & 226.0568 & & $x$ \\
\hline \multirow{4}{*}{$\begin{array}{c}{\left[\mathrm{ETN}-\mathrm{HNO}_{2}\right]} \\
\left(\mathrm{C}_{4} \mathrm{H}_{5} \mathrm{~N}_{3} \mathrm{O}_{10}\right)\end{array}$} & \multirow{4}{*}{$\prod_{\mathrm{ONO}_{2}}$} & Chloride & 289.9669 & & $x$ \\
\hline & & Formate & 299.9957 & & $x$ \\
\hline & & Proton Loss & 253.9902 & & $x$ \\
\hline & & Acetate & 314.0113 & & $x$ \\
\hline \multirow{4}{*}{$\begin{array}{c}{\left[\mathrm{ETN}-\mathrm{HNO}_{3}\right]} \\
\left(\mathrm{C}_{4} \mathrm{H}_{5} \mathrm{~N}_{3} \mathrm{O}_{9}\right)\end{array}$} & \multirow{4}{*}{$\left.\right|_{\mathrm{ONO}_{2}}$} & Chloride & 273.9720 & & $X$ \\
\hline & & Formate & 284.0008 & & $x$ \\
\hline & & Proton Loss & 237.9953 & & $x$ \\
\hline & & Acetate & 298.0164 & & $x$ \\
\hline \multirow{4}{*}{$\begin{array}{c}{[\mathrm{ETN}-\mathrm{H}]} \\
\left(\mathrm{C}_{4} \mathrm{H}_{5} \mathrm{~N}_{4} \mathrm{O}_{12}\right)\end{array}$} & \multirow{4}{*}{$\left.\right|_{\mathrm{ONO}_{2}}$} & Chloride & 335.9598 & & $x$ \\
\hline & & Formate & 345.9886 & & $x$ \\
\hline & & Proton Loss & 299.9831 & & $x$ \\
\hline & & Acetate & 360.0042 & & $x$ \\
\hline \multirow{4}{*}{$\begin{array}{l}\text { ETN Polymer } \\
\left(\mathrm{C}_{8} \mathrm{H}_{12} \mathrm{~N}_{6} \mathrm{O}_{18}\right)\end{array}$} & \multirow{4}{*}{$\prod_{\mathrm{ONO}_{2}}$} & Chloride & 530.9851 & & $x$ \\
\hline & & Formate & 541.0139 & & $x$ \\
\hline & & Proton Loss & 495.0084 & & $x$ \\
\hline & & Acetate & 555.0296 & & $x$ \\
\hline
\end{tabular}




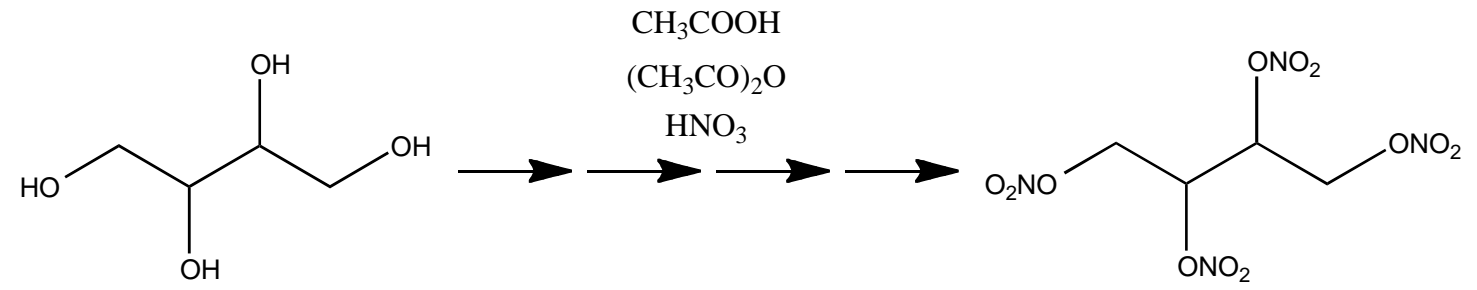

Figure 2.1: Nitration of erythritol to ETN, stepwise nitration of each alcohol 


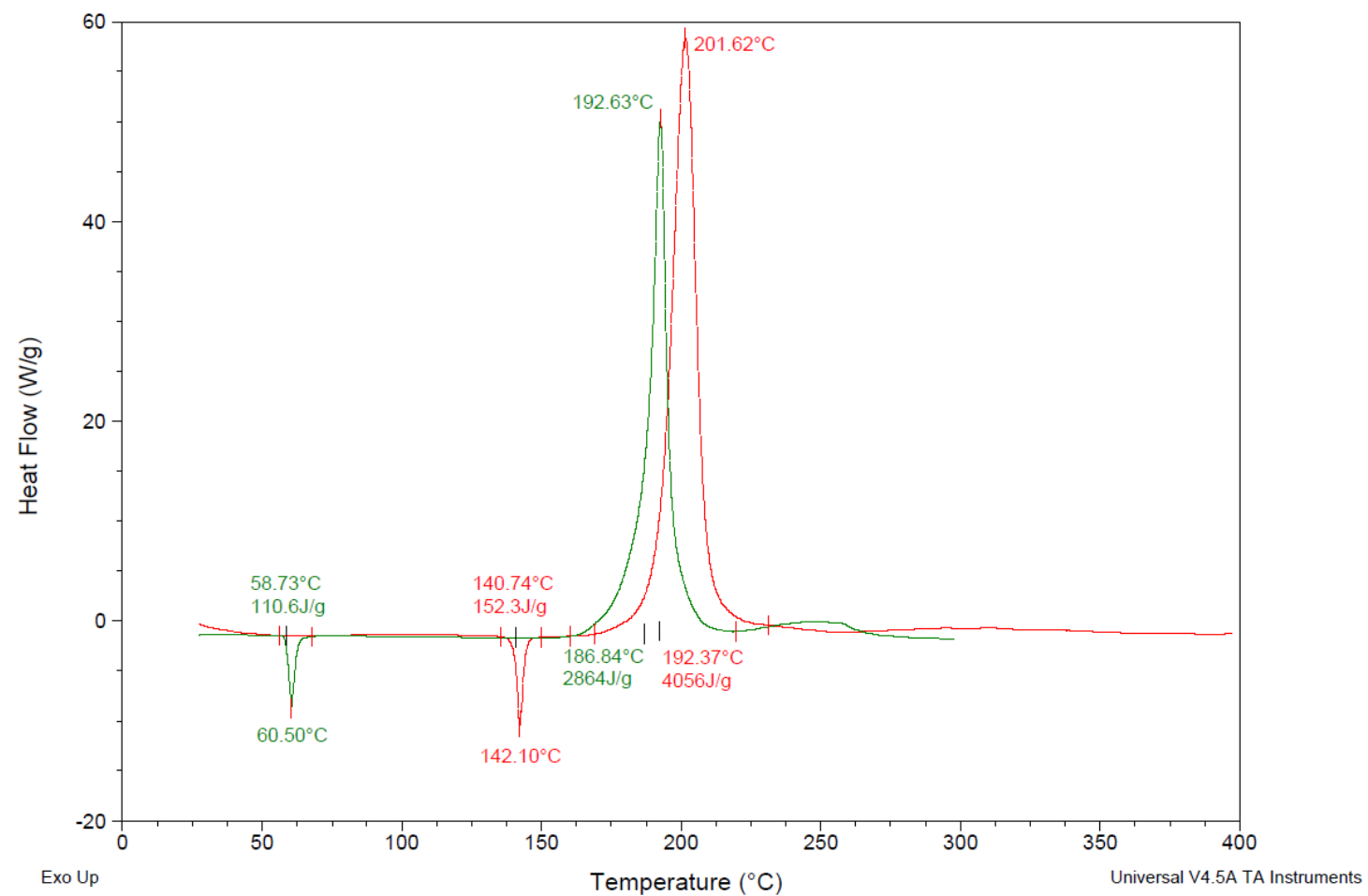

Figure 2.2: DSC overlay of ETN (Green) and PETN (Red) $\left(10^{\circ} \mathrm{C} / \mathrm{min}\right)$ 


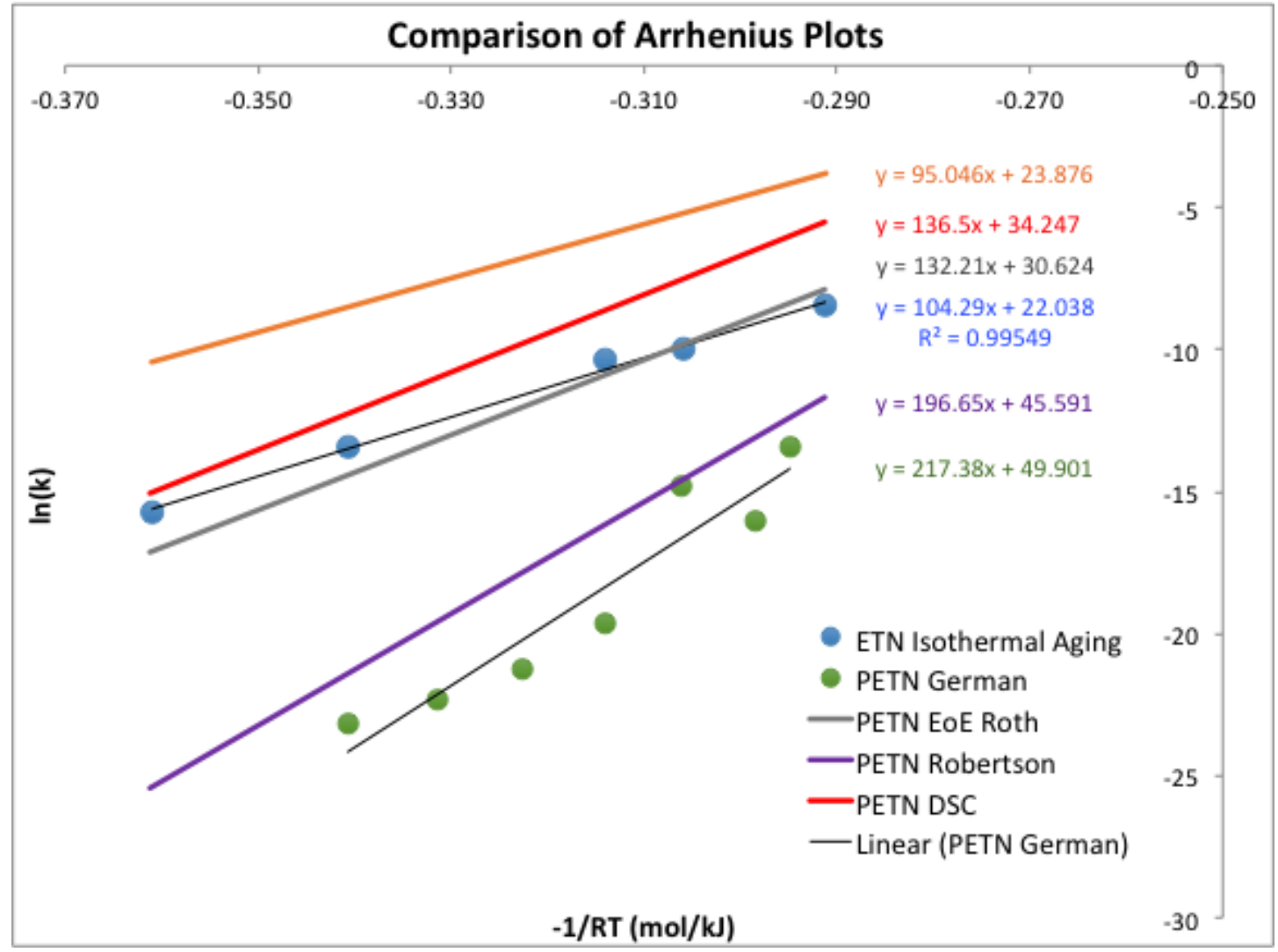

Figure 2.3: Arrhenius plots for ETN and PETN 

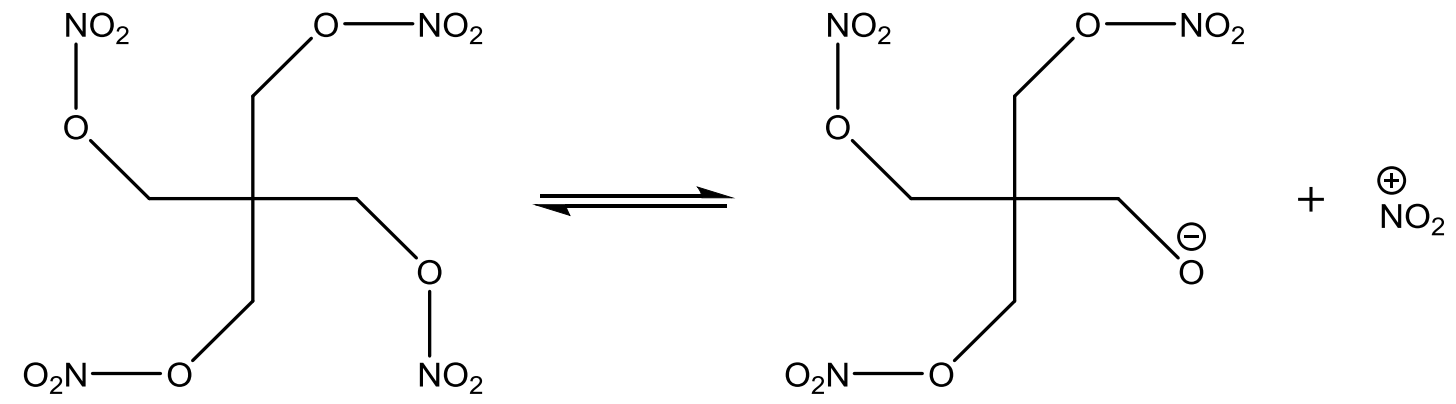

Figure 2.4: PETN loss of $\mathrm{NO}_{2}$ 


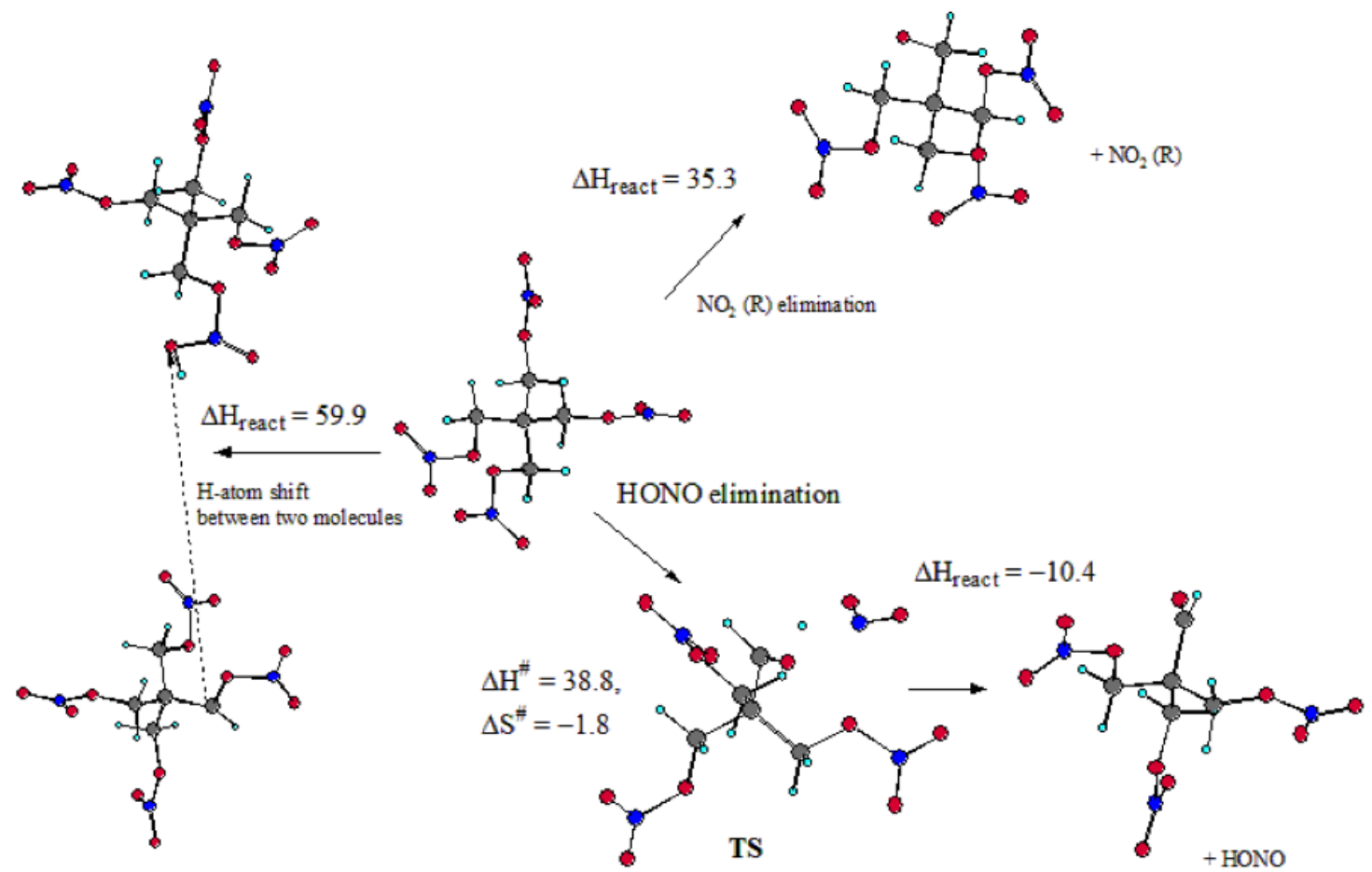

Figure 2.5: Energetics of PETN decomposition calculated by PBE0//cc-pVDZ 


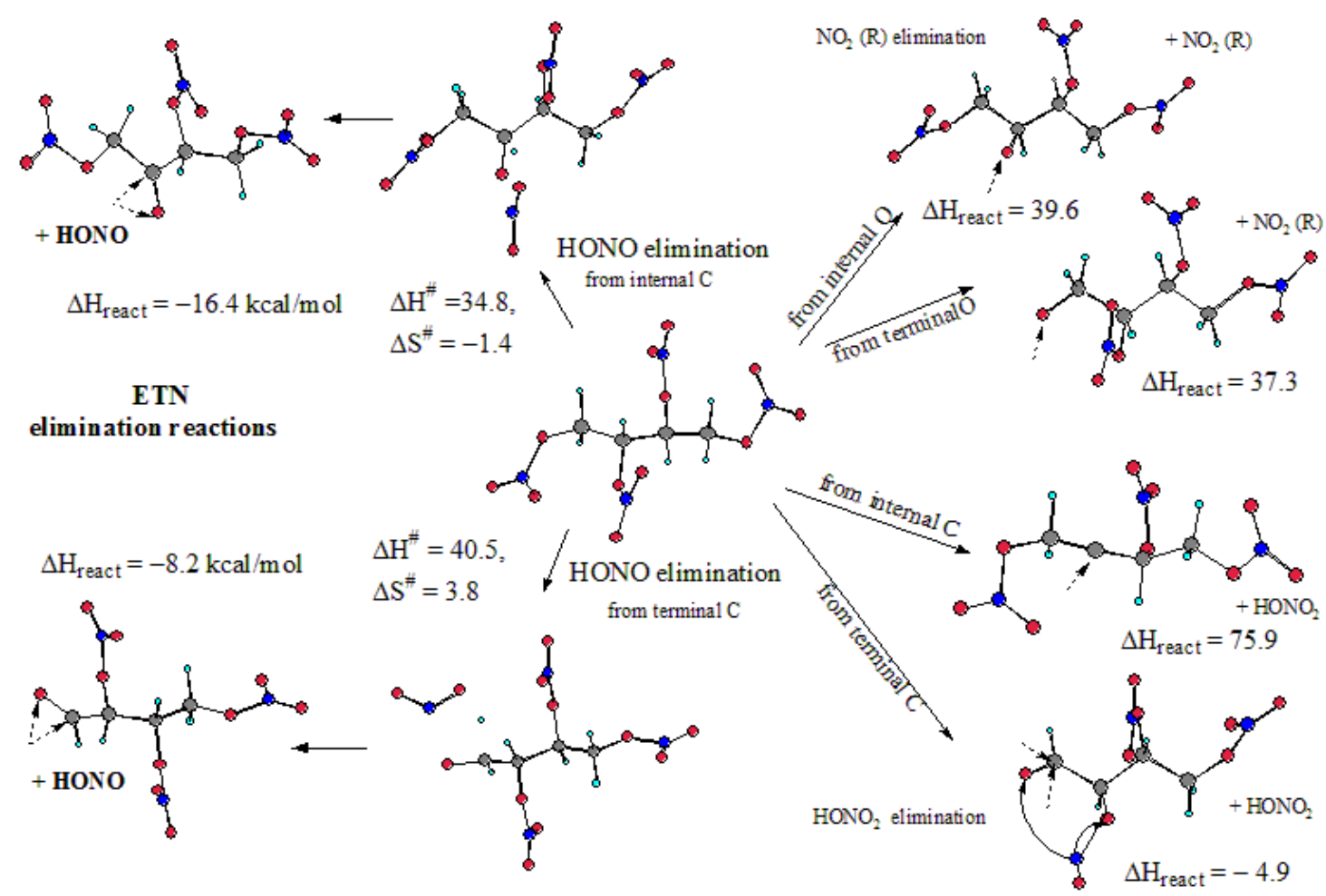

Figure 2.6: Energetics of ETN decomposition, calculated by B3LYP/6-311++G(d,p) method \& basis set 


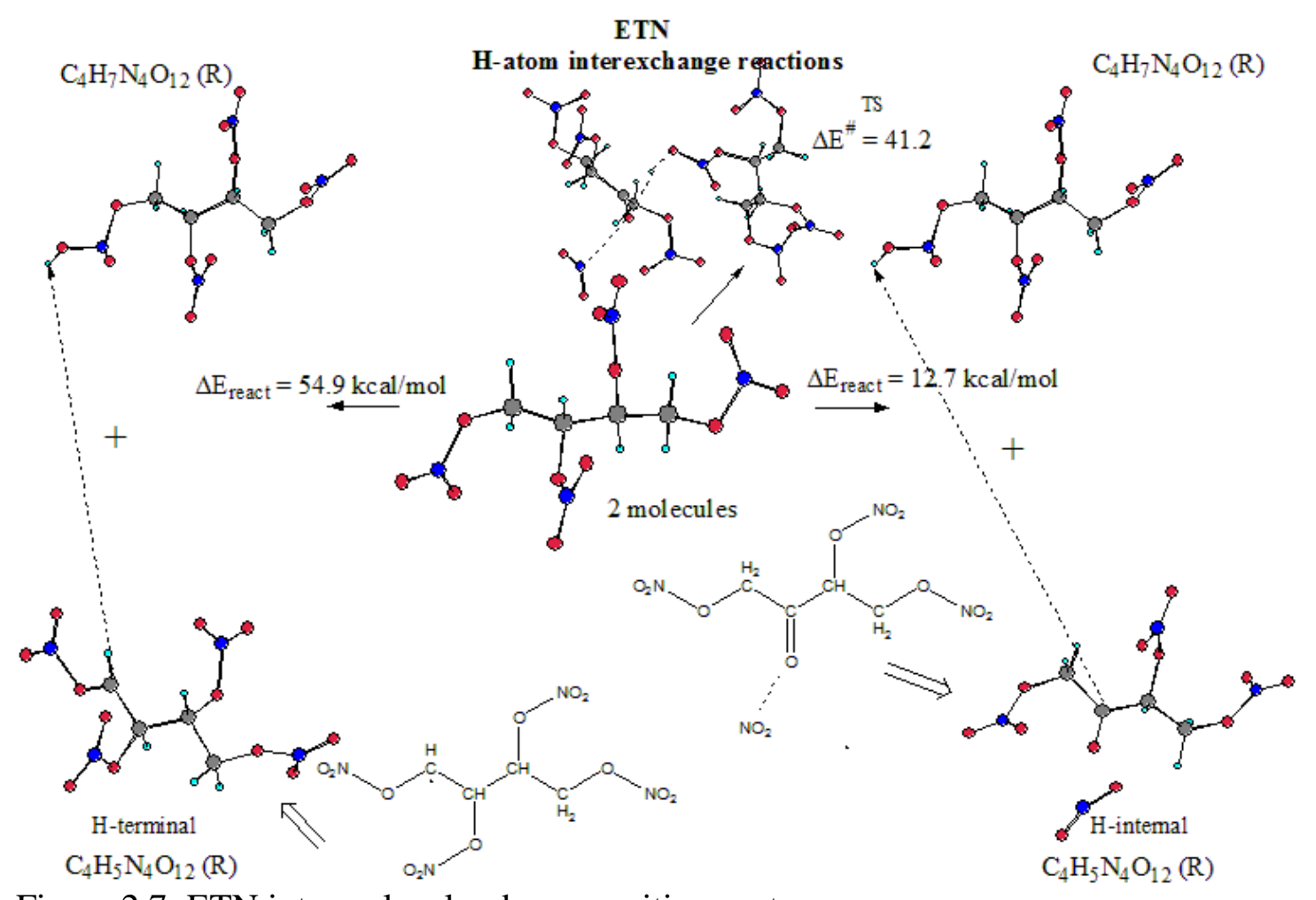

Figure 2.7: ETN intermolecular decomposition routes 
a)

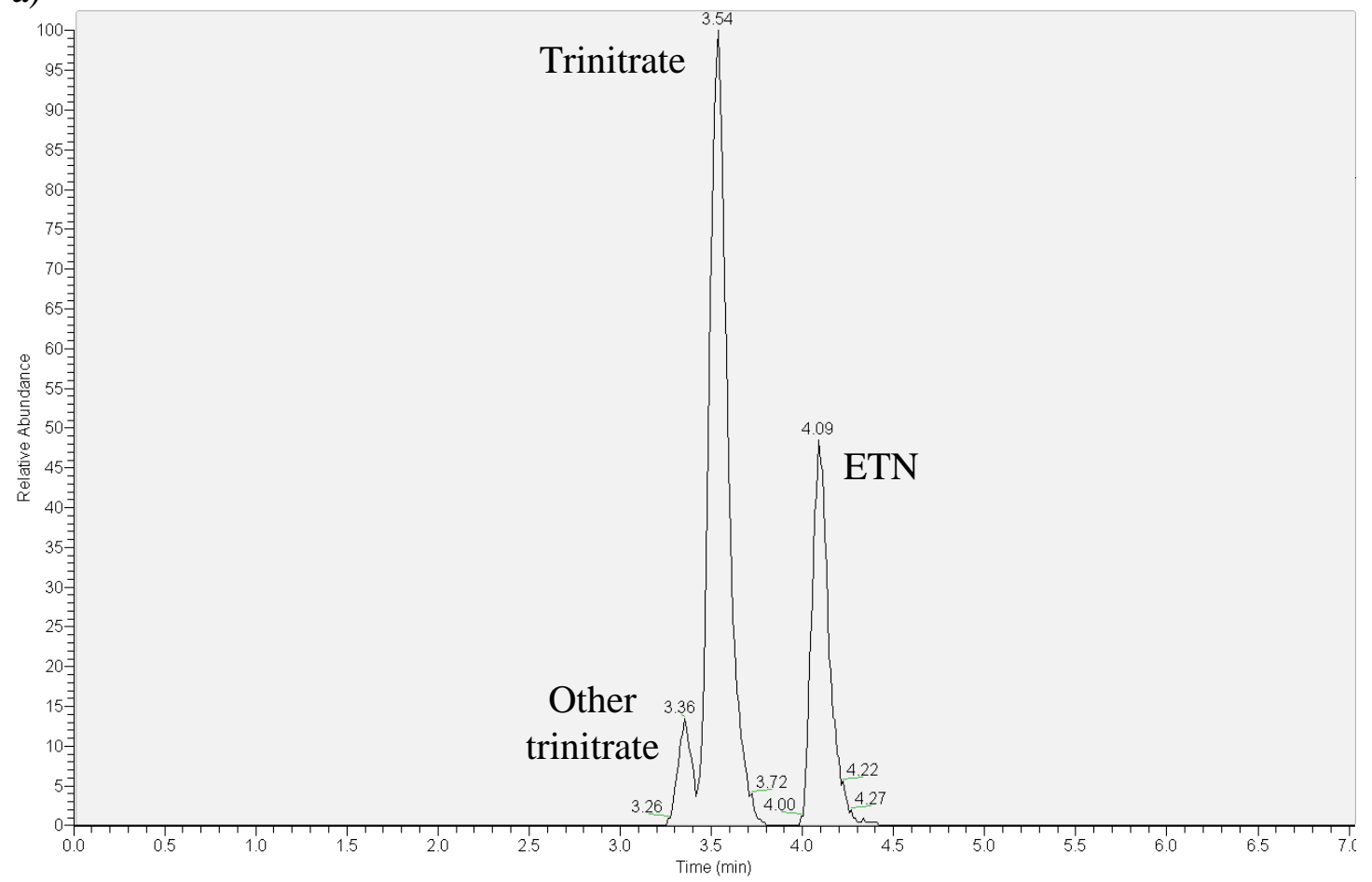

b)

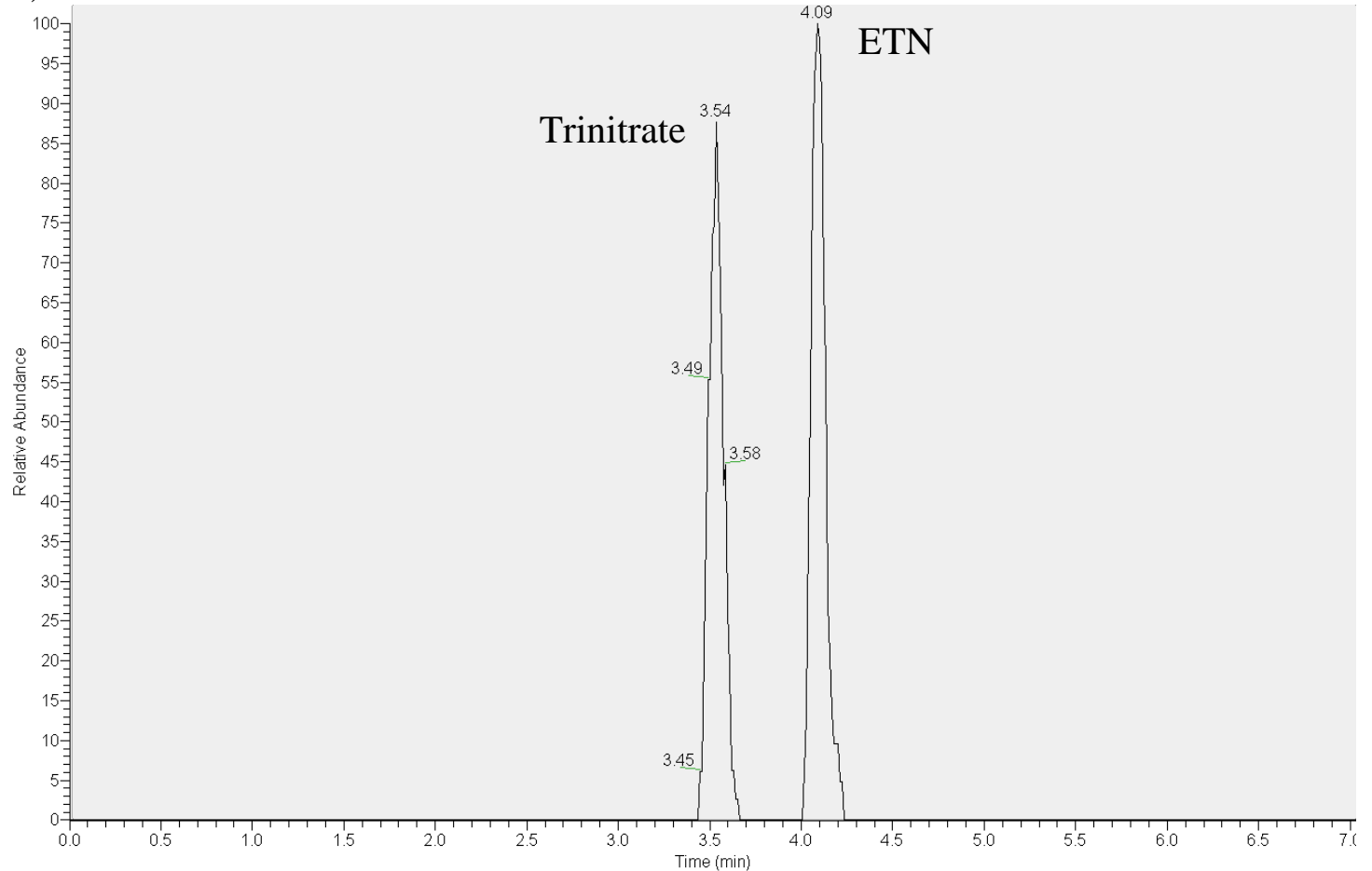

Figure 2.8: Extracted ion chromatograms (291.9825) of erythritol trinitrate a) crude b) decomposed 

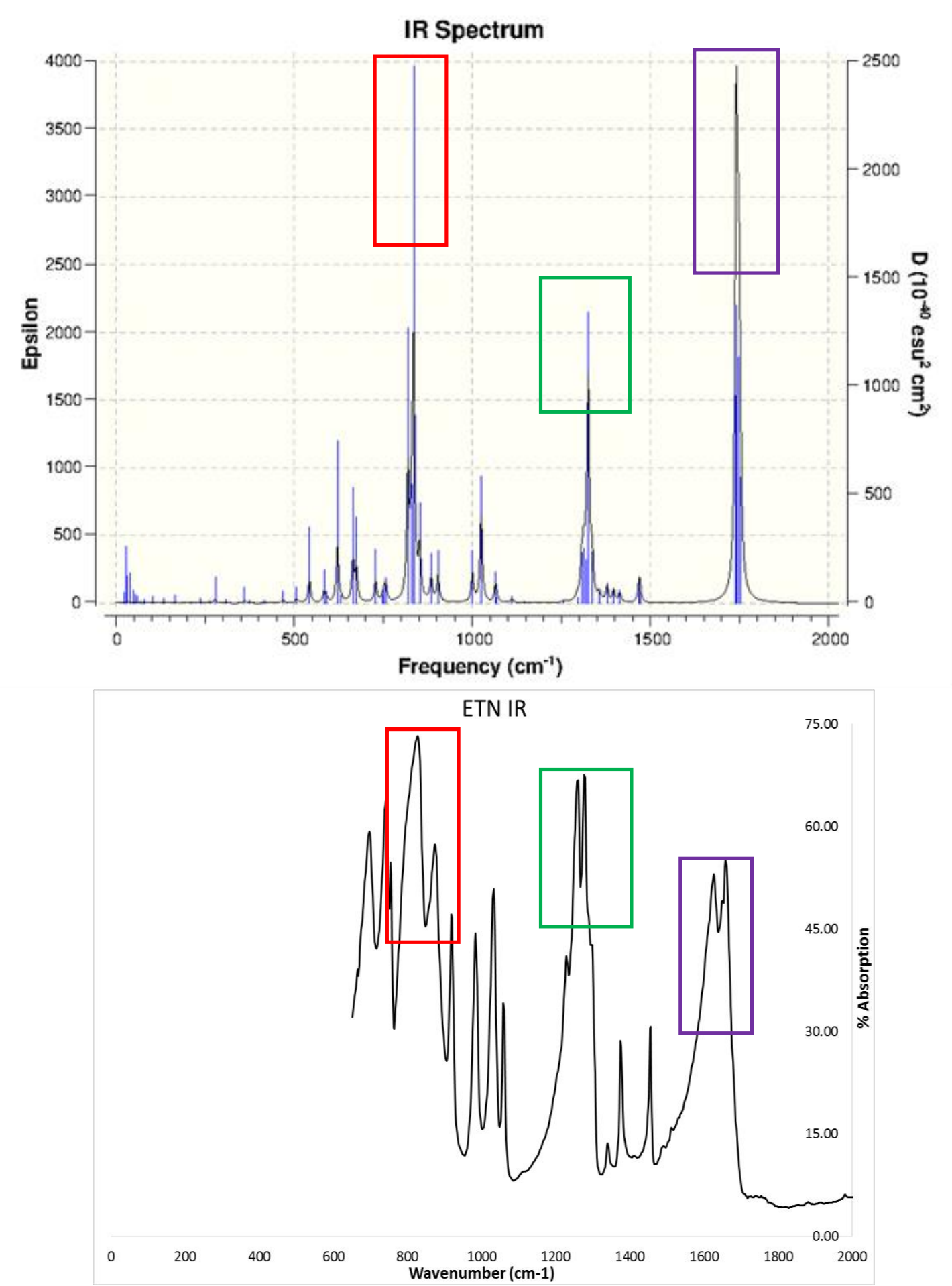

Figure 2.9: IR of ETN, theoretical (top), experimental (bottom). Red: ONO scissoring (Calc: 820-854 cm $\mathrm{cm}^{-1}$, Exp: 827-874 $\mathrm{cm}^{-1}$ ); Green: symmetric $\mathrm{NO}_{2}$ stretching (Calc: 1326-1337 $\mathrm{cm}^{-1}$, Exp: $\left.1259-1277 \mathrm{~cm}^{-1}\right)$; Purple: asymmetric $\mathrm{NO}_{2}$ stretching $($ Calc: 1741-1753 $\mathrm{cm}^{-1}$, Exp: $1626-1659 \mathrm{~cm}^{-1}$ ) 

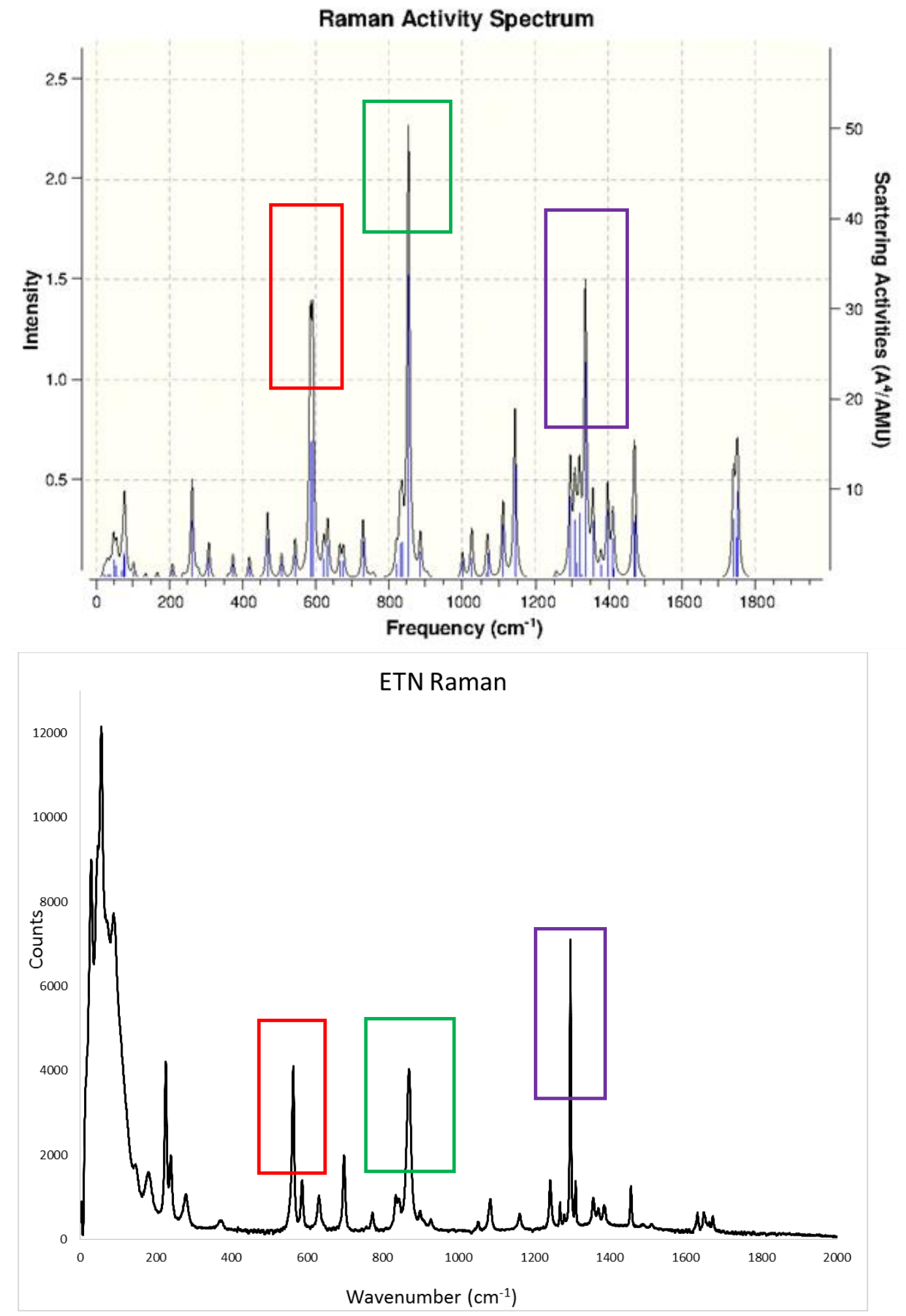

Figure 2.10: Raman of ETN, theoretical (top), experimental (bottom). Red: OCH rocking (Calc: 586-592 cm ${ }^{-1}$, Exp: $564 \mathrm{~cm}^{-1}$ ); Green: $\mathrm{NO}_{2}$ scissoring (Calc: $854 \mathrm{~cm}^{-1}$, Exp: $870 \mathrm{~cm}^{-1}$ ); Purple: $\mathrm{NO}_{2}$ symmetric stretching (Calc: $1337 \mathrm{~cm}^{-1}$, Exp: $1296 \mathrm{~cm}^{-1}$ ) 


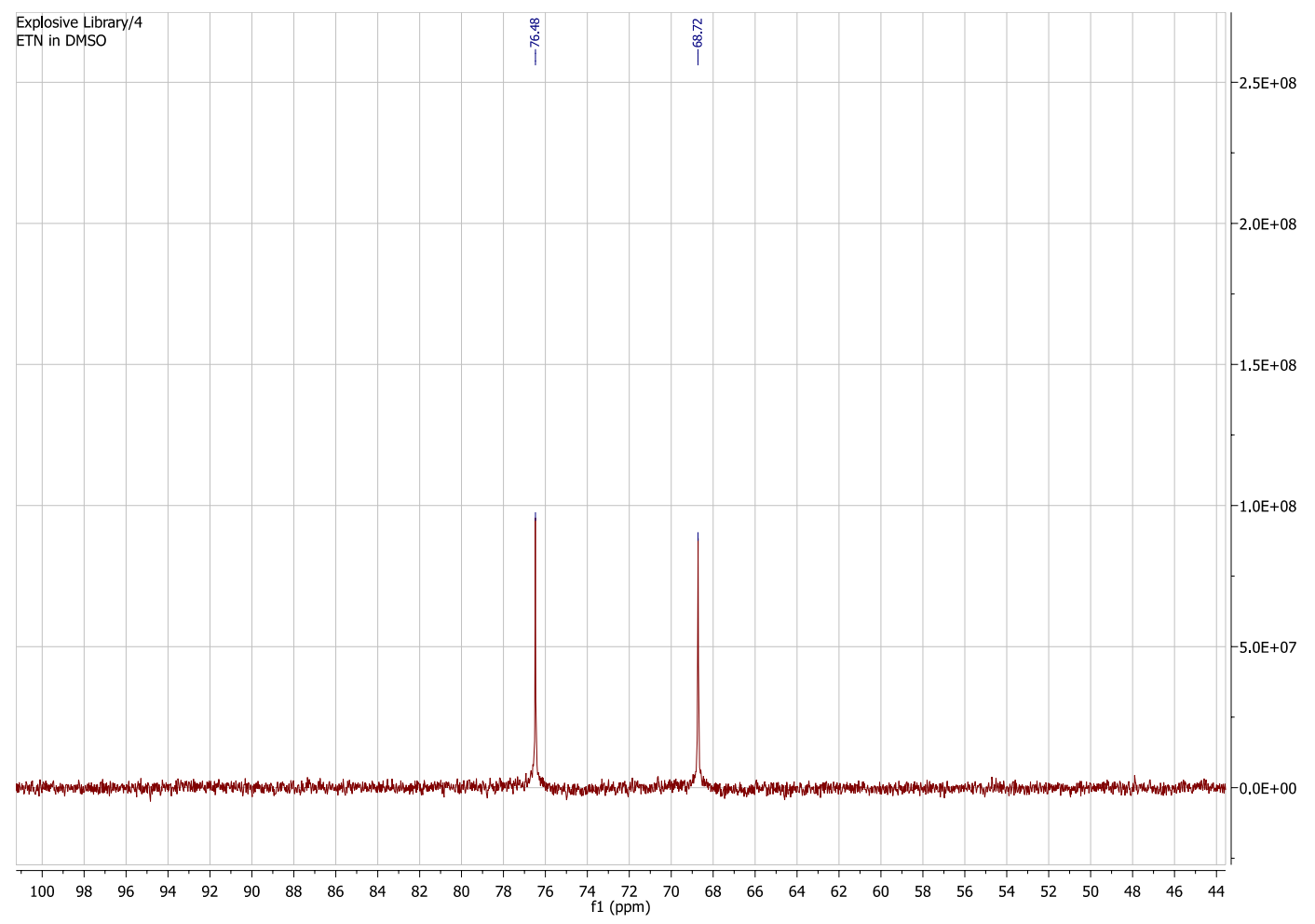

Figure 2.11: Carbon NMR of ETN in DMSO-d6 
a)

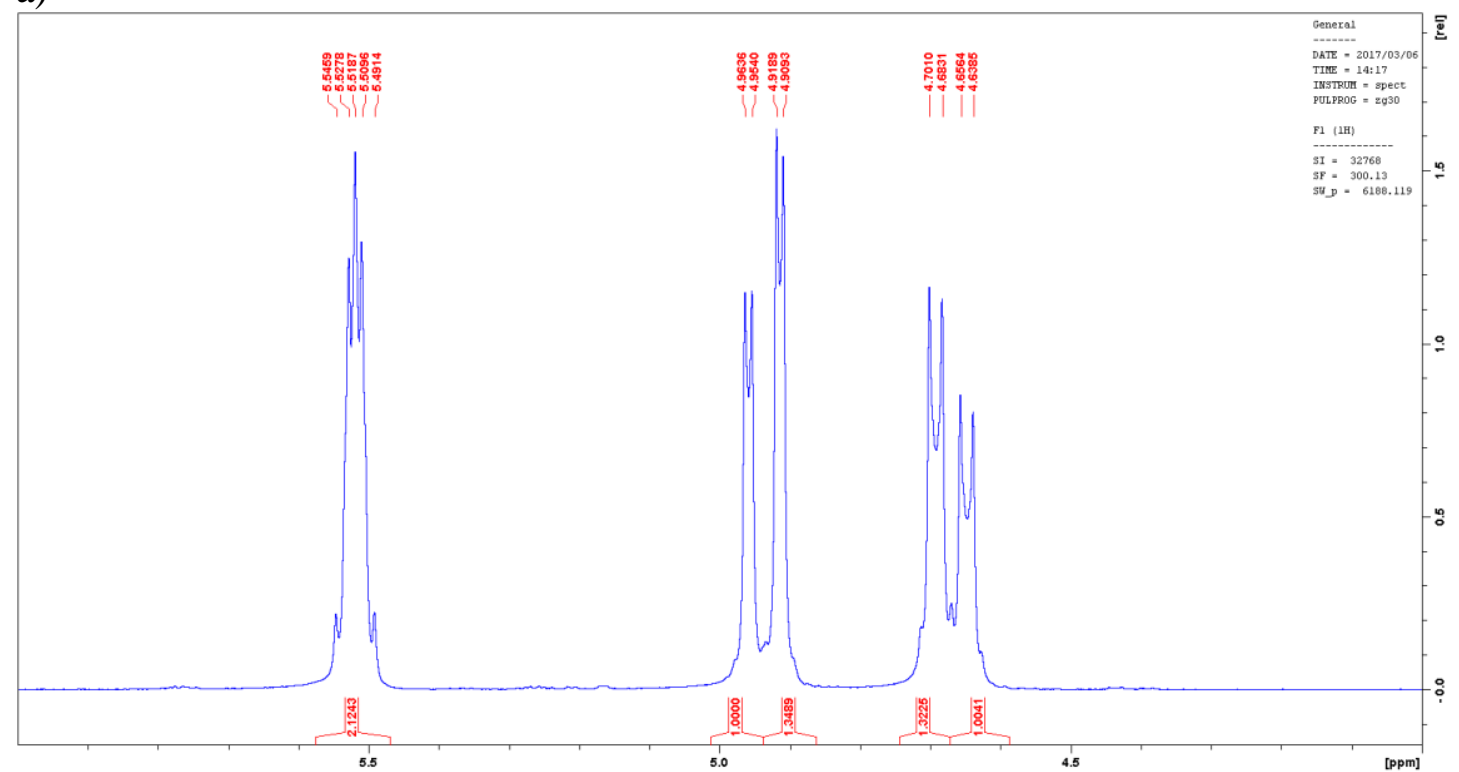

b)

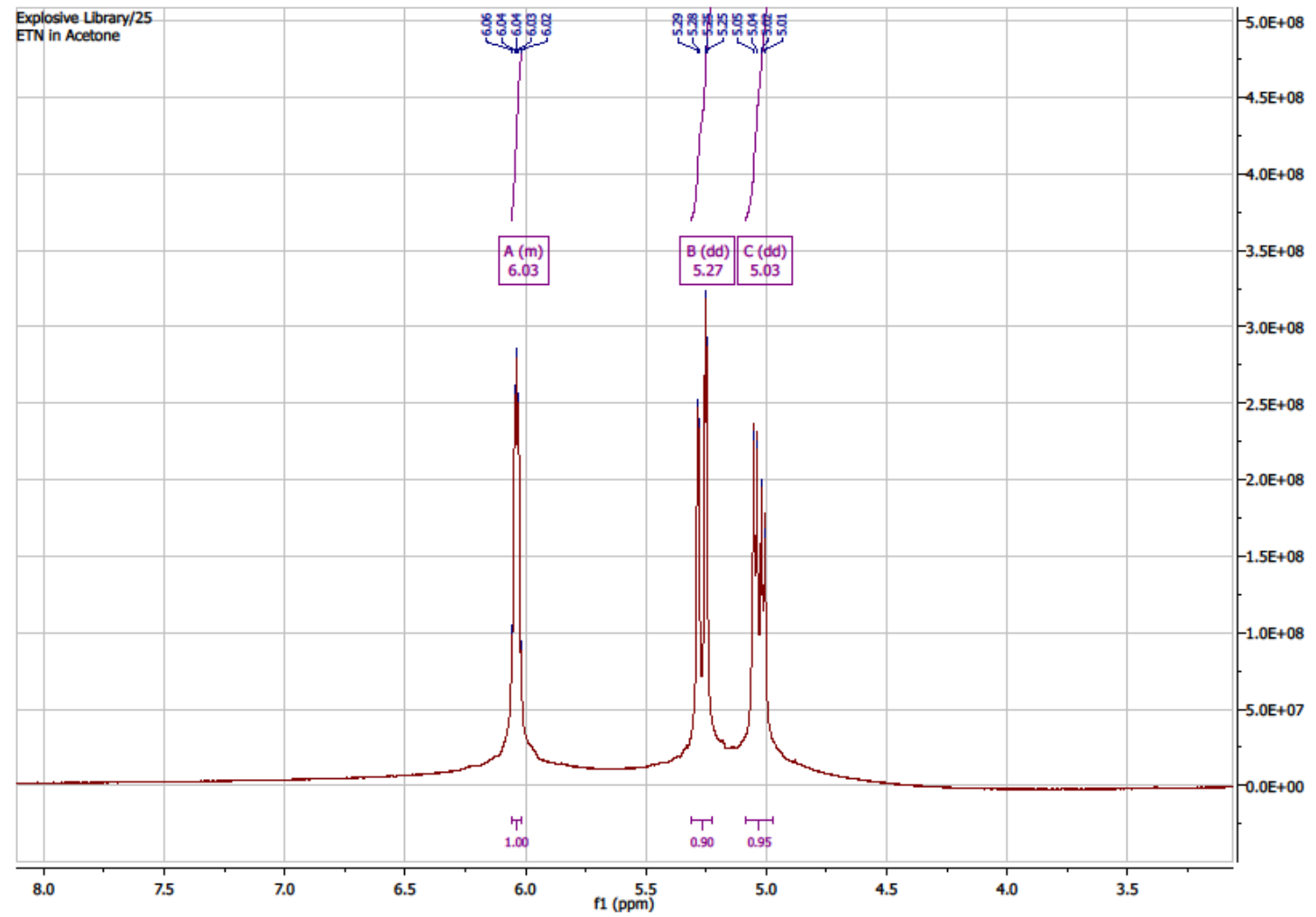

Figure 2.12: Proton NMR of ETN a) in $\mathrm{CDCl}_{3}$ b) in deuterated acetone 


\title{
CHAPTER 3
}

\section{X-Ray Simulants}

\author{
Jimmie C. Oxley*; James L. Smith; Austin C. Brown \\ University of Rhode Island, Chemistry Department
}

140 Flagg Road

Kingston, RI, 02881

joxley@chm.uri.edu

Prepared for submission to the Journal of Energetic Materials

\begin{abstract}
A new approach to develop non-hazardous materials which to x-ray detection instrumentation simulated explosives and other related threats is presented in this work. Rather than trying to make universal simulants, which often do not provide adequate matches across multiple instruments, this method focuses on making more accurate simulants specific to the instruments they are designed on. These simulants could be used in locations where the actual threats cannot, e.g. vendors' facilities, airports, and personnel training.
\end{abstract}

\section{Keywords}

X-ray; explosive; simulant 


\section{Background}

X-ray scanner response (RES) to a compound is based on its density ( $\rho$ ) and effective atomic number ( $\left.Z_{\mathrm{eff}}\right)$ e as well as constants related to the energy of the $\mathrm{x}$-ray. Thus the development of simulants for $\mathrm{x}$-rays has often focused on crafting materials that match both the density and $\mathrm{Z}_{\mathrm{eff}}$ of the threat. One problem with this approach is that it is challenging to match these values, specifically the $Z_{\text {eff; }}$ which is directly related to the energy of the $\mathrm{x}$-rays being used. Thus, a " $Z_{\mathrm{eff}}$ match" is only good for the $\mathrm{x}$-ray energy level for which it was created. The only way to match the $\mathrm{Z}_{\mathrm{eff}}$ across all energies would be to match the exact elemental composition of the material being simulated.

The first step in creating simulants for $\mathrm{x}$-ray systems is understanding how the $\mathrm{X}$-ray instrument response is related to density and $\mathrm{Z}_{\mathrm{eff}}$. $\mathrm{Z}_{\mathrm{eff}}$ is calculated by taking the sum of the Z's for each component of the system raised to some exponential power weighted by their fraction of protons in the entire system. The value of this exponent depends upon the x-ray energy and the type of x-ray interactions being measured (i.e. transmission or scattering). For transmission it is often assumed to be 2.94 (Equation $1) .^{1,2}$

$$
\mathrm{Z}_{\mathrm{eff}}=\left(\Sigma\left(\mathrm{f}_{\mathrm{i}} * \mathrm{Z}_{\mathrm{i}}^{\mathrm{n}}\right)\right)^{1 / \mathrm{n}}
$$

Where $\mathrm{Z}$ is the number of protons in a given atom; $\mathrm{f}$ is the number of protons in that atom divided by the total number of protons in the composition (which means the proton in $\mathrm{H}$ and $\mathrm{O}$ in aqueous solutions must be accounted for); and $\mathrm{n}$ is the exponent constant related to x-ray energy. 
If the $Z_{\text {eff }}$ exponent can be predicted based on the energy of the $\mathrm{x}$-ray system, the simulant development method of matching the density and $Z_{\text {eff }}$ of a hazardous solution becomes an option. Originally, the goal of this project was to develop a theoretical model that could be used to create simulants for hazardous solutions based on density, the energies of the $\mathrm{x}$-rays in a system, and $Z_{\text {eff }}$ at those energies. Our approach was to run sufficient samples of known composition and density so that by an iterative process the data could be fit to equation 2 .

$$
\operatorname{RES}=\left(f n\left(\rho * Z_{\text {eff }}\right)\right)
$$

The value of $\mathrm{n}$ in equation 1 and the form of equation 2 were varied systematically as part of the iterative process. Based on the best fit, the exponent $\mathrm{n}$ in equation 1 could be established for that $\mathrm{x}$-ray instrument. Unfortunately, this approach did not feasible, due to the polychromatic nature of x-ray sources. Nevertheless, we were able to identify a number of effective simulants for threat liquids and elucidate a method for simulant development applicable to certain instruments.

Explosive precursors were used as the threat materials in this study: nitrobenzene (NB), hydrogen peroxide (HP), and nitric acid (NA). Non-energetic materials used as potential simulant components are listed in Table 3.1. Nitrobenzene was used as purchased. Hydrogen peroxide and nitric acid were concentrated or diluted as required. Urea was ground by hand with mortar and pestle and diluted with magnesium sulfate. Other simulant components listed in Table 3.1 were dissolved in water, making a suite of aqueous solutions for investigating $\mathrm{x}$-ray response. The primary x-ray detector used in this study, designed to examine hazardous liquids, was capable of examining materials at two energy levels above and below $35 \mathrm{keV}$. This 
detector analyzed samples based on $\mathrm{x}$-ray scattering rather than attenuation. Samples were also examined on a computed-tomography (CT) single-energy instrument and on a CT of dual-energy. Materials used to gauge instrument response were categorized by their density and $\mathrm{Z}_{\mathrm{eff}}$ (Table 3.2). Density was either measured, found in the literature ${ }^{3}$ or calculated as reported by Laliberte. ${ }^{4-6}$ Equation 1 with an exponent of 4 was used to estimate $\mathrm{Z}_{\mathrm{eff}}$, and mole percentage of water was accounted for in aqueous solutions. List of aqueous solutions employed and their estimated density and $\mathrm{Z}_{\text {eff }}$ are shown in Table 3.2.

\section{Results and Discussion}

Rather than trying to match the actual density and elemental composition of a threat material, we attempted to match the output signals that the instrument produced through other methods. Initial experiments varied the concentration of each liquid by addition of water. The instrument response at high and low X-ray energies (HE and LE, respectively) were plotted. For all solutions the concentration trendlines in a LE vs HE plot intersected at the water $\mathrm{LE} / \mathrm{HE}$ response, a point which corresponded to $0 \%$ solute and $100 \%$ water (Fig. 3.1), which we termed the "zero" point. This observation led to the idea that solutions could be mixed to produce the desired concentration trendline. Figure 3.2 shows the trends for aqueous $\mathrm{BaCl}_{2}$ and aqueous 2-propanol as well as the shift in $\mathrm{LE} / \mathrm{HE}$ that could be expected when $\mathrm{BaCl}_{2}$ is dissolved in $40 \%$ 2-

propanol solution. When prepared in $40 \%$ 2-propanol, the trendline for $\mathrm{BaCl}_{2}$ shifts its lower end (its $0 \%$ origin) from that LE/HE of water to the LE/HE of the $40 \% 2$ propanol. This being the case it became possible to calculate how the innocuous 
liquids could be combined to simulate the hazardous materials. Figure 3.2 shows that a solution of approximately $40 \%$ 2-propanol with barium chloride $(0.2 \%)$ might act as a simulant for nitrobenzene.

Calculated Trendline Shifting: Microsoft Excel was used to estimate what innocuous liquids (e.g. A, B) and quantities or concentrations of A and B would simulate a threat liquid. In order to calculate the concentrations of A and B needed to create a simulant, four plots were created: HE vs wt\% A; LE vs wt\% A; HE vs. wt\% B; and LE vs wt\% B. Trendlines were constructed for each of these plots resulting in four equations that were input into an Excel table to create the formulae for the shifted trendlines. The intercept for each set of equations corresponded to $0 \%$ solute and $100 \%$ water. Finding a simulant for a particular hazardous liquid, i.e matching its LE/HE, was done in two steps (Fig. 3.3a-3.3c). First, the trendline for A had to be shifted so that at some concentration of $\mathrm{A}$ it passed through the desired LE/HE. This resulted in a new $0 \%$ point for A (Fig. 3.3b). Second, the trendline for B had to be adjusted so that the concentration of $\mathrm{B}$ required to pass through the $\mathrm{LE} / \mathrm{HE}$ of the threat material was also determined (Fig. 3.3c). This approach involved solving four equations-LE and HE for each of $\mathrm{A}$ and $\mathrm{B}$ and resulted in a rough estimate of the concentrations of $\mathrm{A}$ and $\mathrm{B}$ necessary to create a simulant.

The Excel approach described above assumed no interaction between component $\mathrm{A}$ and component $\mathrm{B}\left(\mathrm{BaCl}_{2}\right.$ and $\left.\mathrm{KBr}\right)$. Sometimes the resultant match was excellent (Fig. 3.4a), and sometimes it was a bit "off" (Fig. 3.4b). When the simulant did not match exactly the actual threat material, small increases or decreases in the 
component concentrations were made. This resulted in additional LE/HE data gathered on $\mathrm{BaCl}_{2}+\mathrm{KBr}$ mixtures as the ratios of $\mathrm{BaCl}_{2}$ and $\mathrm{KBr}$ in water were varied. A total of twenty-five mixtures of $\mathrm{BaCl}_{2}+\mathrm{KBr}$ were created during the first attempts to create a hydrogen peroxide (HP) simulant, giving an additional 25 sets of LE/HE data (Table 3.3). By this method simulants were prepared for five concentrations of HP (Fig. 3.5). The simulant attempts and adjustments are included for $65-90 \%$ HP in supplemental information (SF 3.1-3.4), 60\% HP simulant matched on first try.

For liquids with densities lower than water, the LE/HE trends lines approached the water LE/HE value from the lower left corner (Fig. 3.1). To reach these LE/HE values, it was necessary to prepare simulant mixtures using at least one low-density organic material (see Table 3.2, CHNO samples). Figure 3.7 shows the success of this method for creating a simulant for nitrobenzene. Original attempt and honing process for this simulant are included in supplemental information (SF 3.5)

Computed Component Mixing: With the twenty-five additional LE/HE sets of data collected for the HP work, a sophisticated multi-equation problem solver such as Mathmatica could be used to generate two equations; one that predicted HE and one that predicted $\mathrm{LE}$ from the wt $\% \mathrm{BaCl}_{2}$ and $\mathrm{wt} \% \mathrm{KBr}$ mixtures (Equations 2 and 3). With equations 2 and 3, simulants for any liquid threat material bracketed by the original 25 simulants could be prepared. To demonstrate the robust nature of the calculation, equations 2 and 3 were used to create simulants for four concentrations of nitric acid (NA). The three simulants for nitric acid that were within our original simulant boundaries matched on the first attempts. The fourth, which was outside of 
our boundaries, was close but slightly "off," requiring further adjustments (Fig. 3.6). Original fourth simulant attempt that required adjustment is included in supplemental information (SF 3.6).

$$
\begin{array}{cc}
\mathrm{HE}=-0.6738 \mathrm{x}^{2}+0.5865 \mathrm{x}-0.05616 \mathrm{y}^{2}+0.2842 \mathrm{y}+0.6142 & \mathrm{R}^{2}=0.999996 \\
\mathrm{LE}=-0.4693 \mathrm{x}^{2}+0.3160 \mathrm{x}+0.01635 \mathrm{y}^{2}+0.3262 \mathrm{y}+1.061 & \mathrm{R}^{2}=0.999979 \\
\text { where } \mathrm{x}=\mathrm{wt} \% \mathrm{BaCl}_{2} \quad \text { and } \mathrm{y}=\mathrm{wt} \% \mathrm{KBr} &
\end{array}
$$

Potential Extrapolation of Method for Dual-energy CT: Having successfully demonstrated a method for preparing X-ray simulants for a rather unique X-ray device, this method was tested for applicability on a dual-energy computedtomographic (CT) X-ray. Using a subset of the innocuous liquids listed (Table 3.1), we found that as the sample concentration decreased the trendlines for instrument output reported as "Z $Z_{\mathrm{eff}}$ " and "density" trended back toward water in a similar manner as observed on the original x-ray detector (Fig. 3.8).

Using this data we attempted to create simulants for the dual energy CT using the trendline shifting approach described in Figure 3.3. However, the HE and LE of the innocuous liquids were replaced by the appropriate instrument output of density and $\mathrm{Z}_{\mathrm{eff}}$. Simulants were created for three concentrations of HP, the results are shown in Figure 3.9.

During two sessions, threats were analyzed on the dual energy CT. The first session threat data is shown in green, and the second is shown in blue. Simulants, shown in orange, were created from the first session data and analyzed during the 
second. The initial results for the three HP simulants were promising for creating simulants in this fashion. The deviation from the first session threat data and the simulant data was less than $2 \%$ for the three HP simulants in both density and $\mathrm{Z}_{\text {eff. }}$ The $\mathrm{HCl}$ data landed almost directly in the path of one of the aqueous solution trendlines (Figure 3.10), collection of data on a potential simulant is in progress.

Methods for Simulant Development for Single-energy CT: The one dimensionality of the single-energy CT response meant that our previous method could not be applied. On a single-energy CT, the histogram of the instrument response to the threat material, i.e. HP (Fig. 3.11) can be matched. The ratio of the solutes to one another affects the histogram peak shape. Once the desired peak shape is achieved, increasing or decreasing the solutes in this ratio will shift the peak right or left, respectively, until their histogram overlays that of the threat material. A simulant made of aqueous glycerol and $\mathrm{BaCl}_{2}$ was adjusted in this manner for $30 \%$ hydrogen peroxide (Fig. 3.11). Such an adjustment would not be possible on a dual energy X-ray; one of the approaches described above would be required.

Investigating Trendline Generation for Solids: An attempt was made to investigate whether a series of solid solutions could be made that would also trend linearly to a single "zero" point, such as was observed with water. To simulate solid solutions, ground urea was chosen as the solvent and $\mathrm{MgSO}_{4}$ as the solute; thus, the "zero" point would be $100 \%$ urea. Urea and $\mathrm{MgSO}_{4}$ were mixed together in a variety of ratios. These solutions were examined on single-energy CT. Figure 3.12 compares shifts in 
the response of the single-energy CT to various concentrations of hydrogen peroxide in water to various concentrations of $\mathrm{MgSO}_{4}$ in urea. No clear trend of signal response with concentration is observed in the solid. Without a clear trend, the trendline method could not be used for predicting simulants. The samples used to collect the data used in Figure 3.10 were remade. The set of histograms collected with the new samples did not match those of the first sample set (Figure 3.13). Evidently, discrepancies in bulk packing density overwhelmed the effects of the inherent density and $\mathrm{Z}_{\mathrm{eff}}$ of the two components.

\section{Conclusions}

Several methods, which generated successful simulants for threat liquids, have been outlined. These methods do not require knowledge of $\mathrm{Z}_{\mathrm{eff}}$ nor density. The simulants developed (Table 3.4) proved to be quite accurate for the instrument for which they were designed. Each of these methods require that a database be created for a particular model of X-ray instrument and the response to both hazardous and benign materials be recorded. Application of these methods to solid threat materials may be possible, but bulk packing density inconsistencies need to be overcome.

\section{References}

(1) Ying, Z.; Naidu, R.; Crawford, C. R. J. Xray. Sci. Technol. 2006, 14, 235-256.

(2) Khan, F. M. The Physics of Radiation Therapy, 3rd ed.; Lippincott Williams \& Wilkins: Philadelphia, 2003.

(3) CRC Handbook of Chemistry and Physics, CD-ROM Version 2005, 85th ed.; 
Lide, D. R., Ed.; CRC Press: Boca Raton, Fl, 2005.

(4) Laliberte, M.; Cooper, W. E. J. Chem. Eng. Data 2004, 49 (5), 1141-1151.

(5) Laliberte, M. J. Chem. Eng. Data 2009, 54 (6), 1725-1760.

(6) Reynolds, J. G.; Carter, R. Fluid Phase Equilib. 2008, 266, 14-20. 
Table 3.1: Compounds used to make liquid x-ray samples

\begin{tabular}{|c|c|}
\hline \multicolumn{2}{|c|}{ Liquid Scanner Samples } \\
\hline Compounds & wt\% \\
\hline Acetic Acid & 100 \\
\hline Acetone & $5,10,15$ \\
\hline Ammonium Acetate & 30 \\
\hline Ammonium Nitrate & $17,24,31$ \\
\hline Ammonium Sulfate & 24 \\
\hline Barium Chloride & $0.5,1,1.5,2,3$ \\
\hline Benzonitrile & 100 \\
\hline Calcium Chloride & 10,20 \\
\hline Diethylene Glycol & 100 \\
\hline Ethylene Glycol & 100 \\
\hline Formamide & 100 \\
\hline Glycerol & 100 \\
\hline Hydrogen Peroxide & $30,35,40,45,50,55,60,65,80,85,90$ \\
\hline Magnesium Sulfate & 16 \\
\hline Methanol & $8,16,24,100$ \\
\hline $\mathrm{N}, \mathrm{N}$-Dimethyl Formamide & 100 \\
\hline Nitric Acid & $40,50,60,70$ \\
\hline Nitrobenzene & 100 \\
\hline Nitromethane & 100 \\
\hline Potassium Bromide & $0.5,1,1.5,2,4,12$ \\
\hline Potassium Carbonate & 10,27 \\
\hline Potassium Chloride & 17,20 \\
\hline Potassium lodide & $1,2,4$ \\
\hline Potassium Sulfate & 4 \\
\hline 2-Propanol & $2,4,8,40$ \\
\hline Quinoline & 100 \\
\hline Sodium Nitrate & 29,34 \\
\hline Sodium Thiosulfate & 20,29 \\
\hline Sucrose & $0.2,0.4,0.6,0.8,1,4,9,16,20,32,40$ \\
\hline Sulfuric Acid & $35,96.5$ \\
\hline Triethylene Glycol & 100 \\
\hline Urea & 41 \\
\hline Zinc Sulfate & 11,22 \\
\hline
\end{tabular}

\begin{tabular}{|c|c|}
\hline \multicolumn{2}{|c|}{ Dual Energy CT Samples } \\
\hline Compounds & wt $\%$ \\
\hline 2-Propanol & $20,40,60,80,100$ \\
\hline Barium Chloride & $0.1,0.2,0.3,0.4,0.5,1.0,1.5,2.0,2.5$ \\
\hline Glycerol & $20,40,60,80,100$ \\
\hline Hydrochloric Acid & 37 \\
\hline Hydrogen Peroxide & $30,35,40,45,50,55,60,65,70,75$ \\
\hline Methanol & $20,40,60,80,100$ \\
\hline Potassium lodide & $0.1,0.2,0.3,0.4,0.5,1.0,1.5,2.0,2.5$ \\
\hline Sodium Hydroxide & $10,20,30,40$ \\
\hline Sucrose & $10,20,30,40,50$ \\
\hline
\end{tabular}


Table 3.2: Innocuous liquids used to construct simulants

\begin{tabular}{|c|c|c|c|c|c|}
\hline \multicolumn{3}{|c|}{ Salt Samples } & \multicolumn{3}{|c|}{ CHNO Samples } \\
\hline Sample & $\begin{array}{c}\text { Density } \\
\left(20^{\circ} \mathrm{C}\right)\end{array}$ & $Z_{\text {eff }}(4)$ & Sample & $\begin{array}{c}\text { Density } \\
\left(20^{\circ} \mathrm{C}\right)\end{array}$ & $\mathrm{Z}_{\text {eff }}(4)$ \\
\hline $\mathrm{NaNO}_{3} 29 \%$ & 1.217 & 8.030 & $\mathrm{MeOH}$ & 0.792 & 6.889 \\
\hline $\mathrm{NaNO}_{3} 34.2 \%$ & 1.262 & 8.107 & iPrOH 40\% & 0.93 & 7.151 \\
\hline $\mathrm{MgSO}_{4} 16 \%$ & 1.09 & 8.373 & DMF & 0.944 & 6.535 \\
\hline $\mathrm{K}_{2} \mathrm{SO}_{4} 4 \%$ & 1.031 & 8.703 & MeOH 24\% & 0.964 & 7.434 \\
\hline$\left(\mathrm{NH}_{4}\right)_{2} \mathrm{SO}_{4} 24 \%$ & 1.138 & 8.990 & $\mathrm{MeOH} 16 \%$ & 0.976 & 7.485 \\
\hline $\mathrm{KBr} 0.5 \%$ & 1.002 & 9.284 & Acetone 15\% & 0.981 & 7.444 \\
\hline $\mathrm{Na}_{2} \mathrm{~S}_{2} \mathrm{O}_{3} 20.3 \%$ & 1.177 & 9.641 & iPrOH 8\% & 0.984 & 7.488 \\
\hline $\mathrm{K}_{2} \mathrm{CO}_{3} 9.9 \%$ & 1.087 & 9.894 & Acetone $10 \%$ & 0.988 & 7.501 \\
\hline $\mathrm{Na}_{2} \mathrm{~S}_{2} \mathrm{O}_{3} 29 \%$ & 1.264 & 10.244 & MeOH 8\% & 0.989 & 7.533 \\
\hline KBr New 1\% & 1.005 & 10.395 & iPrOH 4\% & 0.99 & 7.527 \\
\hline $\mathrm{CaCl}_{2} 9.6 \%$ & 1.079 & 10.578 & Acetone 5\% & 0.993 & 7.531 \\
\hline $\mathrm{KBr} 1.5 \%$ & 1.009 & 11.219 & iPrOH 2\% & 0.994 & 7.547 \\
\hline $\mathrm{KCl} 16.8 \%$ & 1.11 & 11.735 & Water DDDI & 0.998 & 7.566 \\
\hline KBr New 2\% & 1.012 & 11.845 & Benzonitrile & 1.01 & 6.050 \\
\hline $\mathrm{KBr} 2 \%$ & 1.013 & 11.895 & Sucrose 4\% & 1.013 & 7.550 \\
\hline $\mathrm{K}_{2} \mathrm{CO}_{3} 26.9 \%$ & 1.257 & 12.002 & Sucrose 9\% & 1.034 & 7.527 \\
\hline KCl 19.7\% & 1.131 & 12.137 & Acetic Acid & 1.05 & 7.096 \\
\hline $\mathrm{BaCl}_{2} 0.5 \%$ & 1.003 & 12.847 & Sucrose $16 \%$ & 1.064 & 7.495 \\
\hline $\mathrm{CaCl}_{2} 20 \%$ & 1.277 & 13.422 & $\mathrm{NH}_{4} \mathrm{NO}_{3} 16.8 \%$ & 1.069 & 7.553 \\
\hline $\mathrm{ZnSO}_{4} 11 \%$ & 1.119 & 13.638 & Sucrose $20 \%$ & 1.081 & 7.477 \\
\hline $\mathrm{KBr} 4 \%$ & 1.028 & 13.866 & Quinoline & 1.09 & 5.977 \\
\hline KI 1\% & 1.006 & 14.982 & $\mathrm{NH}_{4} \mathrm{NO}_{3} 23.7 \%$ & 1.099 & 7.548 \\
\hline $\mathrm{BaCl}_{2} \mathrm{New} 1 \%$ & 1.007 & 15.046 & Glycol & 1.113 & 6.992 \\
\hline $\mathrm{BaCl}_{2} 1 \%$ & 1.012 & 15.116 & Diglycol & 1.115 & 6.877 \\
\hline $\mathrm{ZnSO}_{4} 21.9 \%$ & 1.261 & 16.079 & Urea 41.4\% & 1.115 & 7.332 \\
\hline $\mathrm{BaCl}_{2} 1.5 \%$ & 1.007 & 16.619 & Triglycol & 1.12 & 6.832 \\
\hline KI $2 \%$ & 1.013 & 17.700 & Formamide & 1.129 & 6.992 \\
\hline $\mathrm{BaCl}_{2} \mathrm{New} 2 \%$ & 1.016 & 17.736 & $\mathrm{NH}_{4} \mathrm{NO}_{3} 31.3 \%$ & 1.134 & 7.542 \\
\hline $\mathrm{BaCl}_{2} 2 \%$ & 1.016 & 17.864 & Sucrose $32 \%$ & 1.137 & 7.421 \\
\hline KBr 12\% & 1.09 & 18.005 & Nitrotoluene & 1.16 & 6.608 \\
\hline $\mathrm{BaCl}_{2} 3 \%$ & 1.025 & 19.544 & Sucrose $40 \%$ & 1.176 & 7.383 \\
\hline KI 4\% & 1.029 & 20.959 & Glycerin & 1.264 & 7.025 \\
\hline
\end{tabular}


Table 3.3: Twenty-five potential simulant mixtures of $\mathrm{BaCl}_{2}$ and $\mathrm{KBr}$

\begin{tabular}{|l|l|l|l|l|l|l|l|l|l|}
\hline \multicolumn{1}{|c|}{ Sample } & wt\% $\mathrm{BaCl}_{2}$ & wt\% KBr & Ave HE & Ave LE & Sample & $w+\% \mathrm{BaCl}_{2}$ & wt\% KBr & Ave HE & Ave LE \\
\hline Sim I & 0.2297 & 0.4766 & 0.836 & 1.271 & Sim III 5+ & 0.2506 & 0.6931 & 0.889 & 1.359 \\
\hline Sim I U & 0.2296 & 0.4767 & 0.838 & 1.274 & Sim III 6+ & 0.2576 & 0.6842 & 0.890 & 1.340 \\
\hline Sim II & 0.2451 & 0.5104 & 0.845 & 1.283 & Sim IV & 0.3200 & 0.7204 & 0.908 & 1.357 \\
\hline Sim II + & 0.2351 & 0.5157 & 0.847 & 1.278 & Sim IV + & 0.2902 & 0.7301 & 0.905 & 1.355 \\
\hline Sim II ++ & 0.2350 & 0.5622 & 0.857 & 1.308 & Sim IV ++ & 0.2901 & 0.7808 & 0.916 & 1.381 \\
\hline Sim II +++ & 0.2328 & 0.5569 & 0.854 & 1.296 & Sim IV +++ & 0.2827 & 0.7610 & 0.910 & 1.369 \\
\hline Sim II 4+ & 0.2230 & 0.5336 & 0.846 & 1.273 & Sim IV 4+ & 0.2799 & 0.7624 & 0.914 & 1.376 \\
\hline Sim II U & 0.2451 & 0.5107 & 0.849 & 1.283 & Sim V & 0.2947 & 0.7996 & 0.920 & 1.384 \\
\hline Sim III & 0.2999 & 0.6598 & 0.892 & 1.338 & Sim V + & 0.2946 & 0.8433 & 0.931 & 1.414 \\
\hline Sim III + & 0.2851 & 0.6659 & 0.891 & 1.334 & Sim V ++ & 0.2847 & 0.8149 & 0.918 & 1.383 \\
\hline Sim III ++ & 0.2850 & 0.7118 & 0.901 & 1.360 & Sim V +++ & 0.2847 & 0.8317 & 0.925 & 1.390 \\
\hline Sim III +++ & 0.2801 & 0.6996 & 0.897 & 1.347 & Sim V 4+ & 0.2810 & 0.8481 & 0.925 & 1.397 \\
\hline Sim III 4+ & 0.2687 & 0.6711 & 0.886 & 1.329 & & & & &
\end{tabular}


Table 3.4: Successful simulants created in this study

\begin{tabular}{|c|c|c|c|c|c|c|}
\hline reat & de & A & B & $\mathrm{t} \% \mathrm{~A}$ & $\mathrm{t} \% \mathrm{~B}$ & nt \\
\hline 60 & Sim 1 & $I_{2}$ & $\mathrm{KBr}$ & & 6 & nner \\
\hline 65 & & $\mathrm{Cl}_{2}$ & & 0.2451 & 104 & \\
\hline 80 & & $\mathrm{aCl}_{2}$ & & 6 & 42 & er \\
\hline $85 \%$ & ++ & $\mathrm{BaCl}_{2}$ & $3 r$ & 27 & 61 & er \\
\hline $90 \% \mathrm{HP}$ & + & $\mathrm{BaCl}_{2}$ & $3 r$ & 2810 & 0.8481 & ner \\
\hline $40 \%$ NA & Sim NA 1+ & $\mathrm{BaCl}_{2}$ & $\mathrm{KBr}$ & 0.2249 & 0.401 & Liquid Scanner \\
\hline $50 \%$ NA & NA 2 & $\mathrm{BaCl}_{2}$ & $\mathrm{KBr}$ & 0.255 & 0.5136 & canner \\
\hline $60 \%$ NA & NA 3 & $\mathrm{BaCl}_{2}$ & $\mathrm{KBr}$ & 0.2812 & 0.6275 & Liquid Scanner \\
\hline $70 \%$ NA & & $\mathrm{BaCl}_{2}$ & $3 r$ & 046 & 0.7109 & nner \\
\hline $\mathrm{N}$ & Sim NB & $\mathrm{BaCl}_{2}$ & $\mathrm{PrOH}$ & 0.3029 & 40.11 & nner \\
\hline $30 \% \mathrm{HP}$ & $30 \%$ HP Sim & $\mathrm{BaCl}_{2}$ & Glycerol & 0.0485 & 33.19 & sy CT \\
\hline $45 \% \mathrm{HP}$ & 45\% HP Sim I & $\mathrm{BaCl}_{2}$ & ol & 03 & .19 & y CT \\
\hline $60 \% \mathrm{HP}$ & $60 \% \mathrm{H}$ & $\mathrm{BaCl}_{2}$ & erol & .171 & 76.65 & Dual Energy CT \\
\hline $30 \% \mathrm{HP}$ & 30\% HP Sim II & $\mathrm{BaCl}_{2}$ & Glycerol & 0.125 & 37.40 & Single Energy $\mathrm{CT}$ \\
\hline
\end{tabular}




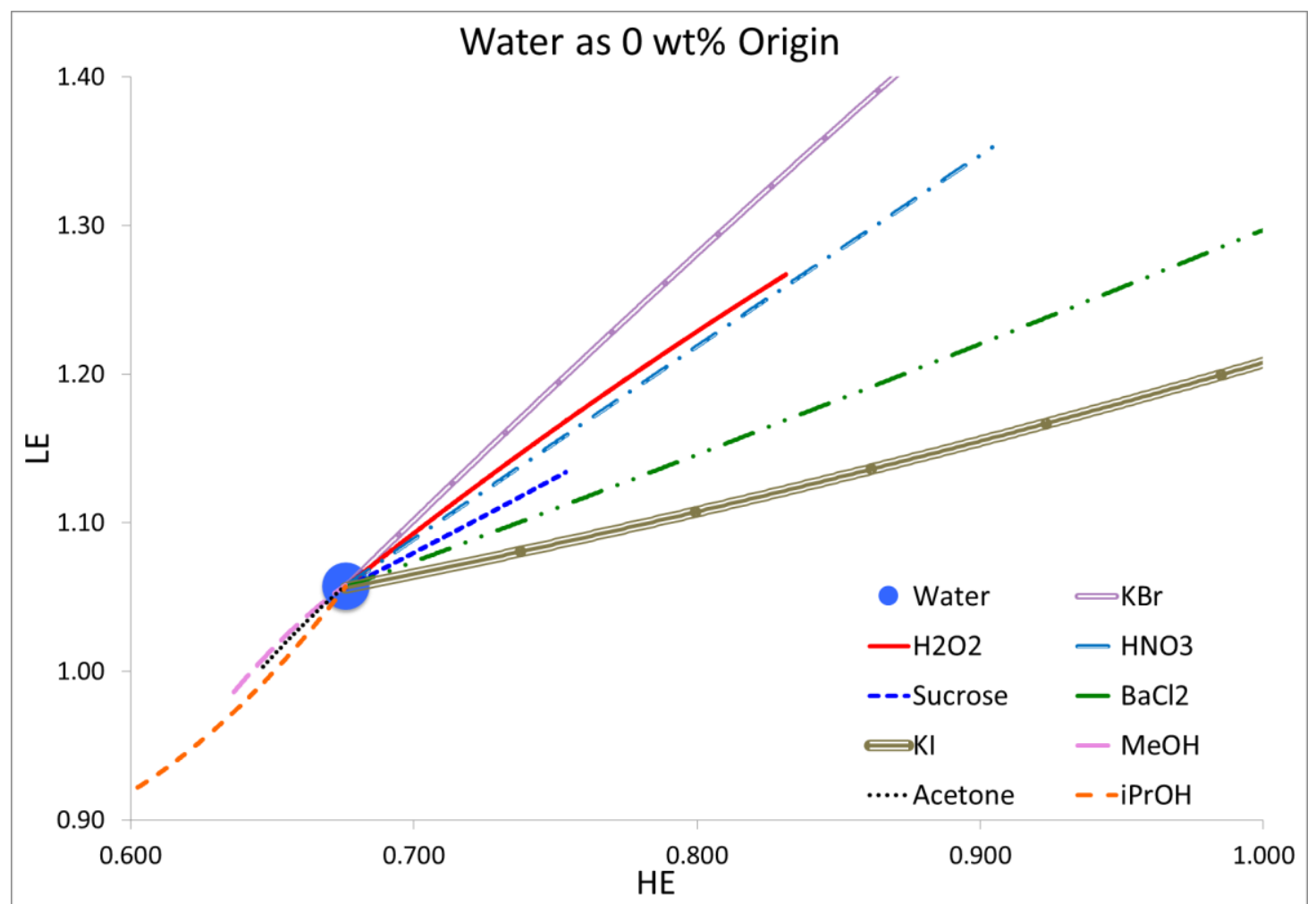

Figure 3.1: Response trendlines originating from water for many aqueous solutions 


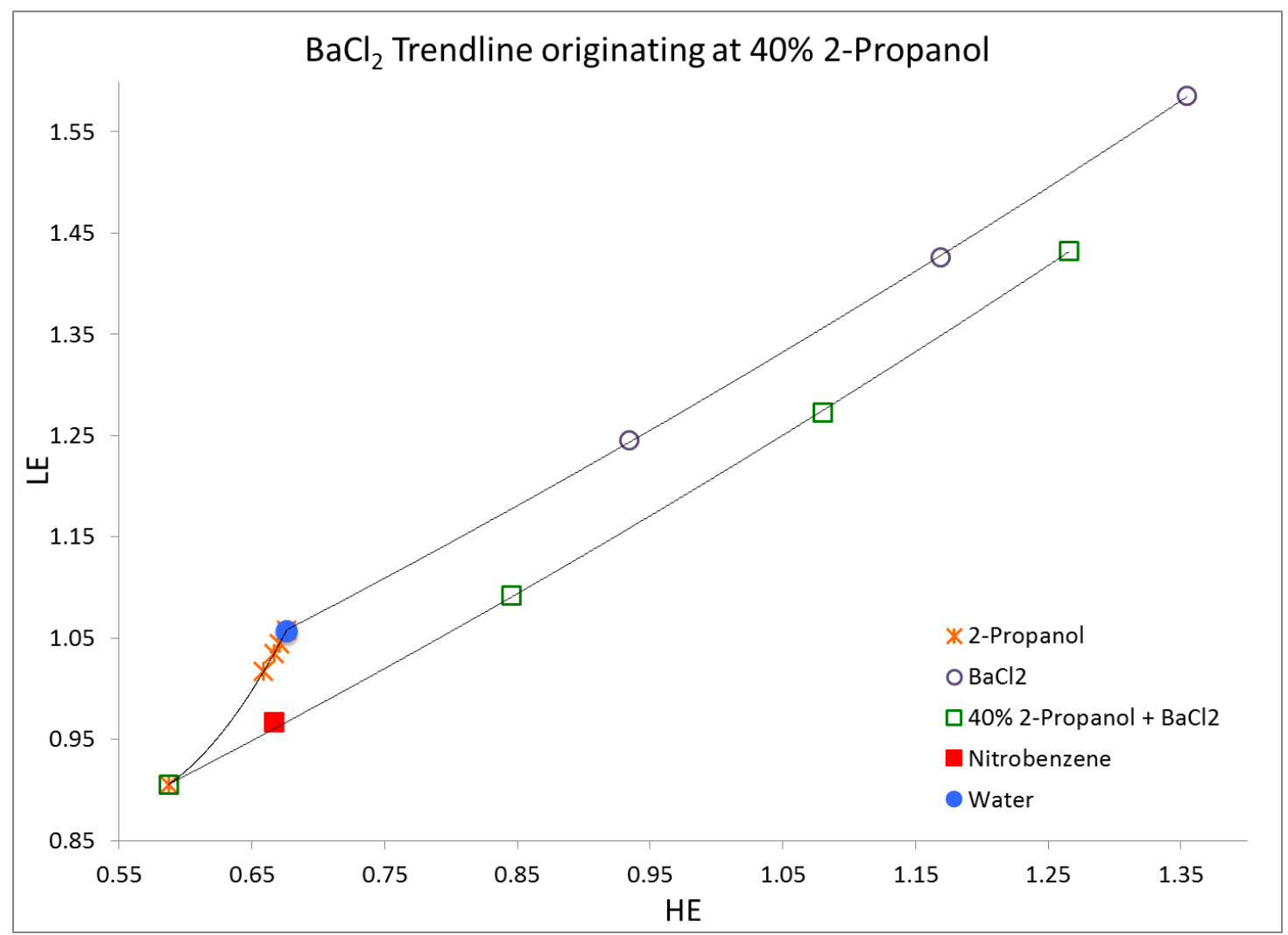

Figure 3.2: $\mathrm{BaCl}_{2}$ response trendline shifted from origin of water to propanol passing through nitrobenzene response 
a)

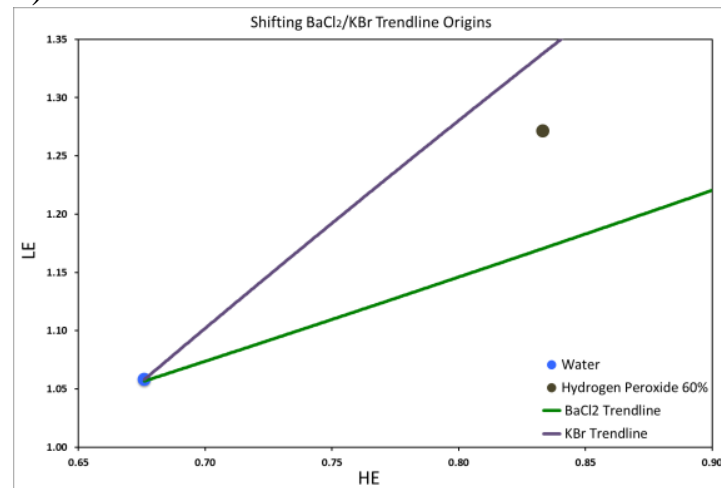

\begin{tabular}{|c|c|c|c|c|c|c|}
\hline \multirow{2}{*}{ Solute } & \multirow{2}{*}{ wt $\%$} & \multirow{2}{*}{ RES } & \multicolumn{3}{|c|}{ Trendline Parameters } & \multirow{2}{*}{\begin{tabular}{|c|} 
RES \\
$\mathrm{KBr}$ Origin
\end{tabular}} \\
\hline & & & a & b & c & \\
\hline \multirow{2}{*}{$\mathrm{BaCl}_{2}$} & \multirow{2}{*}{0} & $\mathrm{HE}$ & -0.0134 & 0.269 & 0.676 & 0.676 \\
\hline & & $\mathrm{LE}$ & -0.00440 & 0.191 & 1.058 & 1.058 \\
\hline \multirow{3}{*}{$\mathrm{KBr}$} & & & & & & \begin{tabular}{|l|} 
Prediction \\
\end{tabular} \\
\hline & \multirow{2}{*}{0} & $\mathrm{HE}$ & -0.00498 & 0.200 & 0.676 & 0.676 \\
\hline & & LE & -0.0204 & 0.361 & 1.058 & 1.058 \\
\hline
\end{tabular}

b)

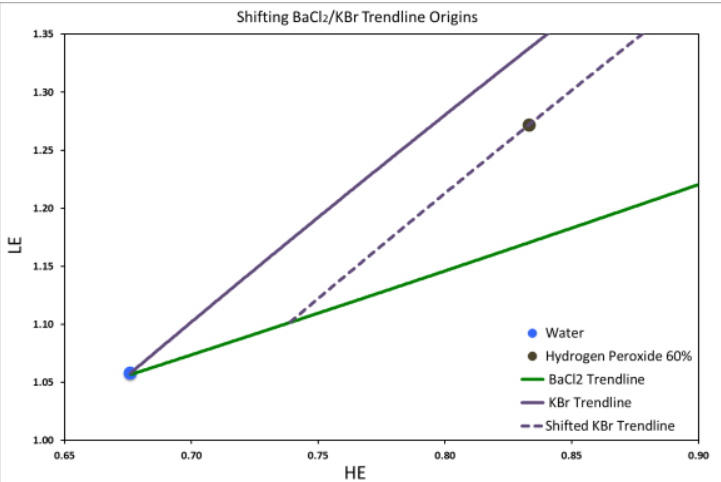

\begin{tabular}{|c|c|c|c|c|c|c|}
\hline \multirow{2}{*}{ Solute } & \multirow{2}{*}{ wt\% } & \multirow{2}{*}{ RES } & \multicolumn{3}{|c|}{ Trendline Parameters } & \multirow{2}{*}{\begin{tabular}{|c} 
RES \\
KBr Origin \\
\end{tabular}} \\
\hline & & & a & $b$ & c & \\
\hline \multirow{2}{*}{$\mathrm{BaCl}_{2}$} & \multirow{2}{*}{0.23} & $\mathrm{HE}$ & -0.0134 & 0.269 & 0.676 & 0.737 \\
\hline & & LE & -0.00440 & 0.191 & 1.058 & 1.102 \\
\hline & & & & & & \begin{tabular}{|l|} 
Prediction \\
\end{tabular} \\
\hline \multirow{2}{*}{$\mathrm{KBr}$} & \multirow{2}{*}{0} & $\mathrm{HE}$ & -0.00498 & 0.200 & 0.737 & 0.737 \\
\hline & & LE & -0.0204 & 0.361 & 1.102 & 1.102 \\
\hline
\end{tabular}

c)

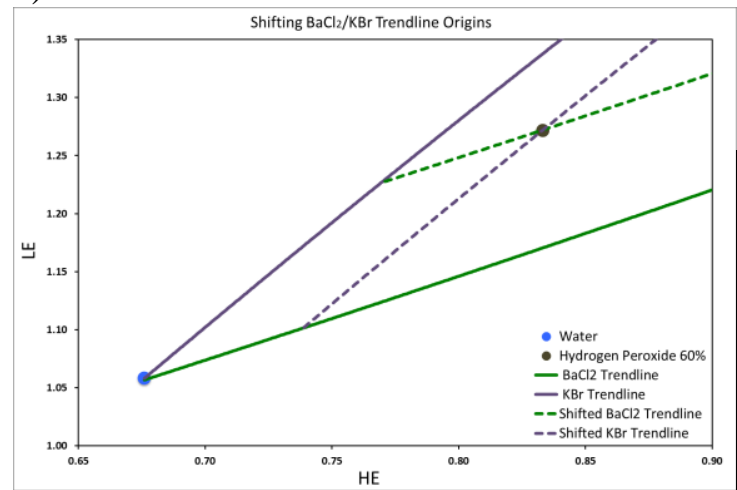

\begin{tabular}{|c|c|c|c|c|c|c|}
\hline \multirow{2}{*}{ Solute } & \multirow{2}{*}{ wt\% } & \multirow{2}{*}{ RES } & \multicolumn{2}{|c|}{ Trendline Parameters } & RES \\
& & & $a$ & $b$ & $c$ & KBr Origin \\
\hline \multirow{2}{*}{$\mathrm{BaCl}_{2}$} & \multirow{2}{*}{$\mathbf{0 . 2 3}$} & $\mathrm{HE}$ & -0.0134 & 0.269 & 0.676 & $\mathbf{0 . 7 3 7}$ \\
\cline { 3 - 7 } & & $\mathrm{LE}$ & -0.00440 & 0.191 & 1.058 & $\mathbf{1 . 1 0 2}$ \\
\hline \multicolumn{7}{|c}{} \\
\hline \multirow{2}{*}{$\mathrm{KBr}$} & \multirow{2}{*}{$\mathbf{0 . 4 8}$} & $\mathrm{HE}$ & -0.00498 & 0.200 & $\mathbf{0 . 7 3 7}$ & $\mathbf{0 . 8 3 2}$ \\
\cline { 3 - 7 } & & $\mathrm{LE}$ & -0.0204 & 0.361 & $\mathbf{1 . 1 0 2}$ & $\mathbf{1 . 2 7 0}$ \\
\hline
\end{tabular}

Figure 3.3: a) Single component trendlines for $\mathrm{BaCl}_{2}$ and $\mathrm{KBr}$, b) $\mathrm{KBr}$ trendline shifted from water "zero" to $0.23 \mathrm{wt} \% \mathrm{BaCl}_{2}$ "zero", c) $\mathrm{BaCl}_{2}$ trendline shifted from water "zero" to $0.23 \mathrm{wt} \% \mathrm{KBr}$ "zero", intersection of shifted trendlines is at threat to be simulated. 
a)

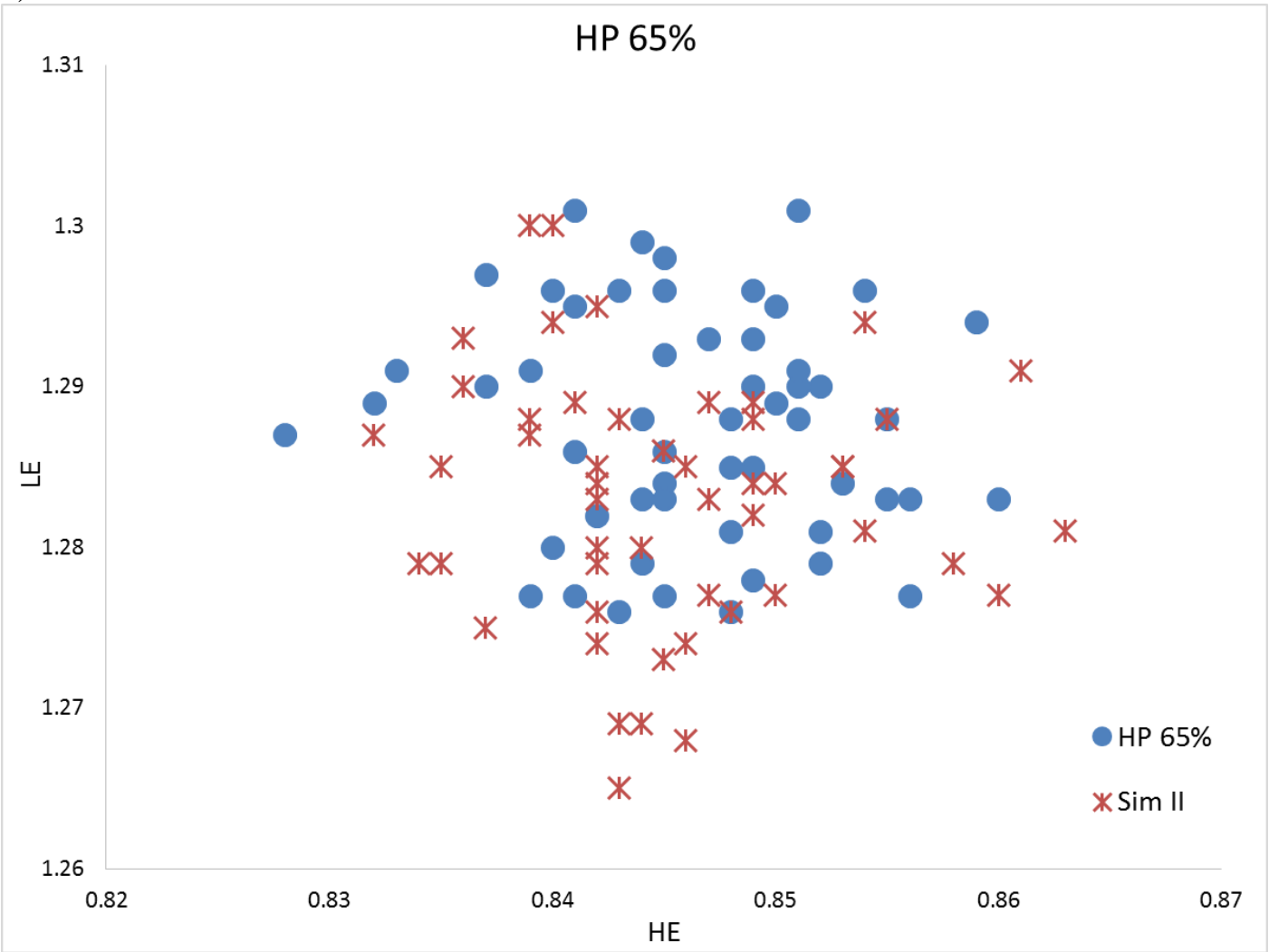

b)

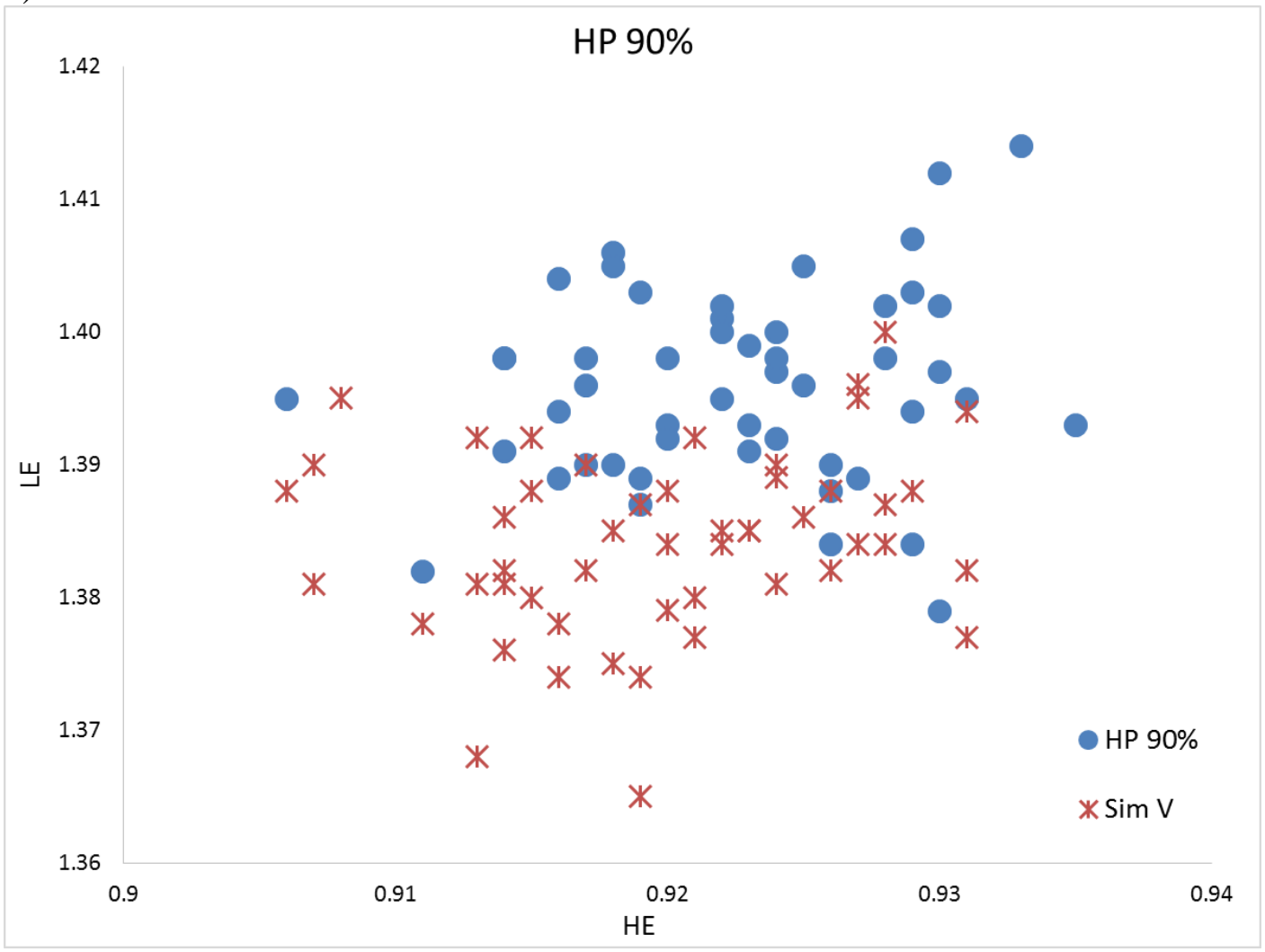

Figure 3.4: First attempt at simulants a) $65 \% \mathrm{HP}$, b) $90 \% \mathrm{HP}$ 


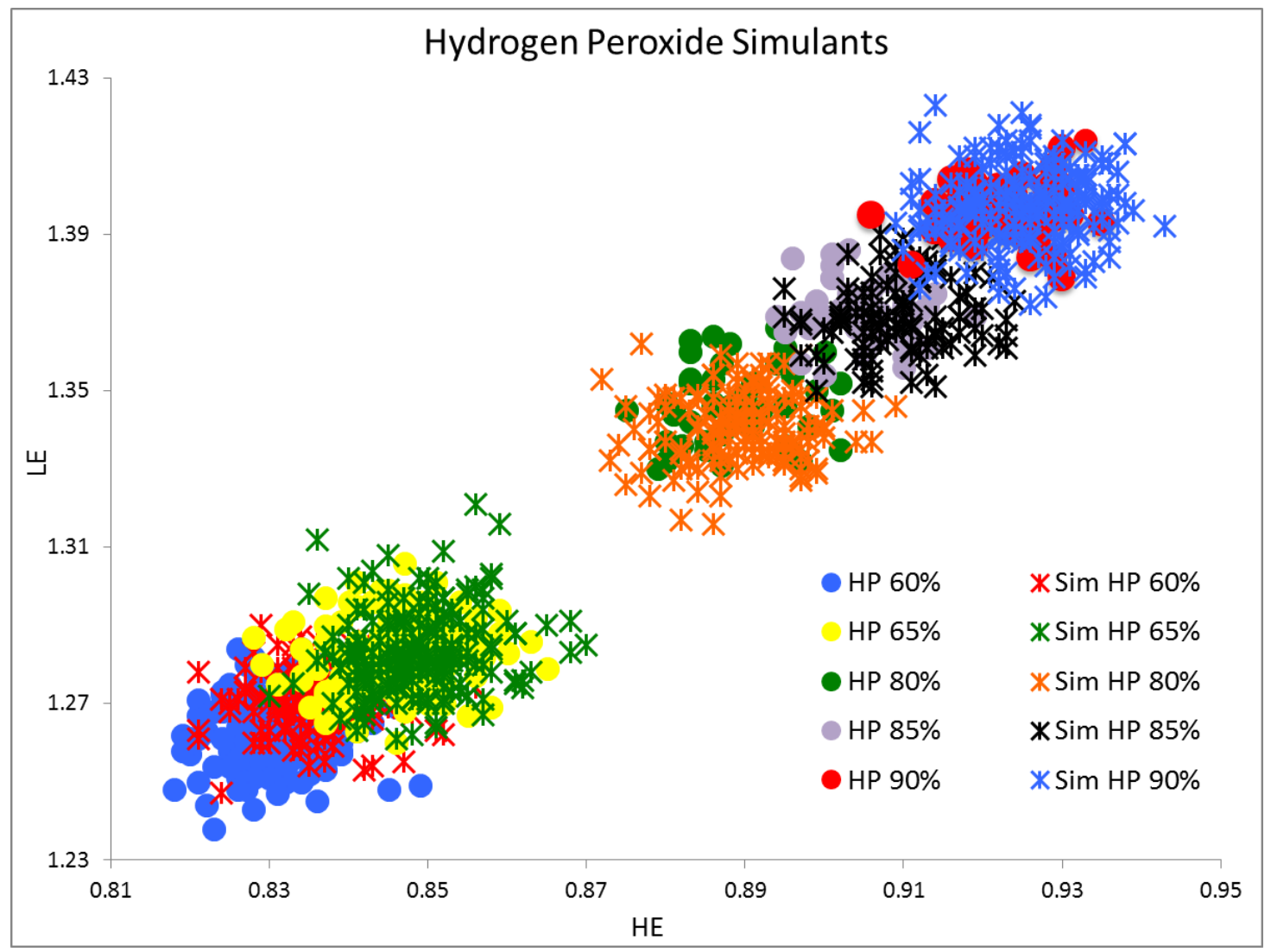

Figure 3.5: Illustration of match between instrument response to HP and simulants 


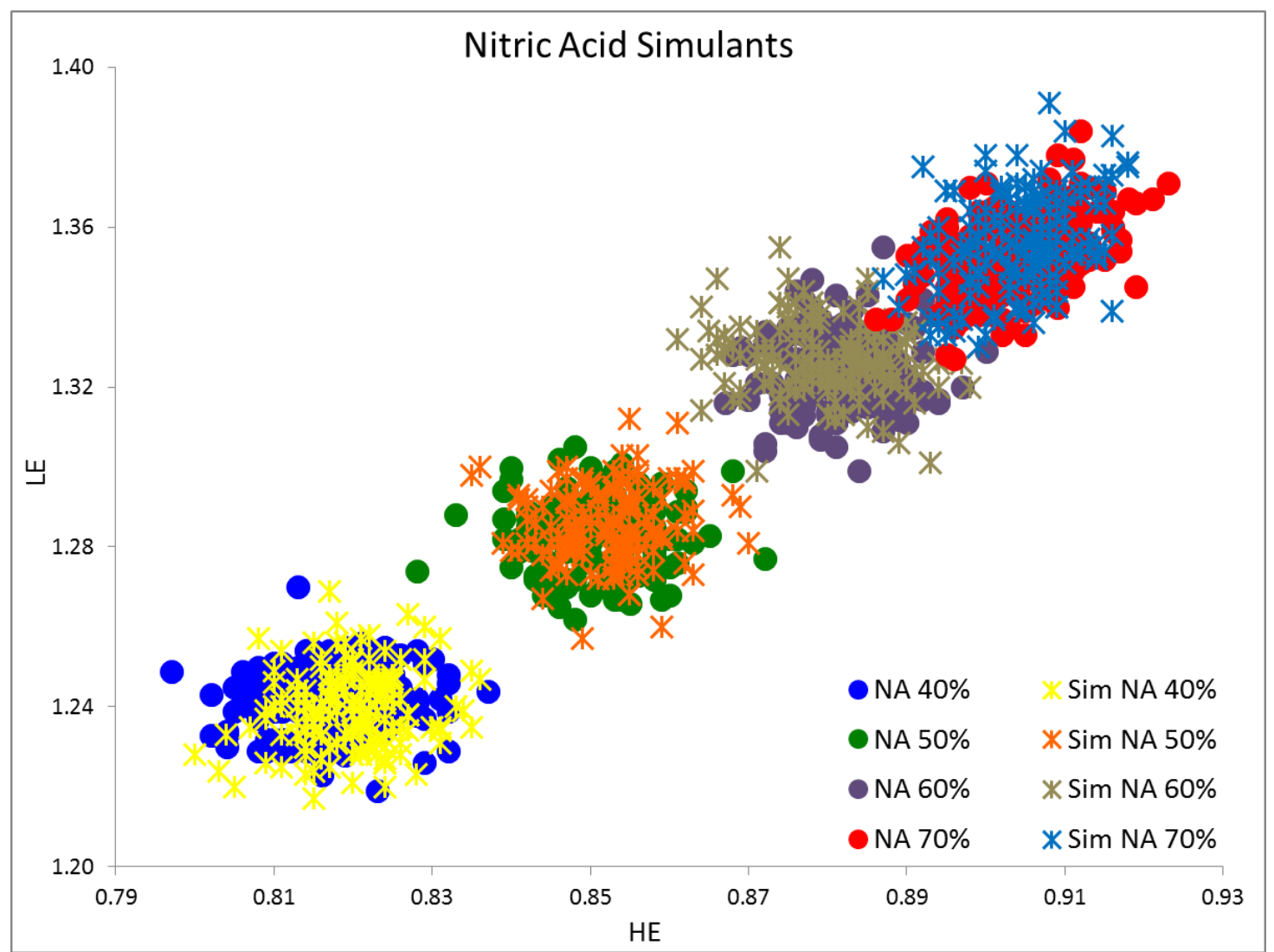

Figure 3.6: Illustration of match between instrument response to NA and simulants 


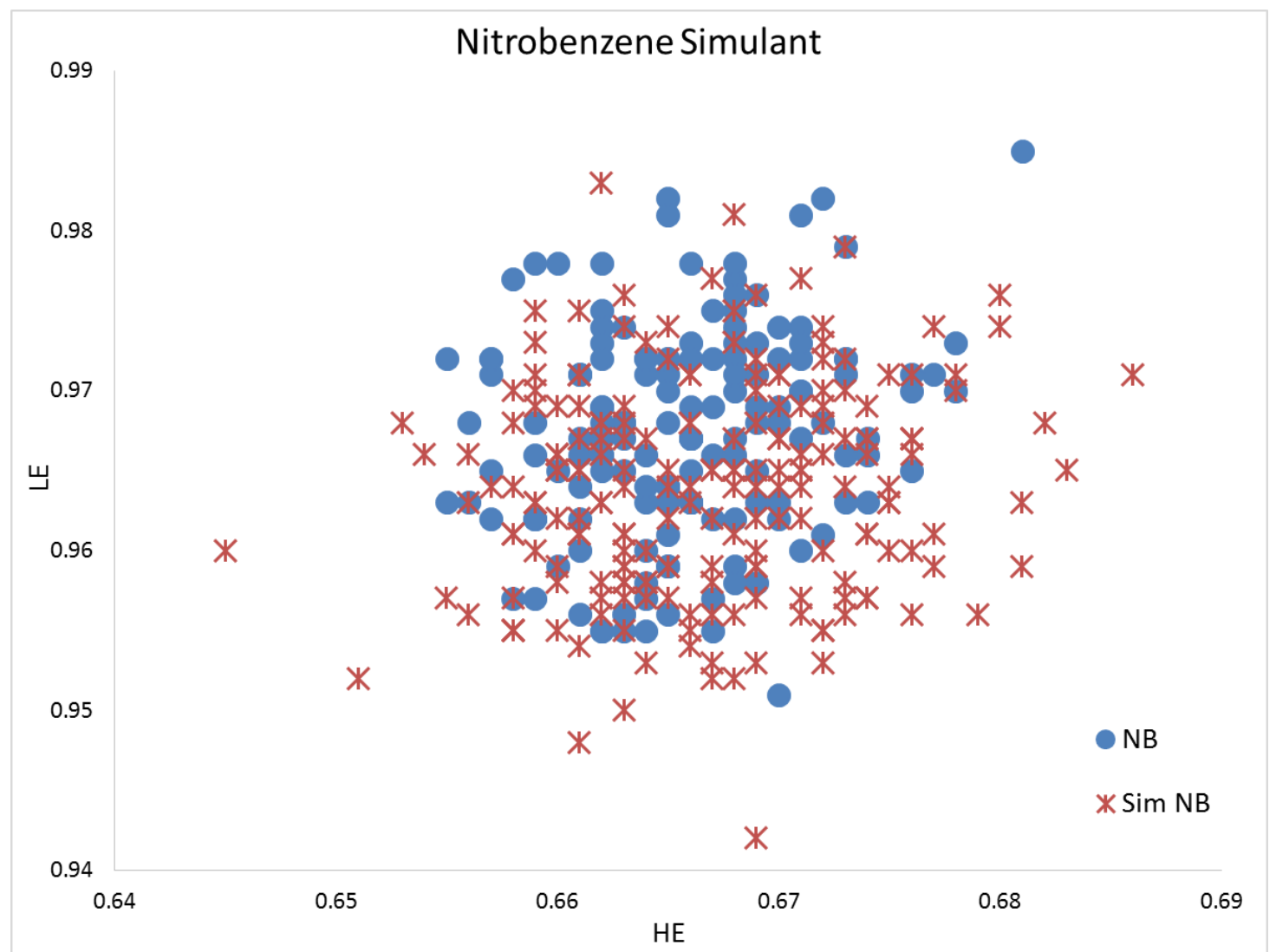

Figure 3.7: Experimental results from collecting 150 and 200 data points of nitrobenzene and a proposed simulant 


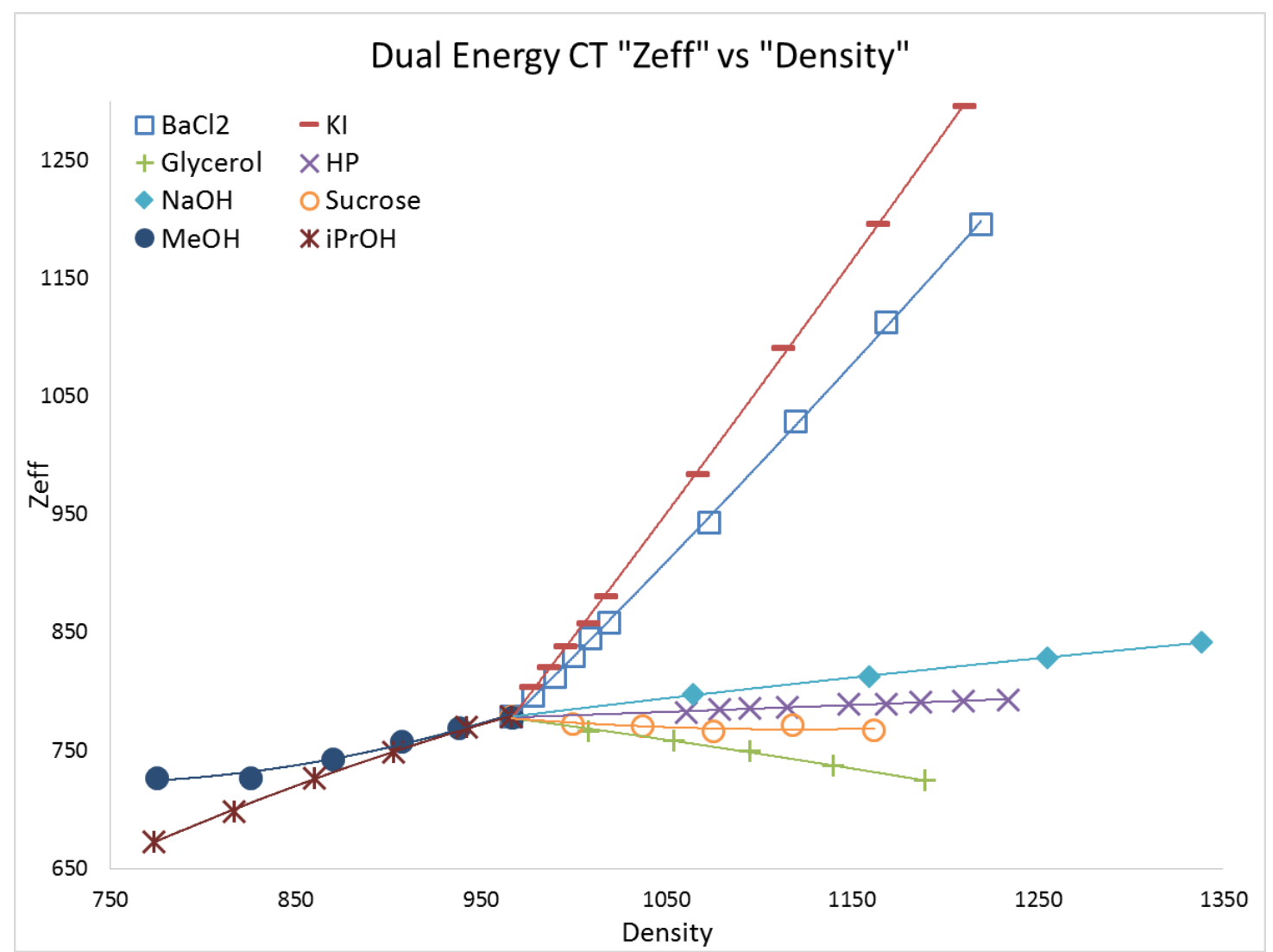

Figure 3.8: Dual-energy CT response to various aqueous solutions 


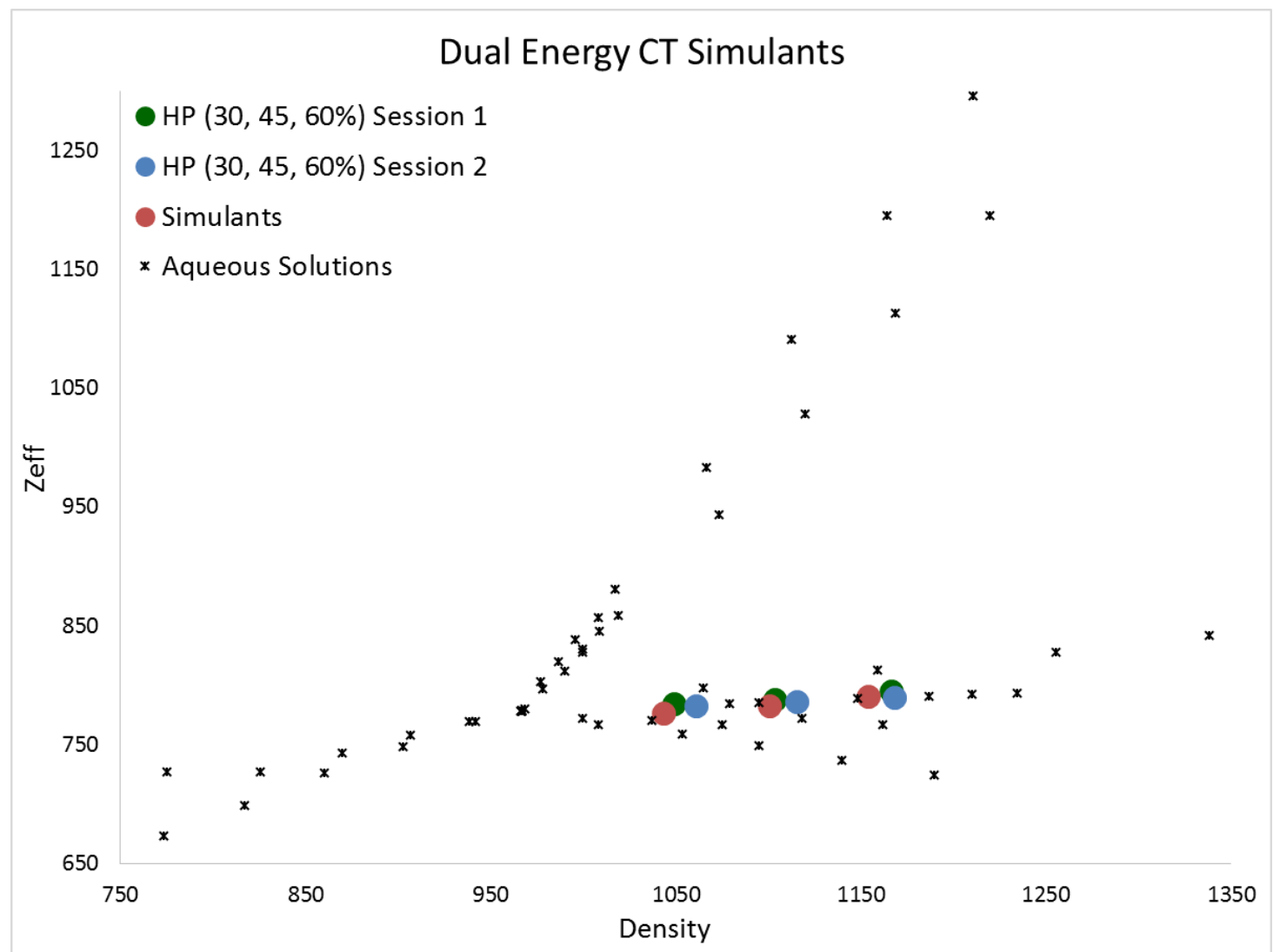

Figure 3.9: Dual-energy CT response to HP and simulants plotted with aqueous solutions shown in Fig. 3.8 


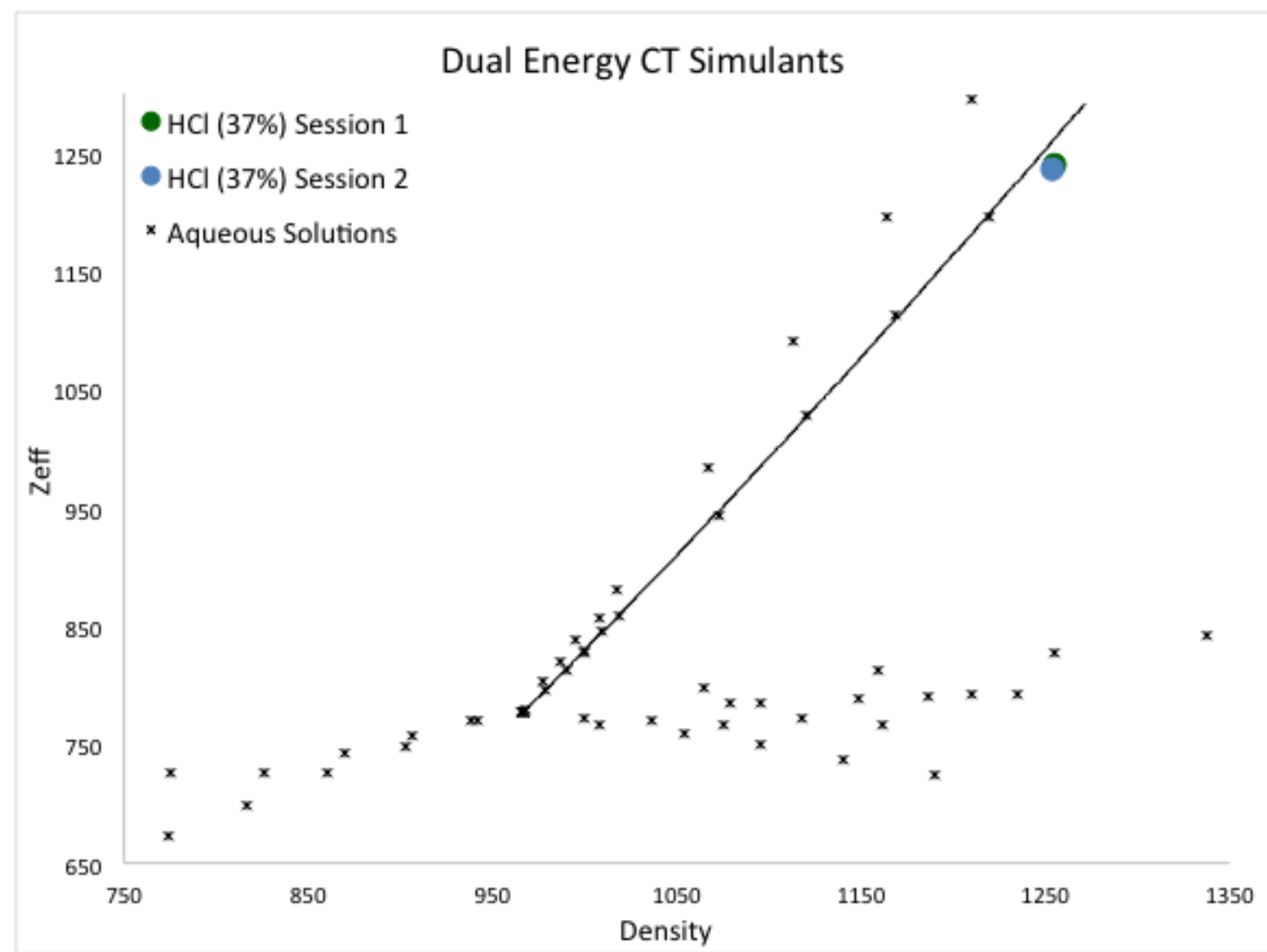

Figure 3.10: Dual-energy CT response to $\mathrm{HCl}$ and simulants plotted with aqueous solutions shown in Fig. 3.8 
a)

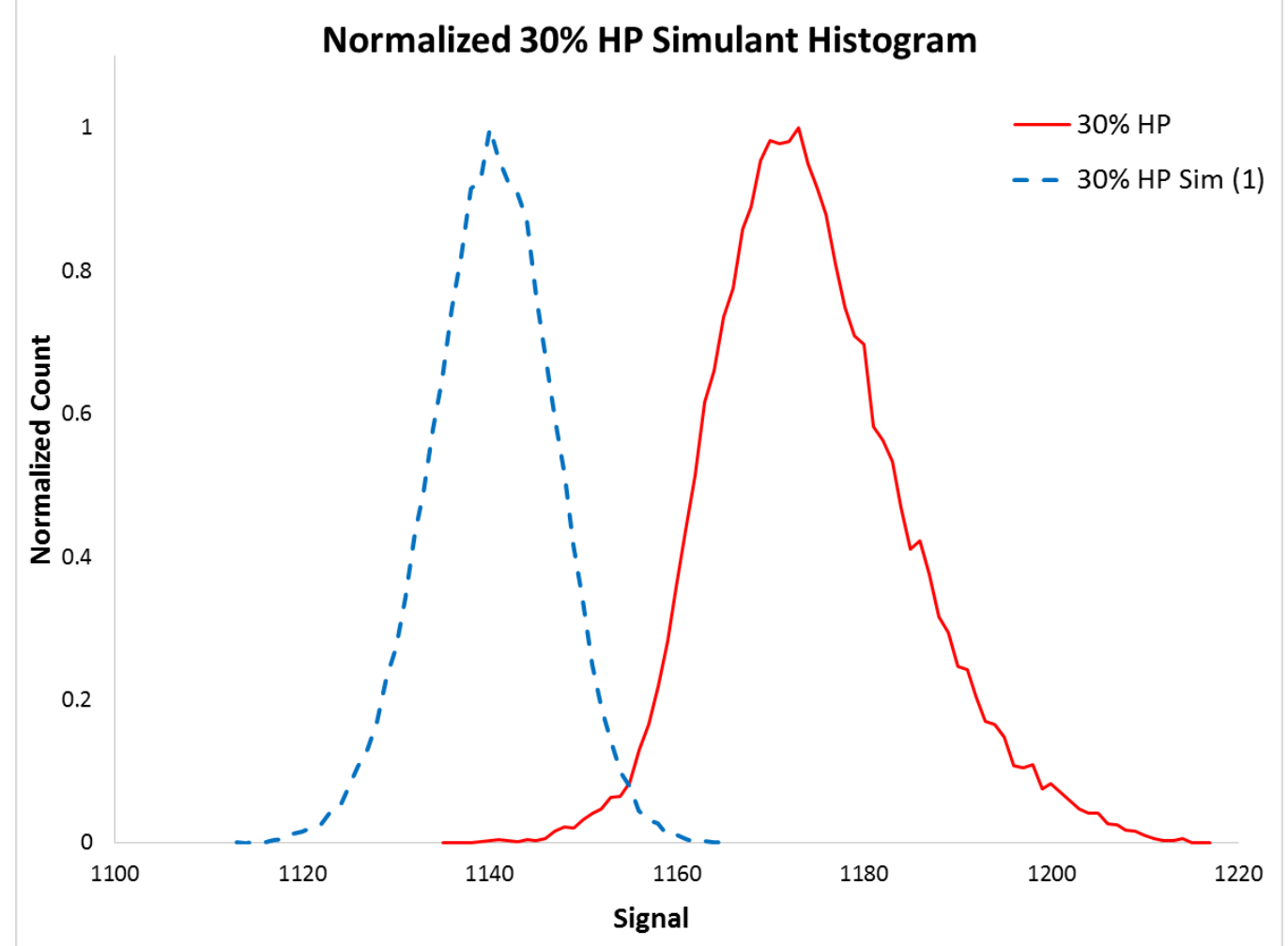

b)

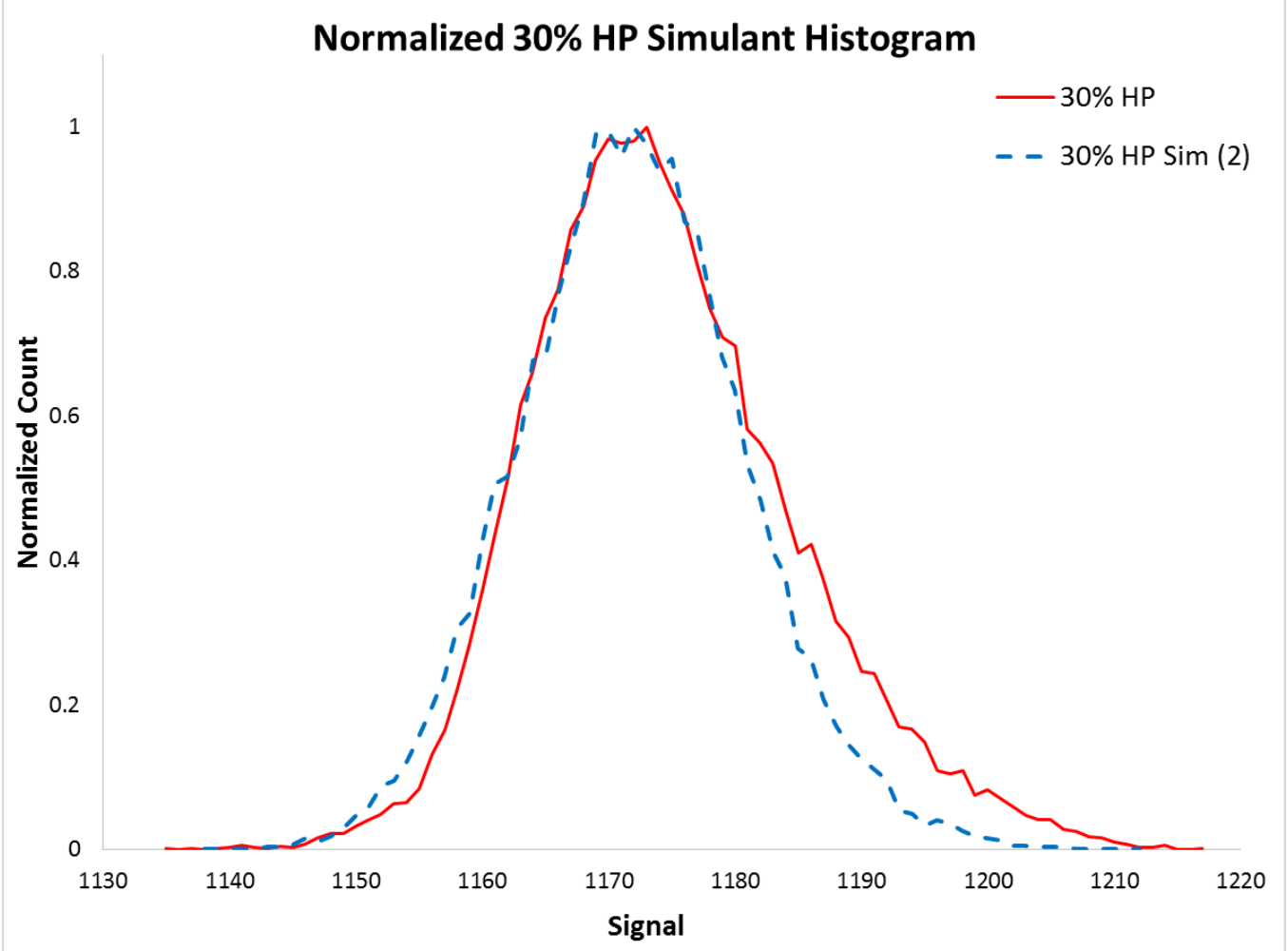

Figure 3.11: Single energy CT histograms a) simulant attempt b) simulant adjustment 
a)

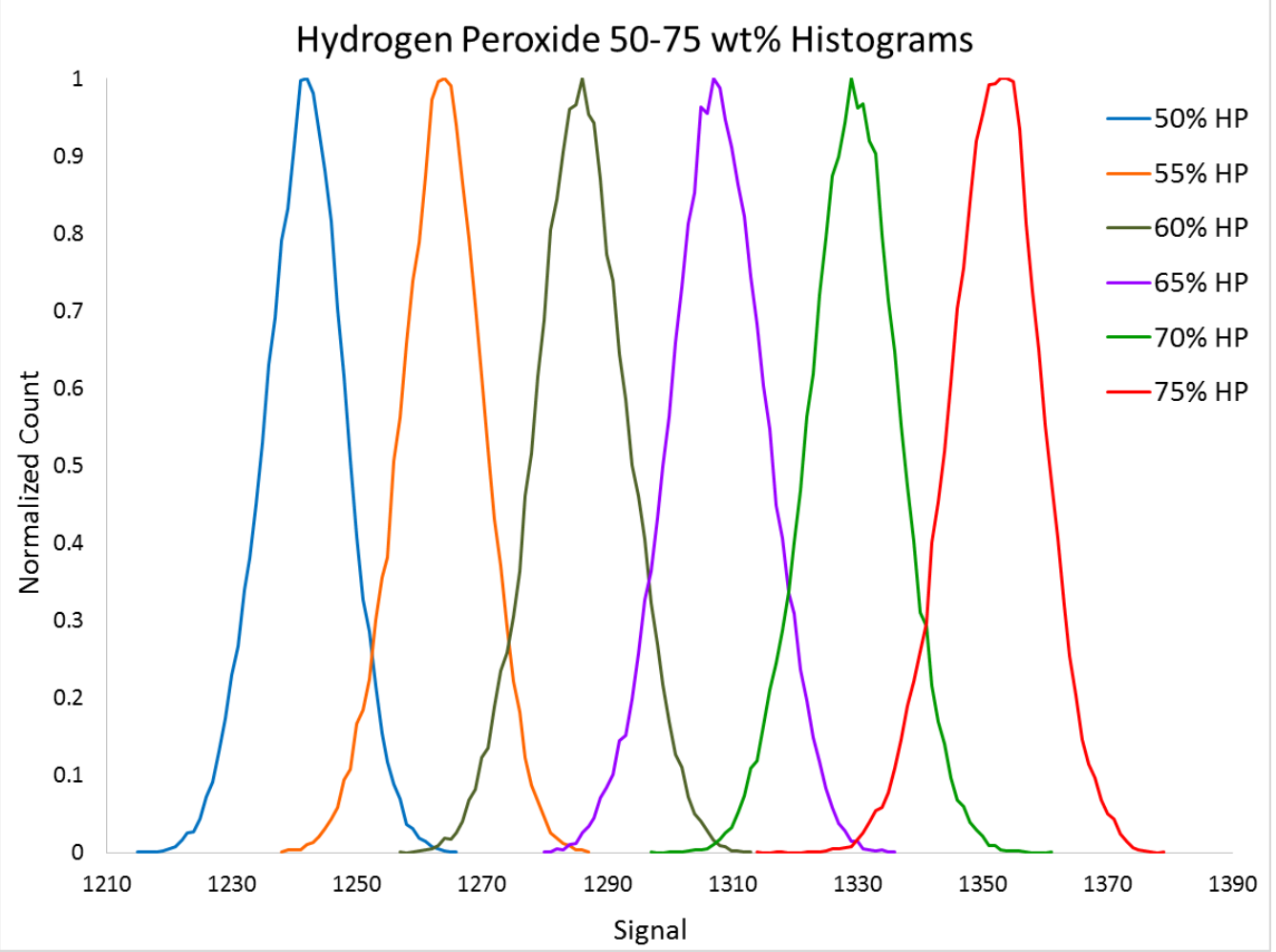

b)

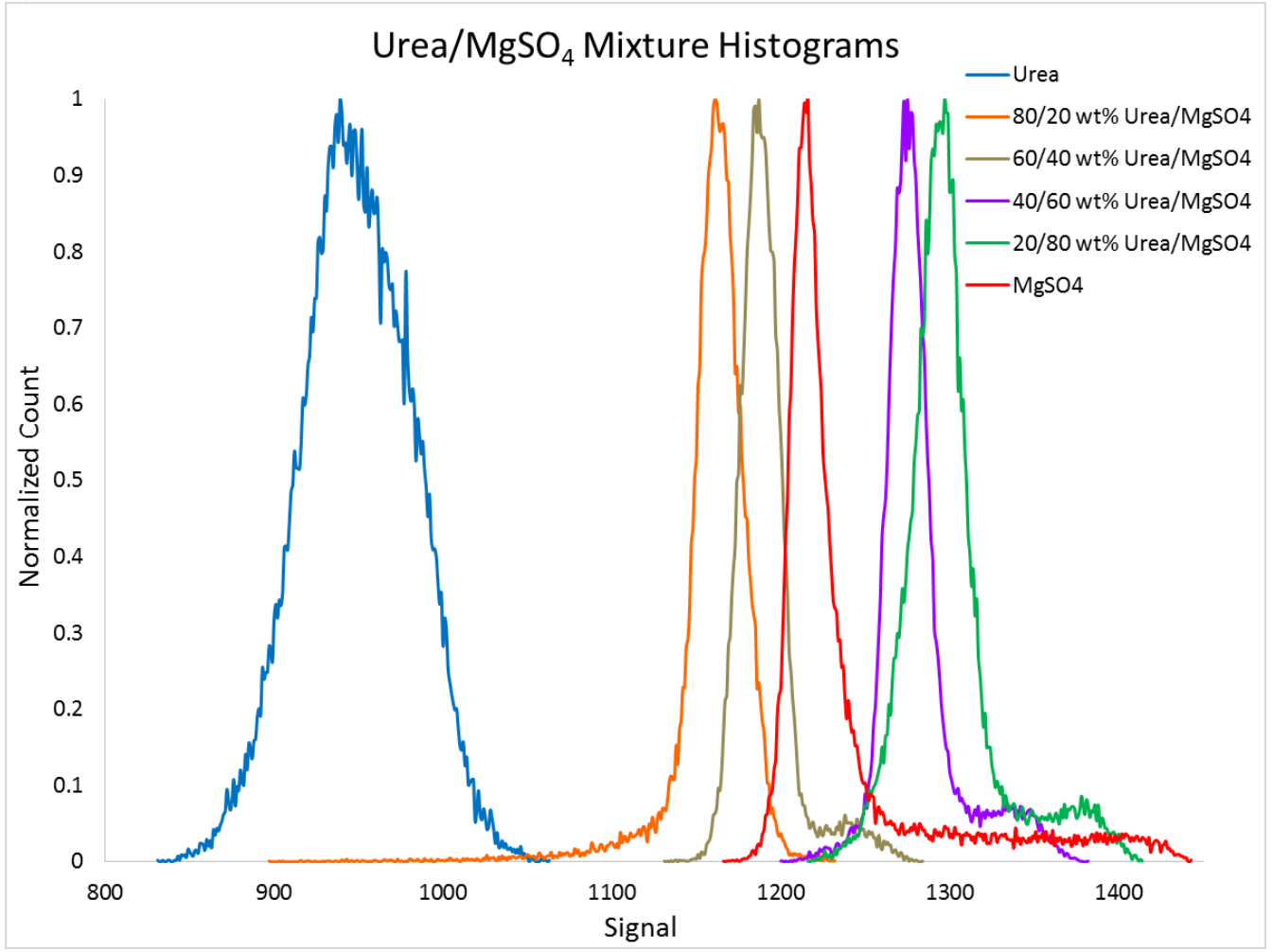

Figure 3.12: Single-energy CT response to uniform variation in concentration a) HP in water, b) $\mathrm{MgSO}_{4}$ in urea 


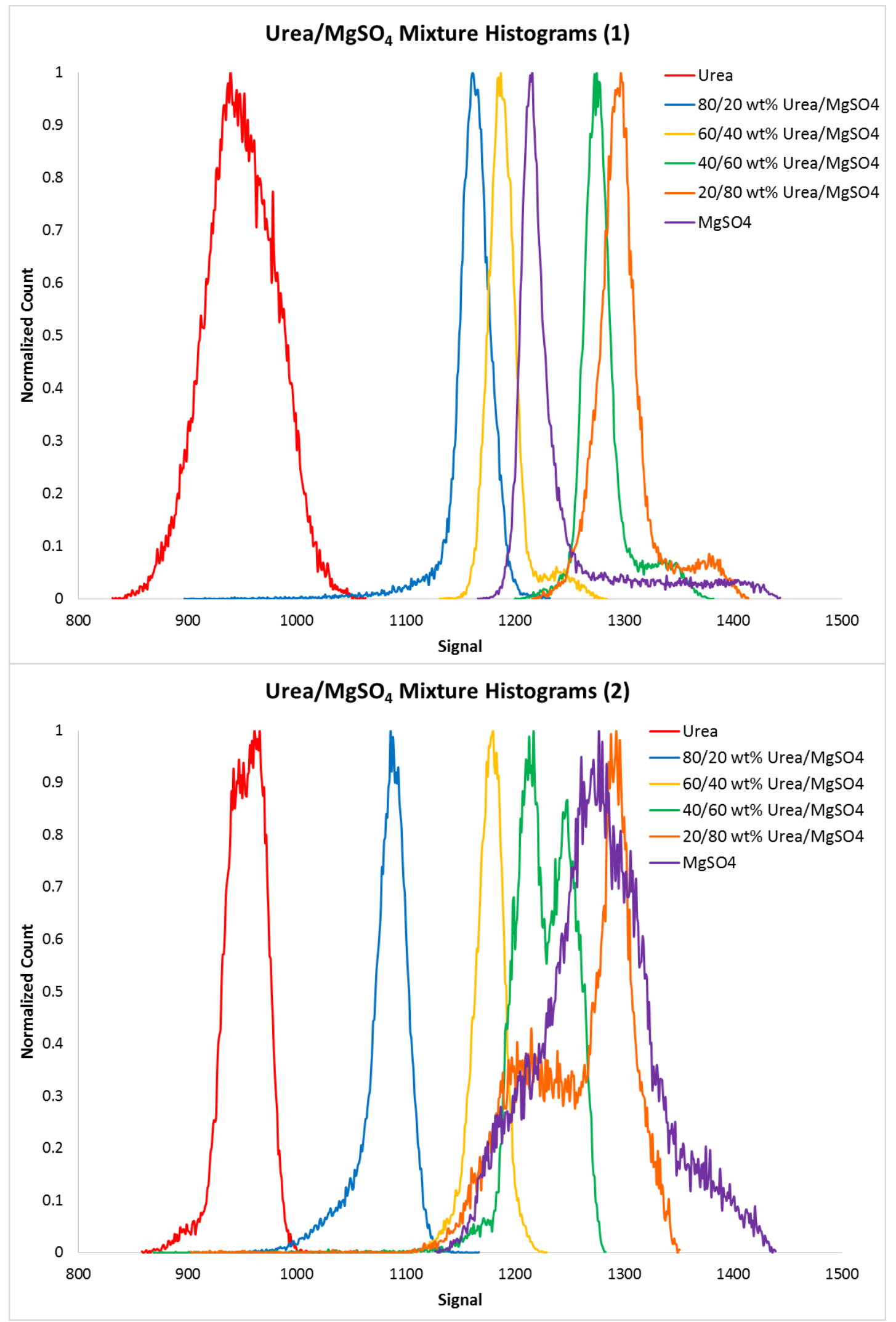

Figure 3.13: Two sets of urea/MgSO 4 mixtures compared 
APPENDICES 
Appendix 1: Supplemental Figures for Chapter 1

Sample: ETN

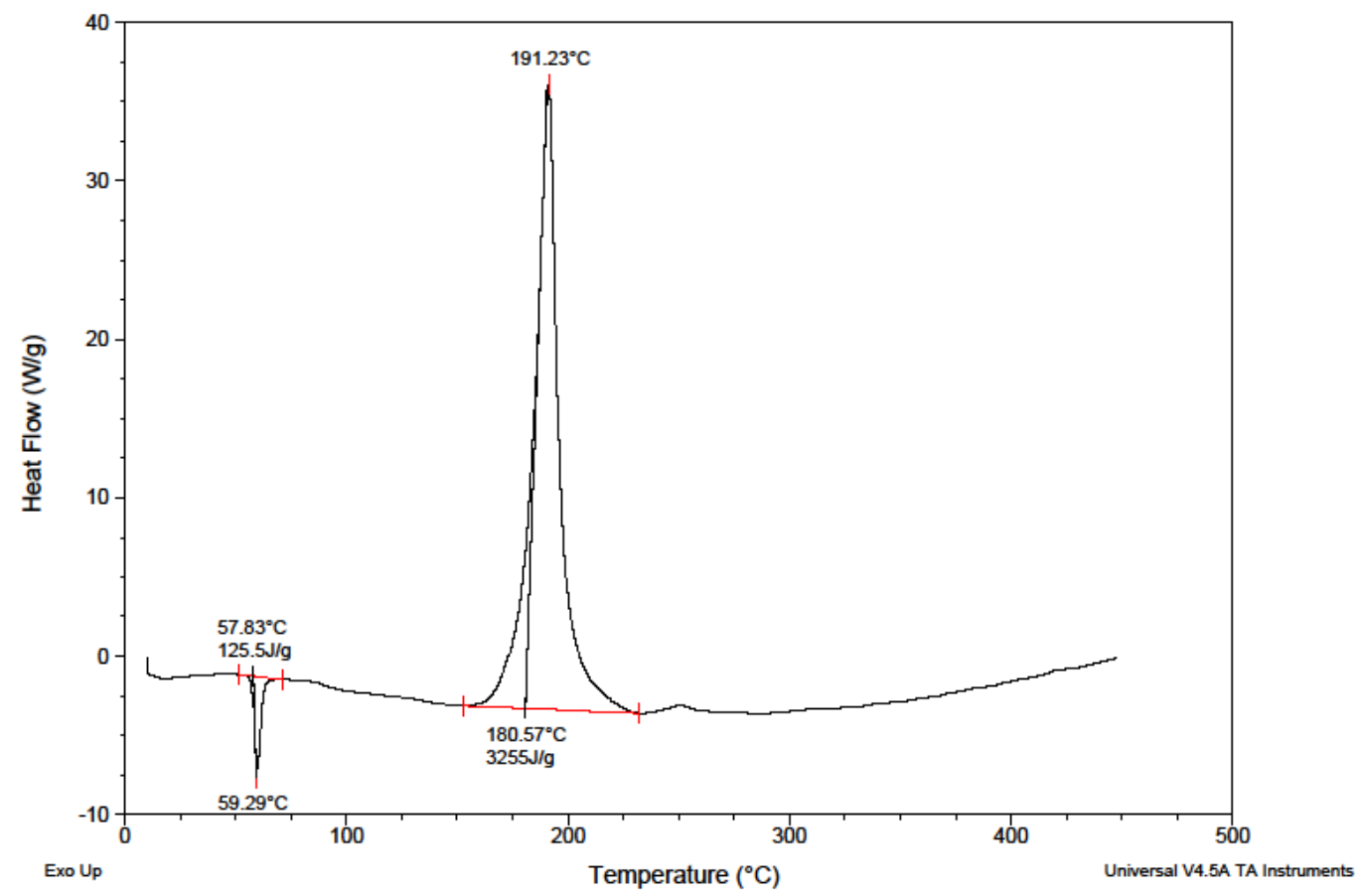

$\mathrm{SF}$ 1.1a: DSC trace for $\mathrm{ETN}\left(10^{\circ} \mathrm{C} / \mathrm{min}\right)$ 
Sample: TNT

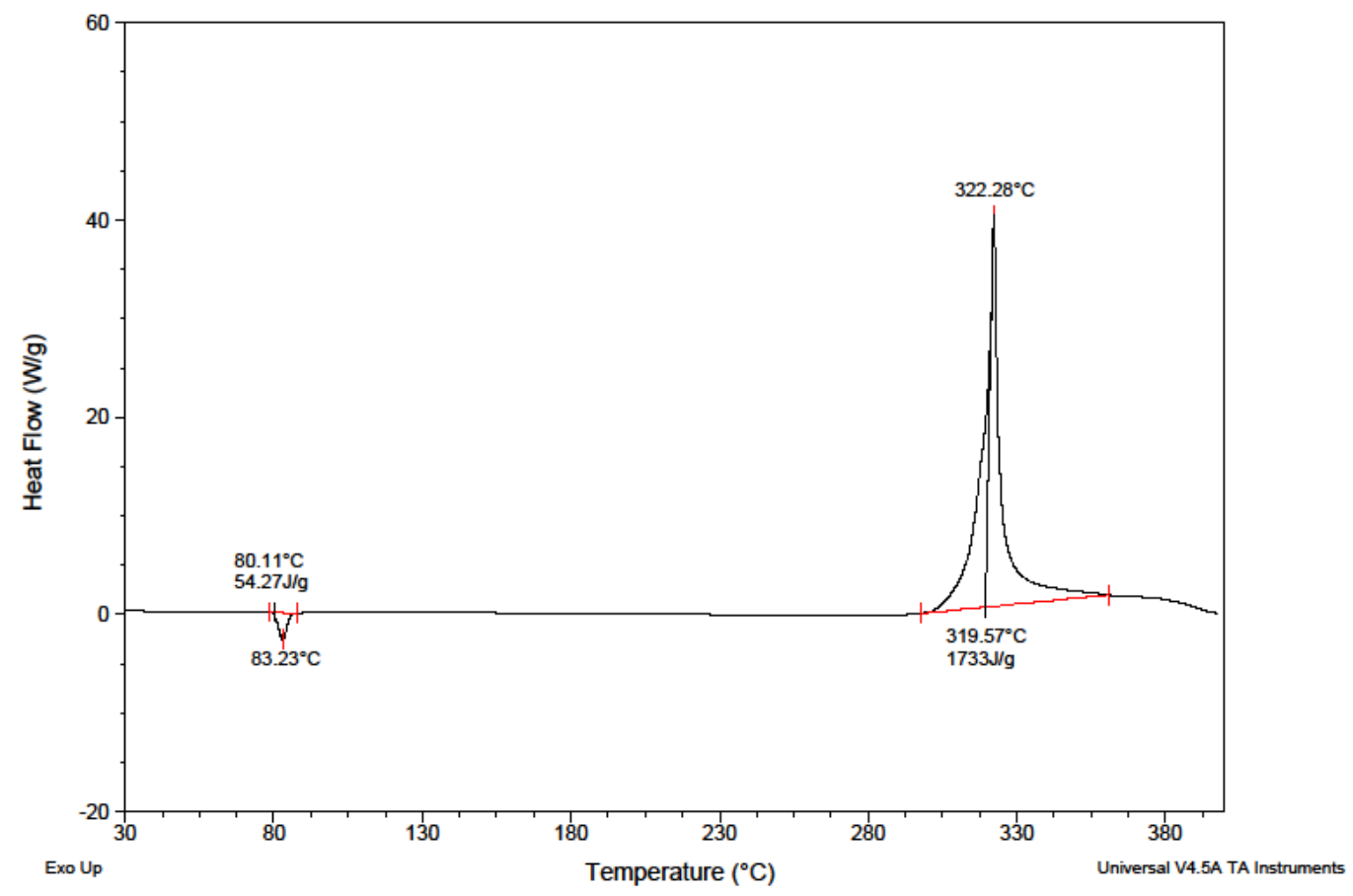

SF 1.1b: DSC trace for $\mathrm{TNT}\left(10^{\circ} \mathrm{C} / \mathrm{min}\right)$ 
Sample: SMX

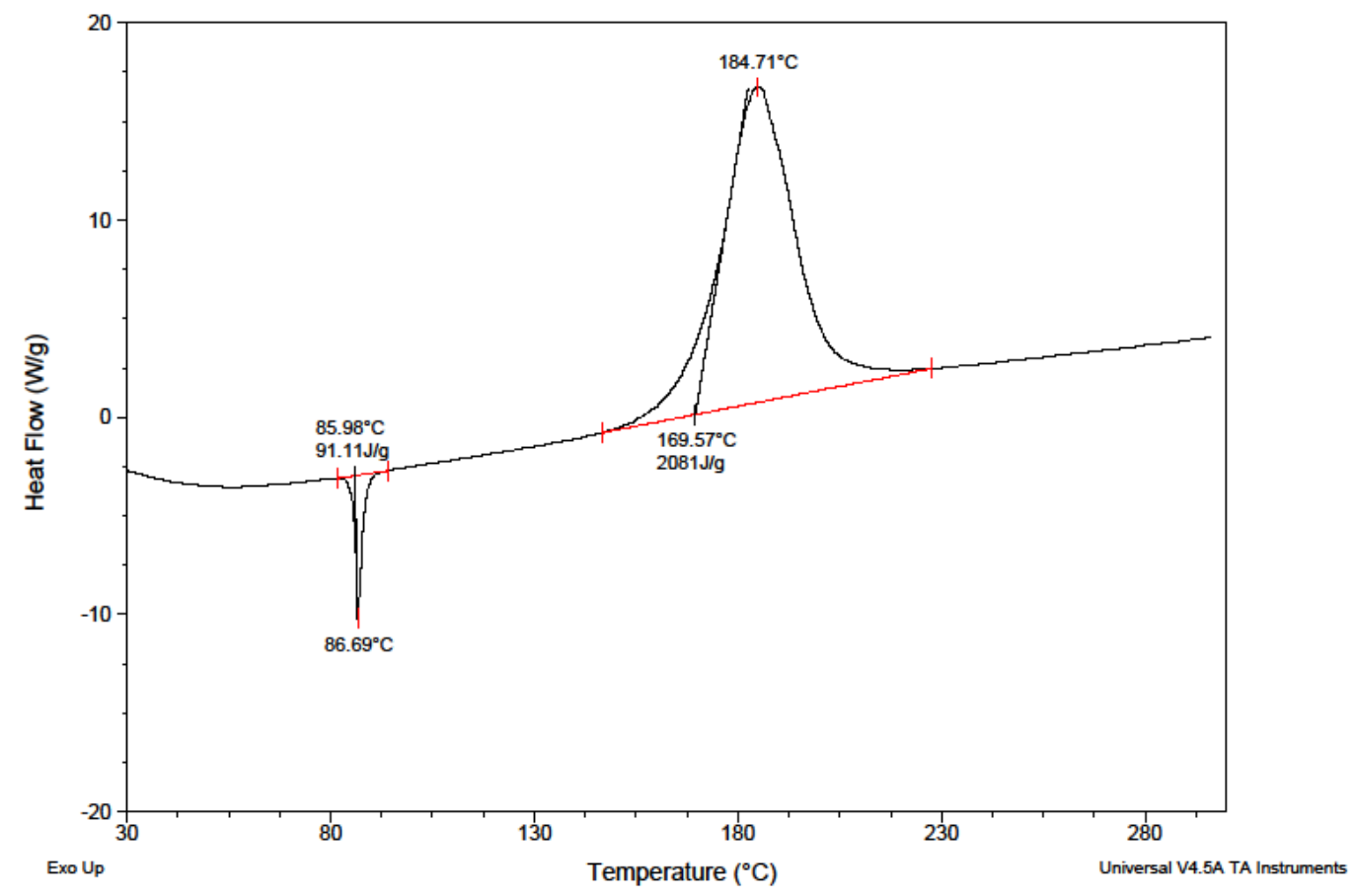

SF 1.1c: DSC trace for $\operatorname{SMX}\left(10^{\circ} \mathrm{C} / \mathrm{min}\right)$ 
Sample: DNAN

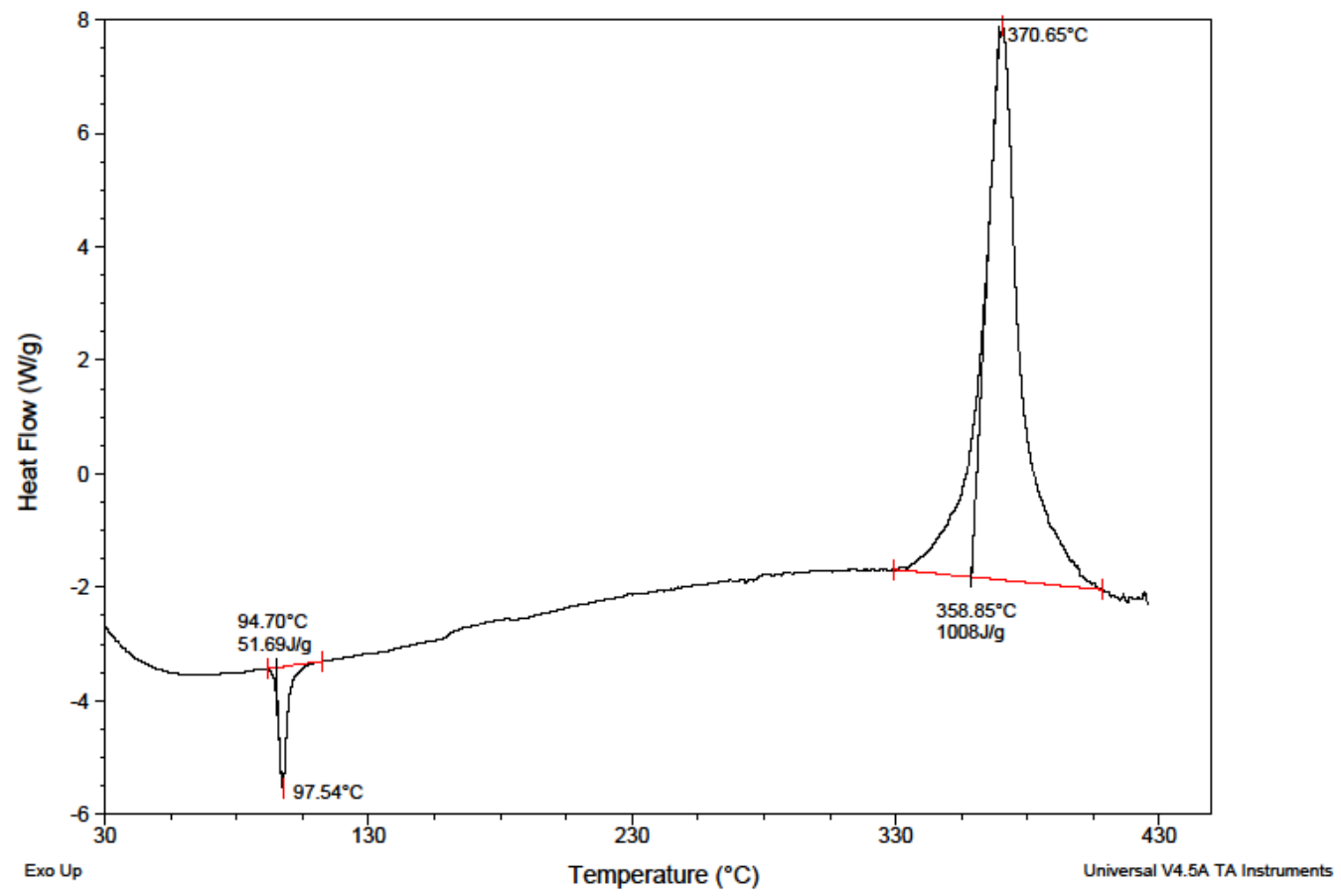

SF 1.1d: DSC trace for DNAN $\left(10^{\circ} \mathrm{C} / \mathrm{min}\right)$ 
Sample: TNAZ

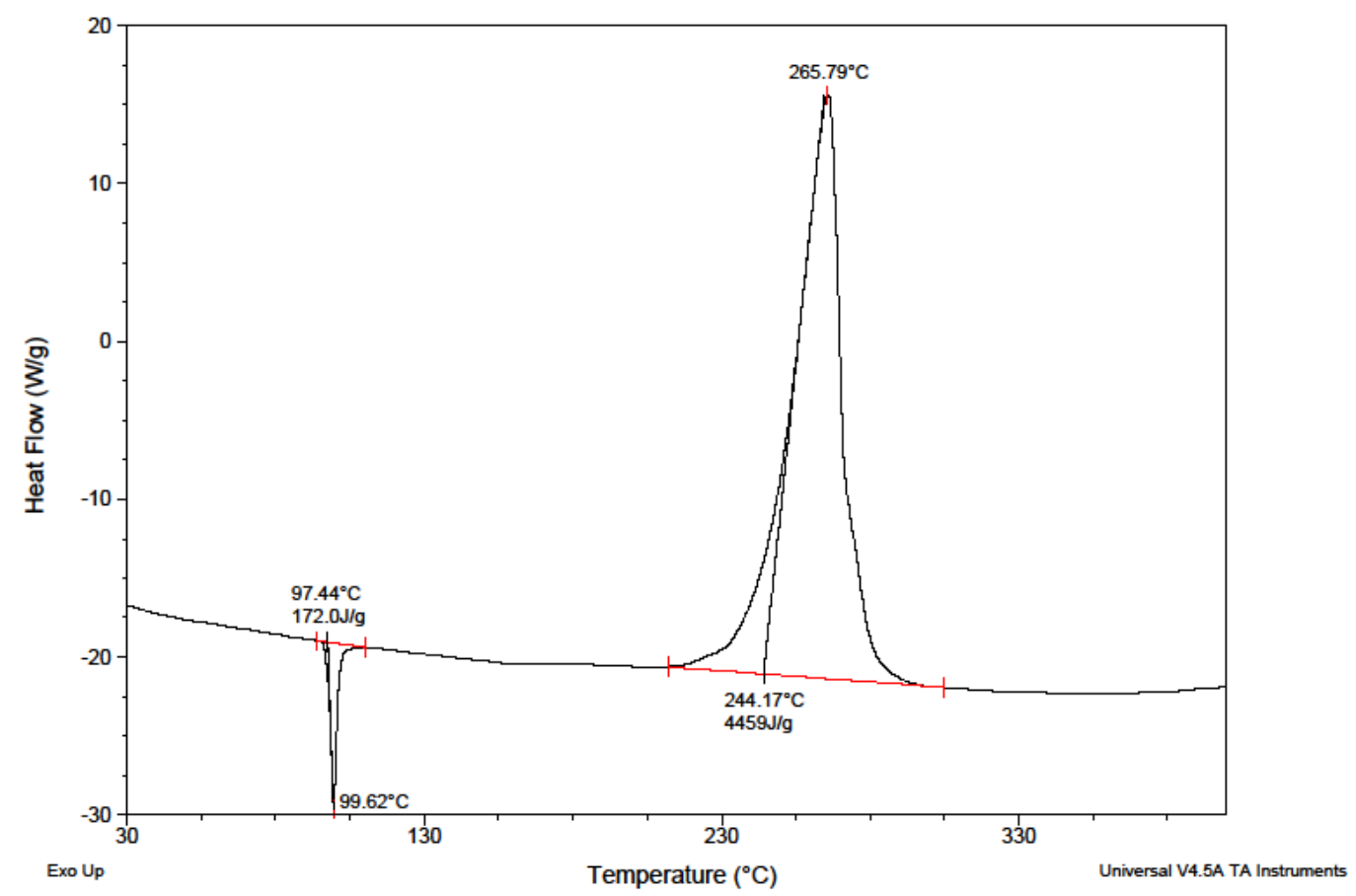

SF 1.1e: DSC trace for $\operatorname{TNAZ}\left(10^{\circ} \mathrm{C} / \mathrm{min}\right)$ 
Sample: PETN

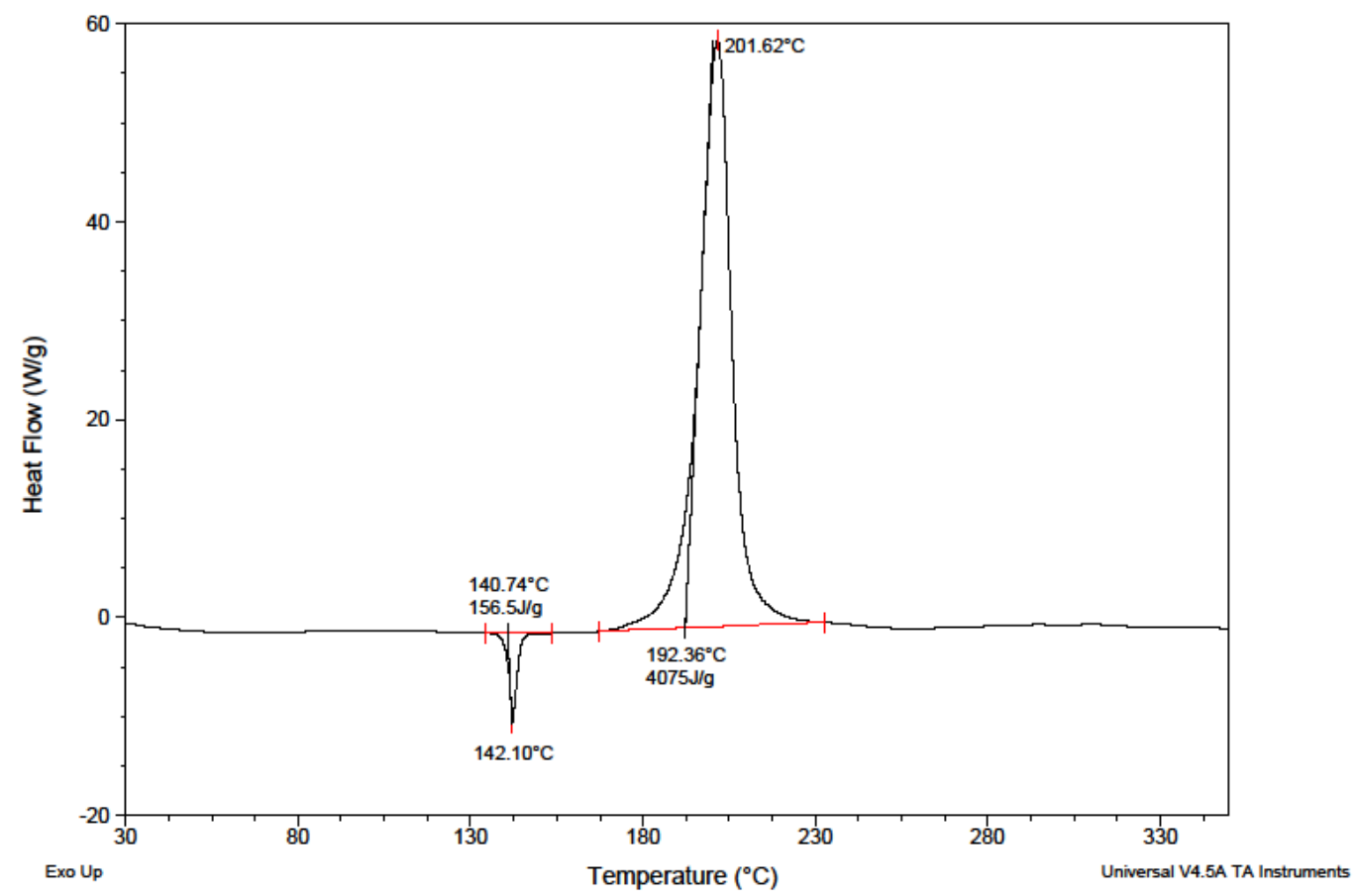

SF 1.1f: DSC trace for PETN $\left(10^{\circ} \mathrm{C} / \mathrm{min}\right)$ 
Sample: R-Salt

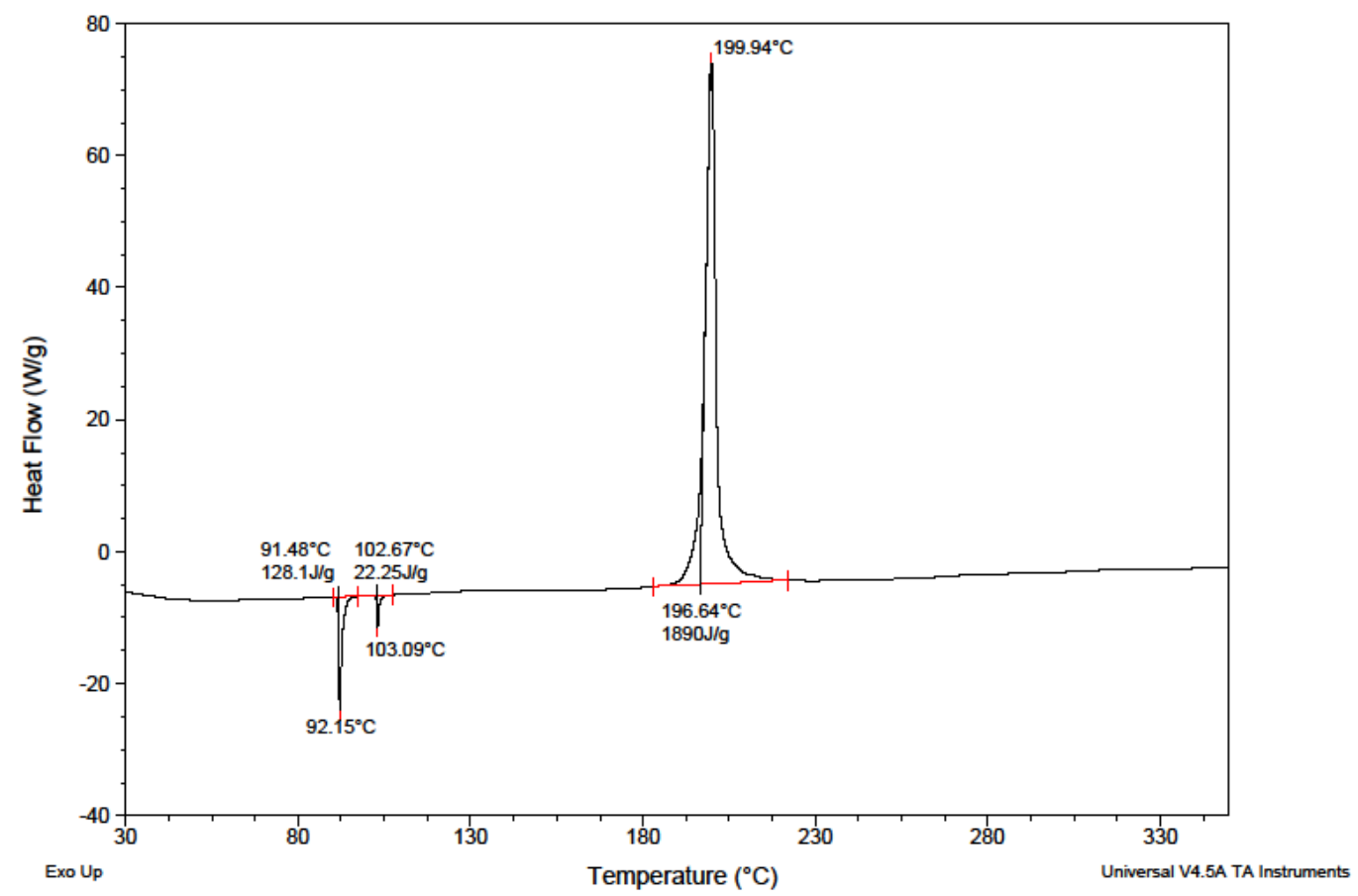

SF 1.1g: DSC trace for R-Salt $\left(10^{\circ} \mathrm{C} / \mathrm{min}\right)$ 
Sample: ETN-TNT

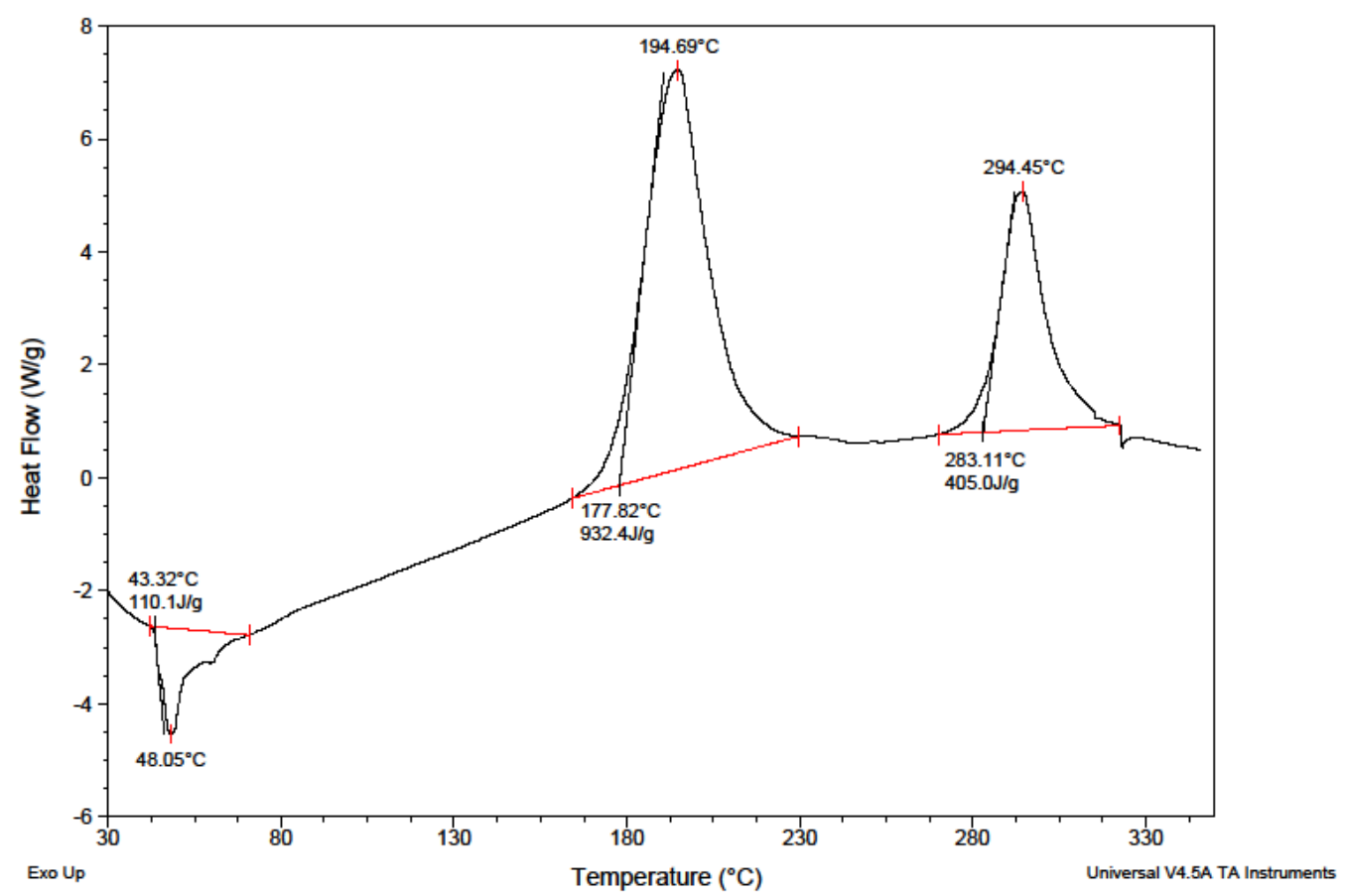

SF 1.2a: DSC trace for ETN-TNT $\left(10^{\circ} \mathrm{C} / \mathrm{min}\right)$ 
Sample: ETN-DNAN

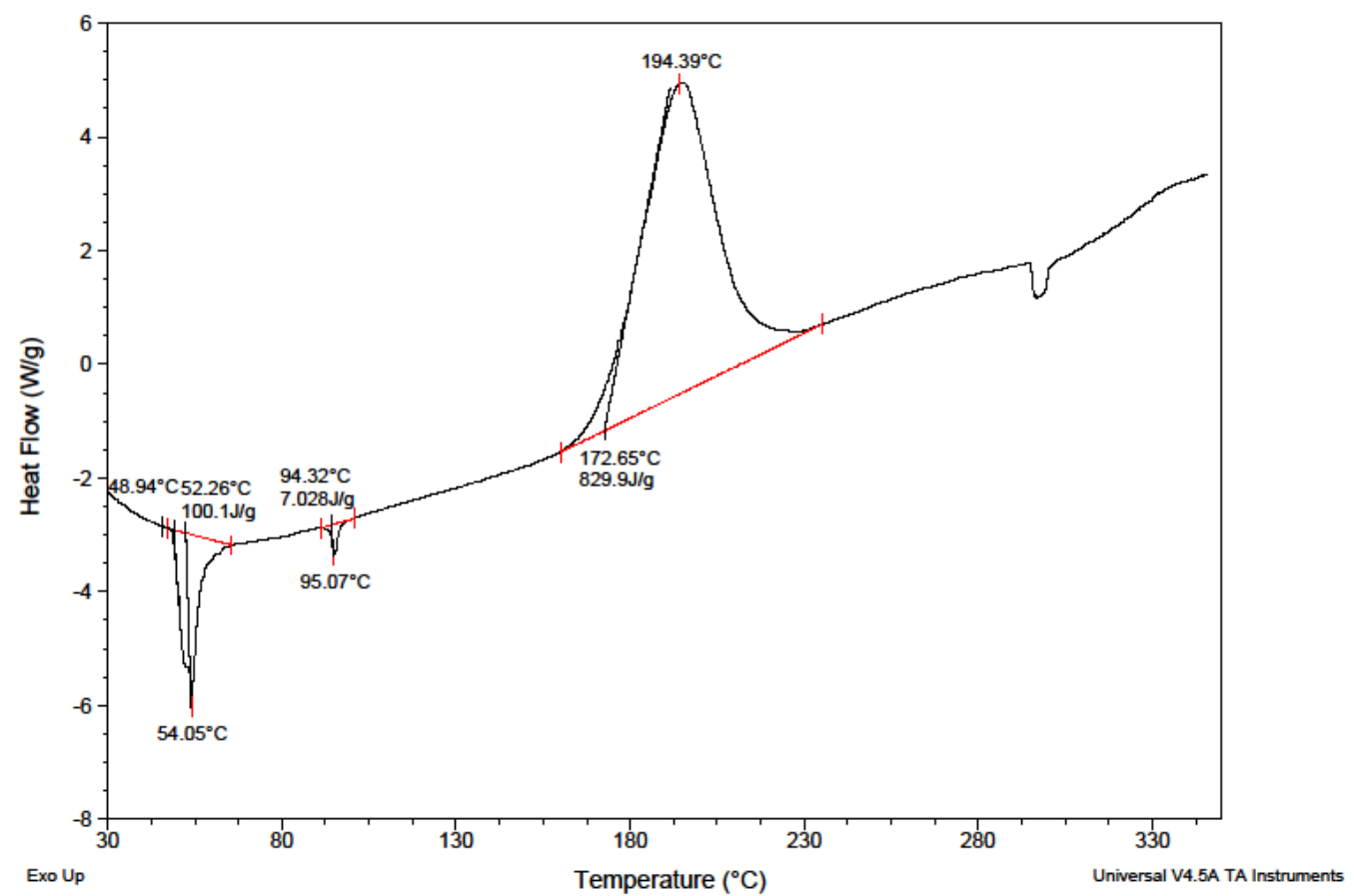

SF 1.2b: DSC trace for ETN-DNAN $\left(10^{\circ} \mathrm{C} / \mathrm{min}\right)$ 
Sample: ETN-TNAZ

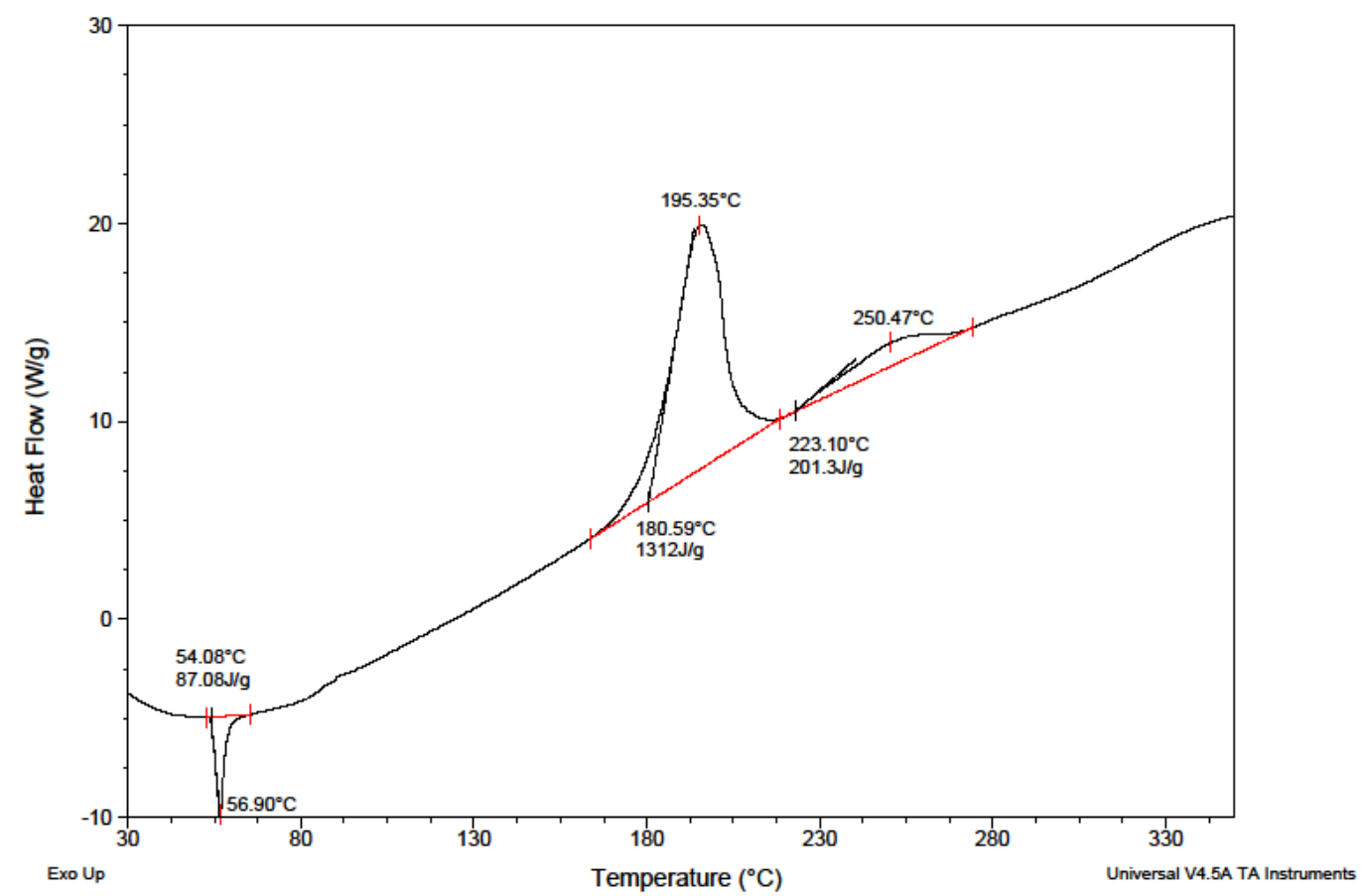

SF 1.2c: DSC trace for ETN-TNAZ $\left(10^{\circ} \mathrm{C} / \mathrm{min}\right)$ 
Sample: ETN-SMX

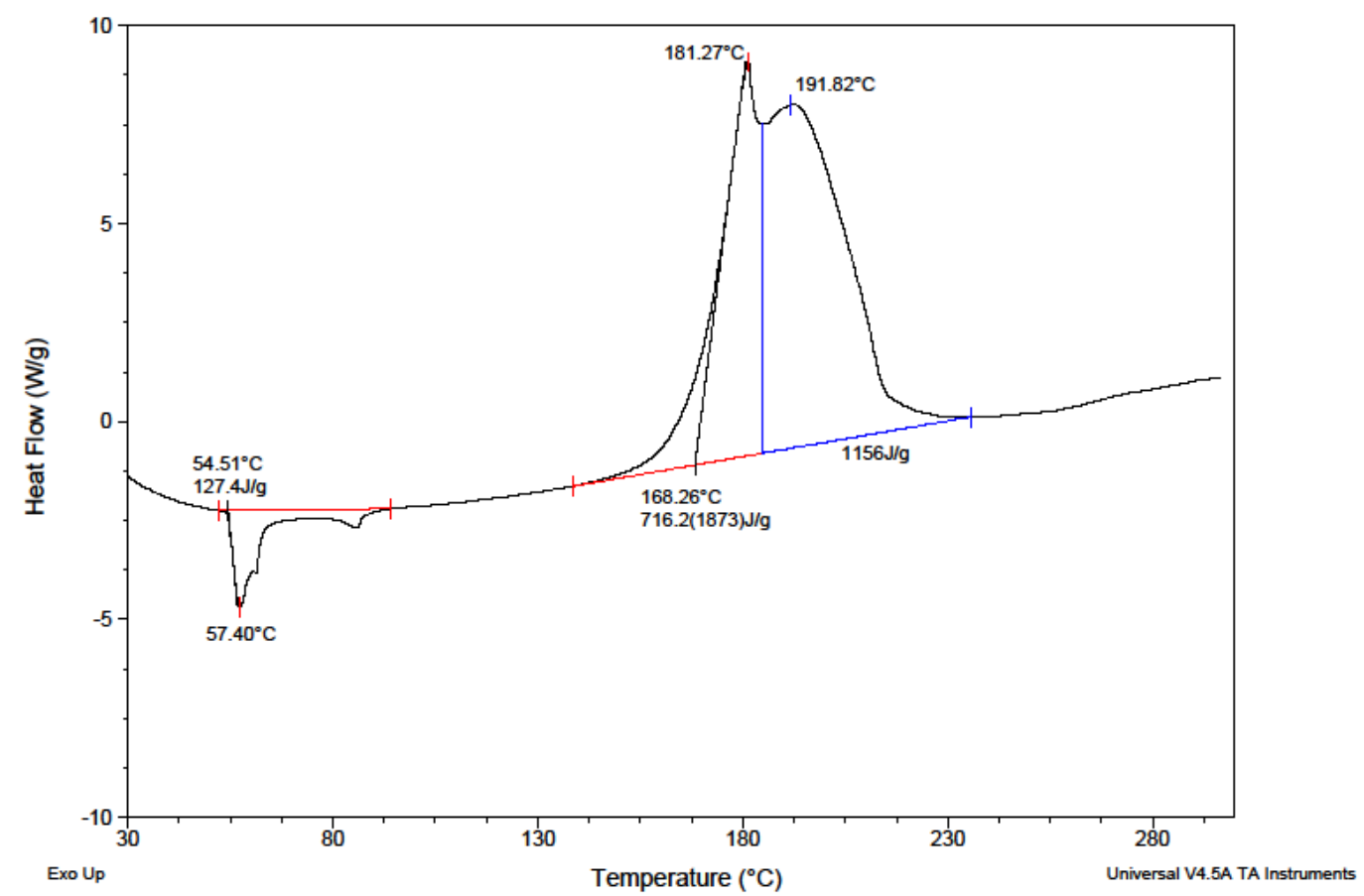

SF 1.2d: DSC trace for ETN-SMX $\left(10^{\circ} \mathrm{C} / \mathrm{min}\right)$ 
Sample: ETN-PETN

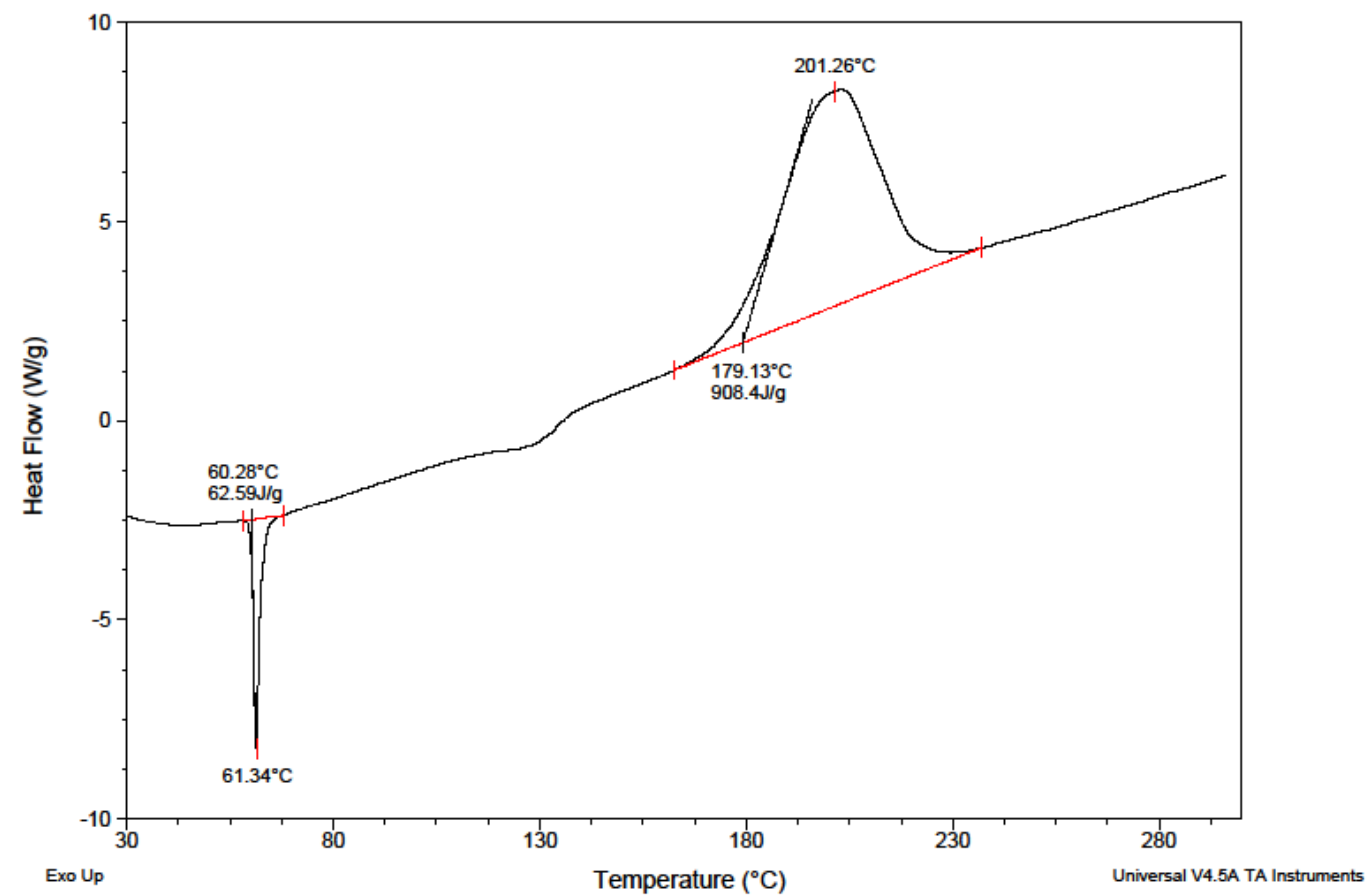

SF 1.2e: DSC trace for ETN-PETN $\left(10^{\circ} \mathrm{C} / \mathrm{min}\right)$ 
Sample: TNT-PETN

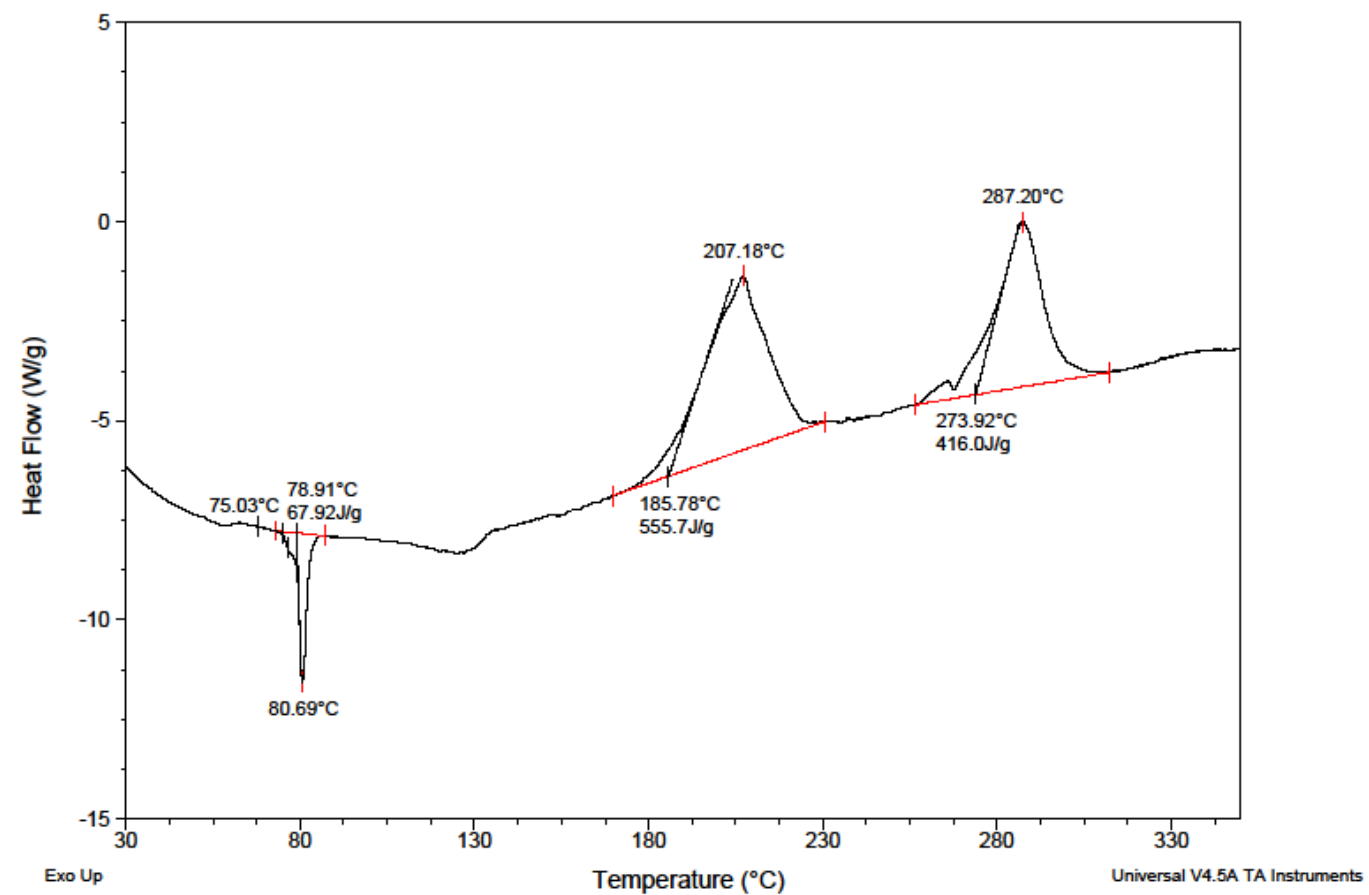

SF 1.2f: DSC trace for TNT-PETN $\left(10^{\circ} \mathrm{C} / \mathrm{min}\right)$ 
Sample: TNT-Rsalt

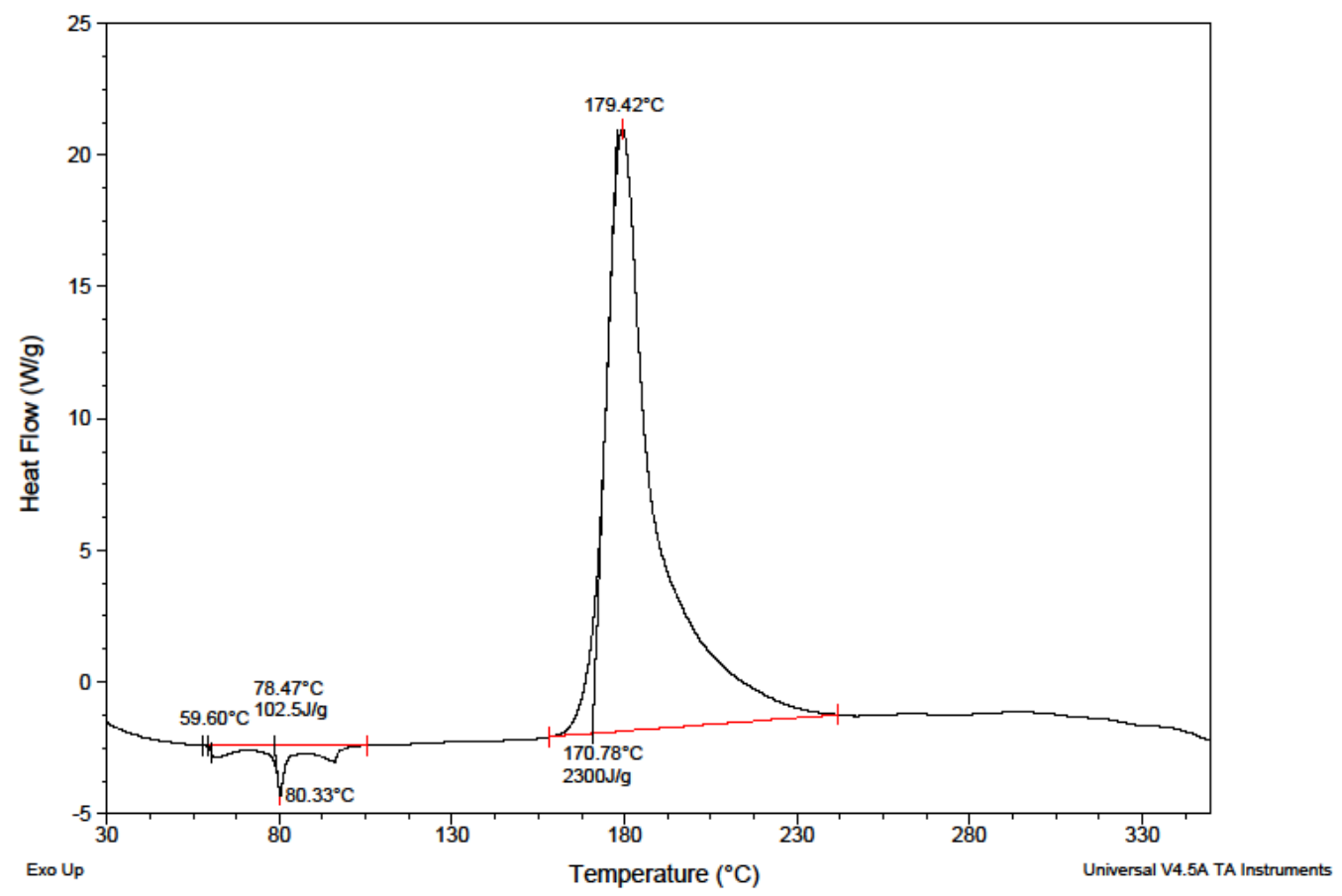

SF 1.2g: DSC trace for TNT-Rsalt $\left(10^{\circ} \mathrm{C} / \mathrm{min}\right)$ 
Sample: DNAN-TNAZ

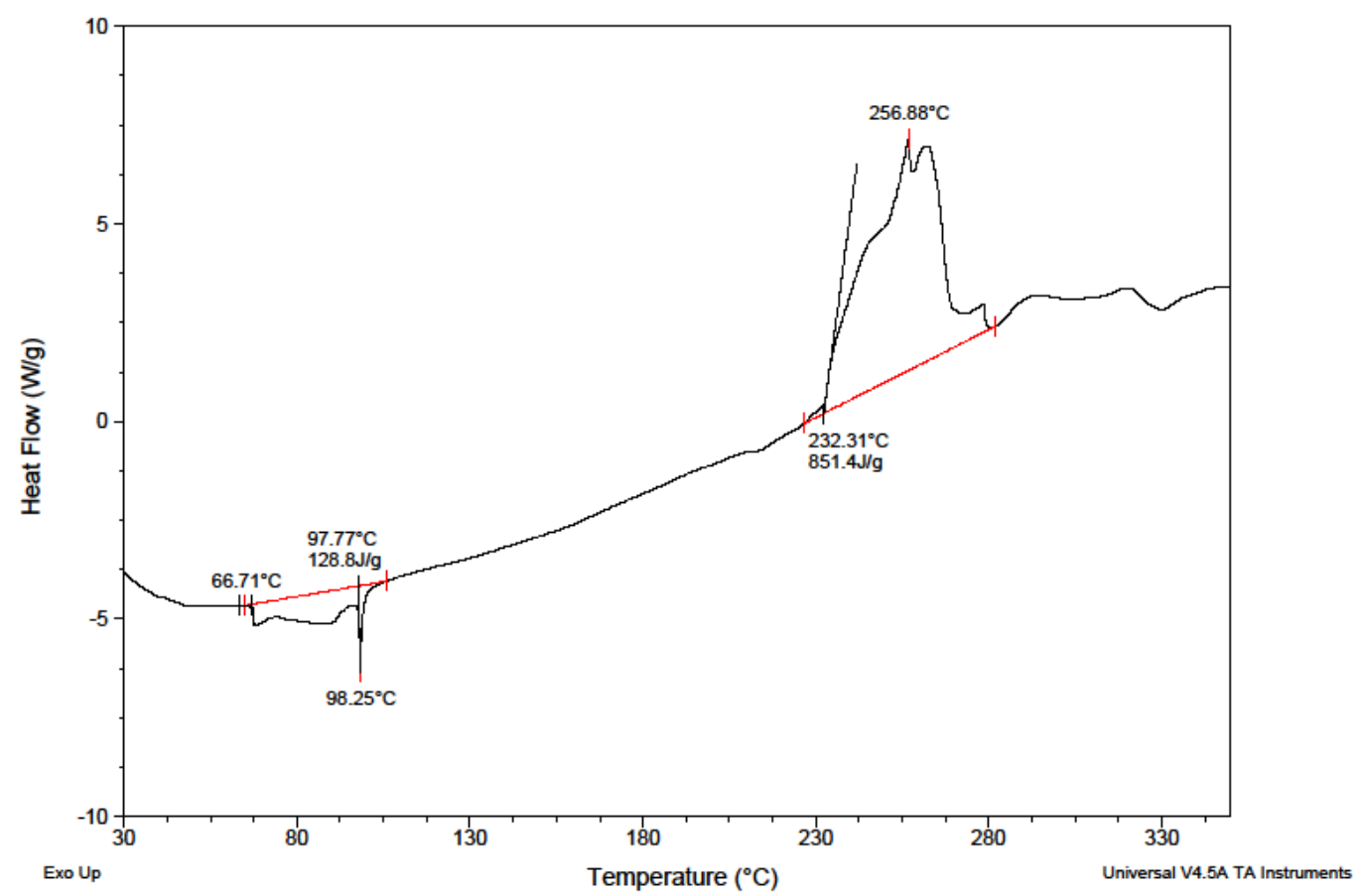

SF 1.2h: DSC trace for DNAN-TNAZ $\left(10^{\circ} \mathrm{C} / \mathrm{min}\right)$ 


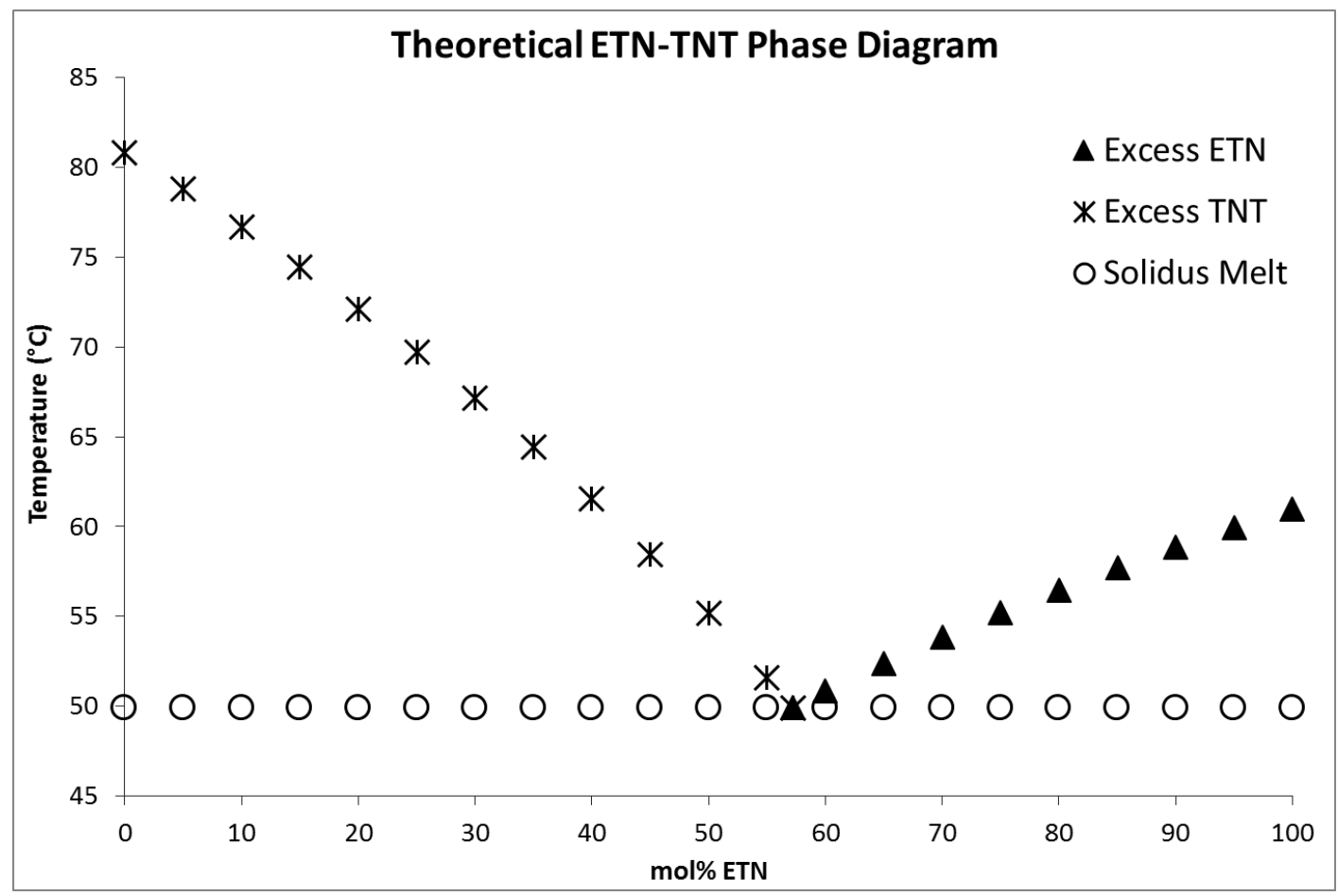

SF 1.3a: Theoretical phase diagram for ETN-TNT predicted by equation 1 


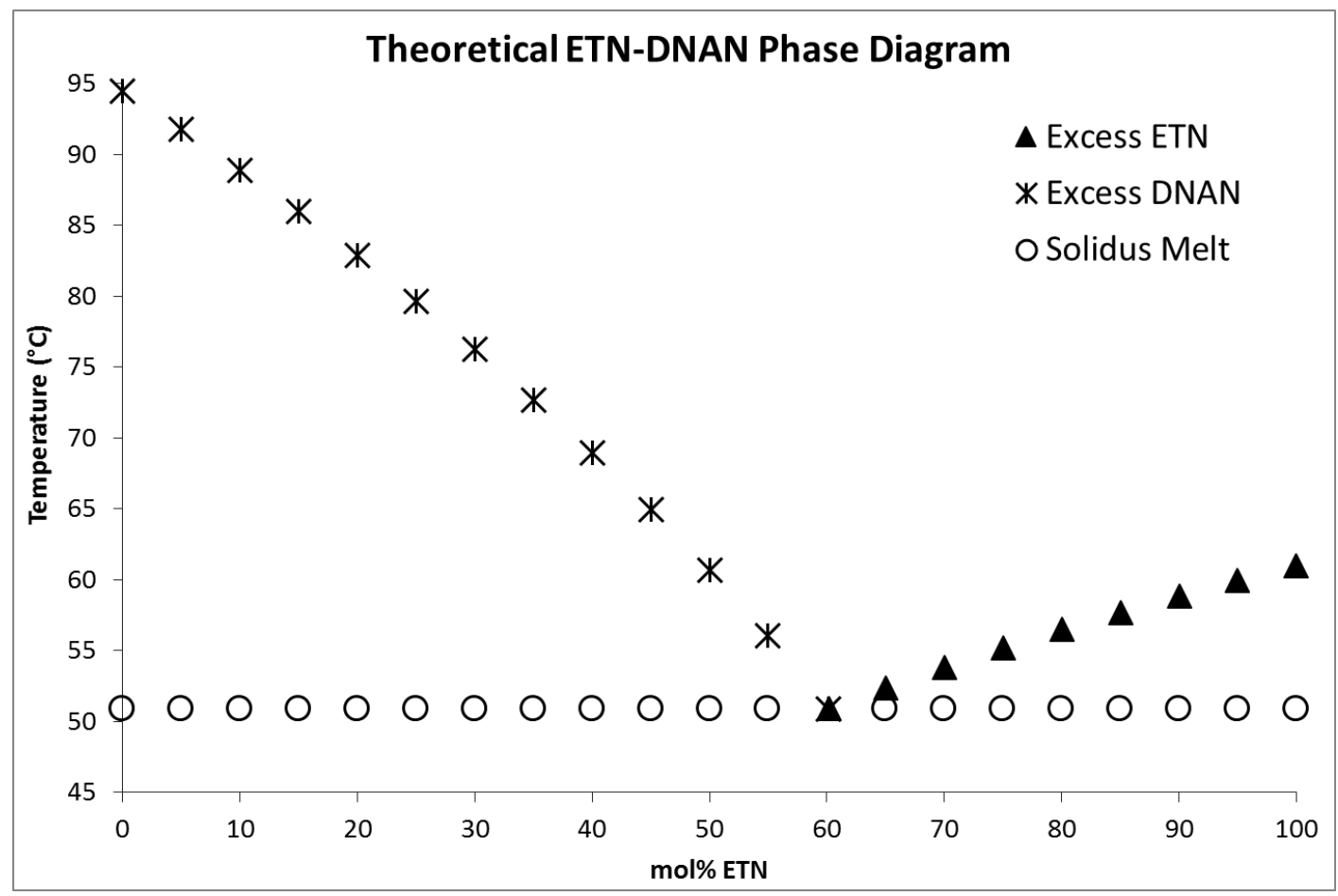

SF 1.3b: Theoretical phase diagram for ETN-DNAN predicted by equation 1 


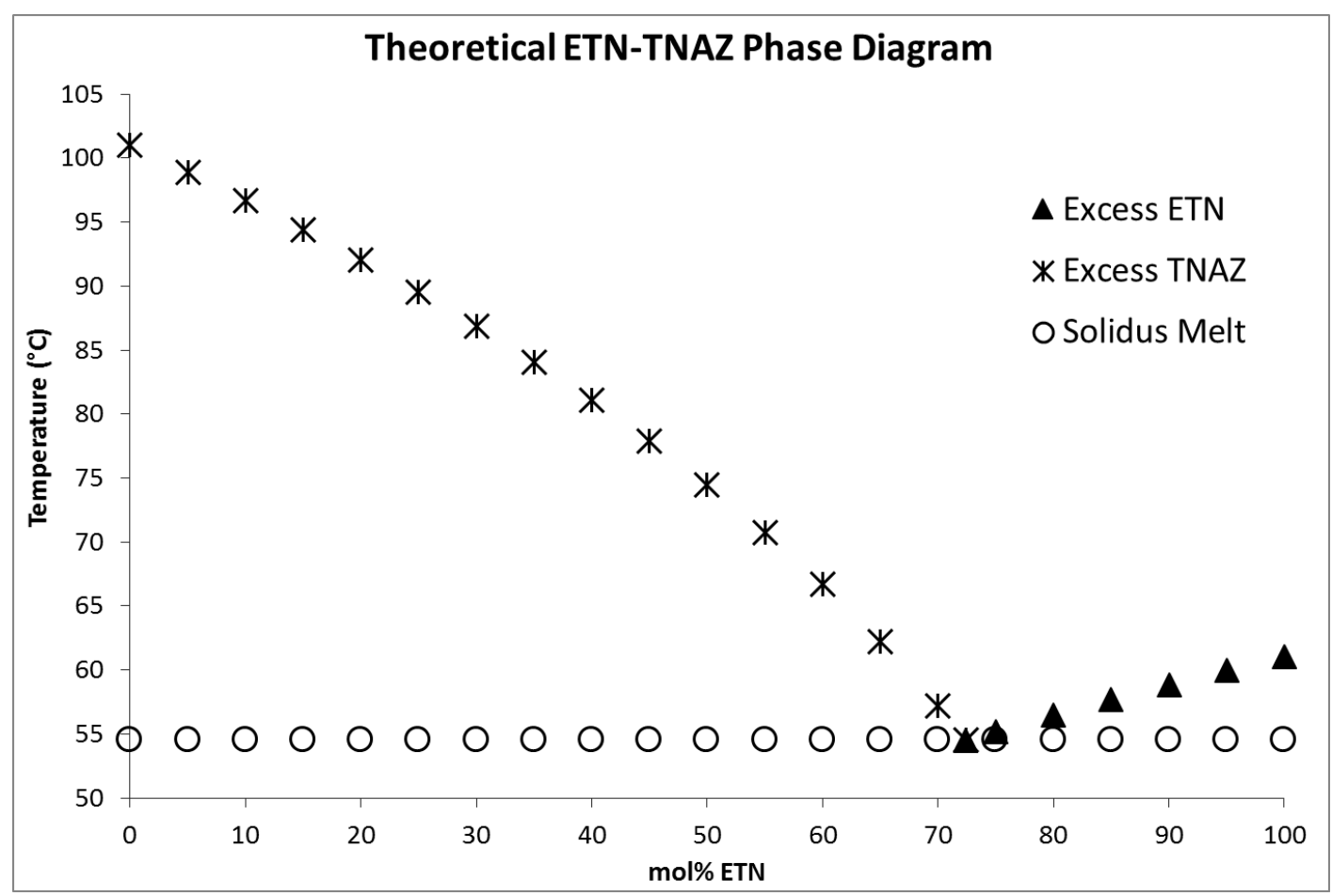

SF 1.3c: Theoretical phase diagram for ETN-TNAZ predicted by equation 1 


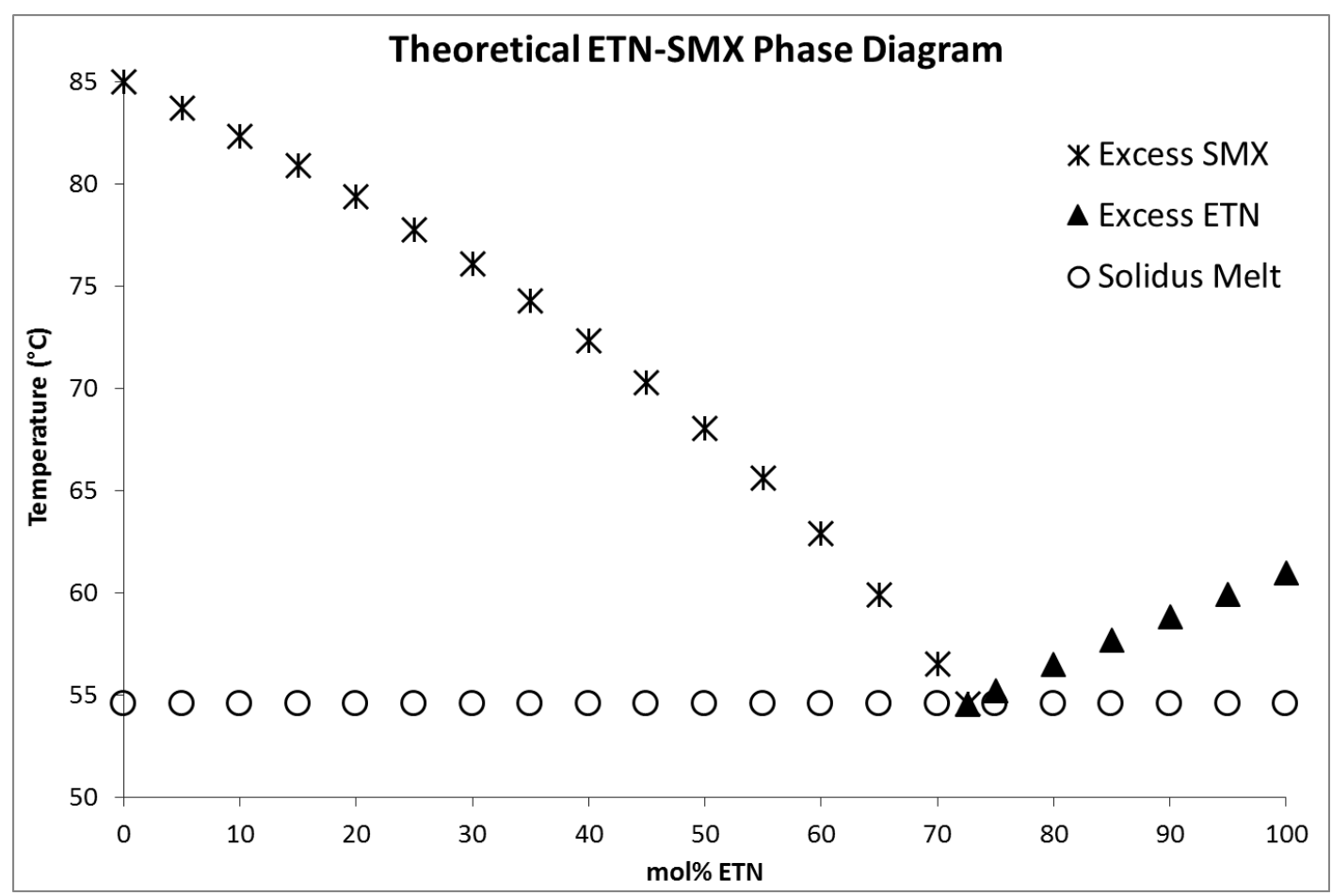

SF 1.3d: Theoretical phase diagram for ETN-SMX predicted by equation 1 


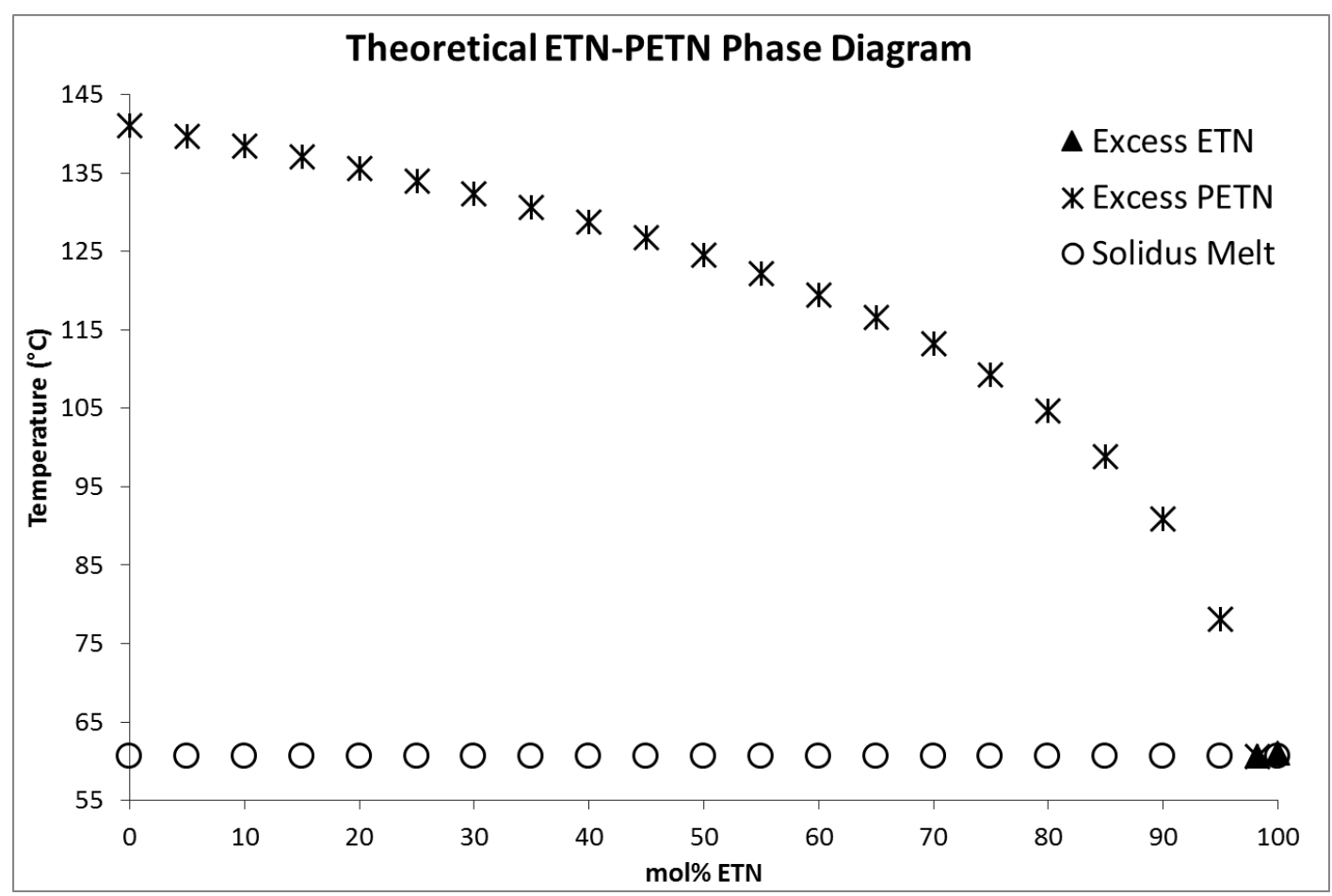

SF 1.3e: Theoretical phase diagram for ETN-PETN predicted by equation 1 


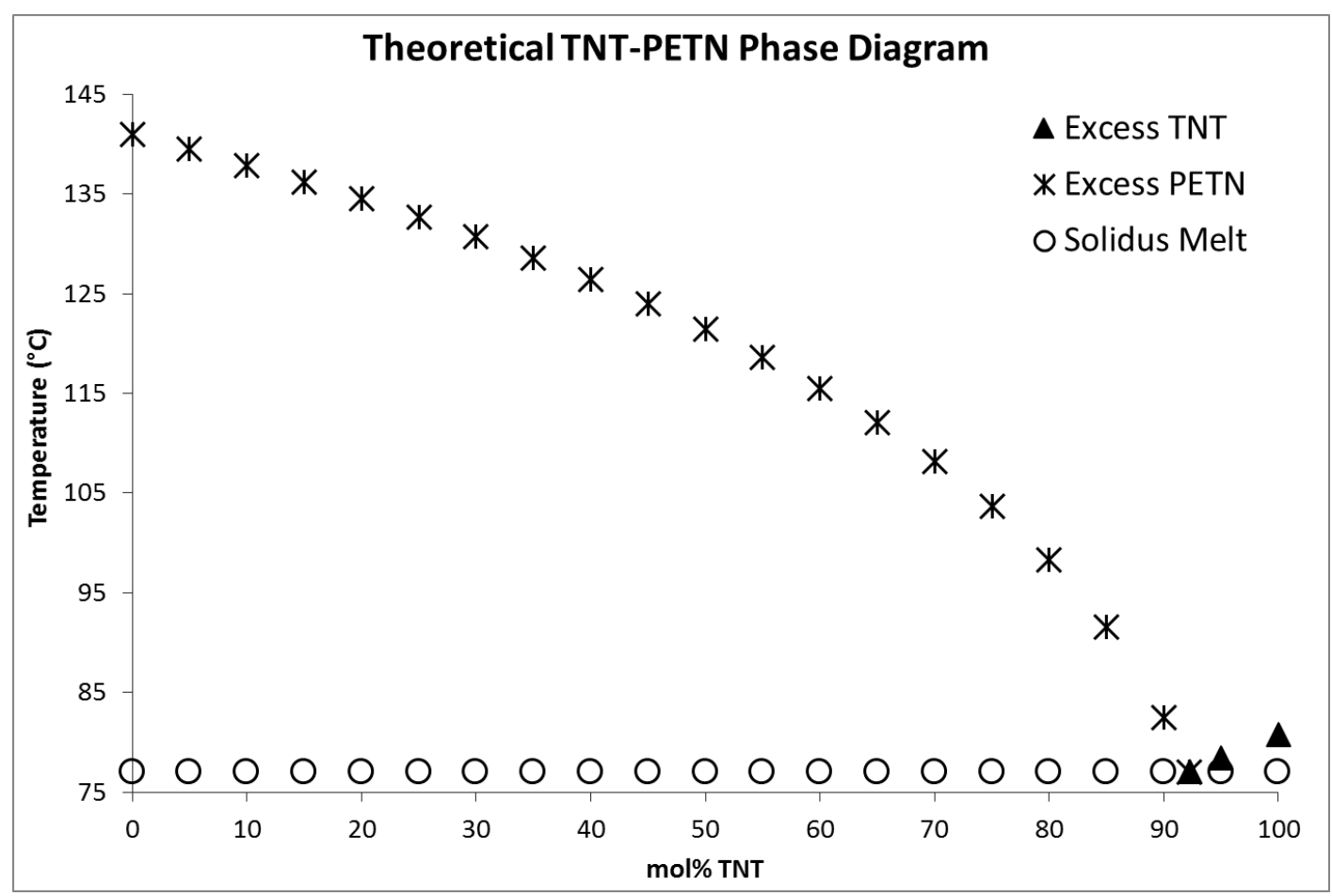

SF 1.3f: Theoretical phase diagram for TNT-PETN predicted by equation 1 


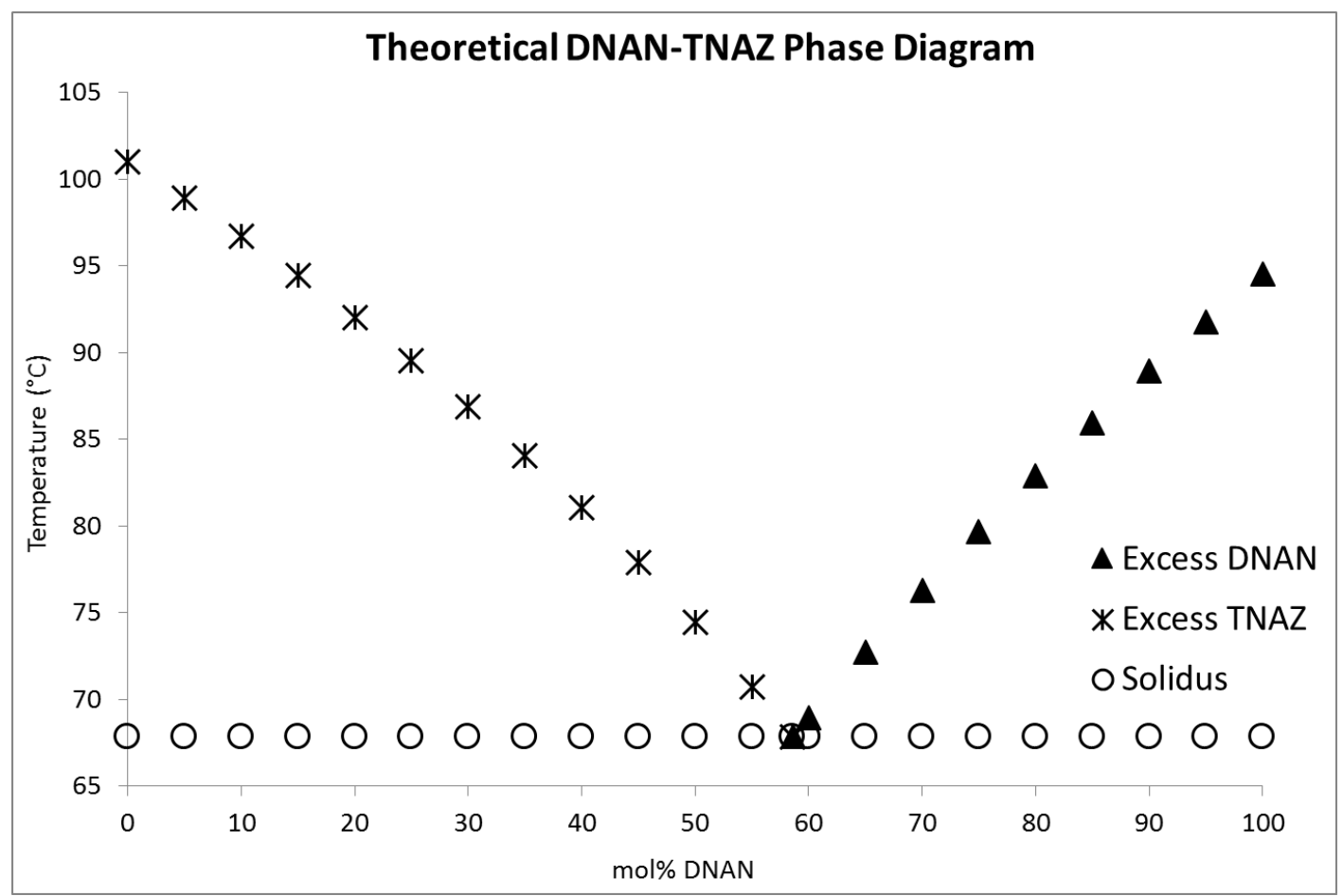

SF 1.3g: Theoretical phase diagram for DNAN-TNAZ predicted by equation 1 
Sample: ETN-TNT Eutectic

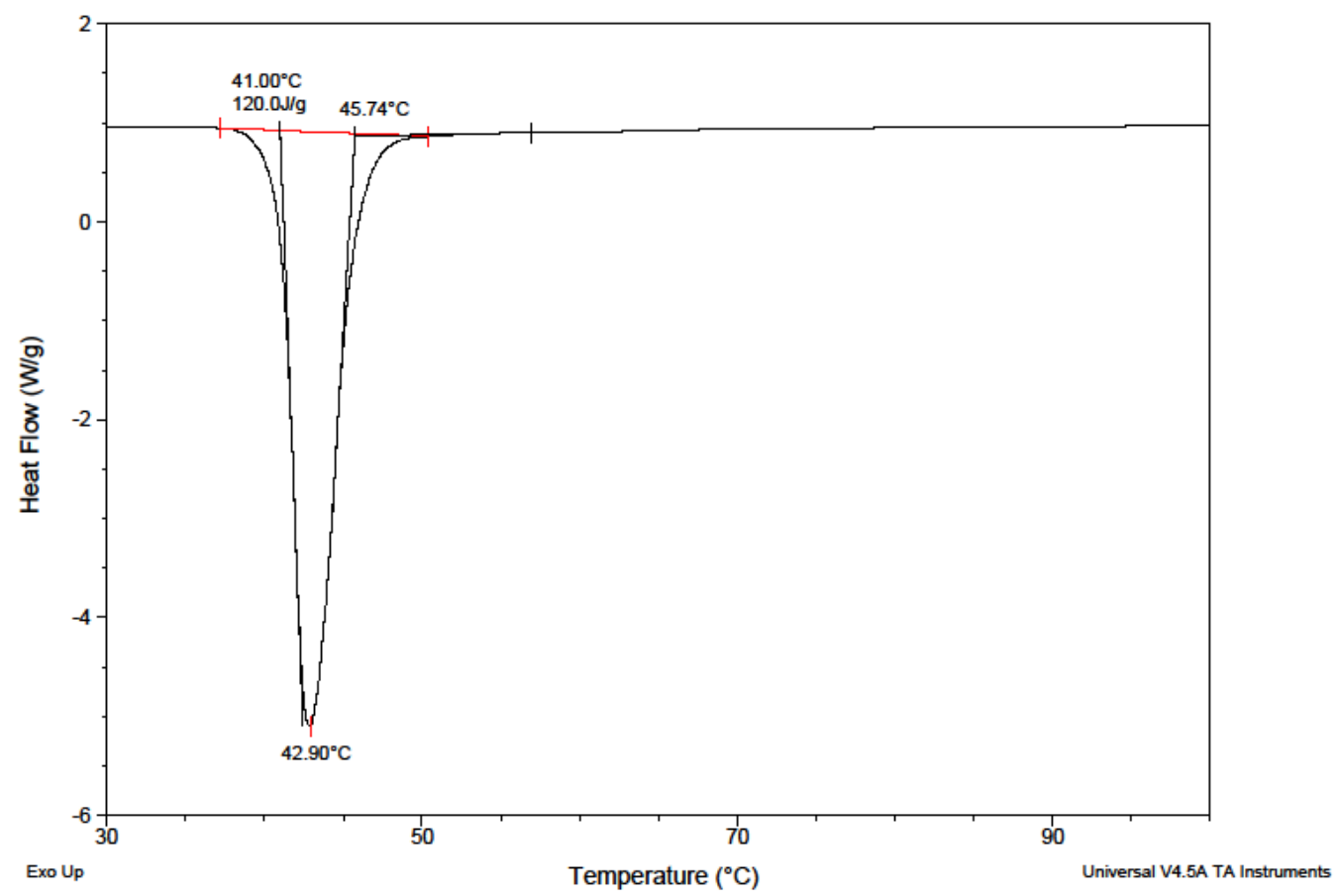

SF 1.4a: DSC trace for ETN-TNT eutectic $\left(10^{\circ} \mathrm{C} / \mathrm{min}\right)$ 
Sample: ETN-DNAN Eutectic

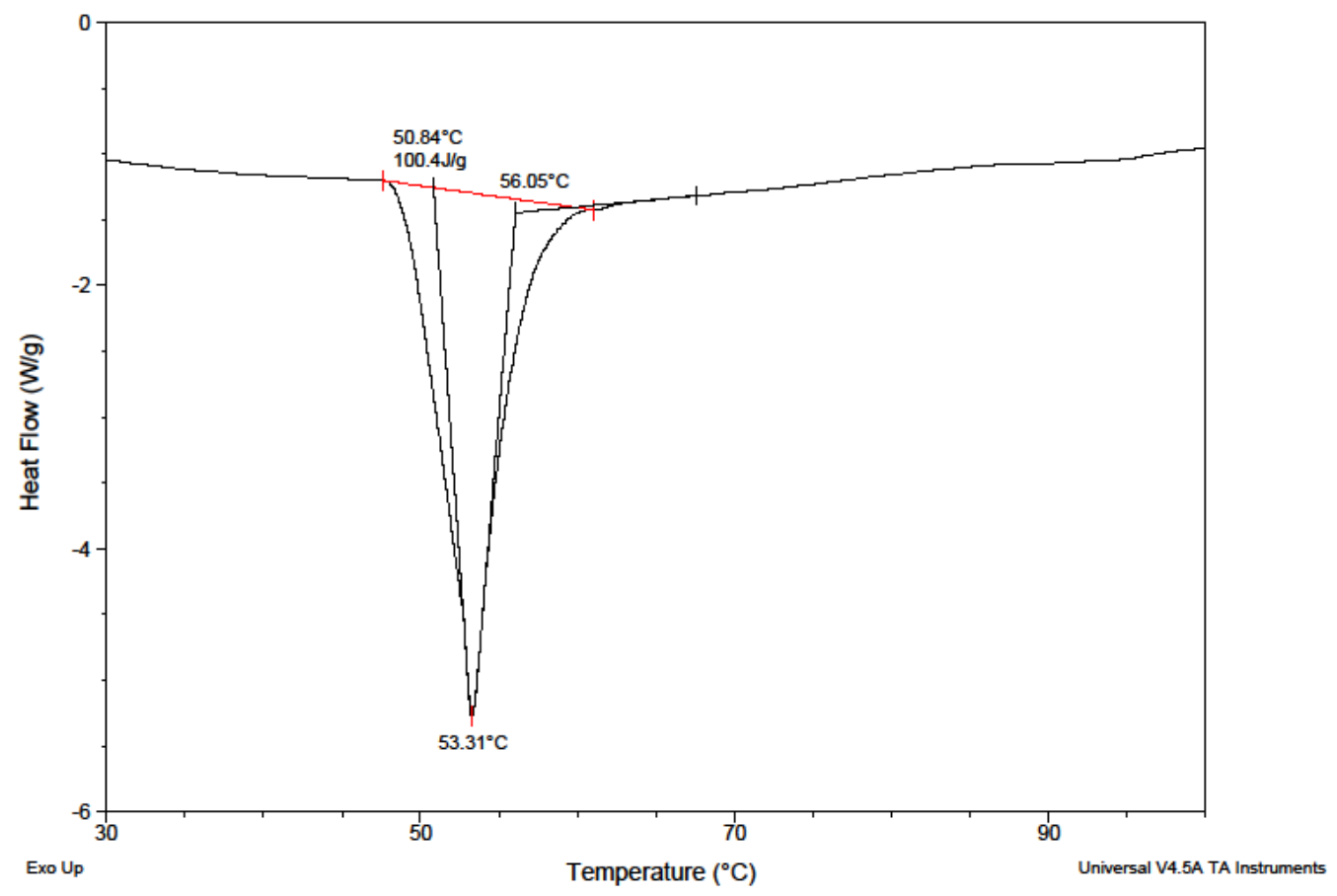

SF 1.4b: DSC trace for ETN-DNAN eutectic $\left(10^{\circ} \mathrm{C} / \mathrm{min}\right)$ 
Sample: ETN-TNAZ Eutectic

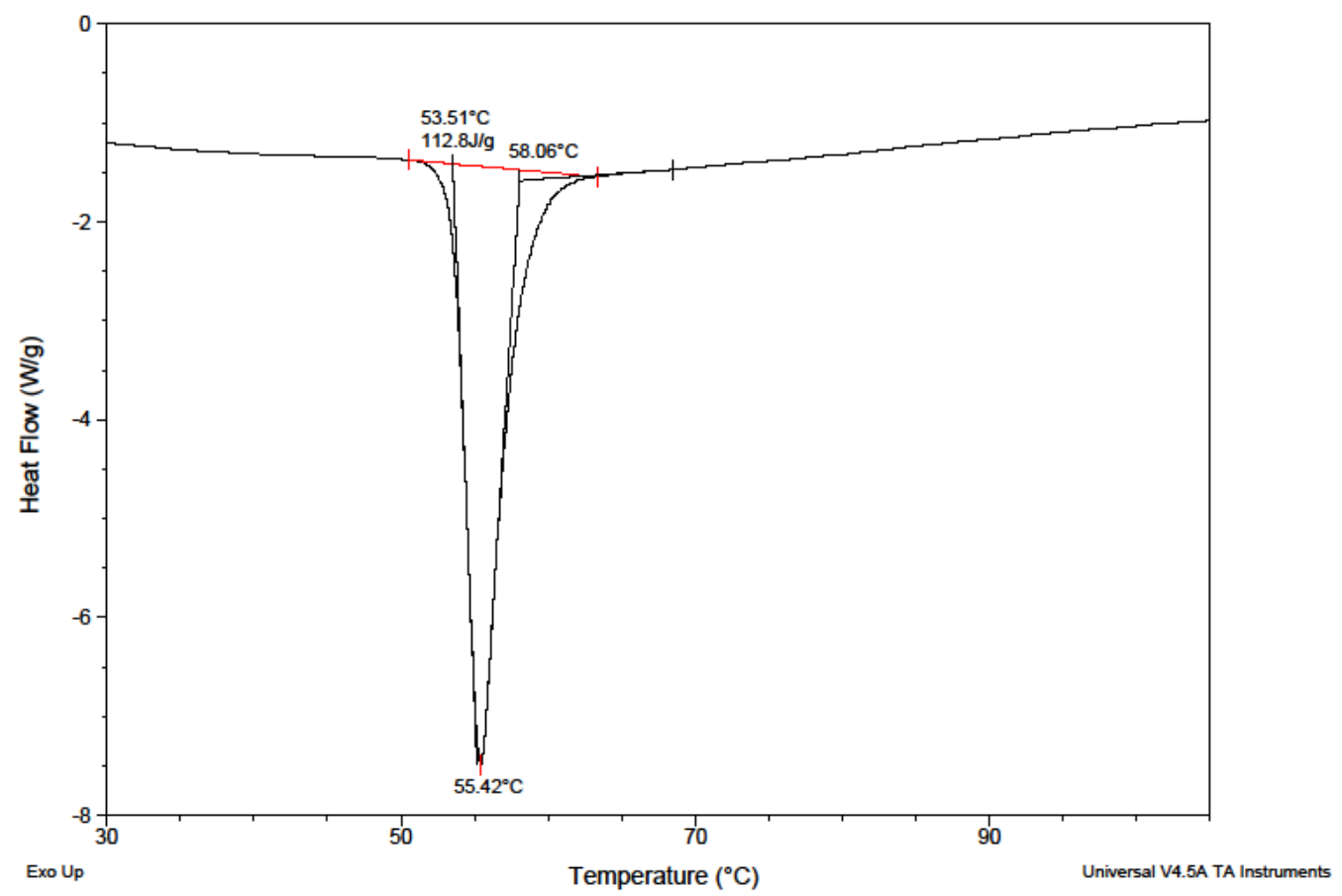

SF 1.4c: DSC trace for ETN-TNAZ eutectic $\left(10^{\circ} \mathrm{C} / \mathrm{min}\right)$ 
Sample: ETN-SMX Eutectic

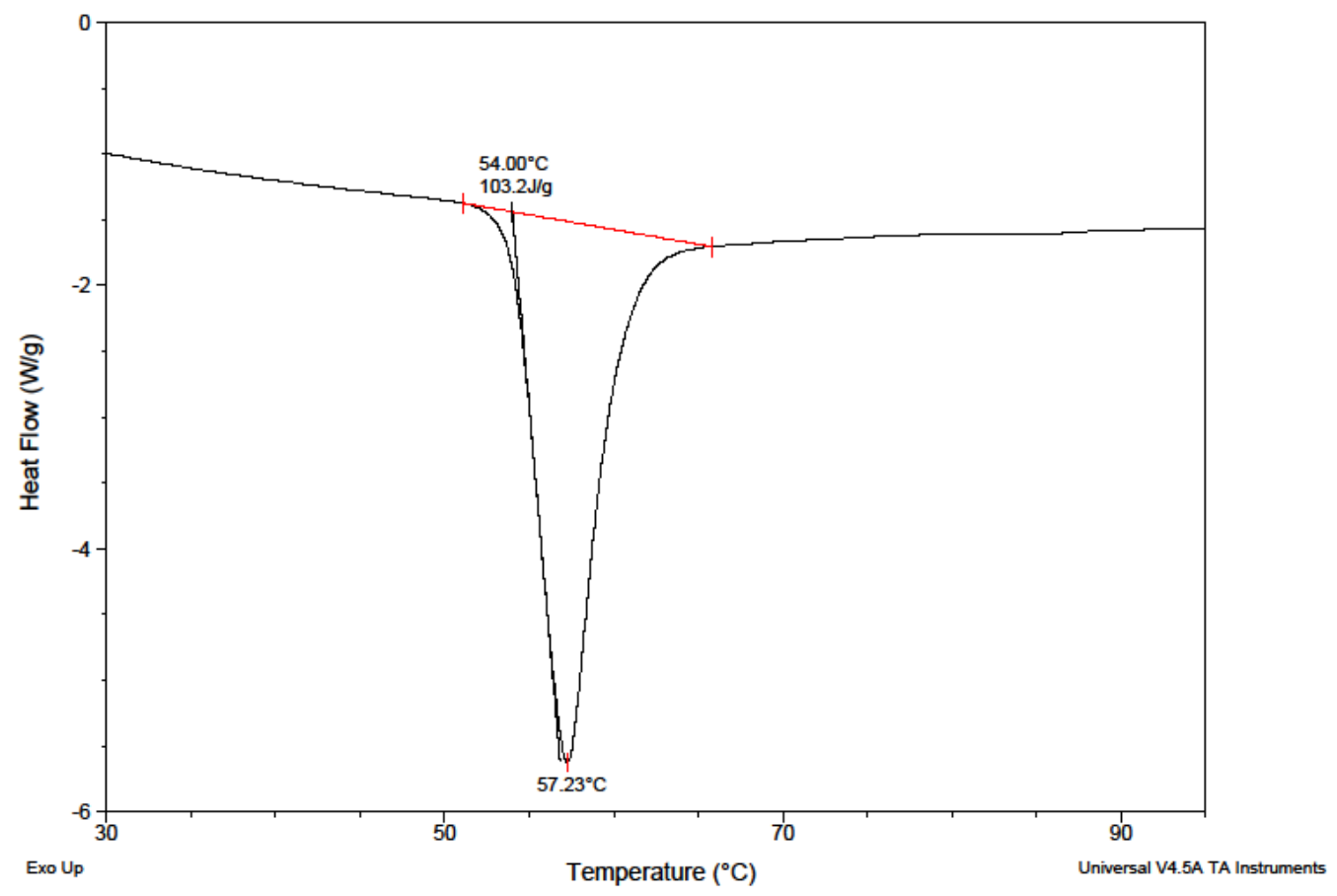

SF 1.4d: DSC trace for ETN-SMX eutectic $\left(10^{\circ} \mathrm{C} / \mathrm{min}\right)$ 
Sample: ETN-PETN Eutectic

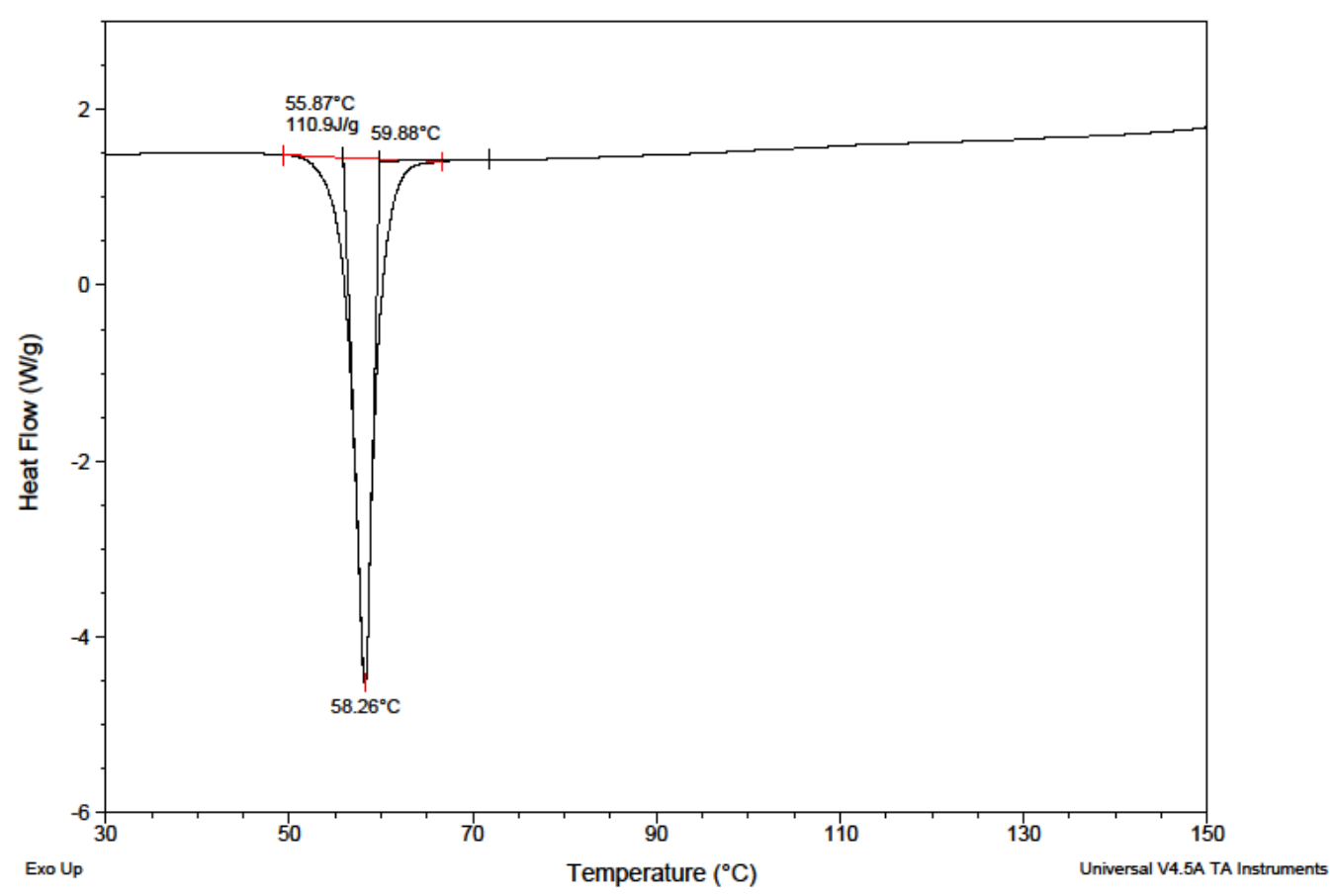

SF 1.4e: DSC trace for ETN-PETN eutectic $\left(10^{\circ} \mathrm{C} / \mathrm{min}\right)$ 
Sample: TNT-PETN Eutectic

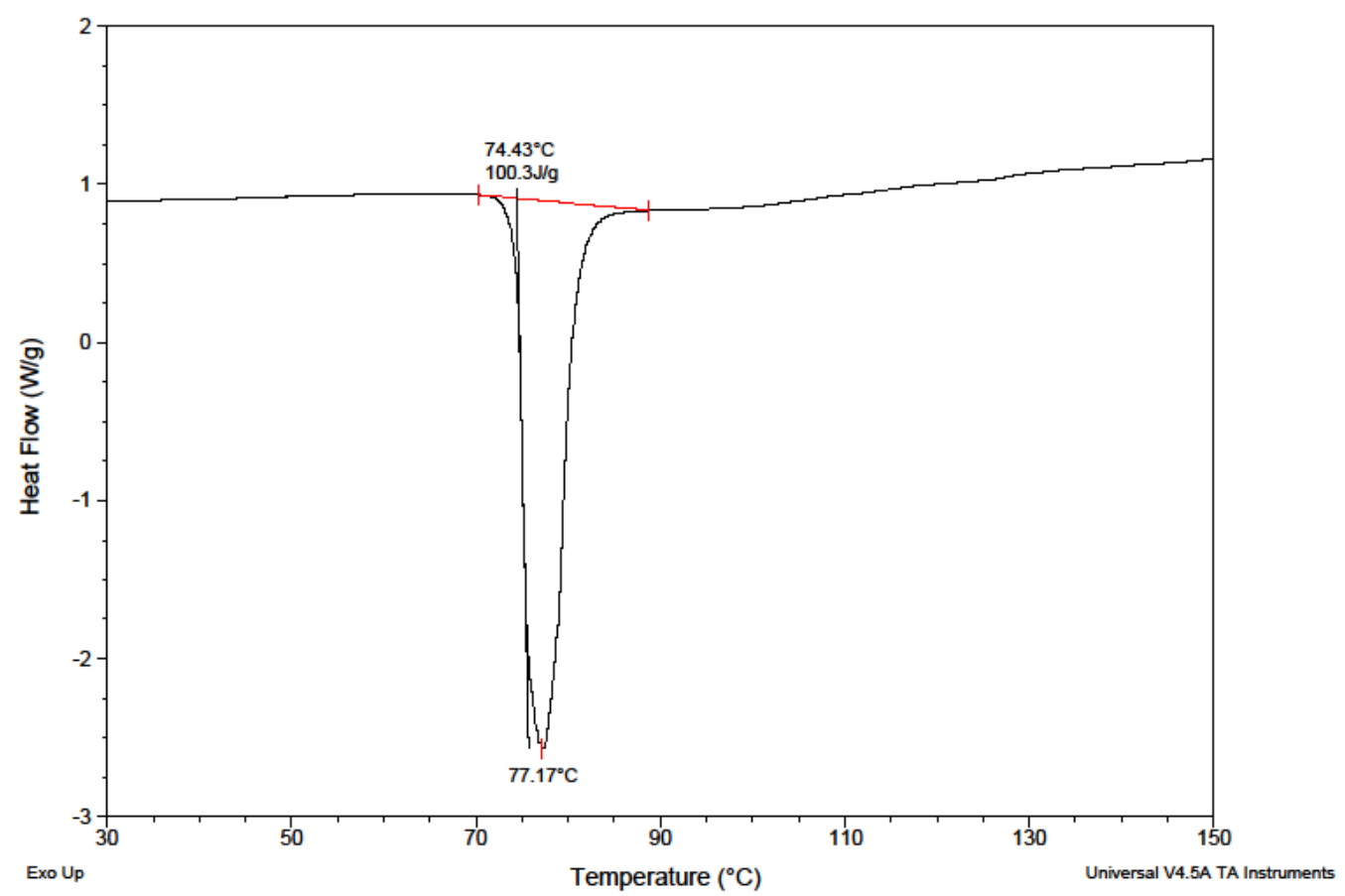

SF 1.4f: DSC trace for TNT-PETN eutectic $\left(10^{\circ} \mathrm{C} / \mathrm{min}\right)$ 
Sample: TNT-Rsalt Eutectic

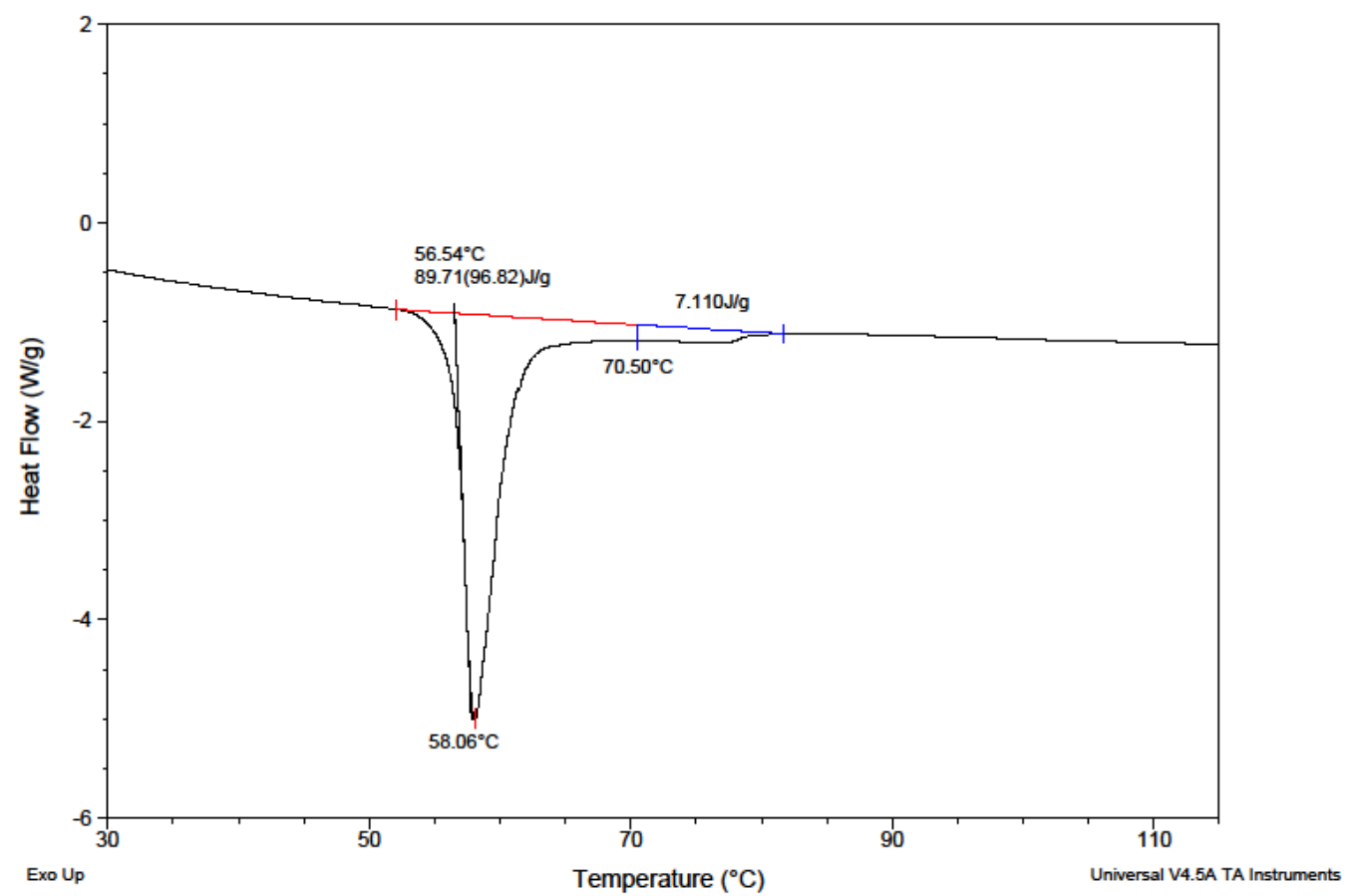

SF 1.4g: DSC trace for TNT-Rsalt eutectic $\left(10^{\circ} \mathrm{C} / \mathrm{min}\right)$ 
Sample: DNAN-TNAZ Eutectic

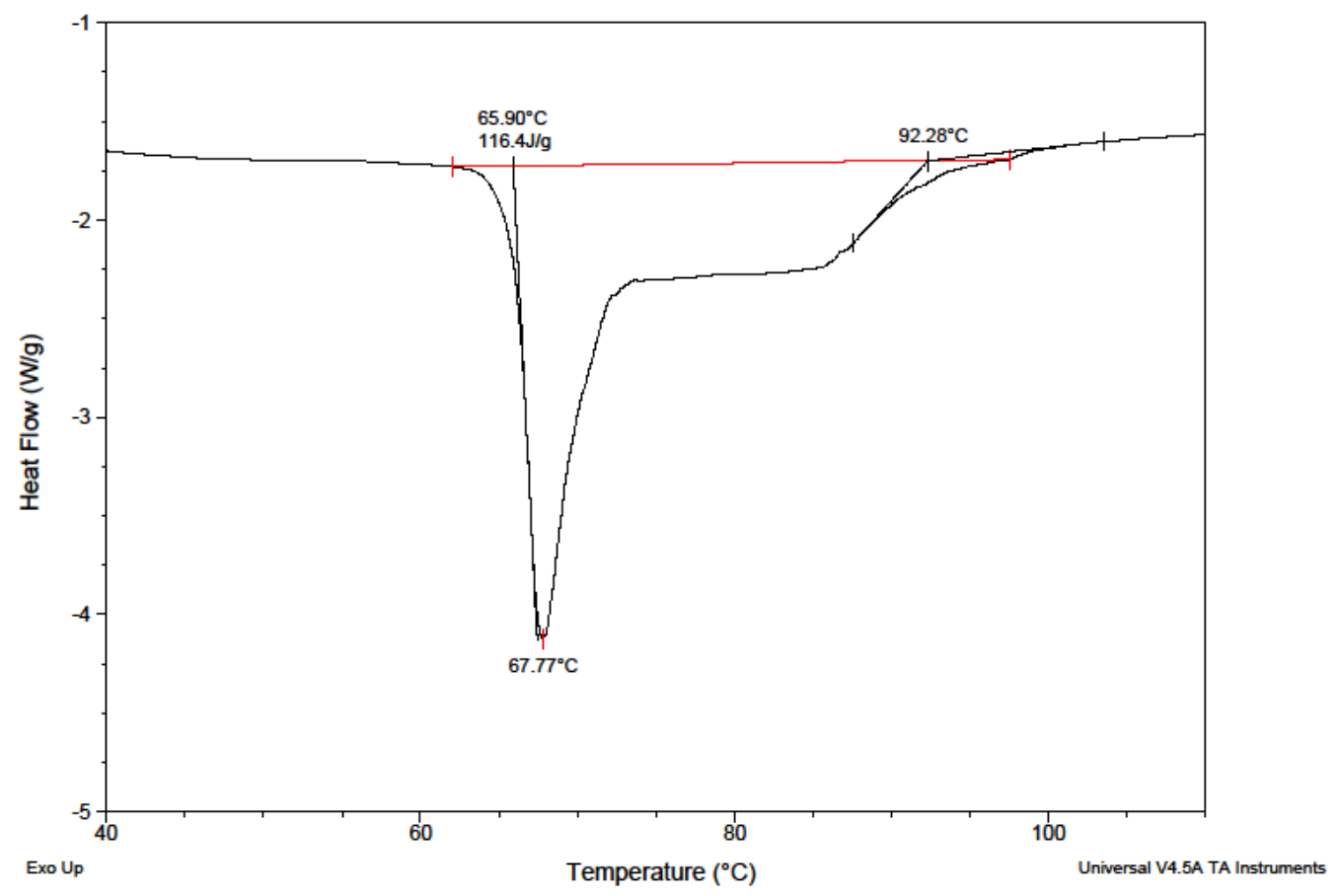

SF 1.4h: DSC trace for DNAN-TNAZ eutectic $\left(10^{\circ} \mathrm{C} / \mathrm{min}\right)$ 
Appendix 2: Supplemental Figures for Chapter 2

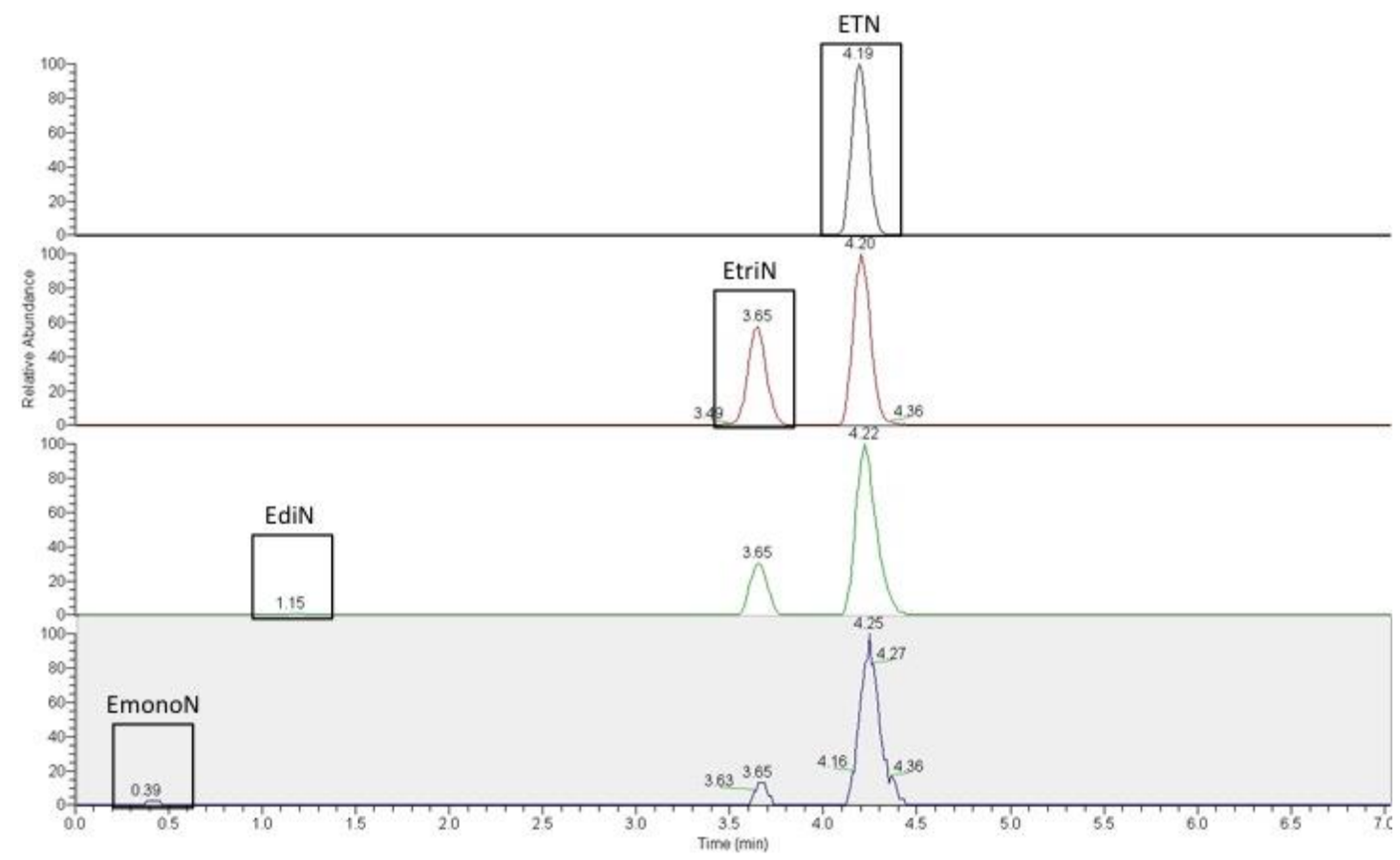

SF 2.1: Extracted ion chromatograms for ETN decomposition products: tetranitrate, trinitrate, dinitrate, mononitrate (top to bottom) 

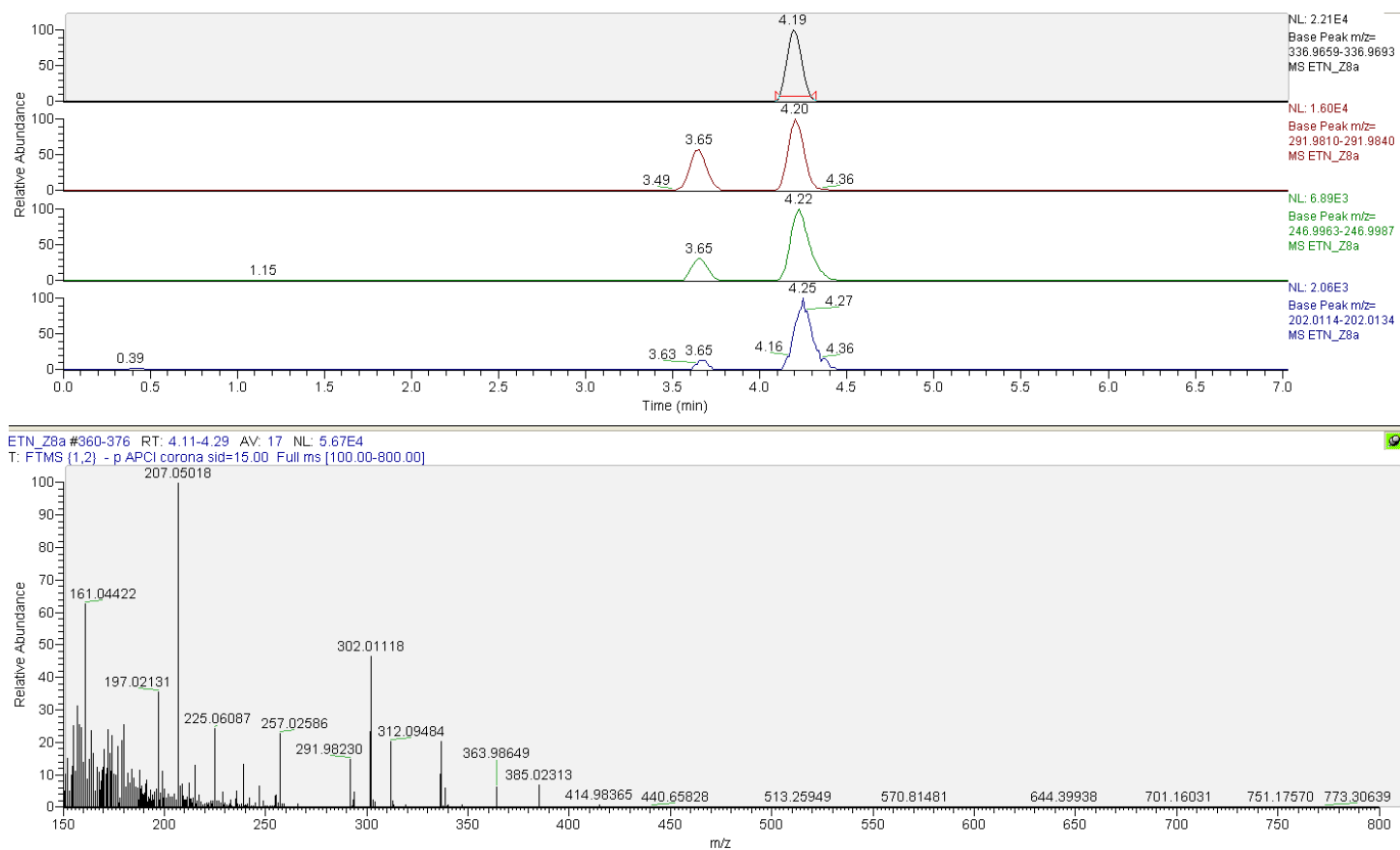

SF 2.2: Mass spec of ETN peak 

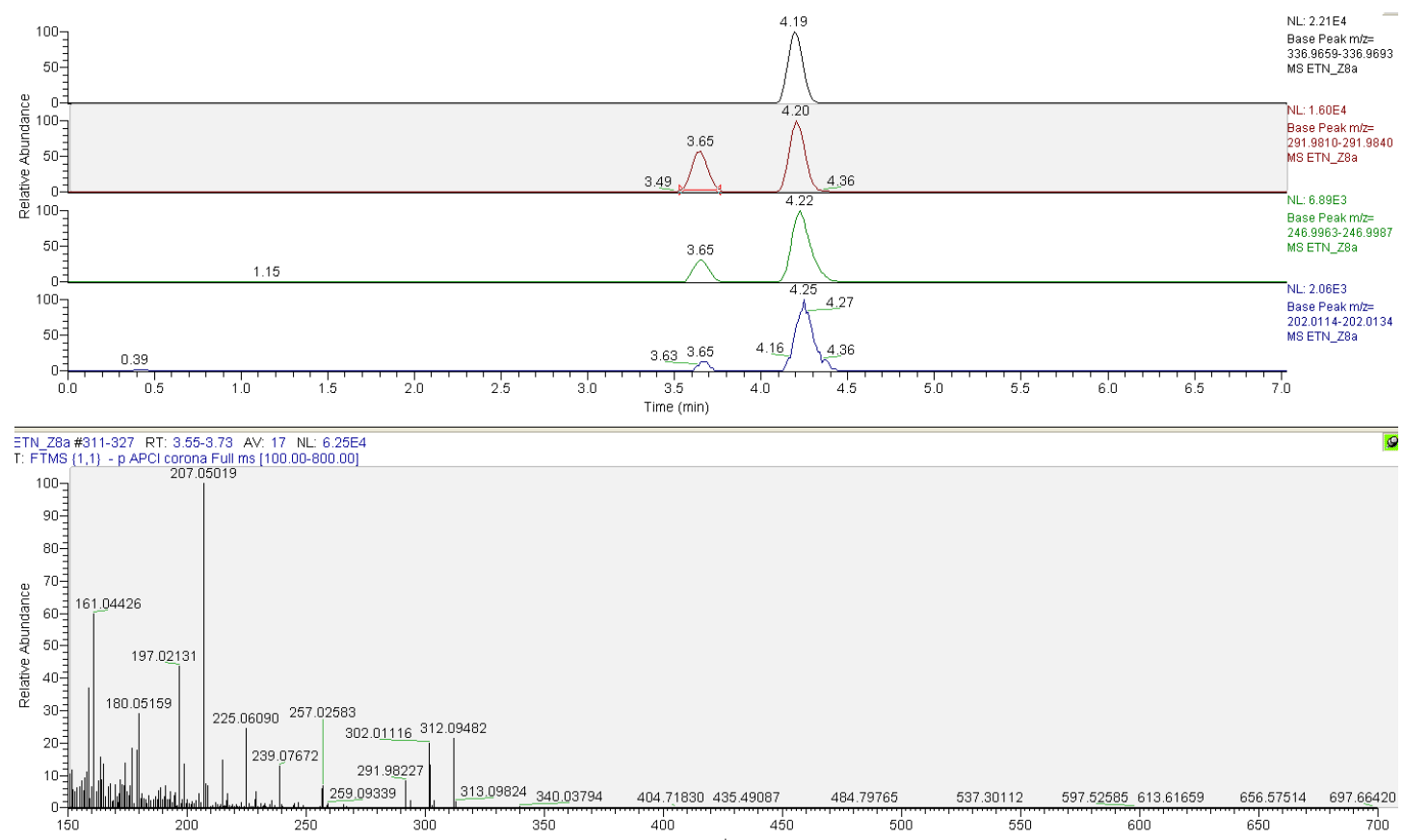

SF 2.3: Mass spec of trinitrate peak.

Did not include dinitrate and mononitrate MS because trinitrate is the lowest nitrated compound with a mass spec that is visible above background without ion extraction. 
Appendix 3: Supplemental Figures for Chapter 3

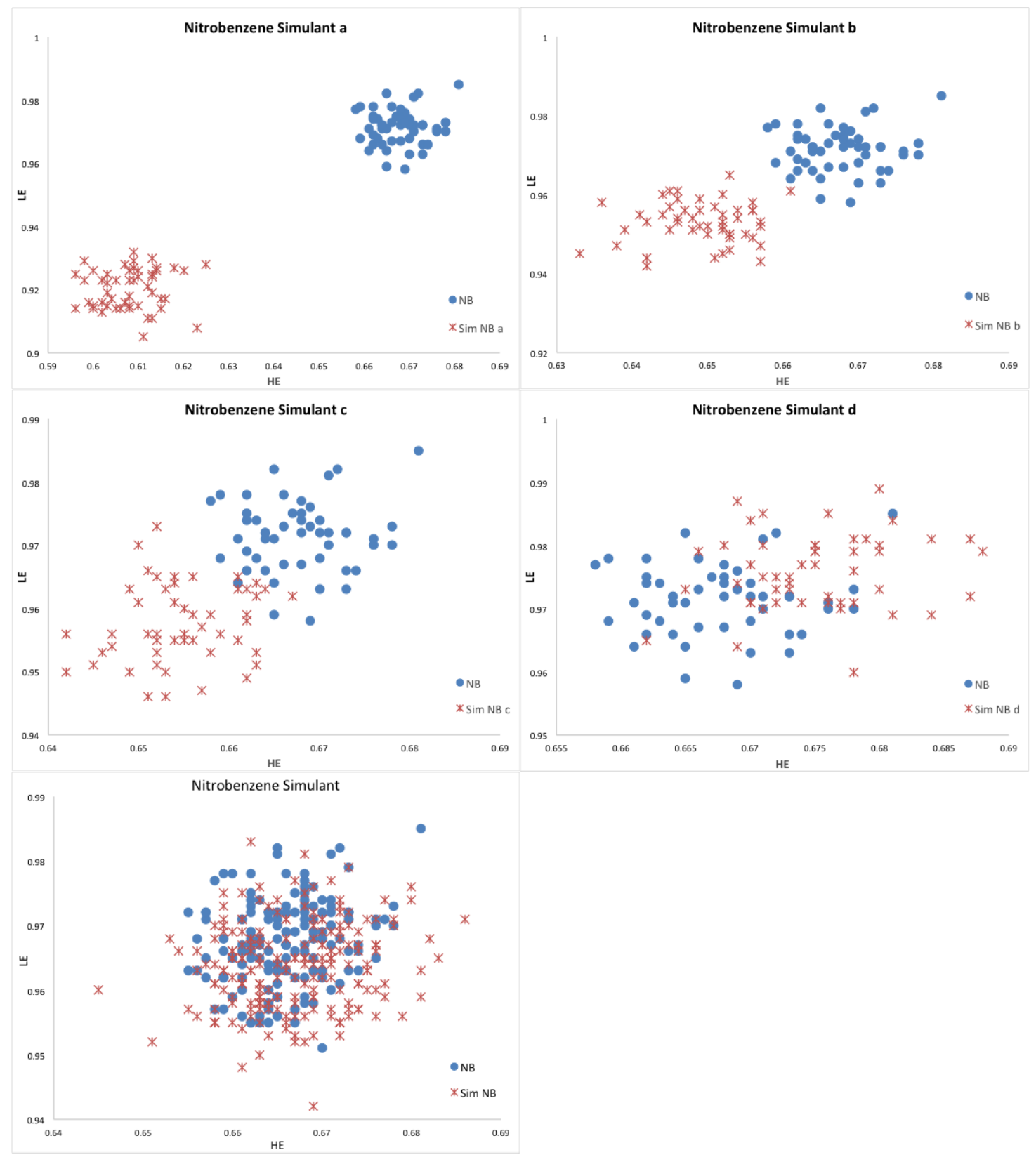

SF 3.1: Nitrobenzene simulant attempts (Success: Sim NB) 

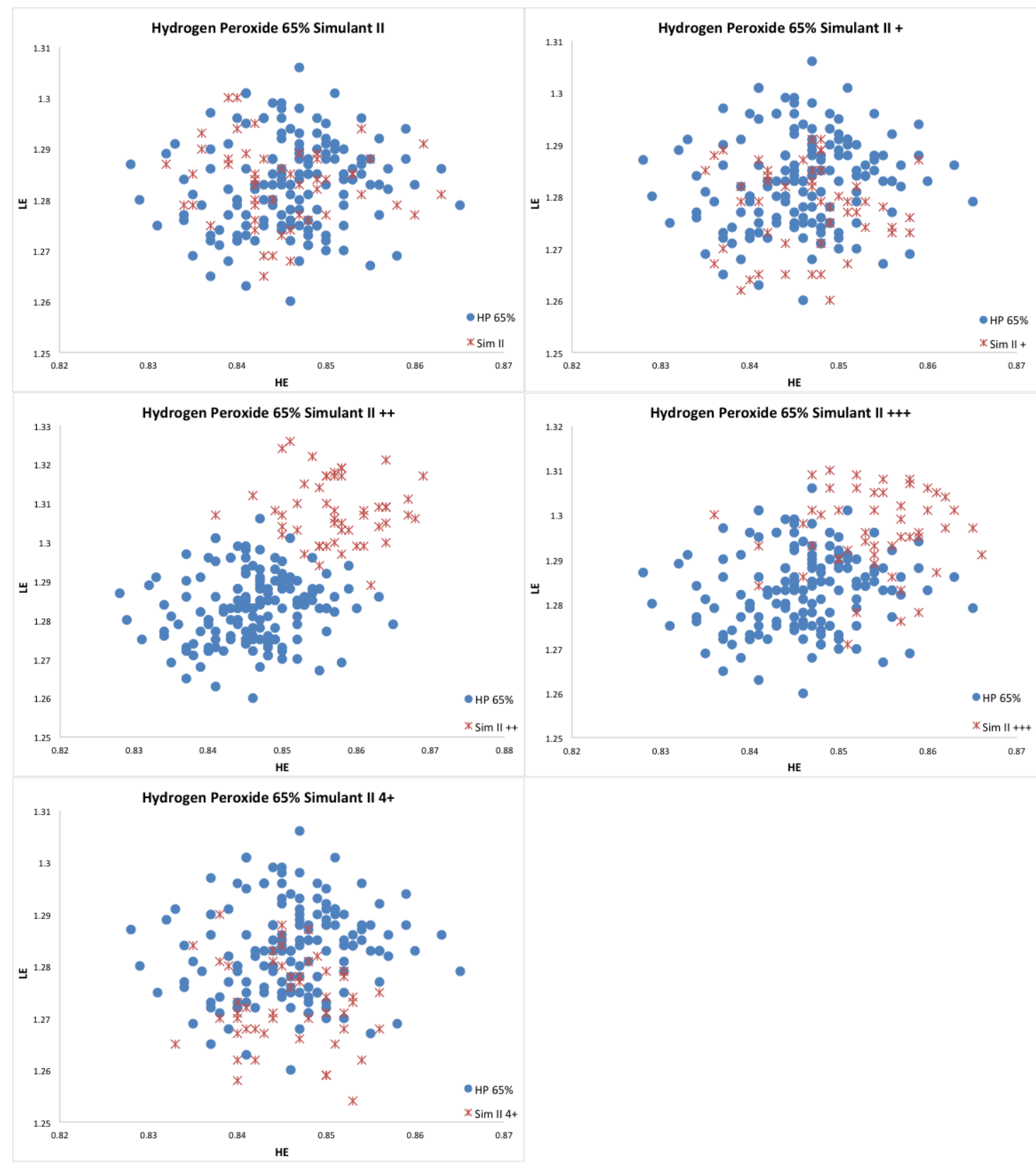

SF 3.2: $65 \%$ hydrogen peroxide simulant attempts (Success: Sim II) 


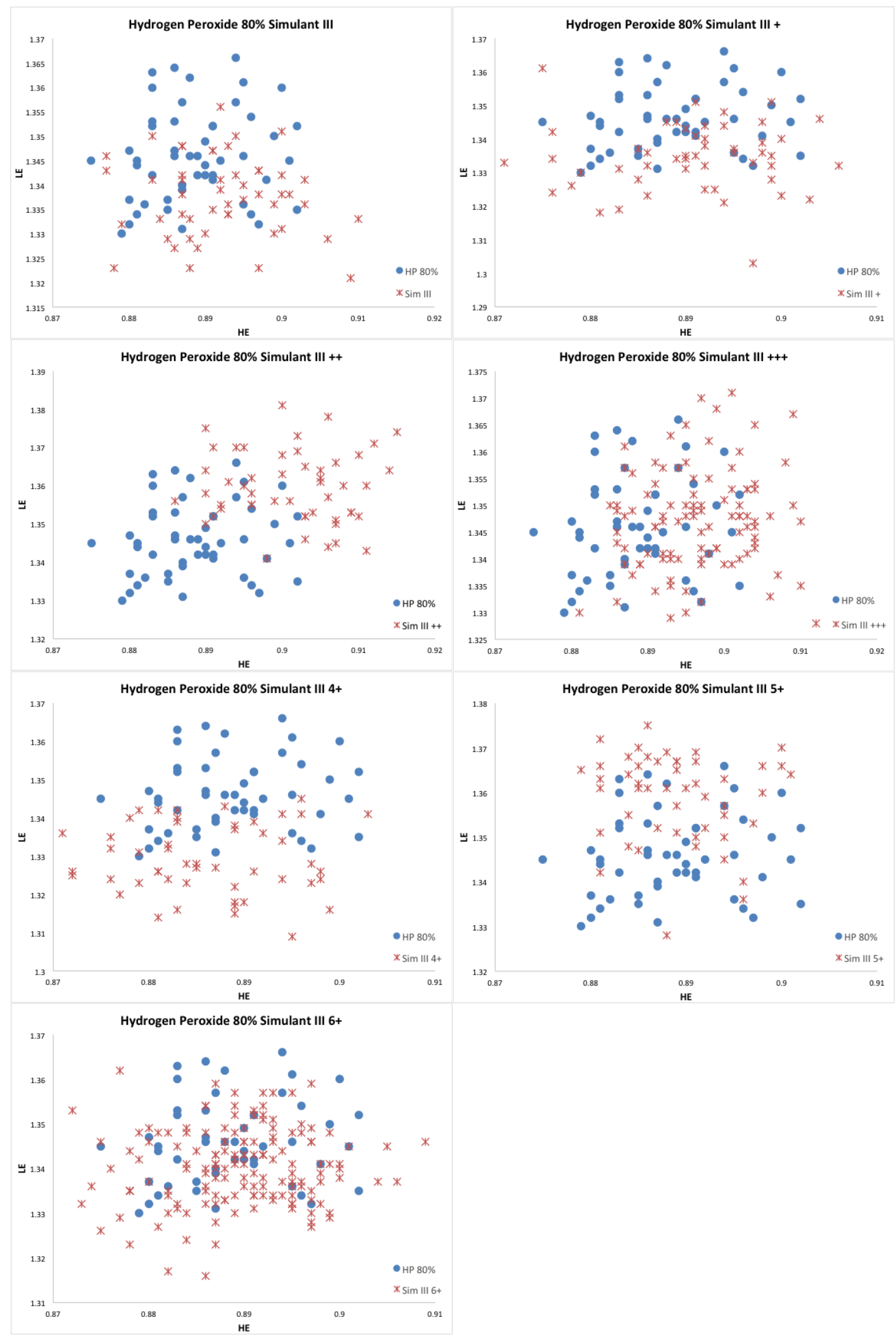

SF 3.3: $80 \%$ hydrogen peroxide simulant attempts (Success: Sim III 6+) 


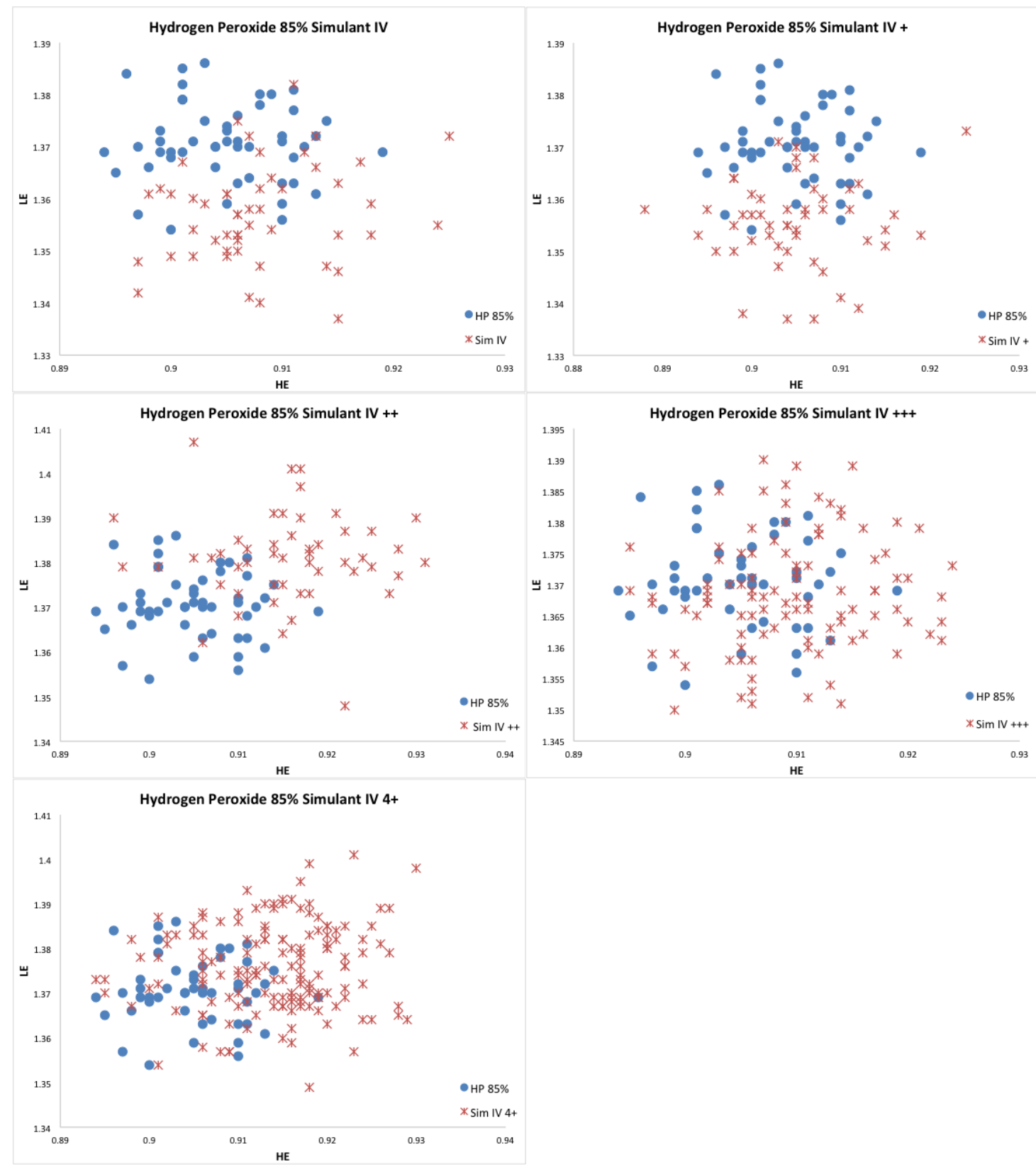

SF 3.4: 85\% hydrogen peroxide simulant attempts (Success: Sim IV +++) 

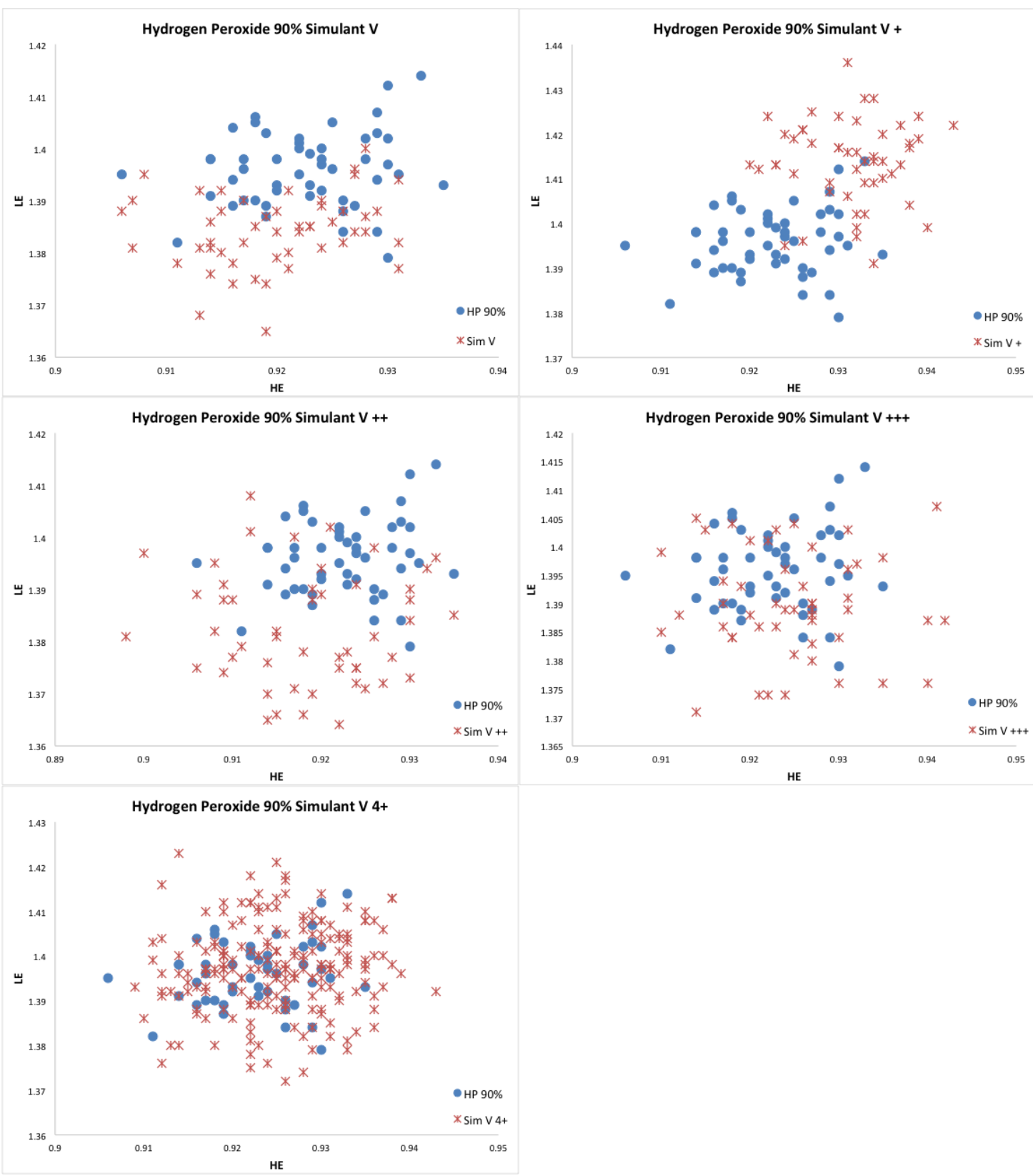

SF 3.5: 90\% hydrogen peroxide simulant attempts (Success: Sim V 4+) 
a)

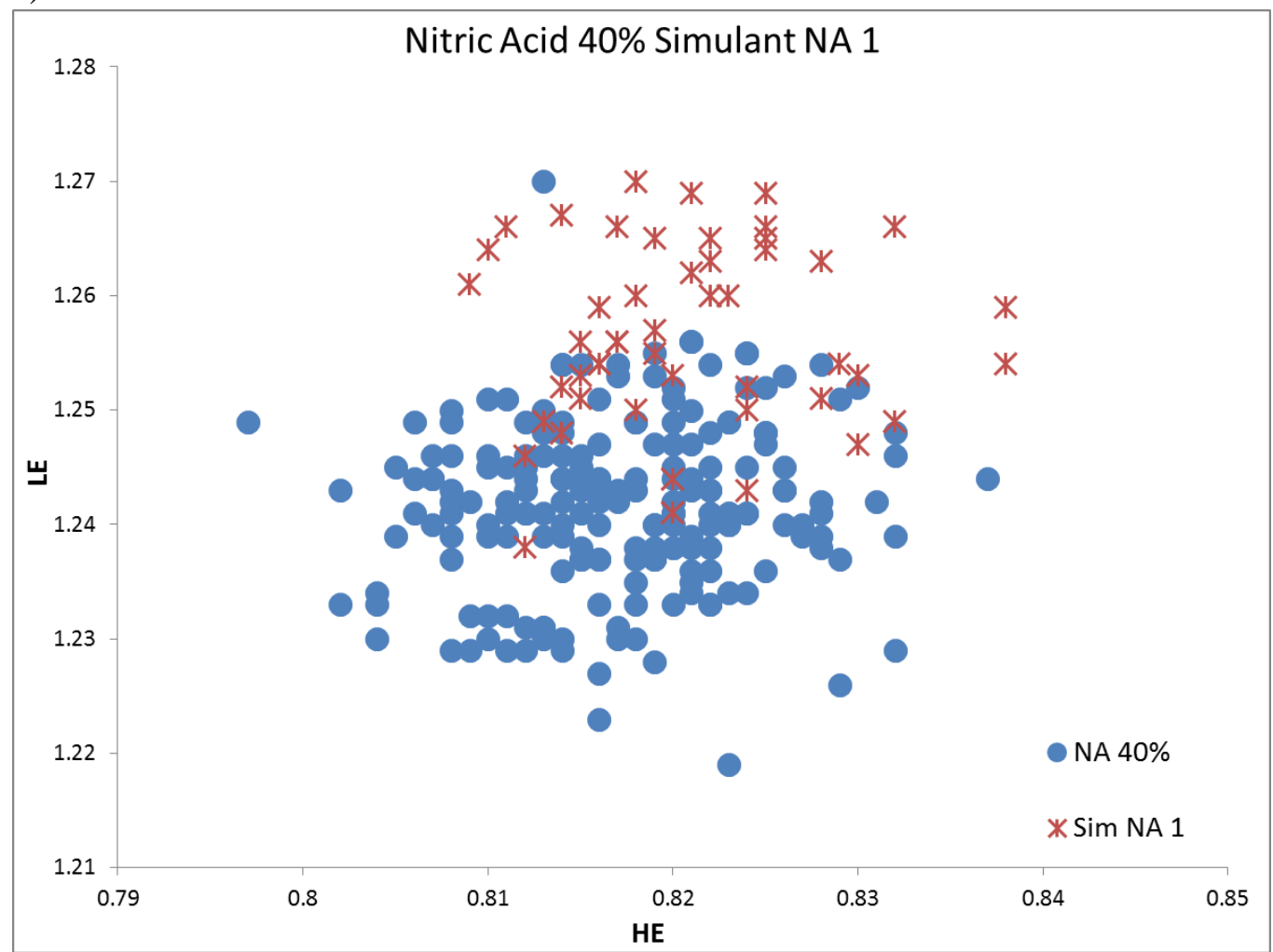

b)

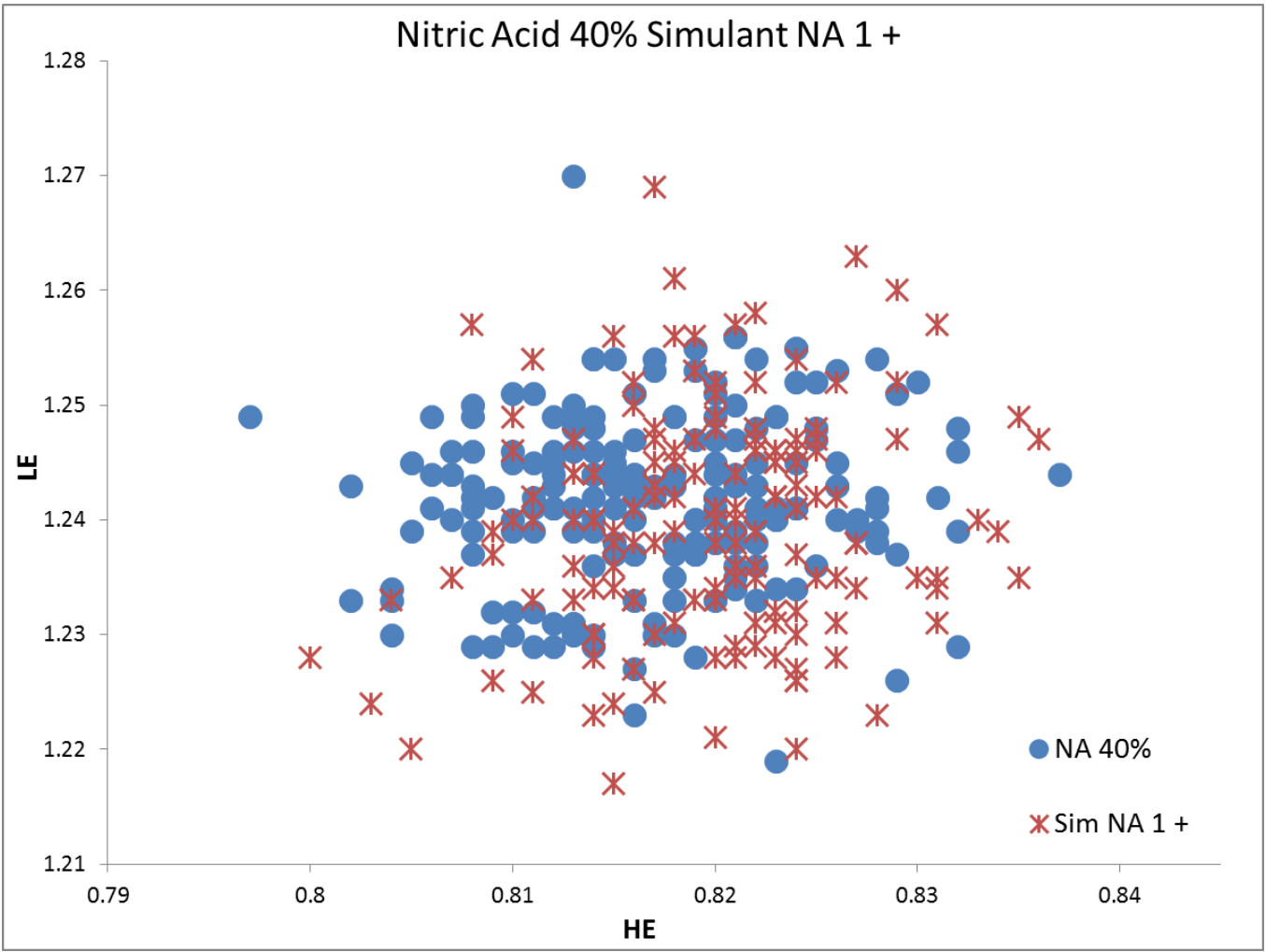

SF 3.6: Nitric acid simulant a) first attempt, b) adjusted simulant 